PNL-2746

UC-12

\title{
Augmented Dry Cooling Surface Test Program: Analysis and Experimental Results
}
H. L. Parry
L. E. Wiles
L. J. MacGowan
D. W. Faletti
D. K. Kreid
B. M. Johnson

September 1979

Prepared for the U.S. Department of Energy under Contract EY-76-C-06-1830

Pacific Northwest Laboratory Operated for the U.S. Department of Energy by Battelle Memorial Institute 
NOTICE

This report was prepared as an account of work sponsored by the United States Government. Neither the United States not the Department of Energy, nor any of their employees, nor any of their contractors, subcontractors, or their employees, makes any warranty, express or implied, or assumes any legal liability or responsibility for the accuracy, completeness or usefulness of any information, apparatus, product or process disclosed, or represents that its use would not infringe privately owned rights.

The views, opinions and conclusions contained in this report are those of the contractor and do not necessarily represent those of the United States Government or the United States Department of Energy.

\author{
PACIFIC NORTHWEST LABORATORY \\ operated by \\ BATTELLE \\ for the \\ UNITED STATES DEPARTMENT OF ENERCY \\ Under Contract EY-76-C-06-1830
}

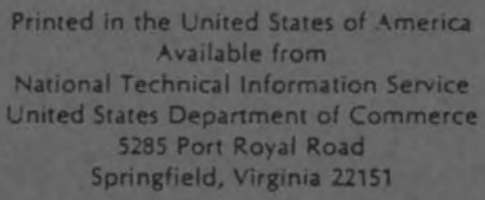

Price: Printed Copy s $\because$ Microfiche $\$ 3.00$

NTIS

- Pages Selling Price

$\begin{array}{lr}001-025 & \$ 4 . \infty 0 \\ 026-050 & \$ 4.50 \\ 051-075 & \$ 5.25 \\ 076-100 & \$ 6.00 \\ 101-125 & \$ 6.50 \\ 126-150 & \$ 7.25 \\ 151-175 & \$ 8.00 \\ 176-200 & \$ 9.00 \\ 201-225 & \$ 9.25 \\ 226-250 & \$ 9.50 \\ 251-275 & \$ 10.75 \\ 276-300 & \$ 11.00\end{array}$


PNL-2746

33679000491839

UC-12

AUGMENTED DRY COOLING SURFACE

TEST PROGRAM: ANALYSIS AND

EXPER IMENTAL RESULTS
H. L. Parry
L. J. MacGowan
D. K. Kreid
L. E. Wiles
D. W. Faletti
B. M. Johnson

September 1979

Prepared for

the U.S. Department of Energy under Contract EY-76-C-06-1830

Pac if ic Northwest Laboratory Richland, Washington 99352 


\section{SUMMARY}

A series of experiments was performed using the Pacific Northwest Laboratory (PNL) Water Augmentation Test Apparatus (WATA) to assess the operating characteristics and potential performance of water-augmented dry cooling systems. The work was aimed at 1 ) evaluating a deluged air-cooled HOTERV plate fin heat exchanger surface proposed for integrated dry/wet cooling systems and 2) using test results to guide the development of a predictive analytical model. In the process, all-dry performance data were obtained for the HÖTERV surface as well as for two Curtiss-Wright chipped fin surfaces.

The dry heat transfer data indicate that a slotted Curtiss-Wright surface slightly outperforms the HOTERV and nonslotted Curtiss-Wright surfaces based on heat rejection rate per unit of fan power. However, all three surfaces are so close in performance that other factors, such as surface cost and piping and mounting costs, will probably determine which surface is preferred at a given installation.

Comparisons of deluged HÖTERV performance with dry HÖTERV and CurtissWright performance under prototypic conditions have established that deluging can provide considerable heat rejection enhancement, particularly at low ITD and low air humidity. A deluged HÖTERV core operating at a $115^{\circ} \mathrm{F}$ primary fluid temperature in $105^{\circ} \mathrm{F}$ air at $10 \%$ relative humidity can reject over seven times as much heat as a dry HÖTERV core operating under the same conditions at the same air-side pressure drop. Even at $70 \%$ relative humidity, enhancement ratios on the order of 2 are seen. Thus, it appears that deluge operation can provide considerable enhancement during those periods of warm weather and resultant low ITD when enhancement of dry cooling systems is most needed.

Deluged tests were performed to evaluate the effect of airflow rate, deluge flow rate and core tilt angle on performance. Increased airflow increases both heat rejection rate and required fan power. Optimal airflow rate will thus be determined for a given location by the competing costs of 
heat exchanger surface area versus fan operation. Increased deluge flow rate also increases both heat rejection capability and required fan power. Maximum heat rejection per unit of fan power occurs at a deluge flow of 1.5 to $2.0 \mathrm{gpm}$ per lineal foot of heat exchanger core measured in the direction of the primary tubes. Above a deluge flow of about $3 \mathrm{gpm}$ per lineal foot, deluge water begins to be blown from the surface, particularly if approach air velocity is increased to over $6 \mathrm{ft} / \mathrm{sec}$. Within the experimental uncertainty of the data, changes in core tilt angle from vertical to $16^{\circ}$ from vertical have a negligible effect on performance. At tilt angles greater than $16^{\circ}$ from vertical, deluge water tended to separate from the system edge of the core. Thus, tests were performed to greater tilt angles. Surface mounting requirements and tower layout will probably be more important in determining tilt angle than performance. 
SUMMARY

FIGURES

TABLES

NOMENCLATURE

1.0 INTRODUCTION

1.1 DRY/WET COOLING AMMONIA SYSTEMS.$\quad \cdot \quad \cdot \quad \cdot \quad \cdot \quad \cdot 2$

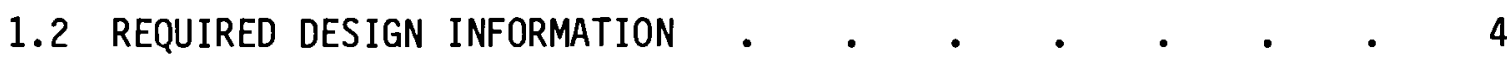

1.3 PACIFIC NORTHWEST LABORATORY TEST PROGRAM SCOPE $\cdot$. $\quad .4$

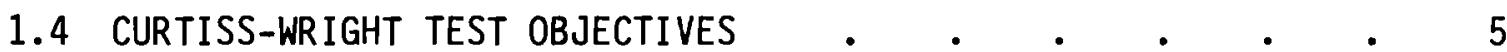

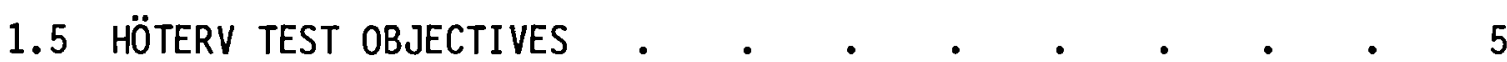

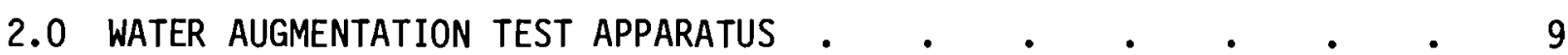

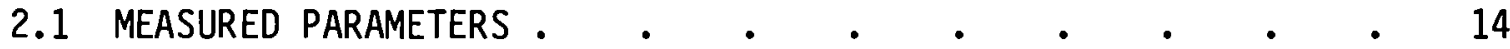

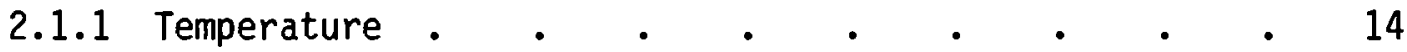

2.1.2 Air Dewpoint . • • . . • • • • 15

2.1 .3 Airflow . . . . . . . . . . . . . 15

2.1 .4 Water Flow . . . . . . . . . . 15

2.1 .5 Pressures . $. \quad . \quad . \quad . \quad . \quad . \quad . \quad . \quad 15$

2.2 TEST CORE HEAT REJECTION RATE

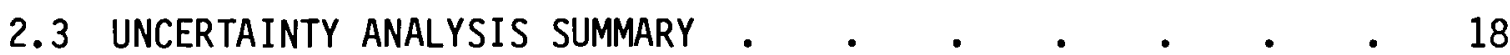

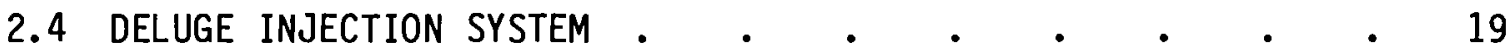

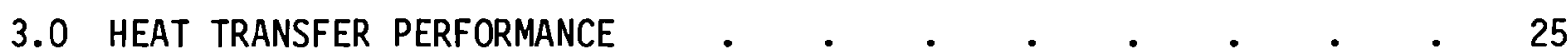

3.1 BASELINE PERFORMANCE OF DRY HÖTERV AND

3.2 ENHANCEMENT DUE TO DELUGE AT PROTOTYPIC

3.3 THE EFFECT OF OPERATING PARAMETERS ON DELUGED
PERFORMANCE

3.3.1 Observed Deluge Flow Characteristics . . . . 37

3.3.2 Heat Transfer Performance . . . . . . 40

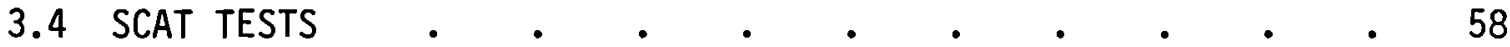

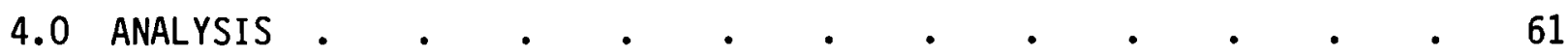

4.1 SUMMARY OF THE DELUGE HEAT TRANSFER MODELS • • • • 
4.1.1 Derivation of the Enthalpy Driving Potential for Uniform Wetting $. \quad . \quad . \quad . \quad .62$

4.1.2 Alternative Heat Transfer Formulations . . . 71

4.1.3 Development of a Fin Efficiency Model for the HÖTERV Plate Fin Heat Exchanger . . . . 75

4.1.4 Computation of the Deluge Fin

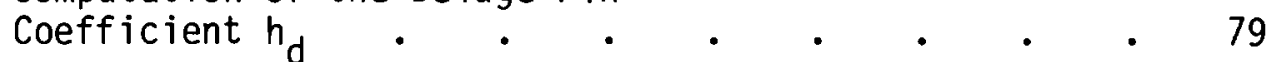

4.1.5 Summary of the Deluge Model for Incomplete Wetting. . . 81

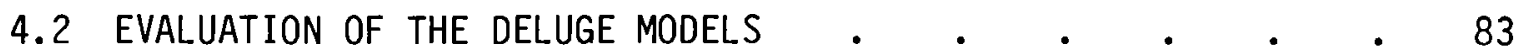

4.2.1 Application of the Deluge Model to Prediction of Heat Transfer for a Uniformly Wetted Core . . 83

4.2.2 Application of the Deluge Model to Prediction of Heat Transfer for Incomplete Wetting . . . 101

4.2.3 Comparison of the Analys is with the Results of the WATA Experiments . • . . . . 108

4.2.4 Summary and Discussion of Results . . . . 115

4.2.5 Conclusions and Recommendations . . . . . . 119

4.3 COST OF DRY/WET COOLING BASED ON THE WATA.

DELUGE DATA • • • • • • • • • • • 120

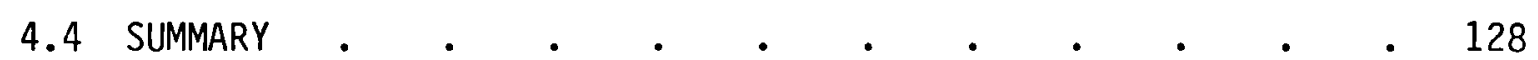

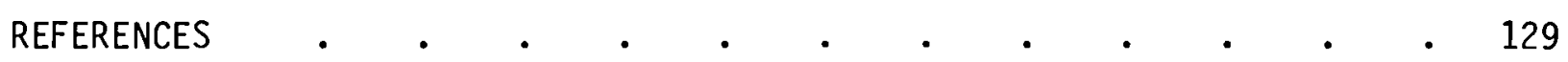

APPENDIX A - DEVELOPMENT OF THE DELUGE MODEL FOR A
UNIFORMLY WETTED HEAT EXCHANGER . . . . . . . A-1

APPENDIX B - DEVELOPMENT OF THE DELUGE MODEL FOR

APPENDIX C - HEATING5 ANALYSIS OF A SCAT CORE . . . . . .

APPENDIX D - CALCULATION OF DIMENSIONAL PARAMETERS

APPENDIX E - SAMPLE CALCULATIONS . . . . . . . . . . . . E-1

APPENDIX $F$ - COMPARISON OF HOTERV SURFACE PERFORMANCE

AS MEASURED IN WATA TO THAT PREDICTED BY

HÖTERV . 
FIGURES

1-1 Separate Condenser Augmentation . . . . . . . 3

1-2 Curtiss-Wright Tubing - General Configuration . . . . 6

1-3 Curtiss-Wright Tubing - Possible SCAT Configuration . . . 7

1-4 HÖTERV Plate Fin Surface . . . . . . . . . . 8

2-1 Water Augmentation Test Apparatus . . . . . . . 10

2-2 WATA Schematic . . . • . • • • . . 11

2-3 WATA Air Ducting - Horizontal Airflow . . . . . . 12

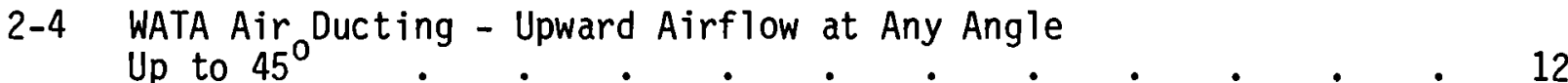

2-5 WATA Air Ducting - Airflow Vertically Upward . . . . 13

2-6 WATA Air Ducting - Airflow Vertically Downward . . . . 13

2-7 Deluge Injection System Used in WATA $. \quad . \quad . \quad . \quad . \quad 20$

2-8 Plastic Distribution Ring . . . . . . . . . . 21

2-9 Other Deluge Injection System Concepts . . . . . . 22

3-1 Curtiss-Wright Surfaces . . . • . • • . . 26

3-2 Curtiss-Wright Test Core . . . . . . . . 27

3-3 HÖTERV Deluged Test Core on Temporary Support Stand . . . 28

3-4 HÖTERV Heat Exchanger Plate Fin and Tube Arrangement . . . 29

3-5 Dry Surfaces Performance . . . . . . . . 30

B-6 Baseline Heat Transfer Performance Based
on Frontal Area . . . . . . . . . . 31

3-7 Performance Comparison of Dry Surfaces Based

3-8 Performance Comparison of Dry Surfaces Based Deluged Enhancement Comparing Deluged HÖTERV Surface with Dry HÖTERV Surface "A" at Equal Air-side Pressure Drop under Prototypic Conditions . . . . . 38

3-10 Deluged Enhancement Comparing Deluged HöTERV Surface with Dry Curtiss-Wright Surface "A" at Equal Fan Power under Prototypic Conditions . . . . . . . 39

3-11 Friction Factors for Wet and Dry HÖTERV Core . . . . 42

3-12 Effect of Airflow on Overall Deluged Surface 
3-13 The Effect of Airflow on the Effective Deluge Film Coefficient, $h_{d}{ }^{*} \cdot \cdot \cdot c \cdot c \cdot c \cdot c \cdot c 45$

3-14 The Effect of Airflow on the Effective Deluge

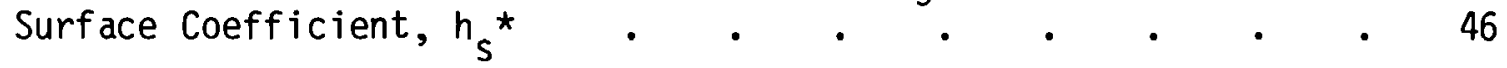

3-15 Effect of Deluge Flow Rate on Deluged Friction

3-16 Effect of Deluge Flow Rate on Overall Deluged Surface Heat Transfer Performance, HÖTERV Core . . . . 48

3-17 The Effect of Deluge Flow on Effective Deluge

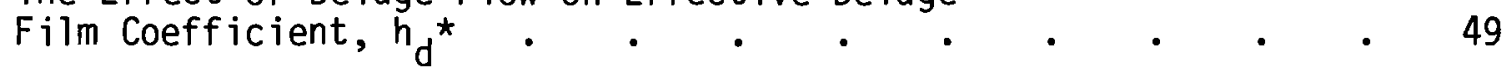

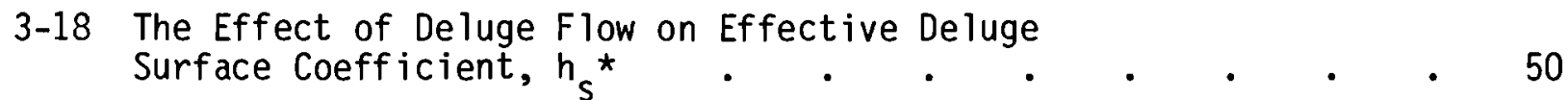

3-19 Effect of Deluge Flow Rate on Overall Deluged Surface

3-20 Effect of Core Tilt Angle on Effective Overall Deluged

3-21 The Effect of Deluge Water Surfactant Concentration on

3-22 The Effect of Deluge Water Surfactant Concentration
on Effective Deluge Film Coefficient, $h^{*}$. . . . 55

3-23 The Effect of Deluge Water Surfactant Concentration on Effective Deluge Surface Coefficient, $h_{s}{ }^{*}$. . . . 56

3-24 The Effect of Deluge Water Surfactant Concentration on Effective Overall Deluged Surface Coefficient Per Unit Fan Power, Based on Frontal Area . . . . . 57

4-1 Temperature Distributions and Mass/Energy Balance

4-2 Heat Transfer Resistance Model for a Deluged

4-3 Fin Efficiency Solution for an Annular Fin . . . . . 66

4-4 The Enthalpy Transformation . . . . . . . . . 68

4-5 Temperature Dependence of the Transformation Parameter . 69

4-6 HÖTERV Plate Fin Design . . . . . . . . . . 75

4-7 Equivalent Annular Fin for the HÖTERV Core . . . . . 76

4-8 Comparison of the Annular Fin Model with Numerical
Computations Using HEATING5 Code . . . . . 77

4-9 Rectilinear Approximation of the HÖTERV Plate Fin
Used in the HEATING5 Efficiency Computations . . . . 78 
4-10 The Annular Fin/Annular Wetting Model

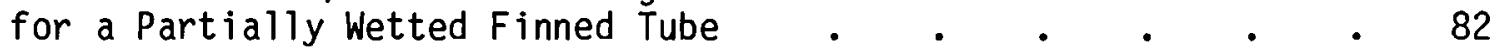

4-11 HÖTERV Surface Heat Transfer Correlation . . • • • • 86

4-12 Correlation for Predicting the Overall Heat Transfer

Coefficient for Wet or Dry Operation . $\quad$ • $\quad$ • $\quad$ • $\quad$. 87

4-13 Plot of Fin Effectiveness $\phi$ for a Condenser . . . . . . . 90

4-14 Computation of the Driving Potential Ratio $\Gamma$. . . . . 94

4-15 Predicted Overall Heat Transfer Coefficients as a Function of Operating Conditions and Assumptions . $\quad$ • 96

4-16 Computation of Effectiveness Ratio as a Function

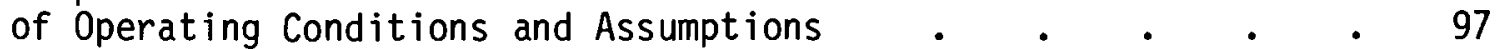

4-17 Prediction of the Heat Transfer Enhancement as a Function of Operating Conditions for $\operatorname{Re}^{\star}=900, \beta=0.5$

4-18 Prediction of the Heat Transfer Enhancement as a Function of Operating Conditions for $\mathrm{Re}^{\star}=900, \beta=1.0$

4-19 Computation of Heat Transfer Using the Partial Wetting Deluge Model • . . . • • . . . 104

4-20 Comparison of Model for Partial Wetting with HEATING5 Computations for Annular Wetting • • • • • . 107

4-21 Comparison of HEATING5 Computations for Annular Model with Rectilinear Model with Nonannular Wetting . . . $\quad$ - 109

4-22 Comparison of Predicted and Measured Values of $U_{0}{ }^{*}$ • . . 111

4-23 Comparison of Predicted and Measured Values of the Heat Transfer Enhancement Ratio for Equal Pressure Drop Operation

4-24 Incremental Costs for Plants with Heat Exchangers with Performance Predicted from WATA Data and from Manuf acturer's Information 


\section{TABLES}

3-1 SCAT Test Data Compared to HEATING5 Predictions . . . . 59

4-1 Summary of Analogous Equations for Computation of

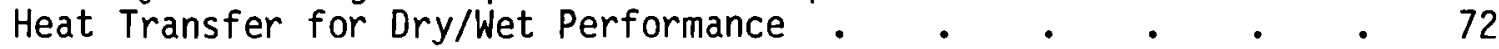

4-2 HÖTERV Core Design Parameters for WATA . . . . . . . 84

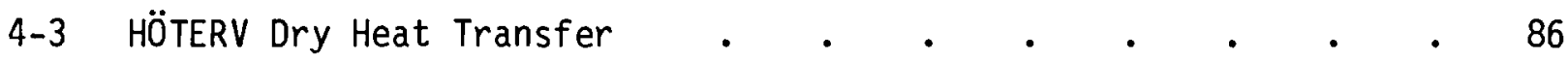

4-4 Computations of $U_{\text {Versus }} h_{s}$ for the HÖTERV

4-5 Computation of the Overall Heat Transfer

Coefficients and Fin Effectiveness for $R^{\star}=450$,

900 and $\beta=0.5,1 . . \quad . \quad . \quad . \quad . \quad . \quad . \quad . \quad . \quad 91$

4-6 Computation of $\Gamma$ and $\xi$ for Varying Inlet Conditions

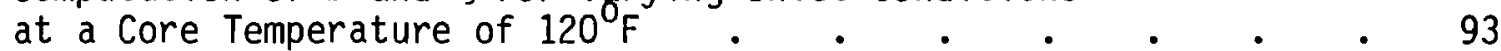

4-7 Computation of Heat Transfer Enhancement Ratio for $\mathrm{Re}^{\star}=450$ at a Core Temperature of $120^{\circ} \mathrm{F} \quad . \quad . \quad . \quad . \quad . \quad 98$

4-8 Computation of Heat Transfer Enhancement Ratio for

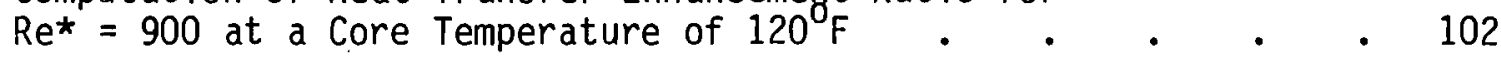

4-9 Computation of $U_{*}^{*}$ and $h_{*}$ Using the Deluge Theory

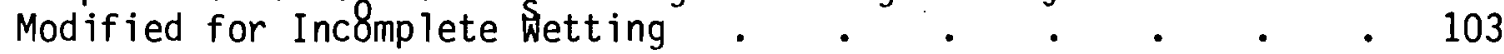

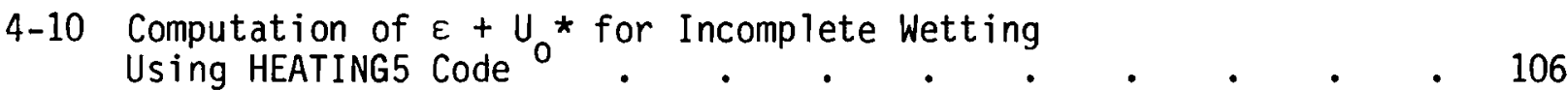

4-11 Computation of the Heat Transfer Coefficients and

Enhancement Ratio for Conditions Typical of the WATA

Experiments (for $h_{p}=625 \mathrm{Btu} / \mathrm{ft}^{2} \mathrm{hr} F$ ) . . . . 110

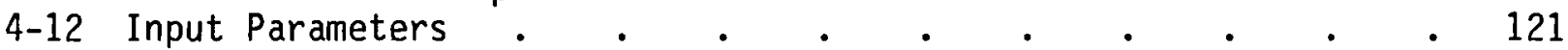

4-13 Optimized Designs Using WATA Data • • • • • . . • . 123

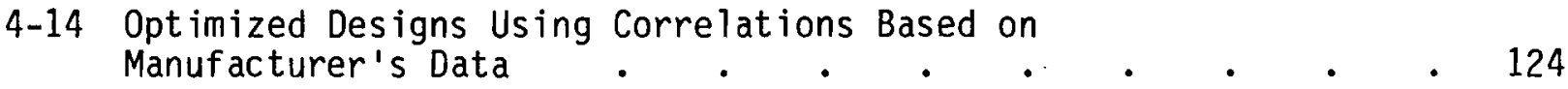


NOMENCLATURE

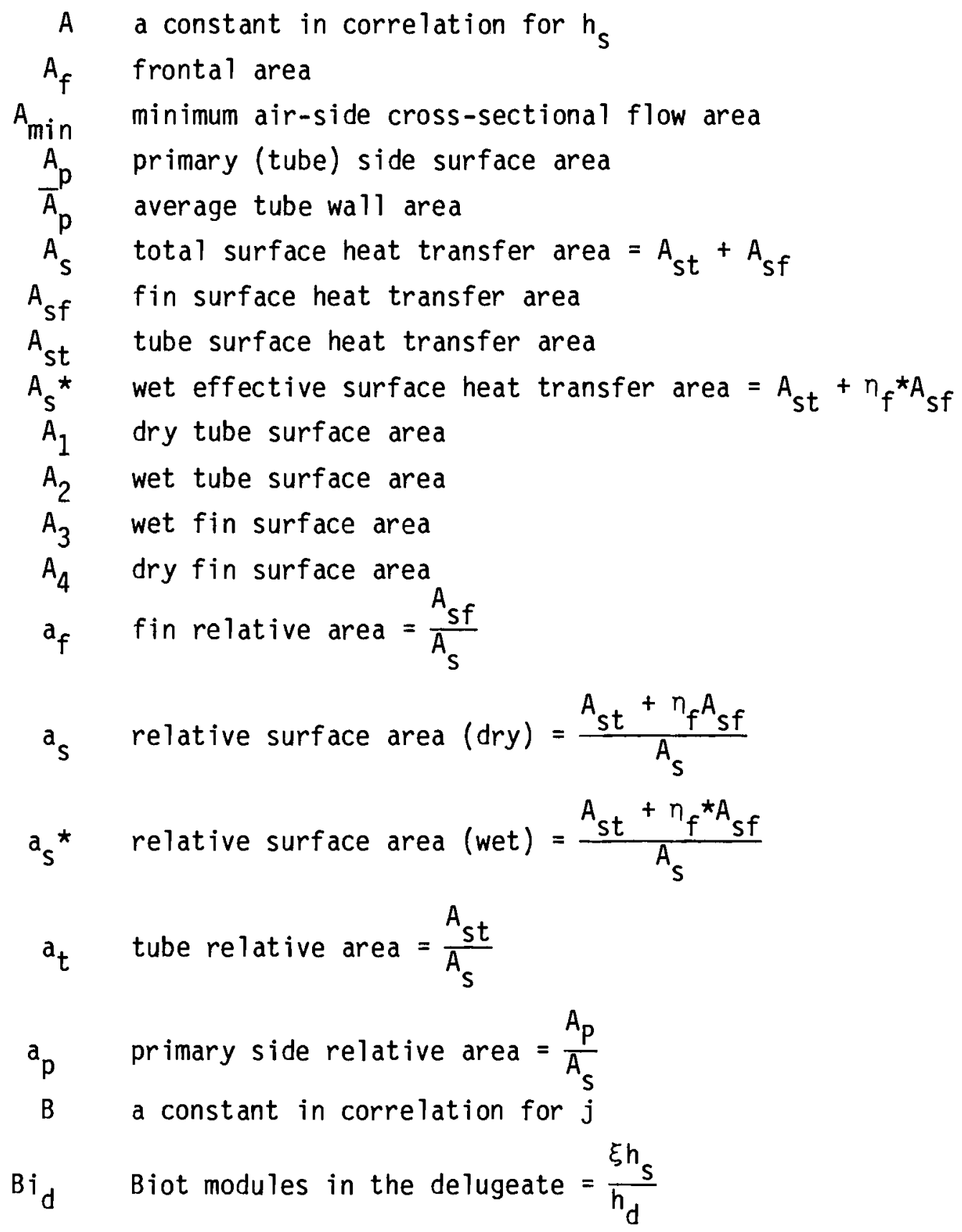


$\mathrm{Bi}_{f} \quad$ Biot modules for the $\mathrm{fin}=\frac{\ell_{f}{ }^{2} h_{s}}{k_{f} Y_{b}}$

$B i_{f}$ Biot modules for a wet $f$ in $=\frac{\ell_{f}{ }^{2} \xi_{h_{s}}}{k_{f} Y_{b}\left(1+B i_{d}\right)}$

$C_{a}$ specific heat of moist air

$C_{p} \quad$ specific heat of the primary fluid

$C_{v} \quad$ specific heat of water vapor

$D_{t} \quad$ diameter of the tubes

$F$ crossflow correction factor

$f$ friction factor, also functional notation

$f_{0}$ effective friction factor including inlet and exit losses

$g_{c} \quad$ gravitational constant, $32.16 \mathrm{ft} / \mathrm{sec}^{2}$

$G_{\infty} \quad$ mass flux per unit area in the free stream

$G_{p} \quad$ mass flux per unit area in the tube

$\mathrm{H}_{\mathrm{S}}$ humidity ratio at surface saturation condition humidity ratio in the free stream

$h_{\infty} \quad$ surface heat transfer coefficient effective surface heat transfer, coefficient (fin efficiency = 1) lumped, effective heat transfer coefficient under wet conditions, includes effects of non-uniform wetness and fin efficiency

$h_{e}{ }^{*} \quad$ a predicted effective heat transfer coefficient $=\xi h_{s}$

$h_{d}$ effective heat transfer coefficient in the delugeate

$h_{p}$ heat transfer coefficient on the primary (tube) side effective surface heat transfer coefficient based on core frontal. area

$i_{v} \quad$ enthalpy of water vapor at saturation

$i_{a}$ enthalpy of liquid water at saturation

$i_{\infty} \quad$ enthalpy of moist air at the free stream conditions

$i_{p}^{\prime}$ air saturation enthalpy at $T_{p}$

$i_{s}^{\prime}$ air saturation enthalpy at $T_{s}$ 


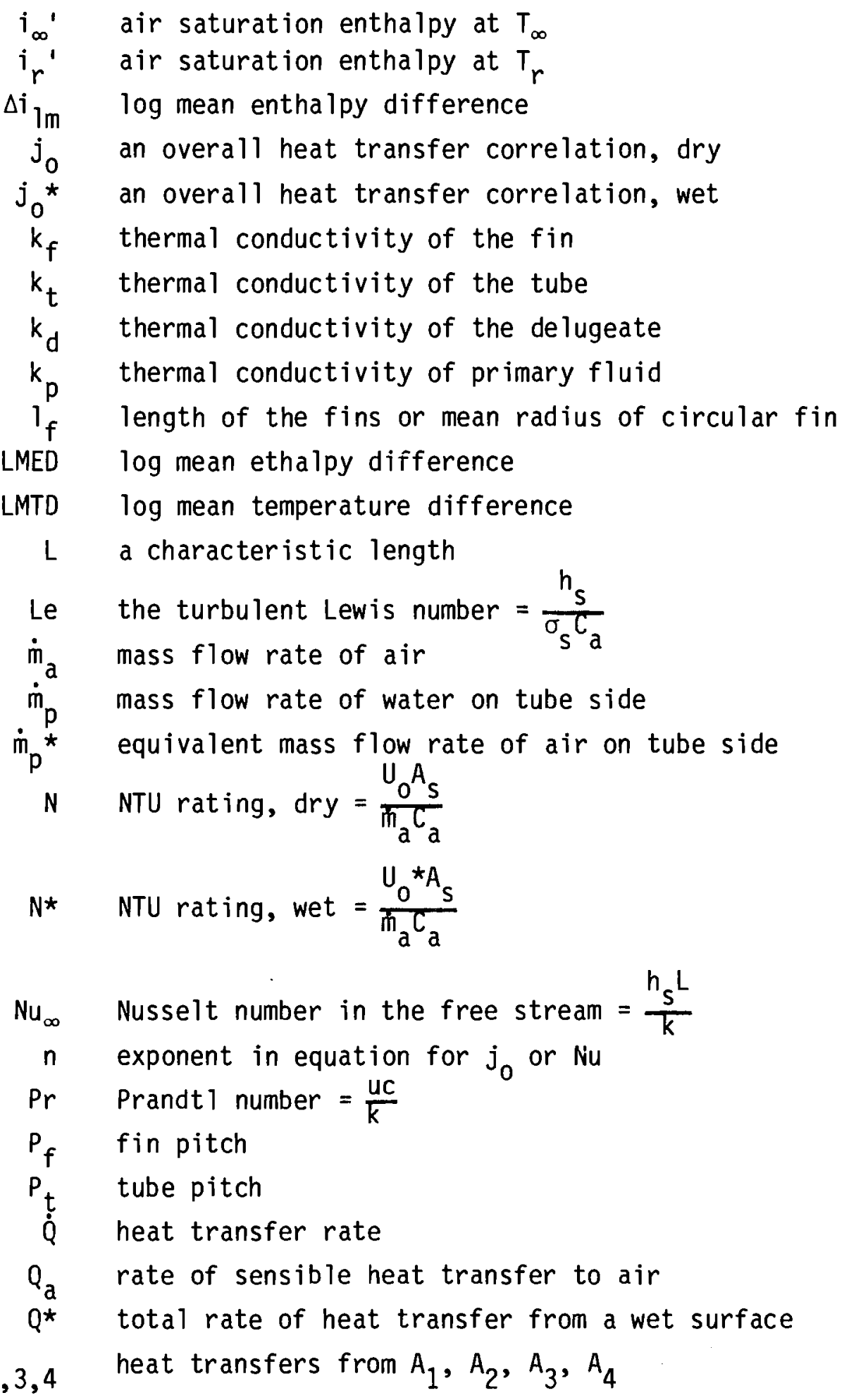




$\begin{array}{cl}R_{\infty} & \text { Reynolds number in the free stream }=\frac{G_{\infty} L}{\mu_{a}} \\ R_{p} & \text { Reynolds number in the tube }=\frac{G_{p} D_{t}}{\mu_{p}} \\ R & \quad \text { capacity ratio }=\frac{\dot{m}_{a} C_{a}}{\dot{m}_{p} C_{p}} \\ & \\ R^{*} & \text { capacity ratio for deluge }=\frac{\dot{m}_{a} \xi C_{a}}{\dot{m}_{p} C_{p}} \\ r_{t} & \text { tube inside radius } \\ r_{2} & \text { fin root radius (also denoted } r_{b} \text { ) } \\ r_{3} & \text { fin radius at dry/wet interface } \\ r_{4} & \text { fin maximum radius (also denoted } r_{e} \text { ) } \\ T_{0} & \text { property table reference temperature } \\ T_{p} & \text { primary fluid temperature } \\ T_{r} & \text { fin root temperature } \\ T_{s} & \text { surface temperature } \\ T_{\infty} & \text { free stream temperature } \\ T_{2} & \text { fin temperature at radius } r_{2} \\ T_{3} & \text { fin temperature at radius } r_{3} \\ T_{4} & \text { fin temperature at radius } r_{4} \\ t_{t} & \text { tube wall thickness } \\ t_{f} & \text { fin thickness } \\ U_{0} & \text { overall heat transfer coefficient, dry } \\ U_{0}^{*} & \text { overall heat transfer coefficient, wet } \\ V_{\infty} & \text { air stream velocity } \\ Y_{b} & \text { half the fin thickness }=t_{f} / 2 \\ V_{a m i n} & \text { air velocity at minimum cross-sectional area }\end{array}$




\section{Greek Symbols}

$\alpha \quad$ overall surface wetness fraction

$\alpha_{t} \quad$ tube wetness fraction

$\alpha_{f}$ fin wetness fraction

$\beta_{c} \quad$ contact resistance

$\Delta \mathrm{P} \quad$ air-side pressure drop

$\delta_{2}$ a temperature correction factor $=\frac{T_{2}-T_{\infty}}{T_{r}-T_{\infty}} \ll 1$

$\delta_{3}$ a temperature correction factor $=\frac{T_{3}-T_{\infty}}{T_{r}-T_{\infty}} \ll 1$

$\delta_{4}$ a temperature correction factor $=\frac{T_{4}-T_{\infty}}{T_{r}-T_{\infty}} \ll 1$

$n_{f}$ fin efficiency, dry

$n_{f} *$ fin efficiency, wet

$\xi \quad$ transformation parameter $=\frac{i_{p}{ }^{\prime}-i_{\infty}{ }^{\prime}}{c_{a}\left(T_{p}-T_{\infty}\right)}$

$\Gamma \quad$ driving potential ratio $=\frac{i_{p}{ }^{\prime}-i_{\infty}}{C_{a}\left(T_{p}-T_{\infty}\right)}$

$\varepsilon \quad$ surface effectiveness $=\frac{h_{s}{ }^{*}}{h_{s}}$

$\varepsilon_{t} \quad$ tube relative surface effectiveness

$\varepsilon_{f} \quad$ fin relative surface effectiveness

$\rho_{a}$ air density

$\mu \quad$ viscosity

$\phi \quad$ fin effectiveness, dry

$\phi * \quad$ fin effectiveness, wet

$\sigma_{s} \quad$ surface mass transfer coefficient 
AUGMENTED DRY COOLING SURFACE TEST PROGRAM:

ANALYSIS AND EXPERIMENTAL RESULTS

\subsection{INTRODUCTION}

This report presents results of an experimental program to evaluate methods for enhancing the performance of dry cooling towers. The work described was performed by the Pacific Northwest Laboratory, operated for the U.S. Department of Energy by Battelle Memorial Institute.

As the world demand for electric power increases, more and larger thermal-electric power plants are being built. Even the most efficient of these plants are capable of converting only about $40 \%$ of their heat input into electricity, leaving $60 \%$ to be rejected to the environment as waste heat. Historically, heat rejection has been accomplished by circulating water from a natural source, such as a lake, river or sea, through the power plant condensers. However, in many cases it is impossible to locate a desired plant adjacent to a suitable cooling water supply. In addition, the environmental effects of returning water to its original source after being heated may be objectionable.

Alternative means of waste heat rejection have been devised to avoid thermal pollution of natural water bodies and to allow greater flexibility in power plant siting. The most common alternative uses evaporative cooling in a pond or wet cooling tower to cool water heated in the plant's condenser. This cooled water is then circulated back to the condenser. Evaporative cooling systems are simple and effective, but they require a fairly large supply of water to make up for that which has been evaporated. Furthermore, the moisture rejected to the air by evaporative coolers may cause fog and icing problems in the local area.

Dry cooling systems have been proposed as a solution to the water consumption problem of evaporative systems. In a dry cooling system cooling water does not come into direct contact with the air, but is passed through 
the tubes of an air-cooled heat exchanger. Air is made to flow over the outside of the tubes by natural or forced convection and heat is transferred from the water through the tube walls and to the air.

\subsection{DRY/WET COOL ING AMMONIA SYSTEMS}

Studies have shown that it may be economically advantageous to use a refrigerant (such as ammonia) instead of water in a dry cooling system. In such a concept liquid ammonia is vaporized in the power plant's condenser as the waste heat is transferred to it. The vapor is then transported to the dry cooling tower where it is condensed back to a liquid as its heat is transferred to the air.

Because no evaporation of water is involved in dry cooling systems, no cooling water is consumed and dry cooling systems do not have the make-up water requirements of evaporative systems. However, air-cooled heat exchangers are more costly than simple evaporative systems. Moreover, during hot weather, high air temperatures reduce the amount of heat that can be rejected by a dry system. It is desirable, then, to have a way to augment the performance of a dry system during hot weather. It is also desirable that such an augmentation system be applicable to an ammonia cycle dry cooling system.

Several concepts have been proposed for augmenting the performance of ammonia cycle dry cooling systems during hot weather. These will be described briefly.

The first and most simple augmentation concept is to not augment at all, but rather use very large dry cooling towers with low-cost efficient dry heat transfer surfaces to provide adequate heat rejection capacity during hot weather. The economic viability of nonaugmented dry cooling systems depends upon the availability of very low-cost air-cooled heat exchangers. Moreover, completely dry cooling would only be considered if water were totally unavailable for less expensive evaporative cooling.

The second most straightforward augmentation concept is shown schematically in Figure 1-1. It involves the use of a separate ammonia condenser to condense any ammonia vapor not condensed by the main dry cooling towers during 


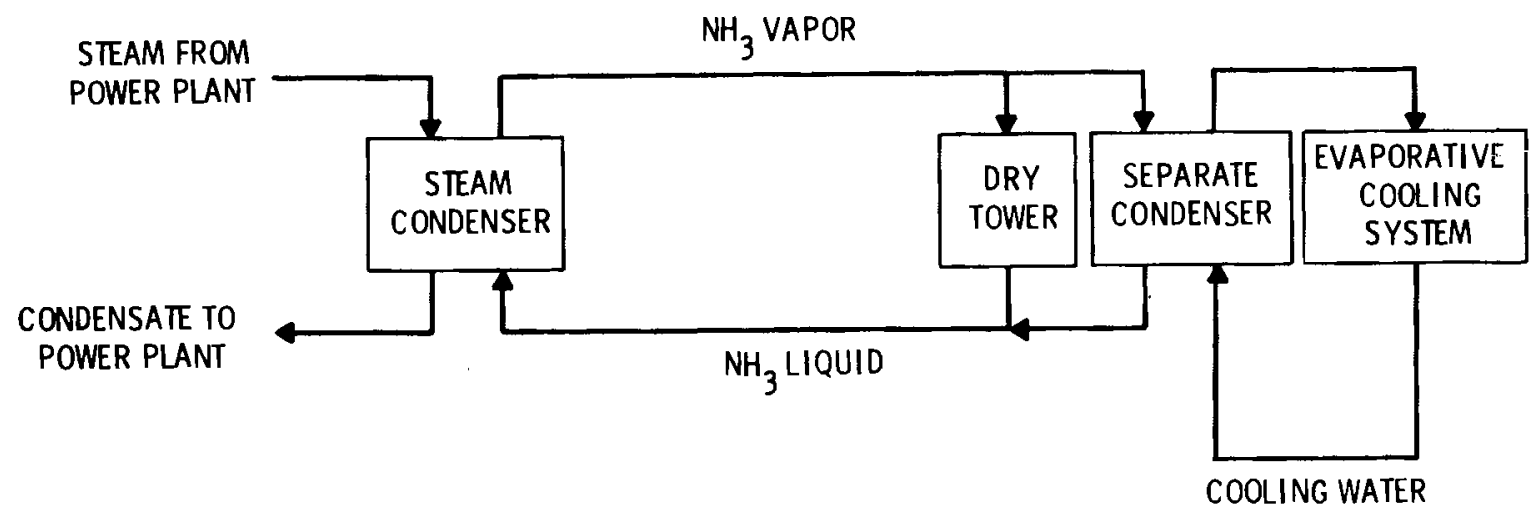

FIGURE 1-1. Separate Condenser Augmentation

hot weather. The separate condenser is in turn cooled by an evaporative system. This means that some water will be consumed during augmentation but the use of that water and the cost of an evaporative cooling tower or pond may be justified by the smaller less costly dry cooling tower.

A third augmentation concept integrates the separate condenser and the dry cooling tower into a unit referred to as the Separate Channel Augmented Tower (SCAT). The SCAT concept uses an air-cooled heat exchanger with small water-carrying passages adjacent to selected ammonia passages. When dry cooling alone is not sufficient, evaporatively cooled water may be passed through the water passages to provide additional cooling capacity. A separate evaporative cooling device (such as a wet cooling tower) is needed to reject the heat transferred from the ammonia to the augmentation water.

The fourth concept eliminates the need for a separate evaporative cooling system by integrating evaporative cooling augmentation into the dry tower itself. In this concept the air-side dry heat exchanger surfaces are wetted during hot weather. Evaporation of water from the surfaces then augments the dry system performance. The cooling tower is thus a combined dry tower and wet tower, and additional costs for evaporative augmentation are minimized. 


\subsection{REQUIRED DESIGN INFORMATION}

Some basic information is required to evaluate the potential cost effectiveness of any heat rejection system and to allow optimization of the system. It must be possible to predict the performance of the system over a wide range of weather conditions, thus accounting for the effect of changes in air temperature and humidity on performance. The effect of air velocity on heat transfer performance and required fan power are needed to optimize system design. The rate of evaporative water consumption is needed for an evaporatively augmented system. A workable concept for injecting water into the heat exchanger surface is required for a deluged tower system. The potential problems of deposition and/or corrosion on wetted surfaces must be evaluated to assess their possible impact on heat rejection performance. Physical characteristics such as heat exchanger weight and mounting requirements are necessary to estimate the support structure needed. Finally, to find the costoptimized system size and configuration, sufficient information to allow estimation of the cost of a potential design is needed.

\subsection{PACIFIC NORTHWEST LABORATORY TEST PROGRAM SCOPE}

The plan of the Pacific Northwest Laboratory's water augmentation test program has been to experimentally measure the parameters needed to evaluate the potential operating characteristics and cost effectiveness of evaporative augmentation systems. Tests carried out to date have been aimed at:

1) evaluating the dry heat transfer performance and air-side pressure drop characteristics of low-cost air-cooled heat exchangers that have been proposed for all-dry nonaugmented cooling towers, SCAT systems, and integrated dry/wet towers

2) evaluating analytical methods that have been used to predict the potential performance of a SCAT cooling system

3) developing systems for injecting a deluging flow of water onto a plate fin heat exchanger and evaluating the heat rejection performance

4) verifying analytical methods developed to predict performance of integrated dry/wet systems. 


\subsection{CURTISS-WRIGHT TEST OBJECTIVES}

Figure 1-2 shows a low-cost finned tubing design developed by the Curtiss-Wright Co. The design has extruded multipassage tubing with chipped fins on the air side. The tubing can be made in a wide variety of shapes and sizes. Because of its claimed low cost, tubing of this configuration has been proposed for use with an all-dry nonaugmented ammonia cooling system. To evaluate the potential cost effectiveness of such a system, testing of the Curtiss-Wright surface was aimed at measuring dry nonaugmented heat transfer performance. In particular, the effect of airflow velocity on the air-side heat transfer coefficient and the air-side pressure drop were needed. It was also desirable to determine the effect of fin spacing and configuration on performance.

The Curtiss-Wright tubing has also been proposed for use with the SCAT concept, in which evaporatively cooled augmentation water would flow through selected passages adjacent to the ammonia passages (see Figure 1-3). A method for predicting performance of such a configuration has been developed at PNL. Tests were performed which verified the accuracy of that method.

In summary, the objectives of the Curtiss-Wright surface tests were:

1) to determine the effect of airflow on the air-side heat transfer coefficient and air-side pressure drop of the all-dry surface

2) to investigate the effects of fin spacing and configuration on performance

3) to verify the accuracy of the analytical method used to predict performance of Curtiss-Wright tubing used in a SCAT system.

\subsection{HÖTERV TEST OBJECTIVES}

A proprietary slotted plate fin heat exchange surface (see Figure 1-4) developed by HÖTERV in Hungary has been proposed for use in an integrated dry/wet tower, in which evaporative augmentation is provided by deluging the air-side surfaces during warm weather. Such a design has been installed in a power plant in the U.S.S.R. 


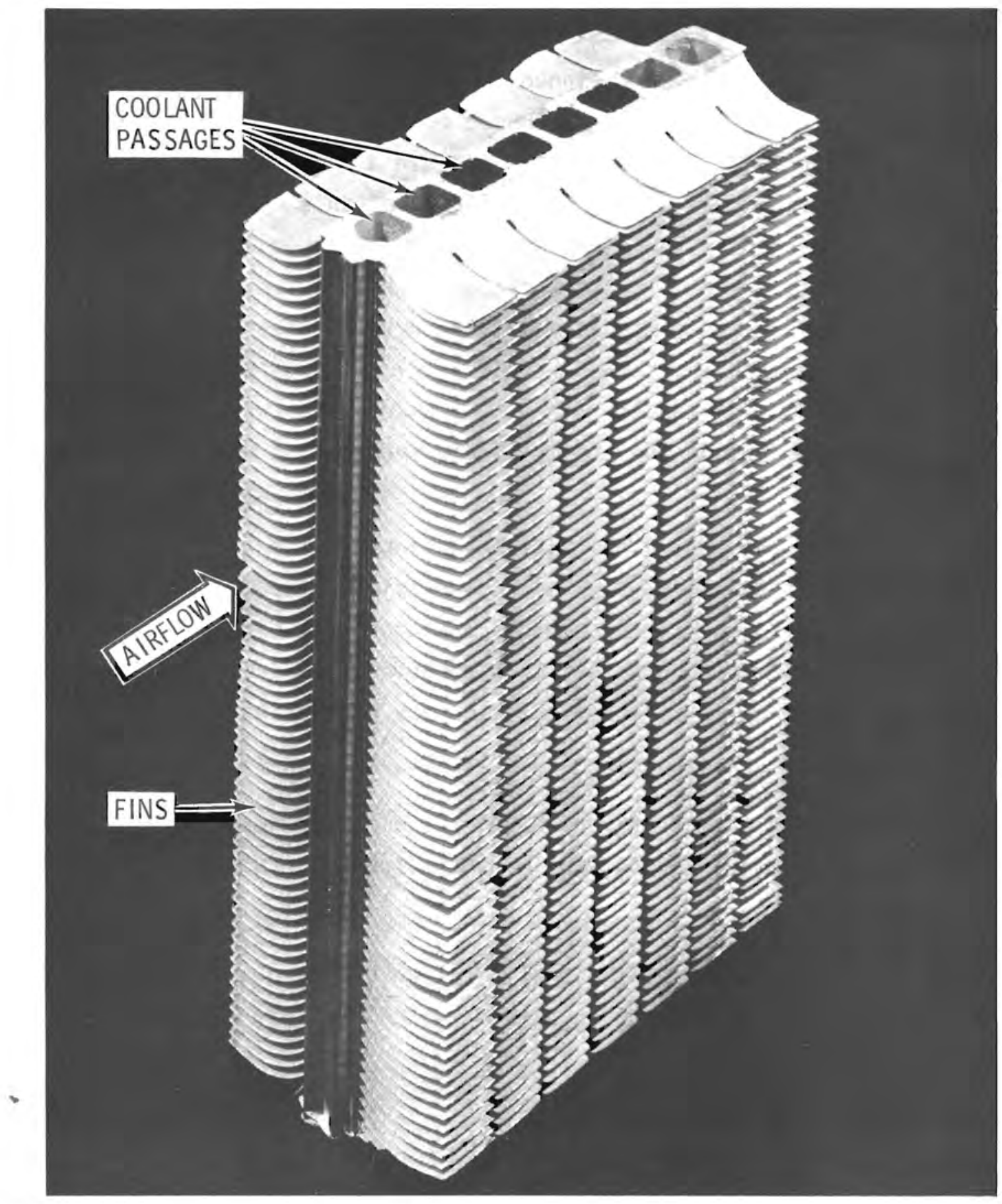

FIGURE 1-2. Curtiss-Wright Tubing - General Configuration 


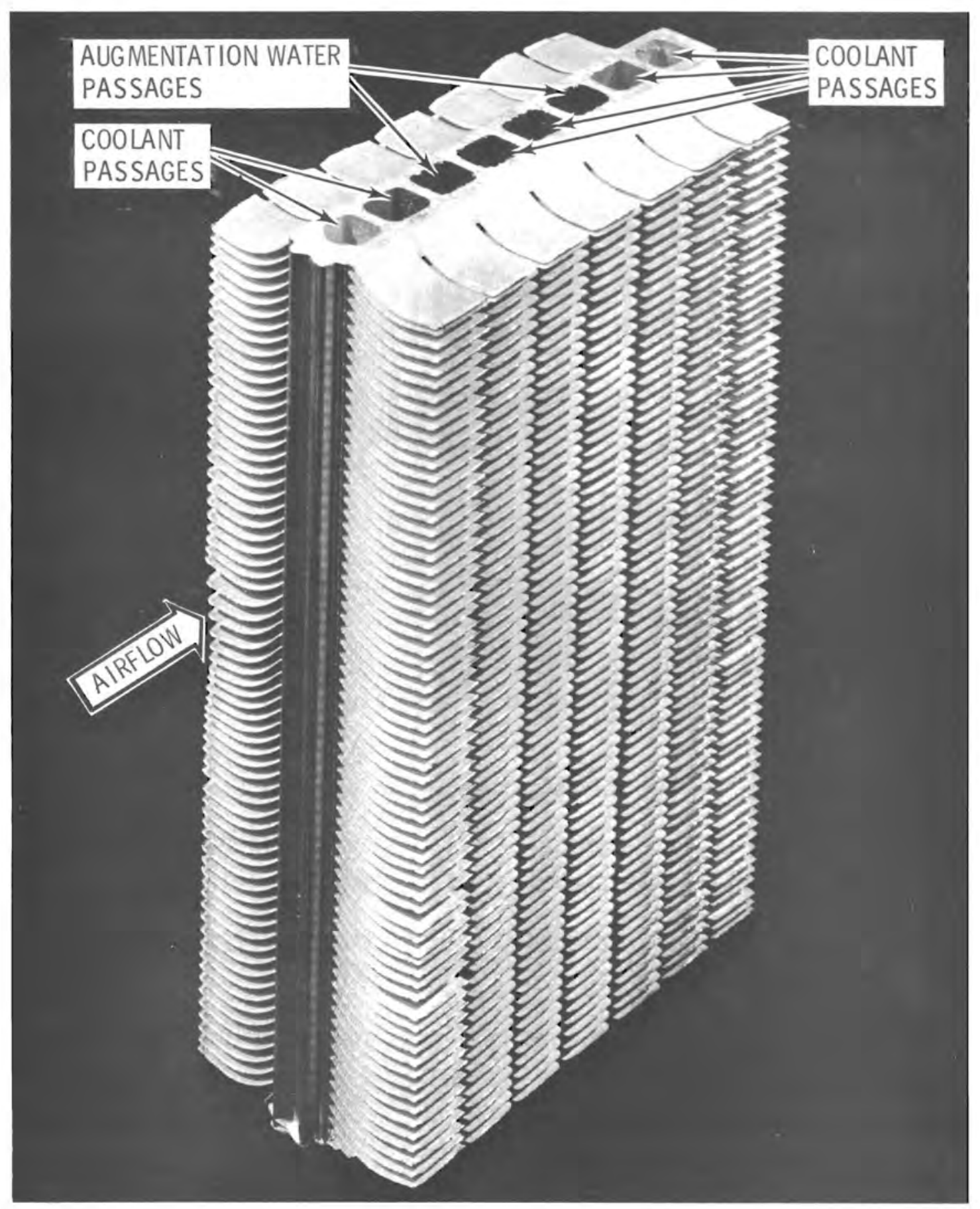

FIGURE 1-3. Curtiss-Wright Tubing - Possible SCAT Configuration 


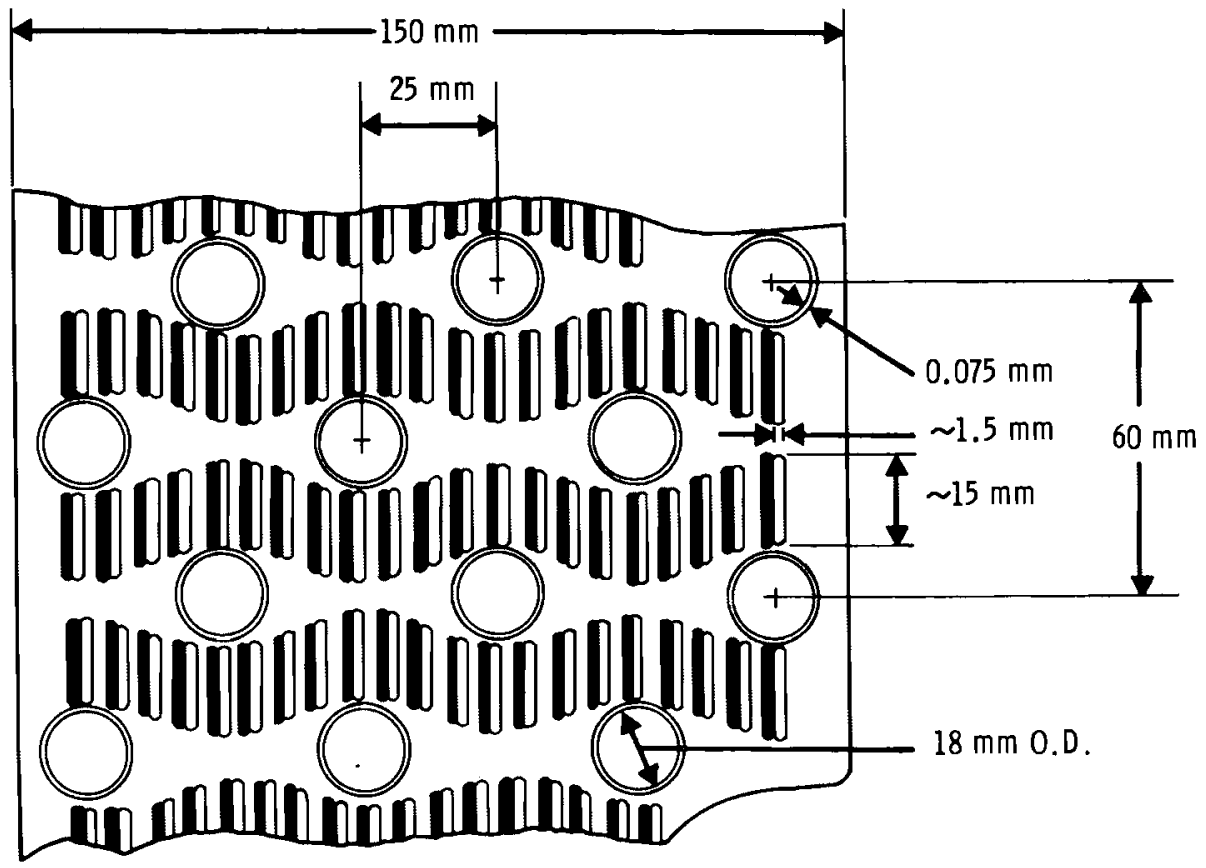

HOTERV SURFACE

FIGURE 1-4. HÖTERV Plate Fin Surface

The objectives of HÖTERV surface testing in WATA were:

1) to determine all-dry nonaugmented performance for comparison with other air-cooled heat exchanger surfaces such as the Curtiss-Wright surface

2) to develop methods for introducing a uniform deluge flow onto the airside heat transfer surface

3) to determine the physical operating limits of the deluged surface, particularly the limits of airflow and deluge flow such that a wetted surface is maintained

4) to establish the magnitude of the potential benefit due to augmentation

5) to measure heat transfer performance and air-side pressure drop as they are affected by weather conditions (air temperature and humidity), airflow rate and deluge flow rate

6) to compare measured performance to performance predicted by analytical models developed at PNL to verify and help refine those models. 


\subsection{WATER AUGMENTATION TEST APPARATUS}

All testing took place in the Water Agumentation Test Apparatus (WATA), an experimental test facility designed by PNL and shown in Figure 2-1. Figure 2-2 shows a schematic diagram of the facility. The WATA consists of three fluid loops: the air loop, circulation water loop, and augmentation water loop. These loops come together in the heat exchanger test section.

The air loop is an open-ended single-pass loop designed to provide uniform airflow through the test section at a desired temperature and humidity and at approach velocities from $3 \mathrm{ft} / \mathrm{sec}$ to $16 \mathrm{ft} / \mathrm{sec}$. Outside air is brought in through a centrifugal blower whose output is variable from $2100 \mathrm{cfm}$ to $12000 \mathrm{cfm}$. After leaving the blower, the air passes through a steam heating unit and then through a steam humidification section to provide inlet air at the desired wet and dry bulb temperatures. The air then flows through a restricted mixing section before passing through a vaned expansion section with a $2 \mathrm{ft} \times 6 \mathrm{ft}$ outlet. A screen pack at the expansion section outlet helps maintain flow uniformity. The air then passes through a vaned $2 \mathrm{ft} x$ $6 \mathrm{ft} 90^{\circ}$ elbow, and another screen pack, and then through a 4-ft approach section of the same cross section as the $2 \mathrm{ft} \times 6 \mathrm{ft}$ test core.

Out of the test core section the air flows through a 3-ft section of $2 \mathrm{ft} \times 6 \mathrm{ft}$ duct, through a contraction, through a flexible duct, then into an 18-in. diameter, 20-ft long section of straight duct before being exhausted to the outside. The straight section is equipped with an Annubar flow sensor used to measure the air mass flow rate through the test section.

The air loop has been designed to permit flexibility in core orientation and airflow direction. Figures 2-3 through 2-6 show the various combinations of core orientation and airflow direction attainable with the WATA.

The circulation loop provides the heat to be rejected by the test core. A centrifugal pump capable of up to $365 \mathrm{gpm}$ flow pulls water from a 400-gal storage tank. Part of the flow is passed through a 90-kW SCR-controlled electric circulation heater. The heated water is then mixed with the remainder of the circulation water flow and fed to the test core inlet manifold. After 


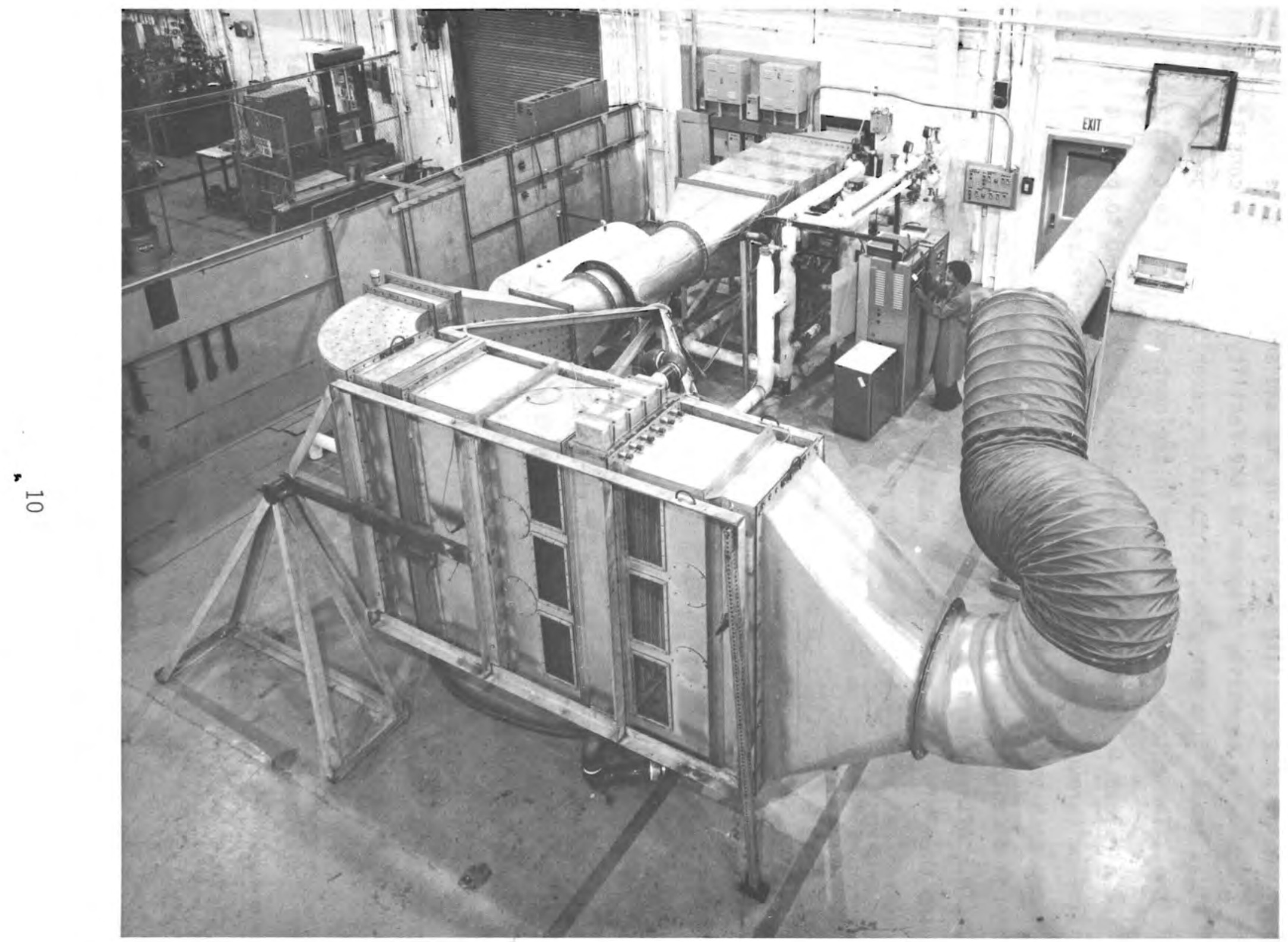

FIGURE 2-1. Water Augmentation Test Apparatus 


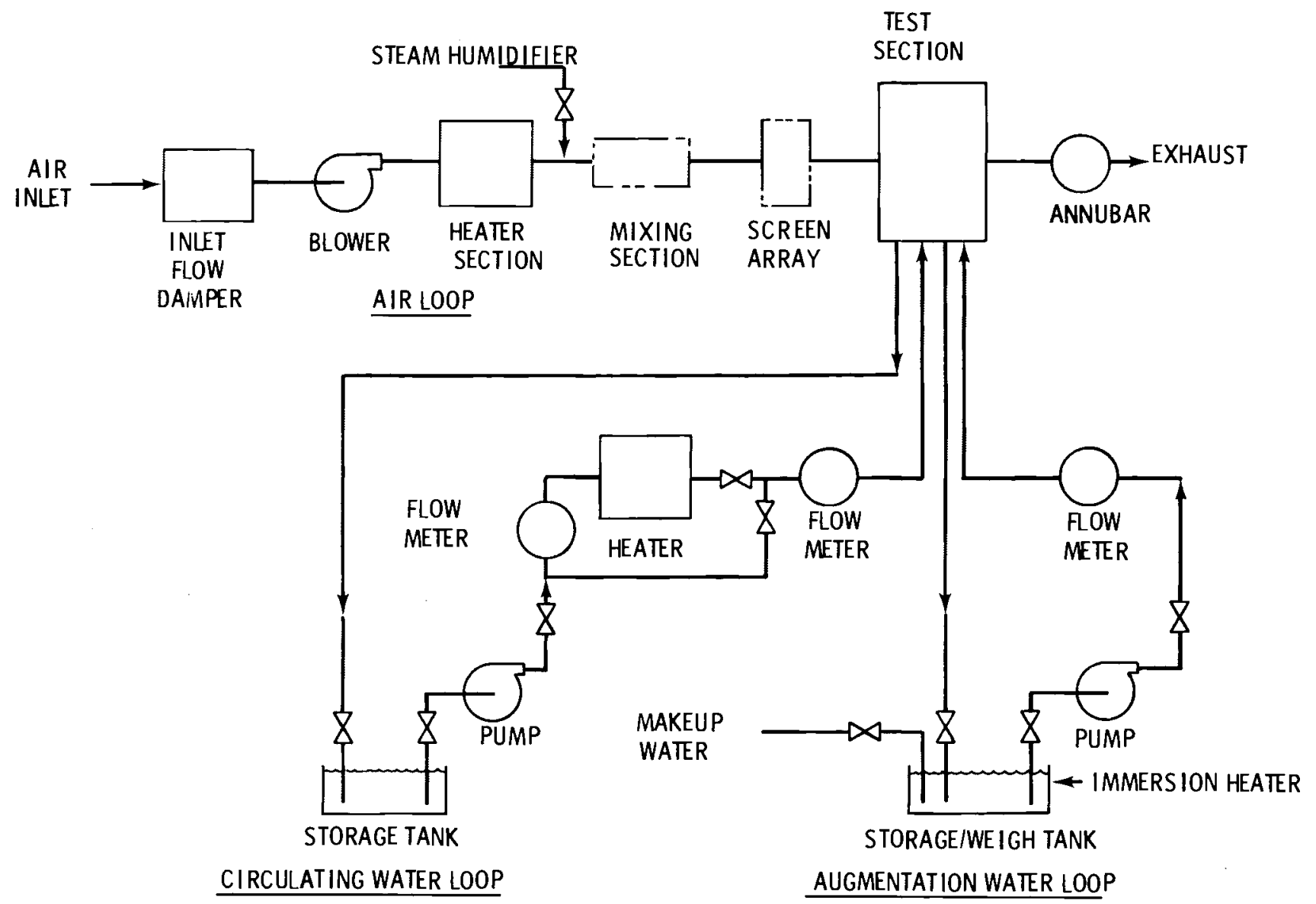

FIGURE 2-2. WATA Schematic 


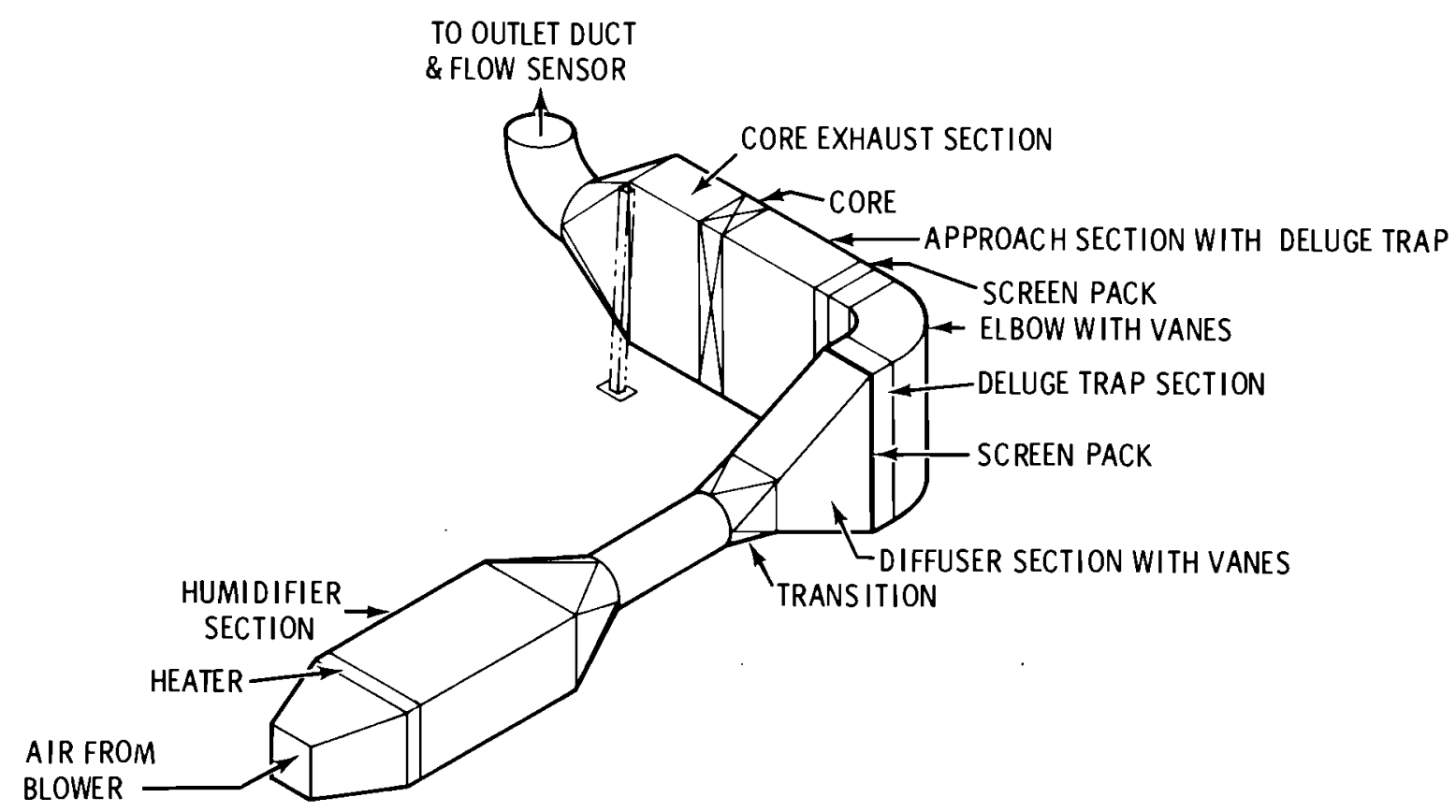

FIGURE 2-3. WATA Air Ducting - Horizontal Airflow

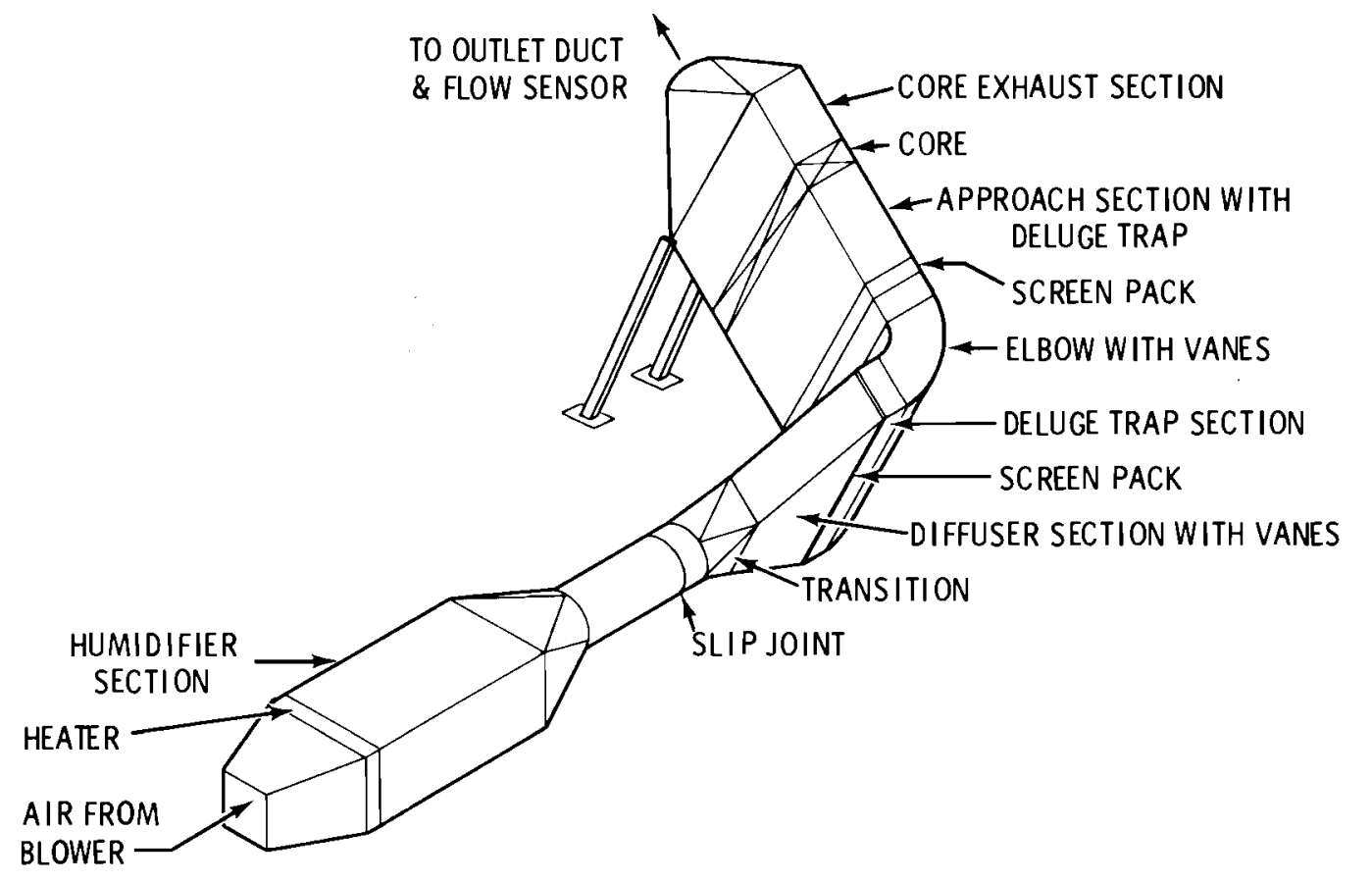

FIGURE 2-4. WATA Air Ducting - Upward Airflow at Any Angle Up to $45^{\circ}$ 


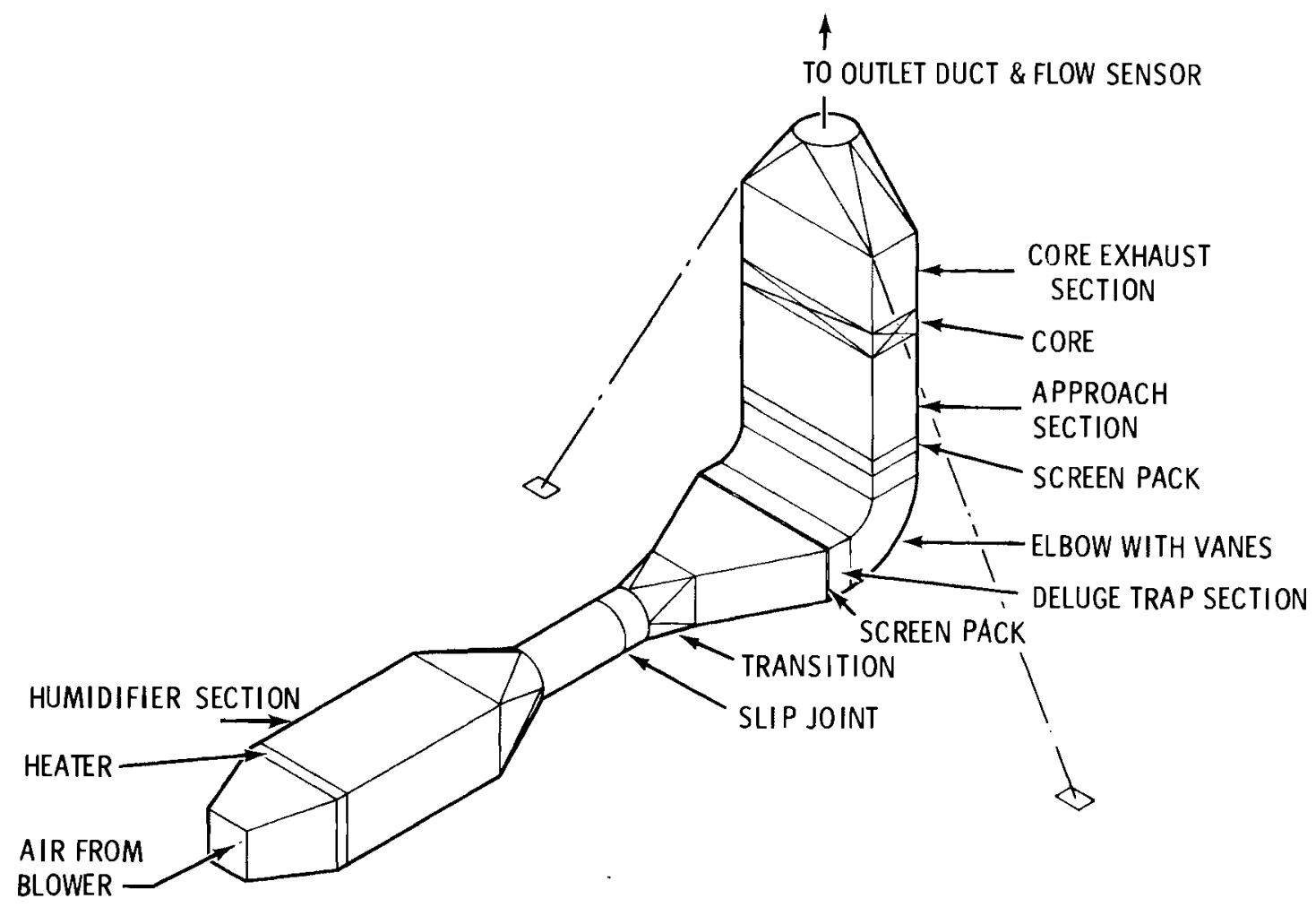

FIGURE 2-5. WATA Air Ducting - Airflow Vertically Upward

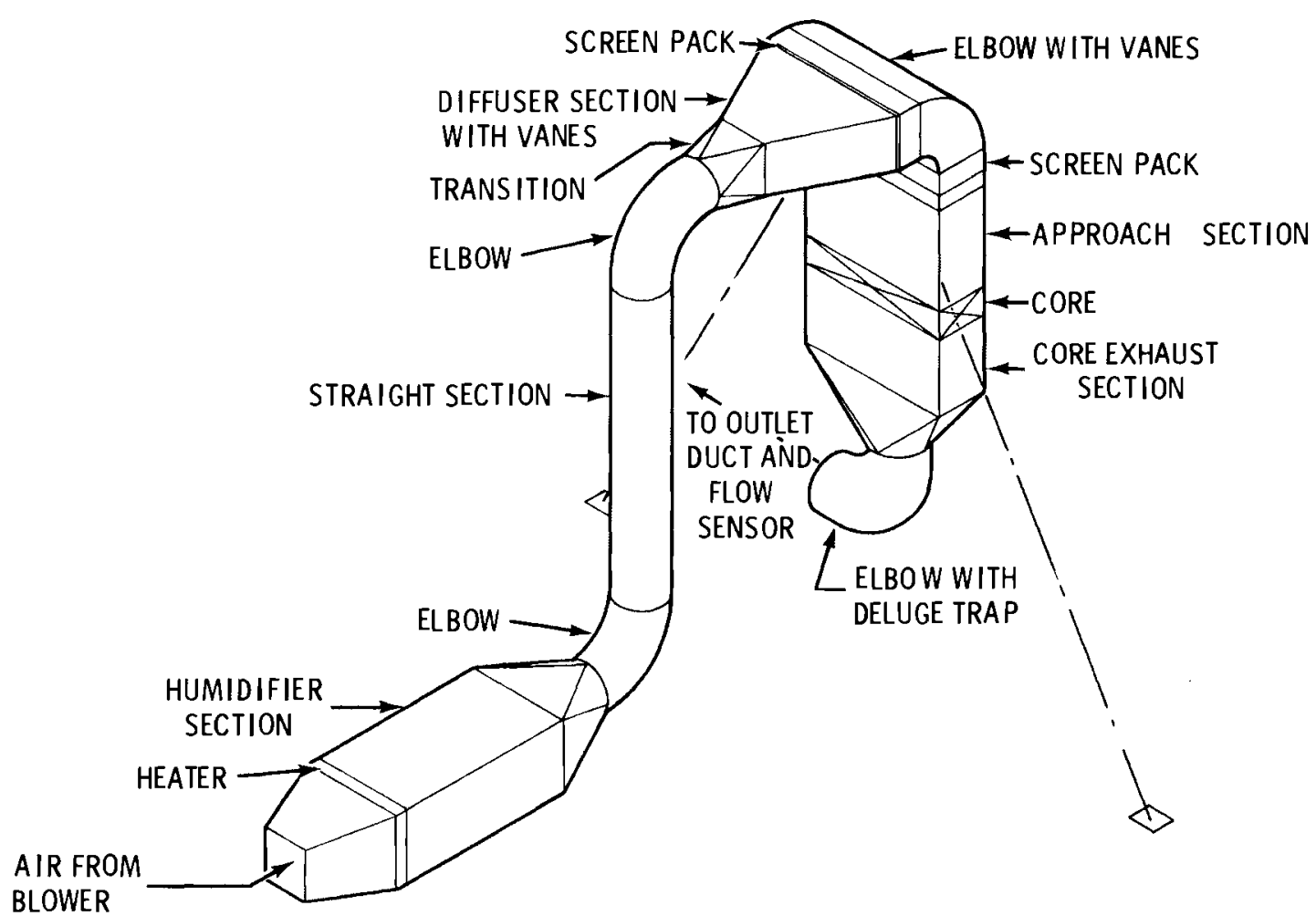

FIGURE 2-6. WATA Air Ducting - Airflow Vertically Downward 
being cooled in the test core, the circulation water returns to the storage tank and is ready for recirculation.

The augmentation loop is used for evaluating deluged heat exchangers for integrated dry/wet towers. A centrifugal pump with a 25-gpm (maximum) capacity draws water from a 40-gal weigh tank and pumps it to the deluge injection point located at the top of the deluged test core. After the deluge water passes over the air-side surfaces of the core, it is collected in a catch basin at the base of the test core. A second pump then returns the deluge water to the weigh tank. Water may be added to the weigh tank from a deluge storage tank when the water in the weigh tank has been depleted by evaporation on the test core.

The three loops come together in the test core. The test core section consists of a $6-\mathrm{ft}$ high $\times 2-\mathrm{ft}$ wide $\times 1-\mathrm{ft}$ deep duct section surrounding the specific heat exchanger core being tested. The specific cores tested will be discussed in Section 3.0.

\subsection{MEASURED PARAMETERS}

Five parameters are measured in the WATA facility:

- temperature

- air dewpoint

- airflow

- water flow

- pressures.

\subsubsection{Temperature}

Calibrated shielded copper constantan thermocouple probes accurate to $\pm 0.5^{\circ} \mathrm{F}$ are located as listed below:
a) blower inlet
b) in the airflow 17 in. upstream of the test core (4)
c) in the airflow 17 in. downstream of the test core (4)
d) in the airflow adjacent to the Annubar
e) exposed to room air adjacent to the test core
f) circulation water storage tank 
g) 90-kW heater inlet (2)

h) $90-\mathrm{kW}$ heater outlet (2)

i) core inlet manifold ( 2 to 4 depending on core)

j) core outlet manifold ( 2 to 4 depending on core)

k) augmentation water storage tank

1) augmentation water weigh tank

m) augmentation water injection point (2)

n) augmentation water collection basin (4)

\subsubsection{Air Dewpoint}

Early tests determined the air dewpoint upstream and downstream of the test core with two General Eastern Mode 1600 saturated salt dewpoint sensors located in the airflow. These units have a claimed accuracy of $\pm 2^{\circ} \mathrm{F}$. Later tests were made with two General Eastern Model 1200 EP optical hygrometers fed by aspirated probes. Two probes were located $15 \mathrm{in}$. upstream of the core and five probes were located $23 \mathrm{in}$. downstream of the core.

\subsubsection{Airflow}

Total airflow is measured with an 18-in. calibrated Annubar with a manufacturer's claimed accuracy of $\pm 4 \%$ of reading. Readout is accomplished through a Dwyer Model 246 inclined manometer with a claimed accuracy of \pm 0.02 in. $\mathrm{H}_{2} \mathrm{O}$. Airflow uniformity may be checked by traverses in front of the test section using a Thermo Systems Model 1054B linearized hot film anemometer with a manufacturer's claimed accuracy of $\pm 1 \%$ of reading.

\subsubsection{Water Flow}

Cox turbine flowmeters, calibrated to an accuracy of $\pm 0.5 \%$ of flow, are used to measure three water flow rates:

a) total deluge flow rate

b) total circulation water flow rate

c) circulation water flow rate through the 90-kW circulation heater.

\subsubsection{Pressures}

Static pressure is measured upstream of the test core and downstream of the test core with a Wallace and Tiernan precision aneroid manometer claimed accurate to $\pm 0.03 \mathrm{in}$. Hg. Ambient barometric pressure is measured with the 
same device. Air-side pressure drop across the core is measured with a Dwyer Model 246 inclined manometer claimed accurate to \pm 0.02 in. $\mathrm{H}_{2} \mathrm{O}$. Four static pressure probes are located 21 in. upstream of the core and four are located 21 in. downstream of the core. The downstream probes are in fully regained flow.

\subsection{TEST CORE HEAT REJECTION RATE DETERMINATION METHOD}

The total rate of heat rejection from a given test core may be determined from the equation

$$
\dot{Q}_{R E J}=\dot{m}_{p} C_{p} \Delta T_{p}
$$

where

$$
\begin{aligned}
\dot{Q}_{\text {REJ }} & =\text { rate of test core heat rejection, } B t u / h r \\
\dot{m}_{p} & =\text { circulation water mass flow rate, } 1 b_{m} / h r \\
C_{p} & =\text { circulation water specific heat, Btu/lb } \mathrm{m} \\
\Delta T_{p} & =\text { temperature drop of circulation water across the core. }
\end{aligned}
$$

However, to insure fully turbulent circulation water flow in the test core and to approximate the near isothermal core tube temperature that would be found in an ammonia cooling tower, it is desirable to maintain high circulation water flow rates during testing. This results in $\Delta T_{p}$ values of only 1 to $2^{0} \mathrm{~F}$. Because of the high percentage uncertainty that would result from measuring such a small temperature drop, an alternative means for determining $\dot{Q}$ was used based on the following equation:

$$
\begin{aligned}
\dot{Q}_{\text {REJ }}= & \dot{m}_{h} c_{c} \Delta T_{h}+\dot{Q}_{\text {PUMP }}-\dot{Q}_{\text {LOSSES }} \\
= & \dot{m}_{h} c_{c} \Delta T_{h}+\dot{Q}_{\text {PERIPHERAL }}
\end{aligned}
$$

where

$$
\begin{aligned}
\dot{Q}_{R E J}= & \text { rate of test core heat rejection, Btu/hr } \\
\dot{m}_{h}= & \text { circulation water mass flow through the circulation } \\
& \text { heater, } 1 b_{m} / \mathrm{hr}
\end{aligned}
$$




$$
\begin{aligned}
C_{c}= & \text { circulation water specific heat, Btu/1 } b_{m}{ }^{0} F \\
\Delta T_{h}= & \text { temperature rise across the circulation heater, }{ }^{o_{F}} \\
\dot{Q}_{\text {PUMP }}= & \text { rate of heat addition to circulation water by the } \\
& \text { circulation pump, Btu/hr } \\
\dot{Q}_{\text {LOSSES }} & \text { rate of heat lost to the atmosphere through piping, tank } \\
& \text { walls, and manifolds, Btu/hr } \\
\dot{Q}_{\text {PERIPHERAL }}= & \dot{Q}_{\text {PUMP }}-\dot{Q}_{\text {LOSSES }}
\end{aligned}
$$

During testing, $\dot{m}_{h}$ was adjusted to give a value of $\Delta \mathrm{T}_{h}$ of over $10^{\circ} \mathrm{F}$ as measured by a differential thermocouple circuit. This insured an acceptably small uncertainty in the measurement of $\Delta T_{h}$. For each test core, families of curves were generated relating $\dot{Q}_{\text {PERIPHERAL }}$ to the average temperature difference between room air and circulation piping and to the circulation water flow rate. These curves were generated by well insulating the air-side heat transfer surfaces of the test core and measuring the rate of temperature change of the known circulation water inventory for various circulation flow rates and circulation water temperatures at zero heater input. Thus,

$$
\dot{Q}_{\text {PERIPHERAL }}=m_{c} c_{c} \frac{\Delta T}{\Delta t}
$$

where

$$
\begin{aligned}
& m_{c}=\text { circulation water inventory, } 1 b_{m} \\
& \frac{\Delta T}{\Delta t}=\text { change in average water temperature over time interval } \Delta t, 0 F / h r
\end{aligned}
$$

Once the family of curves was generated, the value of $\dot{Q}_{\text {PERIPHERAL }}$ could be determined for any test condition and added to the circulation heater rate to obtain the core heat rejection rate. For all cores tested, QPERIPHERAL was positive (i.e., the pump added more heat than was lost by the piping). Typically, $\dot{Q}_{\text {PERIPHERAL }}$ was less than $10 \%$ of the total $\dot{Q}_{\text {REJ }}$. 


\subsection{UNCERTAINTY ANALYSIS SUMMARY}

Any experimentally derived value has an uncertainty associated with it. That uncertainty is caused by the inherent uncertainty in the measured variables and parameters used to derive the value. The purpose of an uncertainty analys is is to estimate the probable uncertainty in an experimentally derived value based on the uncertainty of the measurements used to derive it. In this way the expected magnitude of scatter or inconsistency in the experimental results can be estimated. If the actual observed inconsistency is appreciably greater than that predicted, problems such as the existence of uncontrolled variables may exist in the experimental facility or procedure. This may also indicate that the methods being used to analyze the data or the theory to which the results are being compared do not fully account for all the controlling variables. An uncertainty analys is aimed at predicting probable experimental uncertainty is particularly valuable in the WATA test program where the analytical methods being used to predict deluged performance are as yet unproven and may not fully account for all variables.

The probable uncertainty for the WATA test results to be presented in Section 3.0 is indicated by bars showing the uncertainty range for representative data points. Where data points are very close together, uncertainty bias are shown on representative points. Probable uncertainties have been determined using the method suggested by $\mathrm{Kline}$ and McClintock ${ }^{(1)}$ in which

$$
\delta R=\left[\left(\frac{\partial R}{\partial X_{1}} \delta x_{1}\right)^{2}+\left(\frac{\partial R}{\partial X_{2}} \delta x_{2}\right)^{2}+\cdots\left(\frac{\partial R}{\partial X_{n}} \delta x_{n}\right)^{2}\right]^{1 / 2}
$$

where

$$
\begin{aligned}
R & =\text { the experimental result, a function of several variables }\left(X_{i}\right) \\
\delta R & =\text { the probable uncertainty in } R \text { at } 20: 1 \text { odds } \\
\delta X_{i} & =\text { the uncertainty in } X_{i} \text { where } X_{i}=\bar{X}_{i} \pm \delta X_{j} \text { at } 20: 1 \text { odds }
\end{aligned}
$$

and where $\frac{\partial R}{\partial X_{i}}$ has been evaluated approximately using the expression 


$$
\begin{aligned}
& \frac{\partial R}{\partial x_{i}} \triangleq \lim _{\Delta x_{i} \rightarrow 0} \frac{R\left(x_{i}+\Delta x_{i}\right)-R\left(x_{i}\right)}{\Delta x_{i}} \\
& \simeq \frac{R\left(x_{i}-\delta x_{i}\right)-R\left(x_{i}\right)}{\delta x_{i}}
\end{aligned}
$$

It should be noted that the determination of values for $\delta x_{j}$ to be used in evaluating $\delta R$ requires some judgment on the part of the experimenters. Uncertainties in the individual variables measured in the WATA facility have been estimated based on instrument manufacturers' claims, observed instrument fluctuation noted from repeated readings under steady-state conditions, and past experience. The major sources of uncertainty have been found to be the measurement of temperature rise across the circulation heater and the measurement of air dewpoint temperature upstream and downstream of the test cores. Uncertainty in the circulation heater temperature rise affects the uncertainty of both dry and deluged results, while dewpoint temperature uncertainty affects only deluged results.

\subsection{DELUGE INJECTION SYSTEM}

Before testing the deluged HÖTERV test core it was necessary to develop a system for injecting a flow of deluge water onto the air-side surface. The goal was to develop a system that would distribute the water onto the surface as uniformly as possible over a wide range of deluge flow rates, airflow velocities and core tilt angles. The system adopted is shown in Figure 2-7 and was used for all deluged testing. This simple system consists of a perforated pipe manifold delivering deluge water to a bed of plastic distribution rings placed directly on the top of the test core cooling fins. The particular design of plastic distribution ring used is shown in Figure 2-8. This ring was used because it was readily available at PNL. Other distribution ring styles would probably work as well. Small baffle plates were attached to 


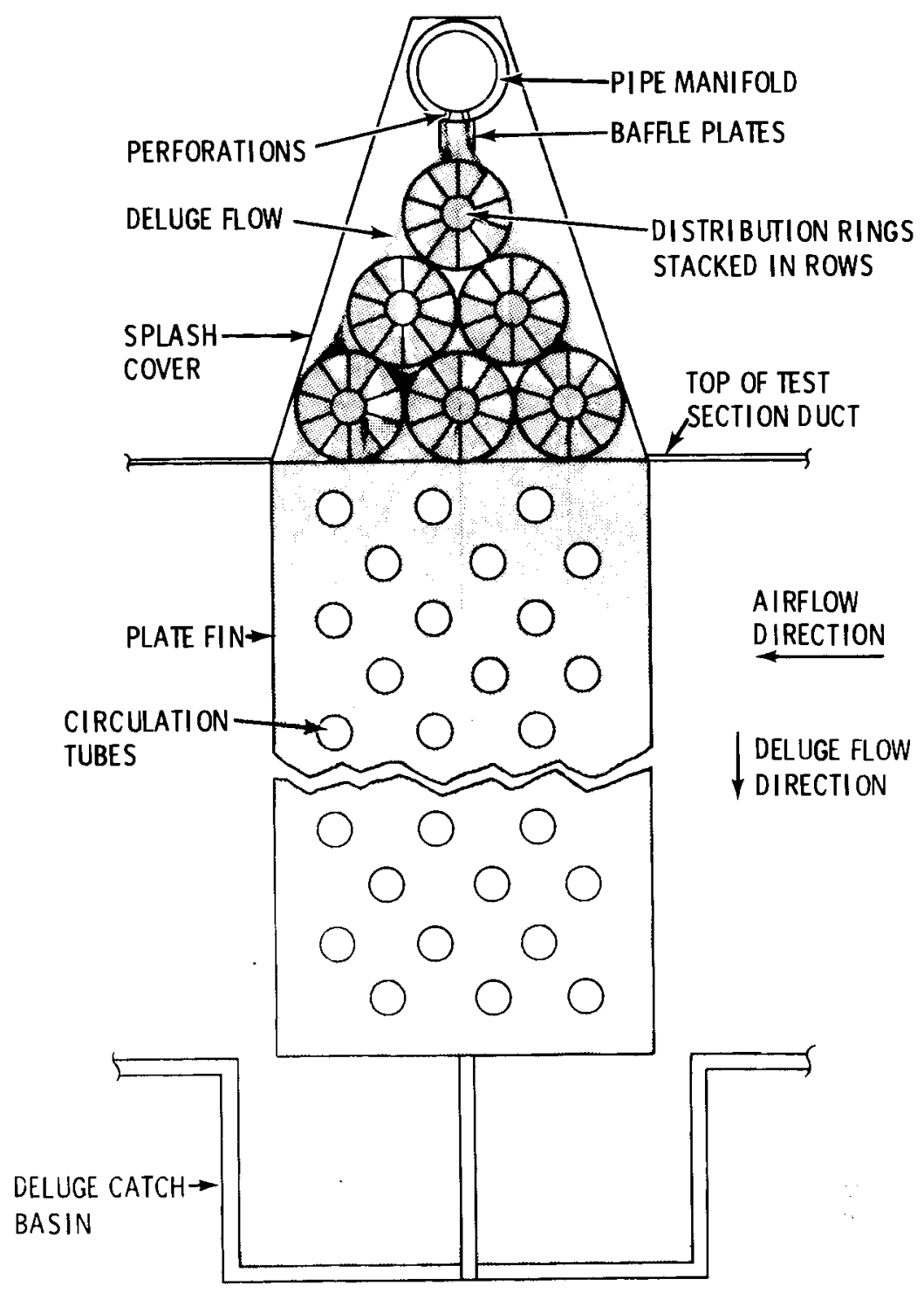

FIGURE 2-7. Deluge Injection System Used in WATA

the perforated manifold as shown in Figure 2-7 to allow the deluge flow to be biased toward the leading or trailing edge of the test core. This encouraged uniform flow distribution to the test core surface at varying core tilt angles and would probably not be needed for an actual installation where tilt angle would be fixed. Observers judged that the distribution system introduced an adequately uniform flow of water to the air-side surfaces over the full range 


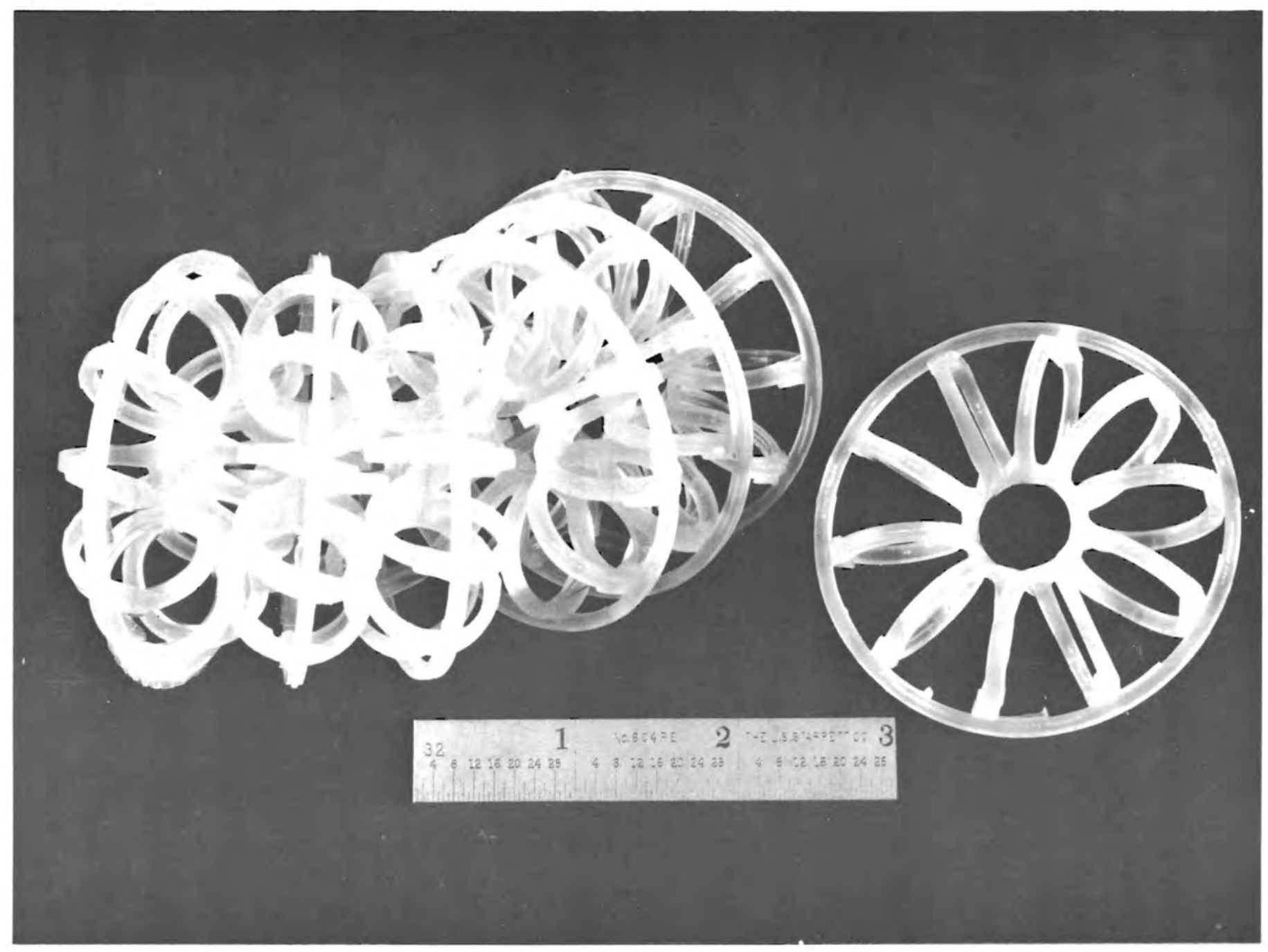

FIGURE 2-8. Plastic Distribution Ring 


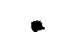

-

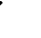

. 
perforated pipe manifold as shown in Figure 2-9b. This concept provided better flow distribution than the single baffle plate concept but flow was not as uniform as with the distribution ring system. Moreover, flow uniformity was seriously degraded as the core was tilted from vertical.

It should be noted that, although the distribution ring system used in the tests provide a fairly uniform flow at the top of the air-side surface, this uniformity was not maintained as the deluge water flowed from the top of the core to the bottom. The characteristics of deluge flow on the finned surface will be discussed in Section 3.3 of this report. 


\subsection{HEAT TRANSFER PERFORMANCE}

\subsection{BASELINE PERFORMANCE OF DRY HOTERV AND CURTISS-WRIGHT SURFACES}

Baseline dry heat transfer performance was evaluated for two CurtissWright tubing designs and for a HÖTERV enhanced plate-fin surface. Figure 3-1 shows the two Curtiss-Wright surfaces evaluated. They differ in fin spacing, fin thickness, and the presence of slots in the fins. Surface "A" has 9 fins/in., an average fin thickness of 0.020 in., and unslotted fins. Surface "B" has 12 fins/in., an average fin thickness of 0.018 in., and slots as shown in Figure 3-1. Tubes of each type were assembled into test cores as shown in Figure 3-2. The cores were 2 tubes deep and 12 tubes wide, creating a core depth of $6.9 \mathrm{in}$. and width of $24 \mathrm{in.}$ Net tube height was $72 \mathrm{in.}$ The HÖTERV test core is shown in Figure 3-3. It used plates $72 \mathrm{in.} \mathrm{high} \mathrm{and} \mathrm{hori-}$ zontal staggered tubes $24 \mathrm{in}$. in length. Core depth was $5.9 \mathrm{in.}(15.0 \mathrm{~cm})$. Figure 3-4 shows the slot-enhanced fin surface and the tube spacing. Details of the physical dimensions and computed geometric properties of each surface are given in Appendix $D$.

Dry testing was performed at high circulation water flow rates (typically $365 \mathrm{gpm}$ ) to simulate isothermal ammonia condensation. Typical circulation water temperature drop in the test cores was 1 to $2^{\circ} \mathrm{F}$. Air-side pressure drop data were collected under isothermal conditions (circulation water heater off).

Figure 3-5 gives the results of the baseline testing for the dry surfaces. Values of effective friction factor, $f_{0}$, and effective air-side Colburn $j$-factor, $j_{0}$, are shown as functions of the air Reynolds number at minimum airflow cross sectional area. The various factors are defined as follows :

$$
f_{0}=\frac{g_{c} \bar{\rho}_{a} D_{H} \Delta P}{2 L G_{\infty}^{2}}=\frac{2 g_{c} \bar{\rho}_{a} A_{\min } \Delta P}{A_{S} G_{\infty}^{2}}
$$

Note that, as defined, $f_{0}$ includes core inlet and outlet pressure losses. 


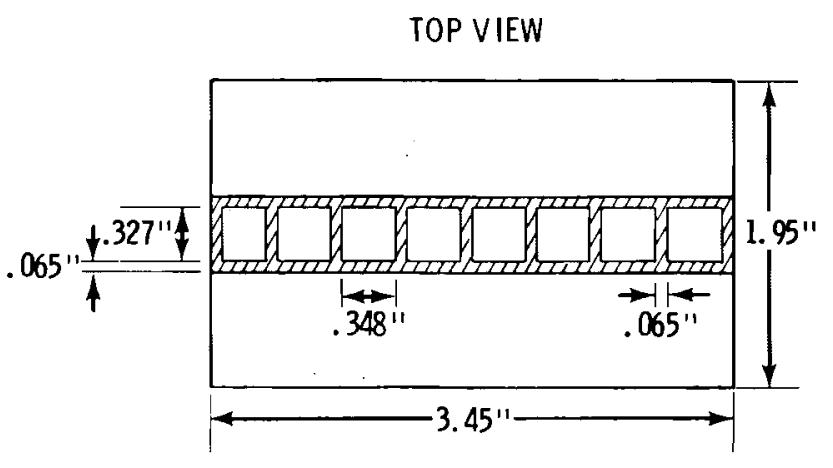

a. Surface "A"
EDGE VIEW

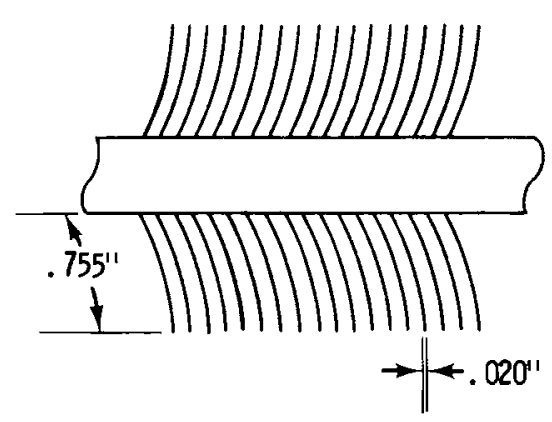

PITCH = 9 FINS/in.

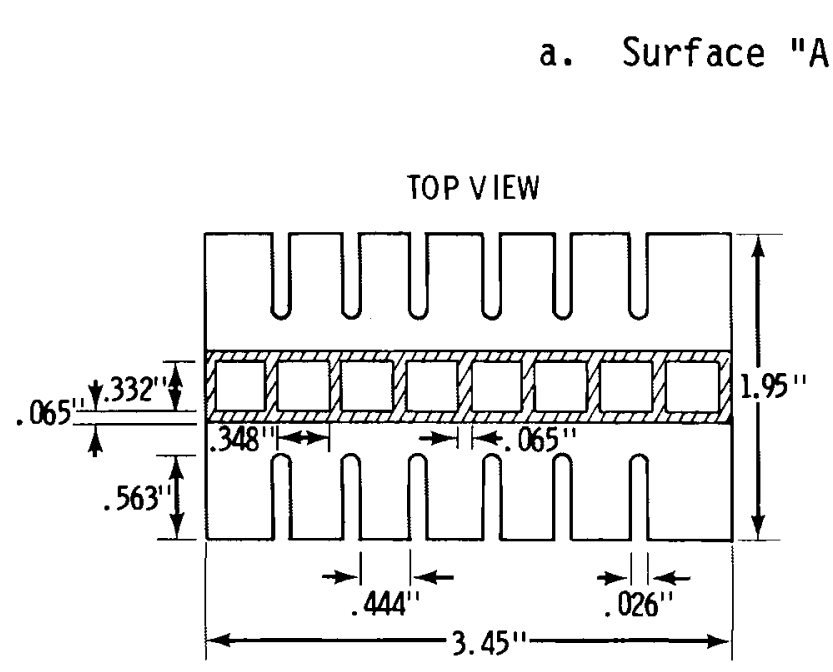

b. Surface "B"

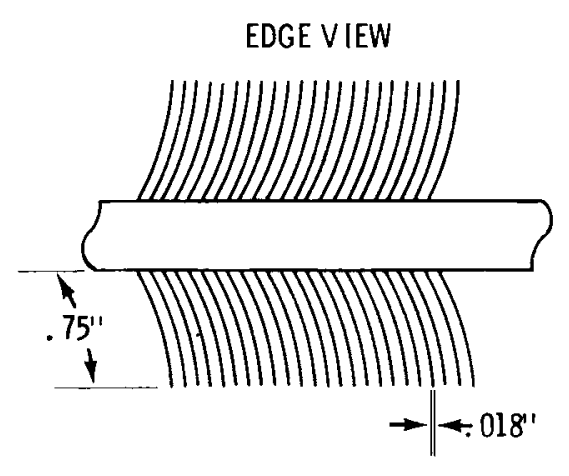

PITCH $=12$ FINS $/$ in.

FIGURE 3-1. Curtiss-Wright Surfaces 


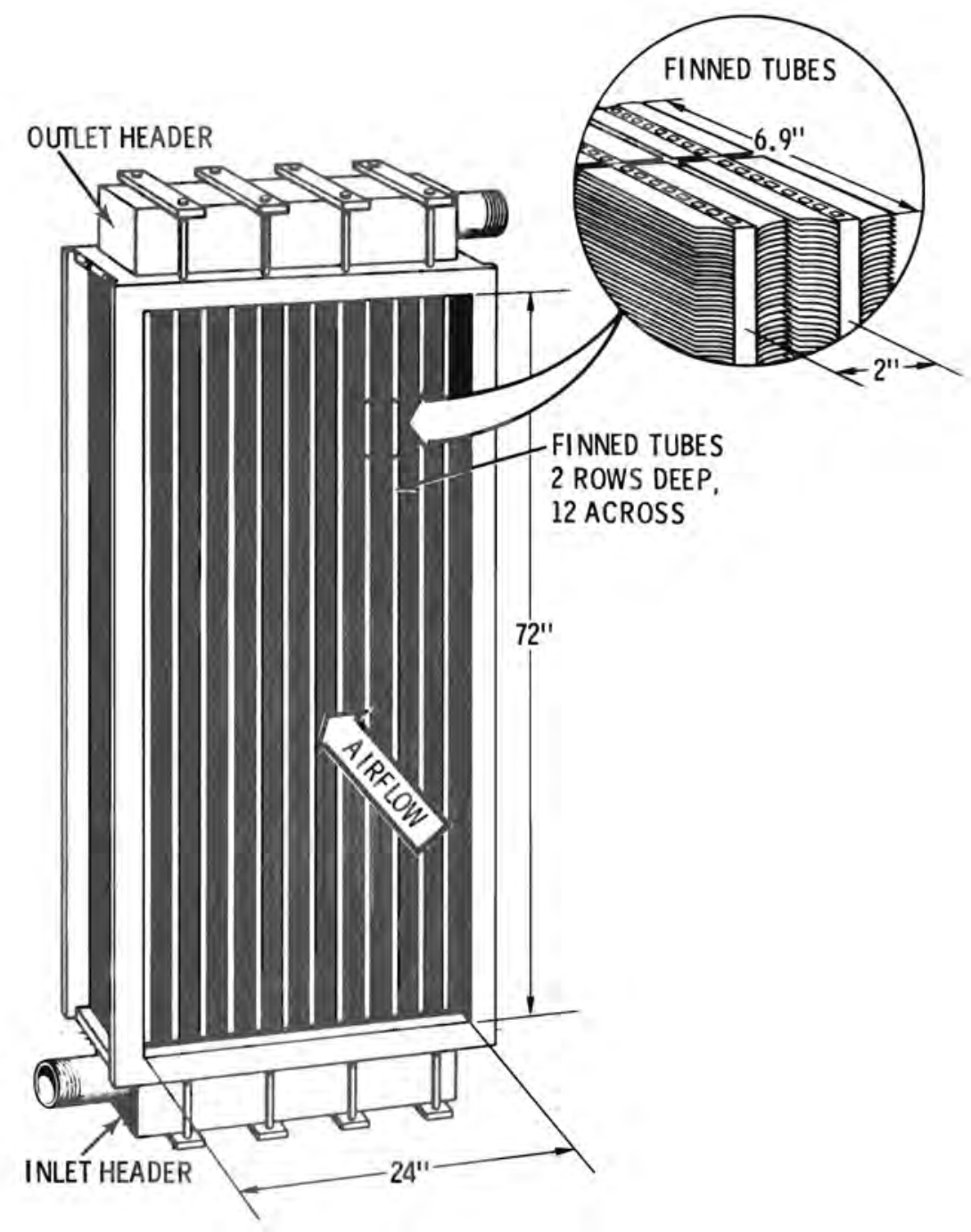

FIGURE 3-2. Curtiss-Wright Test Core 


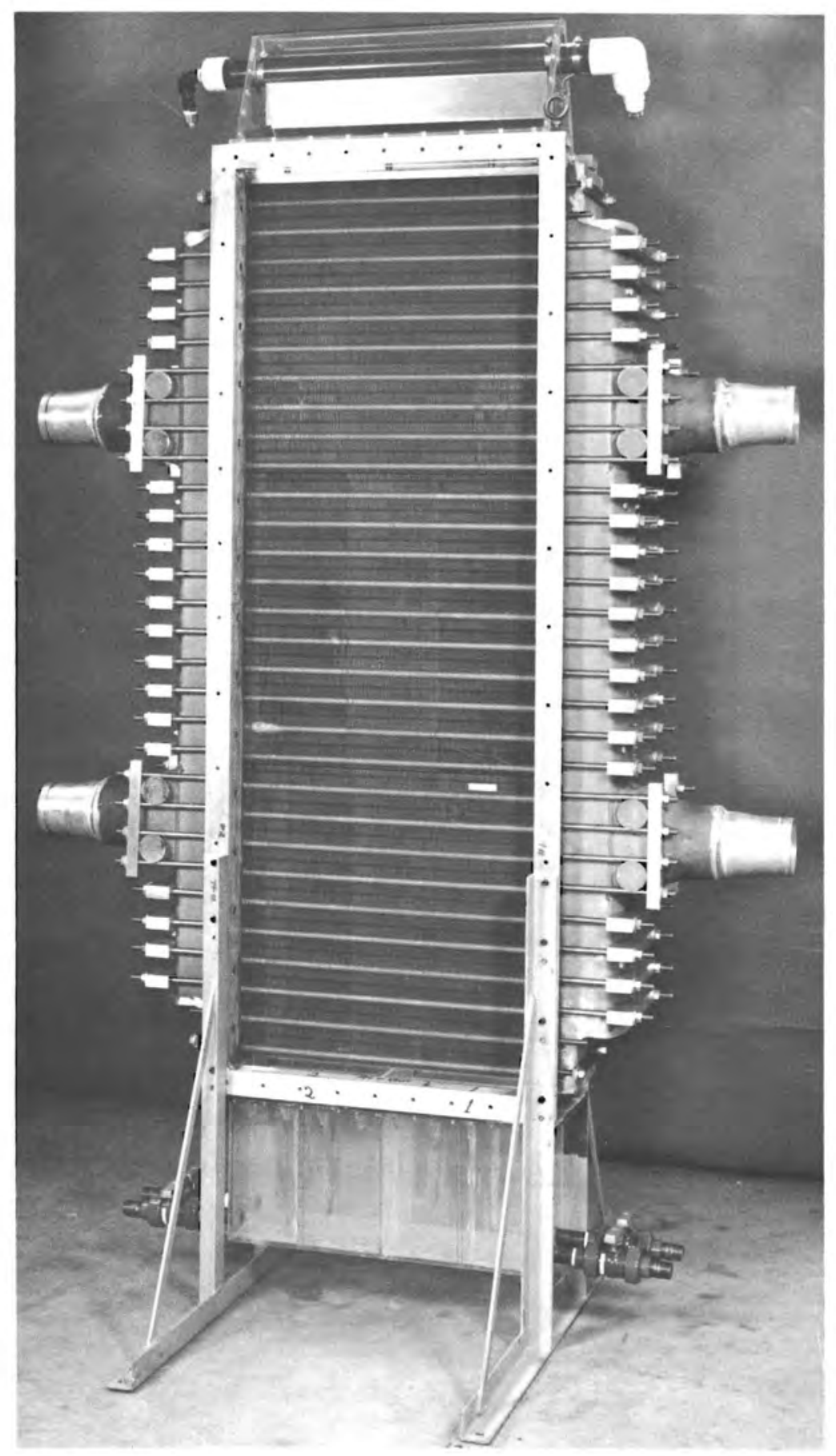

FIGURE 3-3. HÖTERV Deluged Test Core on Temporary Support Stand 


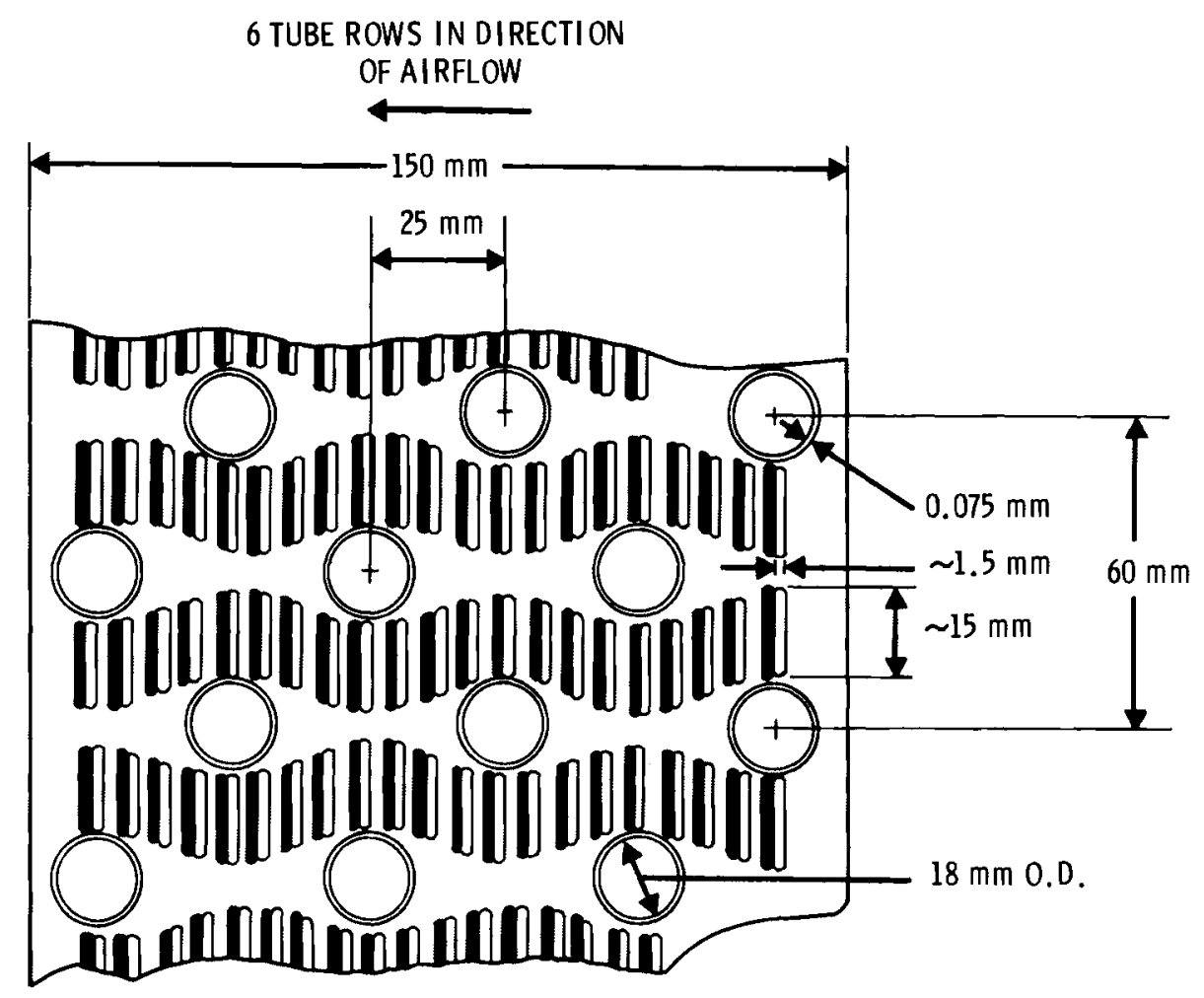

HOTERV SURFACE

FIGURE 3-4. HÖTERV Heat Exchanger Plate Fin and Tube Arrangement

$$
j_{0}=\frac{h_{O S} \operatorname{Pr}^{2 / 3}}{C_{a} G_{\infty}}
$$

where

$$
h_{\text {os }}=\left[\frac{1}{U_{0}}-\left(\frac{A_{s}}{h_{p} A_{p}}+\frac{t_{t} A_{s}}{k \bar{A}_{p}}\right)\right]^{-1}
$$

and $U_{0}$ is obtained directly from test data using the equation

$$
U_{0}=\frac{\dot{Q}_{r e j}}{F\left(A_{s}\right)(\text { LMTD })}
$$




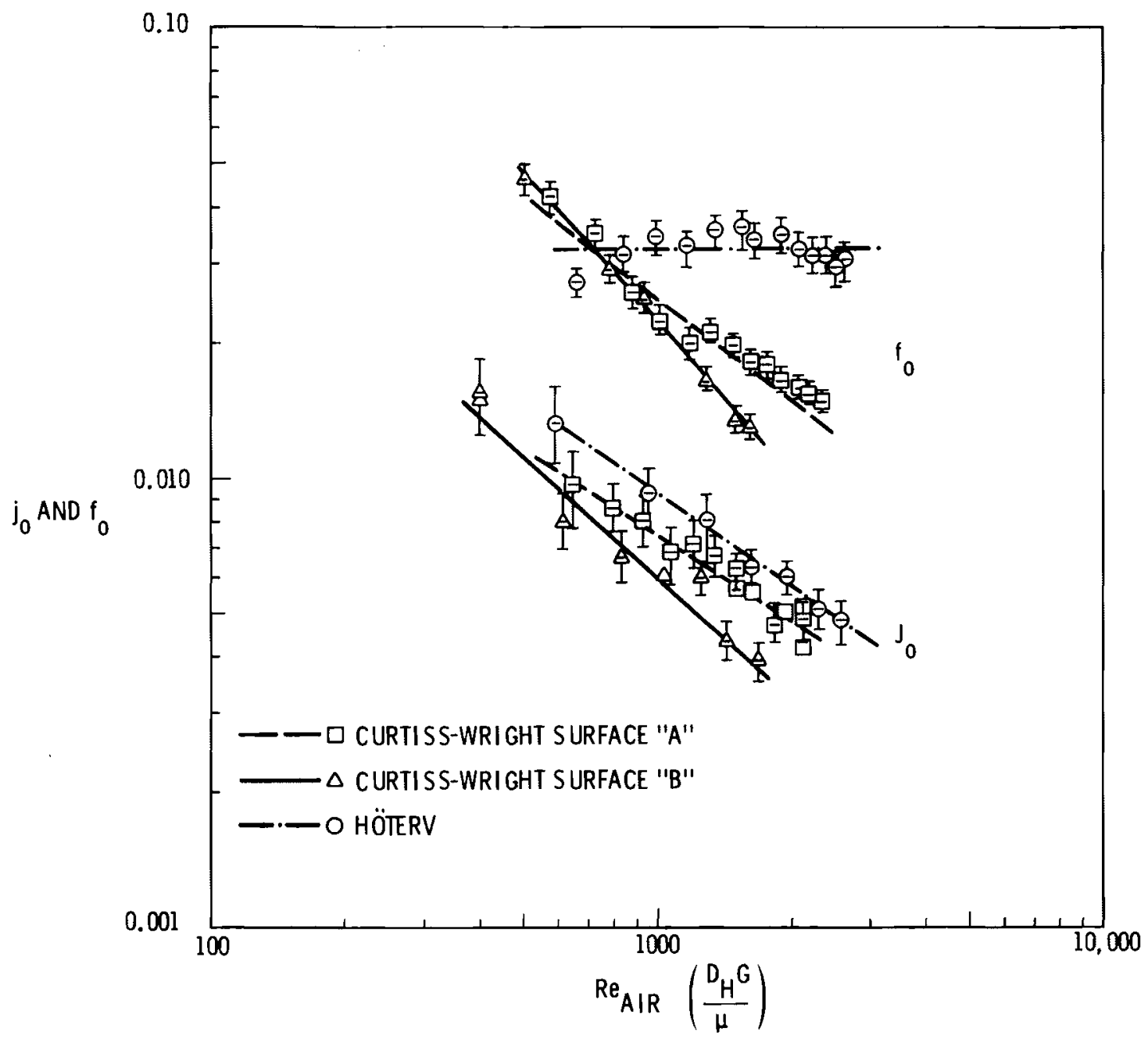

FIGURE 3-5. Dry Surfaces Performance

$\mathrm{F}$, the crossflow correction ractor, is equal to 1.0 for the test conditions and $h_{p}$ is the water-side heat transfer coefficient computed using the Ditus Boelter correlation:

$$
h_{p}=0.023 \frac{k_{p}}{D_{H}} \operatorname{Re}_{p}^{0.8} \operatorname{Pr}_{p} 0.333
$$

A sample calculation of dry performance is shown in Appendix E. 
of particular interest in Figure $3-5$ is the $f_{0}$ curve for the HöTERV surface. It shows a fairly constant value of $f_{0}$ over the range of airflows studied, indicating that form drag is dominant.

Figure 3-5 indicates that, at a given air Reynolds number, the HÖTERV surface will have the highest heat rejection capability, followed by CurtissWright Surface "A" and then "B". However, Figure 3-5 does not give enough information to assess the overall relative merits of the three surfaces. It has been suggested that for heat exchanger cores of similar airflow length, a comparison based on heat rejection capability per unit face area may provide some rational basis for choosing one surface over another, since total cost may be more closely related to frontal area than to heat transfer surface area. Figure 3-6 shows $j_{0}$ based on frontal area as a function of Reynolds number for each surface. For Reynolds numbers less than 1300, Curtiss-Wright

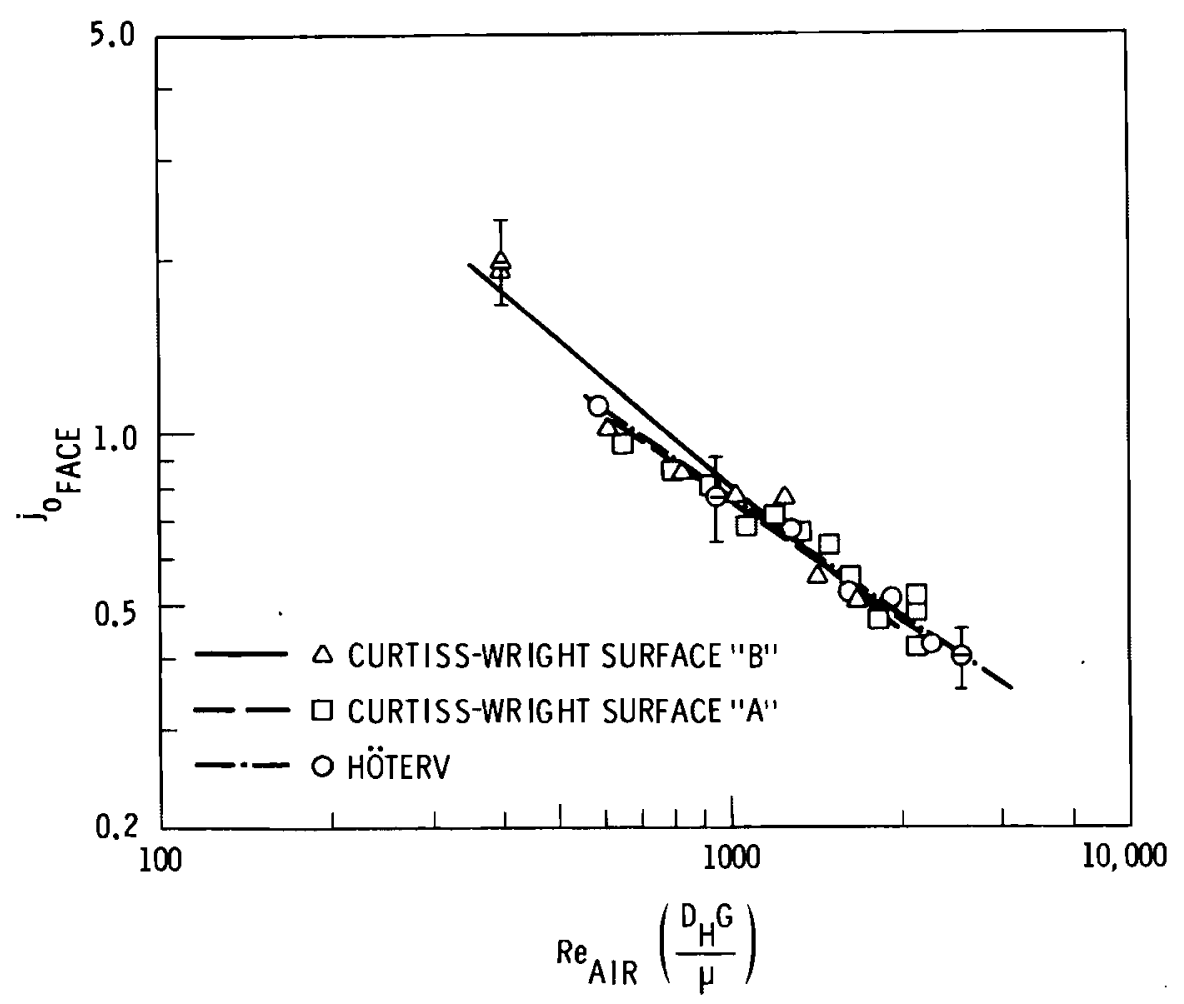

FIGURE 3-6. Baseline Heat Transfer Performance Based on Frontal Area 
Surface "B" appears to be slightly better than the others, with Curtiss-Wright Surface "A" and HÖTERV showing some benefit at Reynolds numbers above 1300 . However, all surfaces are so nearly the same in performance that it is difficult to justify choosing one over the other for an all-dry system based on heat rejection capability alone. Moreover, a choice should consider the differing $f$ an powers needed to force air over each surface. Cox and Jallouk ${ }^{(3)}$ have suggested a means for accounting for fan power in evaluating the relative merits of different surfaces. They suggest plotting air-side standardized heat transfer rate based on frontal area $\left(h_{\text {of }}\right)$ as a function of fan power per unit heat transfer rate, E. This has been done in Figure 3-7, where

$$
h_{\text {of }}=\frac{A_{s}}{A_{f}} h_{o s}
$$

$h_{\text {os }}$ defined per Equation 3-3

$$
E=\frac{\Delta \rho A_{\text {min }} V_{\text {amin }}}{h_{\text {of }}}
$$

When compared on this basis, Curtiss-Wright Surface "B" appears to be preferable, particularly at low fan power per unit heat transfer rate. The same methodology may be used to compare surfaces on a core volume basis where heat transfer rate based on core volume is plotted against fan power per unit heat transfer rate. These results are shown in Figure 3-8. Curtiss-Wright Surface "B" is preferable below fan power per volumetric heat transfer rate values of 0.017 , above which HÖTERV is superior.

The main purpose for conducting all-dry tests on the three surfaces was to provide a baseline against which various augmentation concepts could be evaluated. It was also desired to compare different candidate surfaces for a nonaugmented all-dry cooling system. The results of the all-dry comparison shown in Figures 3-7 and 3-8 indicate that Curtiss-Wright surface "B" is 


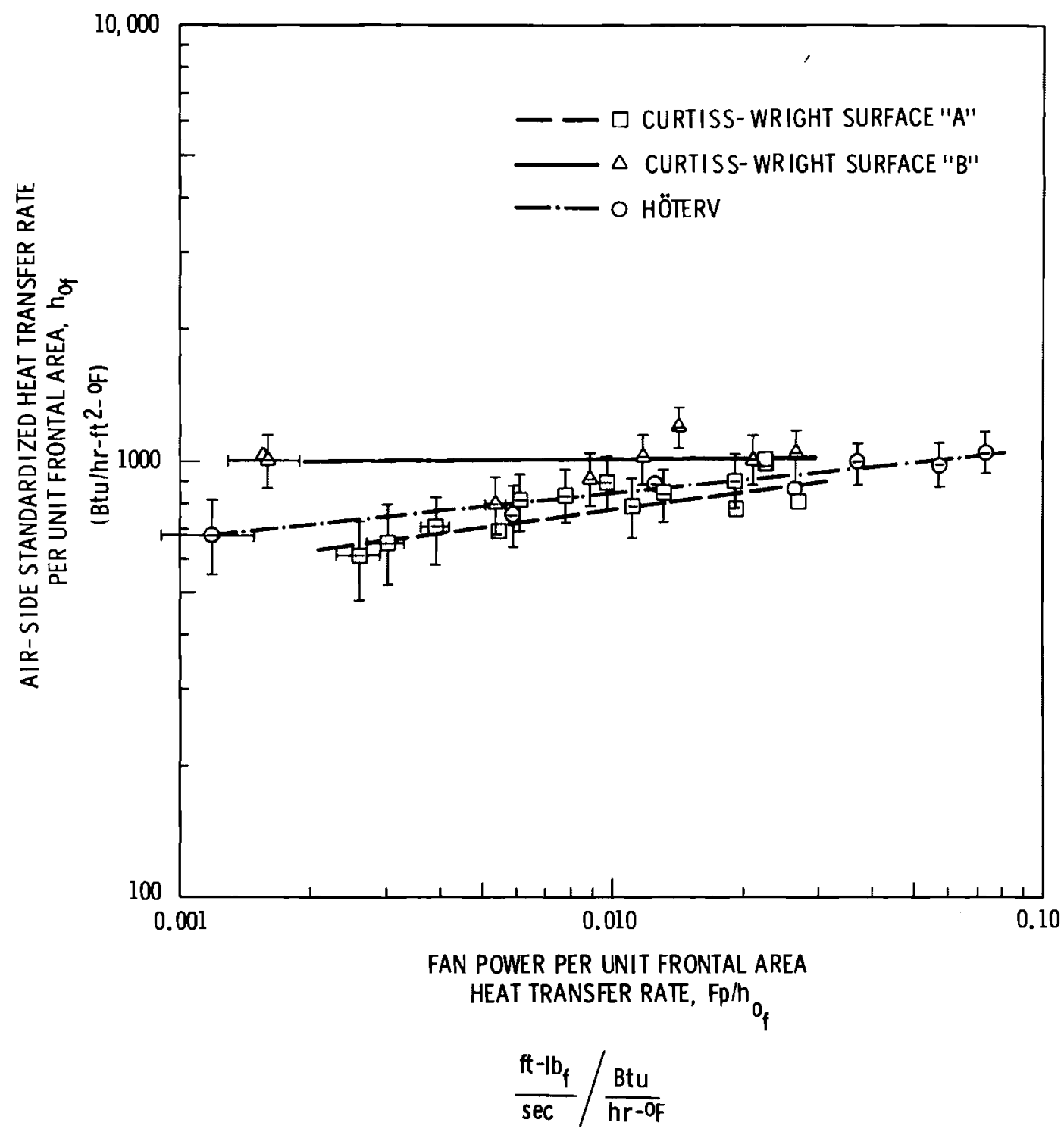

FIGURE 3-7. Performance Comparison of Dry Surfaces Based on Frontal Area

preferable. However, it is not so clearly superior to the other two surfaces that they can be ruled out altogether for an all-dry cooling system. Final selection should be based on a more detailed system analysis that accounts for total system costs, including piping and structural support, as well as heat transfer surface costs. 


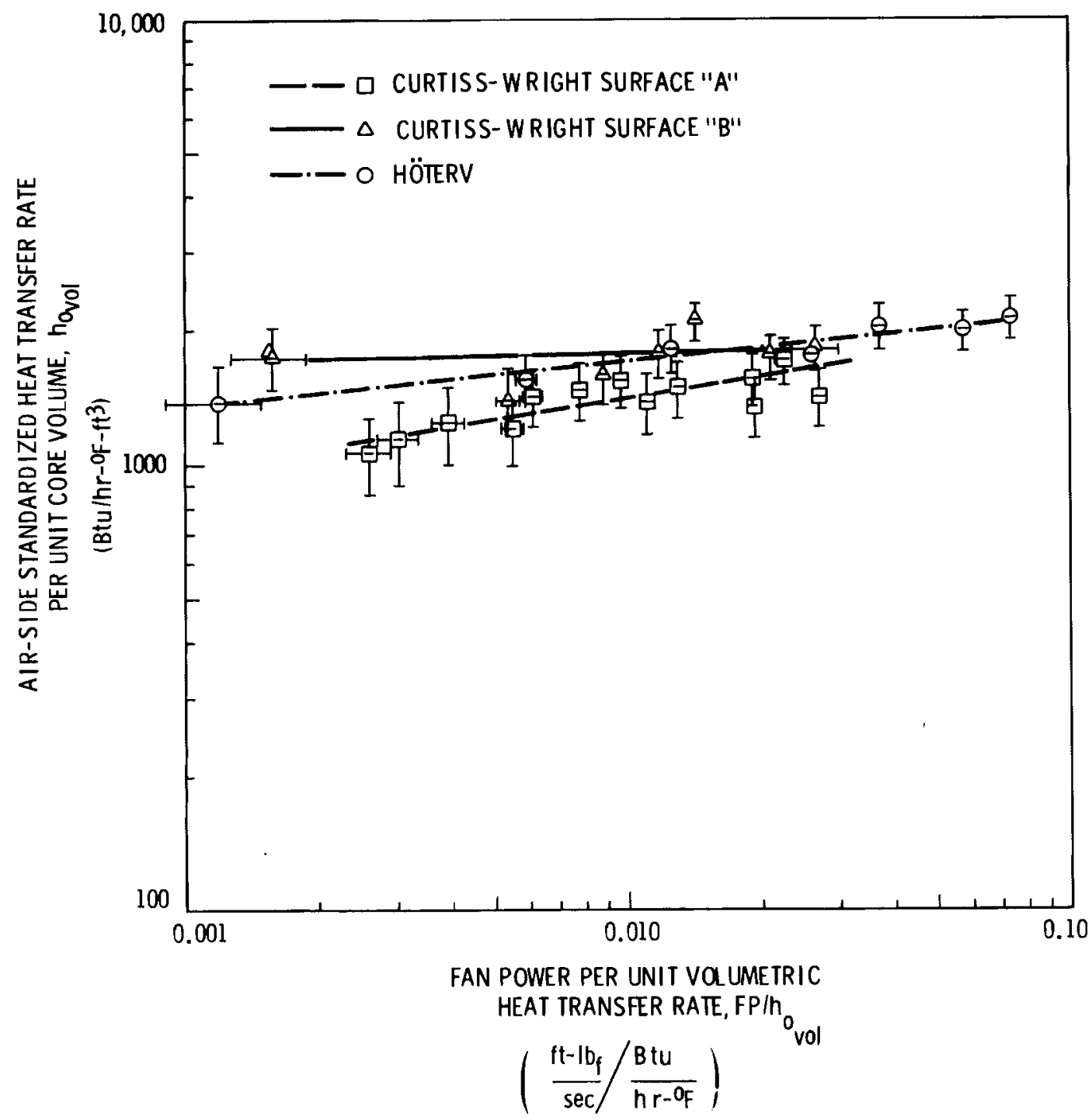

FIGURE 3-8. Performance Comparison of Dry Surfaces Based on Volume

\subsection{ENHANCEMENT DUE TO DELUGE AT PROTOTYPIC CONDITIONS}

Initial tests of the deluge augmented HÖTERV surface were aimed at evaluating the potential improvement in heat rejection capability over that of an all-dry surface under prototypic cooling tower conditions. Five conditions were evaluated: 
Condition 1 -

Circulation water inlet temperature: $115^{\circ} \mathrm{F}$

Air inlet temperature: $105^{\circ} \mathrm{F}$

Air approach velocity: $6 \mathrm{ft} / \mathrm{sec}$

Condition 2 -

Circulation water inlet temperature: $115^{\circ} \mathrm{F}$

Air inlet temperature: $105^{\circ} \mathrm{F}$

Air approach velocity: $3 \mathrm{ft} / \mathrm{sec}$

Condition 3 -

Circulation water inlet temperature: $110^{\circ} \mathrm{F}$

Air inlet temperature: $85^{\circ} \mathrm{F}$

Air approach velocity: $6 \mathrm{ft} / \mathrm{sec}$

Condition 4 -

Circulation water inlet temperature: $110^{\circ} \mathrm{F}$

Air inlet temperature: $85^{\circ} \mathrm{F}$

Air approach velocity: $3 \mathrm{ft} / \mathrm{sec}$

Condition 5 -

Circulation water inlet temperature: $125^{\circ} \mathrm{F}$

Air inlet temperature: $105^{\circ} \mathrm{F}$

Air approach velocity: $3 \mathrm{ft} / \mathrm{sec}$.

For all conditions the deluge flow rate was held constant at $3 \mathrm{gpm}$ (1.5 gpm per lineal foot across the core) and the core tilt angle held at $16^{\circ}$ from vertical (upper end tilted upstream). De-ionized water was used for deluging to reduce possible deposition on the surface. (The question of deposition and corrosion on deluged surface is part of another PNL study presently underway.) Deluge water and circulation water inlet temperatures were allowed to reach a steady state before test data were taken. A complete set of data was then recorded on 5-minute intervals for 20 minutes. Average values were used for data reduction.

For each of the test conditions the heat rejection rate for the $2 \mathrm{ft} x$ $6 \mathrm{ft}$ HÖTERV core was measured as discussed in Section 2.1 at several values of inlet air relative humidity. The measured deluged heat rejection rate for 
each case was then compared to a dry heat rejection rate computed using the "effectiveness/number of transfer units" technique in which the overall dry heat transfer coefficient, $U_{0}$, is determined as follows:

$$
U_{O_{D R Y}}=\left[\frac{1}{h_{O S}}+\frac{A_{s}}{A_{p} h_{p}}+\frac{t A_{s}}{A_{p} k_{t}}\right]^{-1}
$$

$h_{p}$ is computed from Equation 3-5 using the internal flow conditions of the deluged tests (which resulted in a value of $h_{p}$ typically about $625 \mathrm{Btu} / \mathrm{hr}-\mathrm{ft}^{20} \mathrm{~F}$ ) and $h_{o s}$ is taken from the baseline dry data as discussed below.

For comparing the deluged to the dry HÖTERV surface, $h_{\text {os }}$ is that value that would result if the dry airflow were adjusted to provide the same airside pressure drop as observed in the deluged test. This typically results in a deluged airflow of about half the dry airflow. The reason for using constant air-side pressure drop as the point of comparison is that, in an actual dry/wet tower operating with some deluged sections and some dry sections, the airflow paths through the dry and wet sections will be parallel and thus will have whatever air velocities result in the same pressure drop. Consequently, a dry/wet comparison based on constant pressure drop is more realistic for an integrated dry/wet tower than one based on constant air velocity or fan power. However, for comparing the deluged performance of a fully wetted dry/ wet tower to that of an all-dry system, such as proposed for the CurtissWright surface, comparison on the basis of constant fan power is more appropriate. Values of $h_{\text {os }}$ used for such a comparison are those values that would result from an airflow requiring the same fan power as that of the deluged test. Fan power is computed using

$$
\text { Power }=\Delta P A_{\min } V_{\text {amin }}
$$


Figure 3-9 shows the enhancement of the heat rejection rate of the deluged HOTERV surface compared to the dry HOTERV surface at constant air-side pressure drop and at the previously stated operating conditions. Enhancement ratio ranged from a high of over 7 for low relative humidity and low initial temperature difference to a low of 1.5 for high relative humidity and high initial temperature difference. Enhancement ratio can be seen to be a strong function of the initial temperature difference between the air and the primary fluid. Enhancement is also a strong function of air relative humidity for tests run at low ITD. However, the effect of humidity becomes less pronounced at a higher ITD. The effect of air velocity appears to be very slight given that the comparisons are made at constant air pressure drop.

Figure 3-10 shows the improvement in heat rejection of the deluged HOTERV surface over the dry Curtiss-Wright surface "A" at equal fan powers and at the previously stated operating conditions. The results are very similar to those for the deluged HÖTERV/dry HÖTERV comparison of Figure 3-9 with a maximum enhancement ratio of 8 and a minimum ratio of 1.3 over the range of conditions and air relative humidities.

The general conclusion reached from these tests is that a substantial enhancement in heat rejection capability is possible with the deluged system when operating under conditions where ambient air is hot and dry (resulting in a low ITD and low humidity), the very conditions found in many areas where augmented dry cooling may be desirable. Consequently, a more detailed investigation of the factors affecting deluged performance and the development of methods for predicting performance have been undertaken.

\subsection{THE EFFECT OF OPERATING PARAMETERS ON DELUGED PERFORMANCE}

\subsubsection{Observed Deluge Flow Characteristics}

The close fin spacing in the HÖTERV core made observation of deluge flow characteristics extremely difficult. Only the flow in the immediate vicinity of the leading and trailing edges of the fins could be seen. The initial analytical models for deluged operation (see Section 4.1) were developed before actual testing began. The model assumed a thin uniform deluge film 


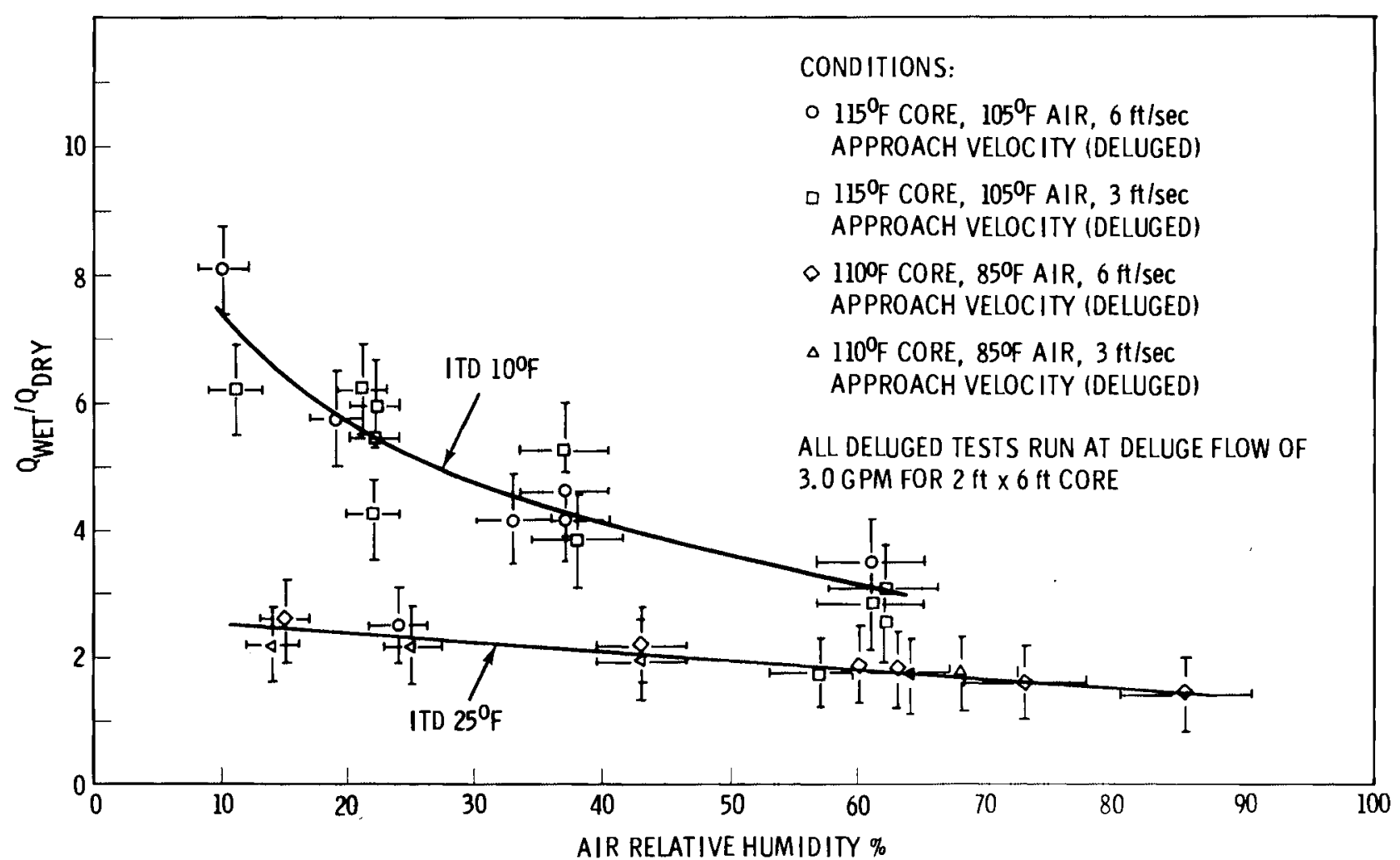

FIGURE 3-9. Deluged Enhancement Comparing Deluged HÖTERV Surface with Dry HÖTERV Surface "A" at Equal Air-side Pressure Drop under Prototypic Conditions 


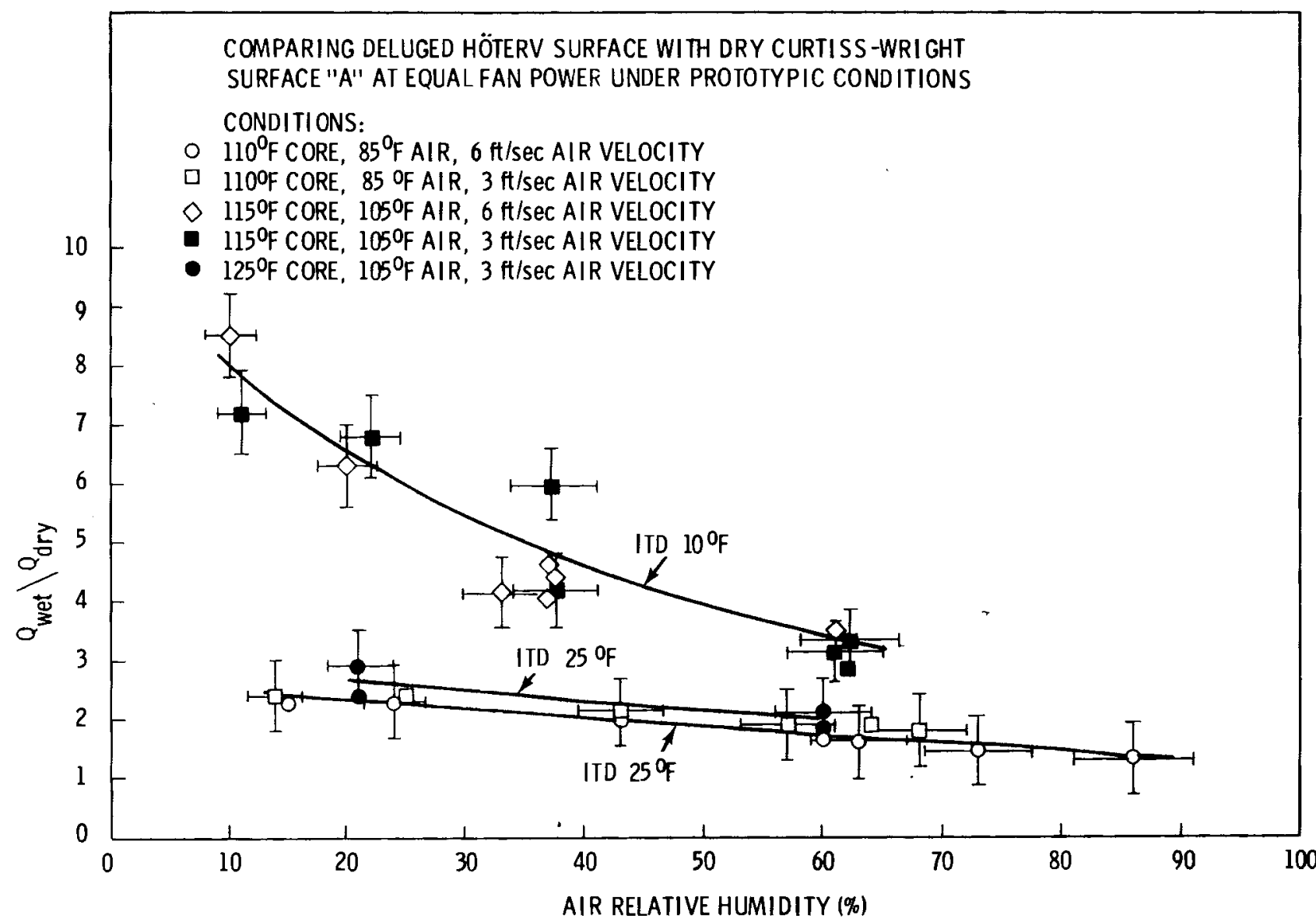

FIGURE 3-10. Deluged Enhancement Comparing Deluged HÖTERV Surface with Dry Curt iss-Wright Surface "A" at Equal Fan Power under Prototypic Conditions 
would cover the fins. Observation of the actual surface, however, showed very nonuniform flow. The flow between any two fins can be qualitatively described as a series of intermittent slugs of water, each bridging the gap between the fins. Dry areas appear on both the leading and trailing edges of the fins. At a deluge flow of $3 \mathrm{gpm}$ for the $2 \mathrm{ft} \times 6 \mathrm{ft}$ WATA core, airflow may be increased from an approach velocity of $3 \mathrm{ft} / \mathrm{sec}$ (the lowest airflow possible in the WATA facility) to $6 \mathrm{ft} / \mathrm{sec}$ and the deluge water remains on the core. Above $6 \mathrm{ft} / \mathrm{sec}$ air approach velocity, water begins to be blown from the trailing edge and considerable entrained water is seen in the downstream airflow. Tilting the core toward the airflow appears to provide more uniform deluge distribution between the leading and trailing surfaces. However, tilt angles up to $20^{\circ}$ from vertical do not prevent the loss of deluge water by entrainment as approach velocity increases above $6 \mathrm{ft} / \mathrm{sec}$. Some difficulty was encountered in consistently maintaining deluge flow stability at tilt angles over $16^{\circ}$ from vertical. A small perturbation in flow would cause a stream of deluge water to attach itself to the test section duct wall and flow down the wall. This stream would divert considerable deluge water from the fin surfaces. Consequently, no heat transfer tests were performed at tilt angles greater than $16^{\circ}$ from vertical.

Deluge flow could be increased as high as $3 \mathrm{gpm}$ per lineal $\mathrm{ft}$ of core (6 gpm for the 2-ft wide WATA core) at an air approach velocity of $6 \mathrm{ft} / \mathrm{sec}$ with gradually increasing entrained moisture observed in the downstream air. Above $3 \mathrm{gpm}$ per $\mathrm{ft}$, considerable deluge water was blown from the surface at $6 \mathrm{ft} / \mathrm{sec}$ air approach velocity. Thus, it is felt that the maximum deluge operating conditions in an actual system are approximately $6 \mathrm{ft} / \mathrm{sec}$ air approach velocity and $3 \mathrm{gpm}$ per lineal $\mathrm{ft}$ of core deluge flow.

\subsubsection{Heat Transfer Performance}

To allow for better optimization of a deluged cooling system design, the effects of various parameters on the performance of the deluged HÖTERV core were evaluated. The parameter of primary interest is airflow rate, as this is one of the major parameters over which the designer has control and can have a 
large effect on performance. In addition, it was desirable to establish the effects of deluge flow rate, core tilt angle, and amount of surface wetting for representative operating conditions.

Surface performance may be characterized by:

1. the effective friction factor, $f_{0}$, as defined by Equation (3-1) using the dry surface geometry and dimensions

2. the effective overall deluged surface heat transfer coefficient, $h_{s}{ }^{\prime}$. This is a measure of the overall deluged surface heat rejection capability, and accounts for the thermal resistances of both the deluge $f i l m$ and the deluge surfaces. Its derivation is discussed in detail in Section 4.1.2 and a sample calculation from experimental data is shown in Appendix E. For predictive purposes the values of the, effective deluge film coefficient, $h_{d}{ }^{*}$, and the effective deluge surface coefficient, $h_{s}{ }^{*}$, are also of interest. Derivation of these two coefficients is discussed in Sections 4.1 .4 and 4.1.2, respectively, and sample calculations are in Appendix E.

Figure 3-11 shows the effect of air Reynolds number on effective friction factor for the HÖTERV test core deluged at $3 \mathrm{gpm}$. Friction factor for the dry core is shown for comparison. Air Reynolds number for both deluged and dry cores is computed using the dry hydraulic diameter and cross-sectional area derived in Appendix D. For the deluged core, friction factor is essentially a constant below a Reynolds number of 1000 . Above $\operatorname{Re}=1000$, deluge water begins to blow off the trailing edge of the core and $f_{0}$ decreases steadily.

Figure 3-12 shows the effect of air Reynolds number on the effective overall deluged surface heat transfer coefficient, $h_{s}{ }^{\prime}$. Data were taken at three basic operating temperatures and several air velocities and humidities as shown on the figure. Deluge flow was held constant at $3 \mathrm{gpm}$ and core tilt was fixed at $16^{\circ}$ from vertical. The figure shows that, within the expected uncertainty of the data, $h_{s}{ }^{\prime}$ is "relatively insensitive to" air humidity at a given operating temperature. However, there appears to be some dependence of $h_{S}$ ' on operating temperature; distinct curves appear for the different core temperatures of $110^{\circ} \mathrm{F}, 115^{\circ} \mathrm{F}$ and $125^{\circ} \mathrm{F}$. 


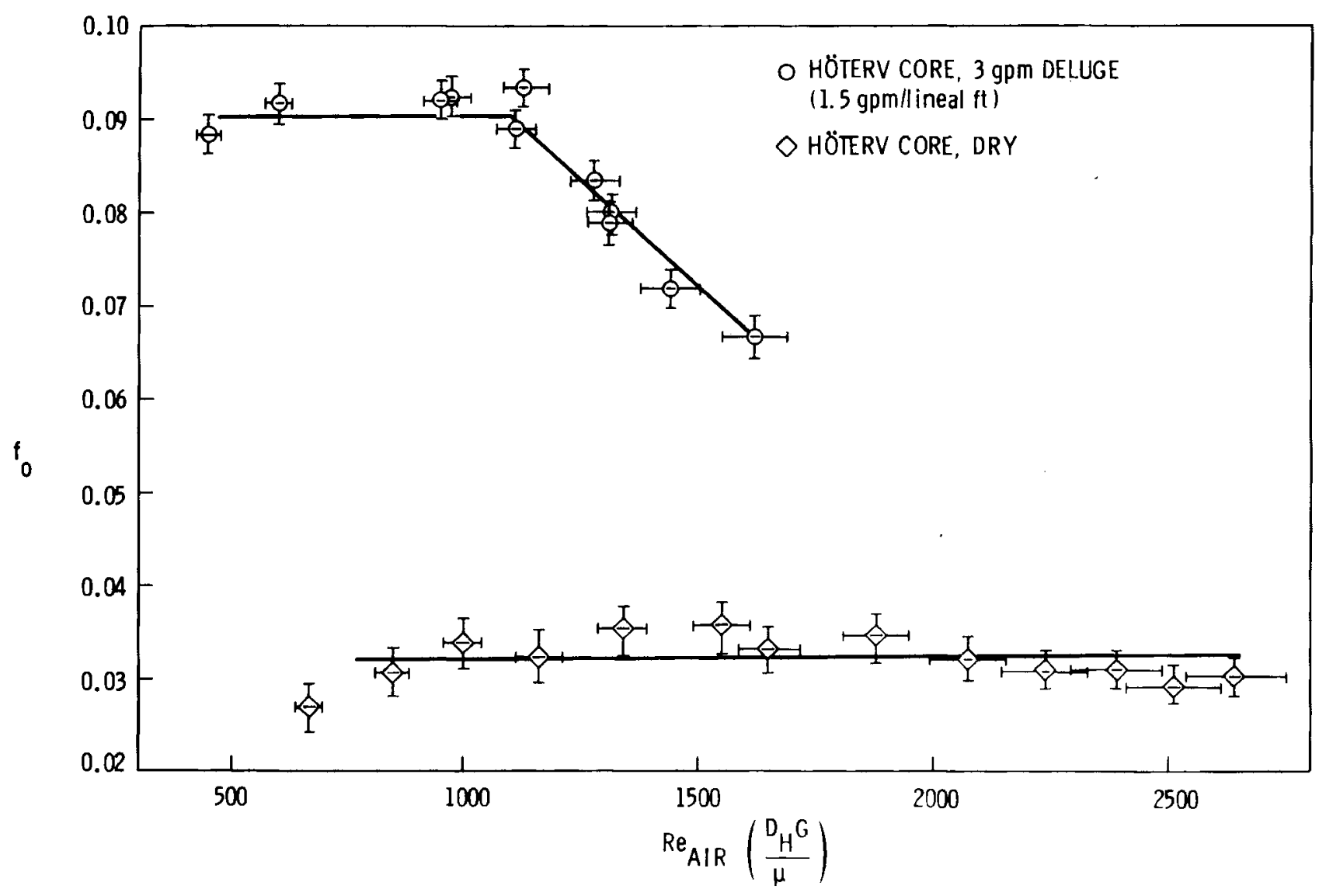

FIGURE 3-11. Friction Factors for wet and Dry HÖTERV Core 


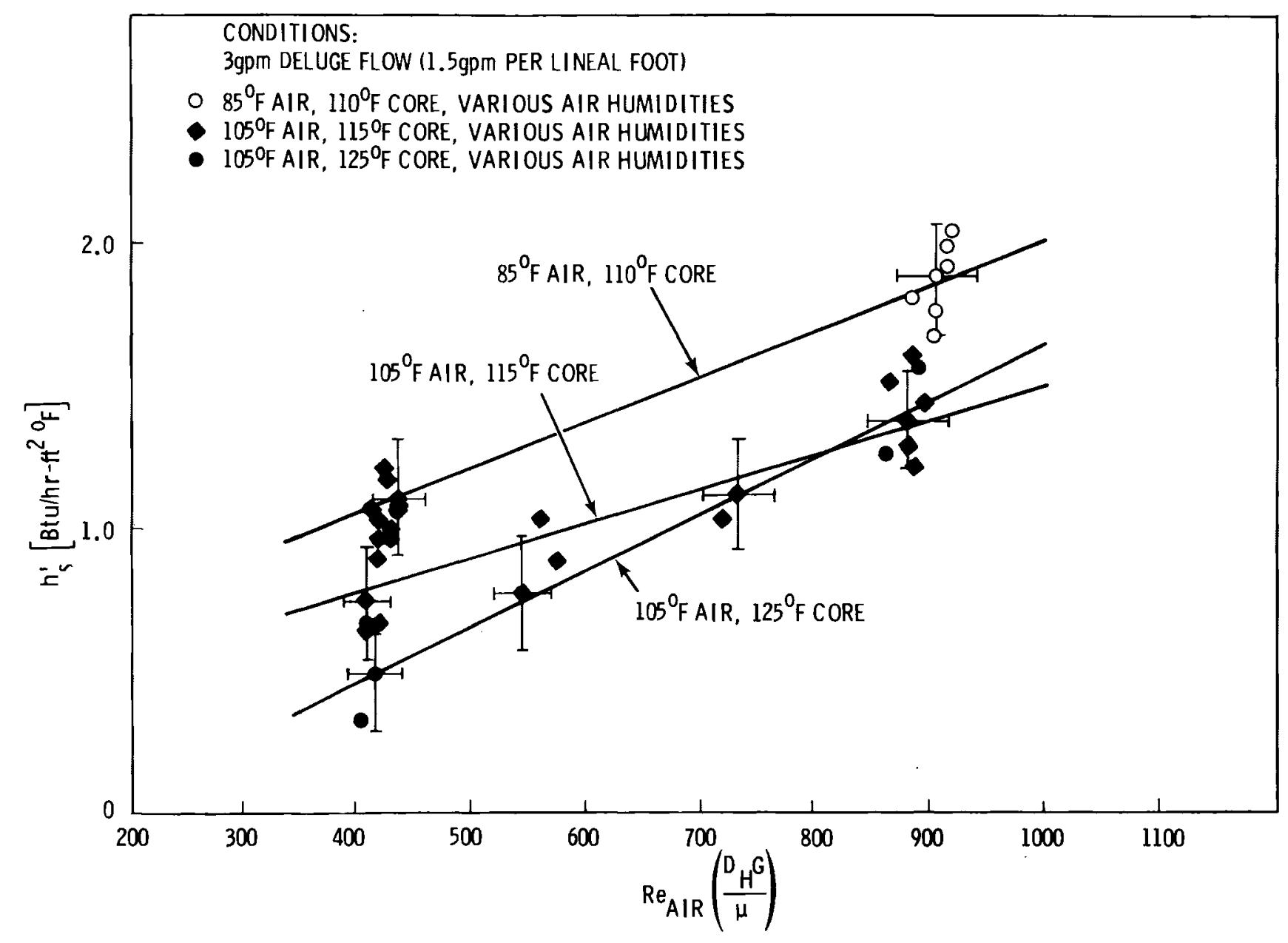

FIGURE 3-12. Effect of Airflow on Overall Deluged Surface Heat Transfer, HÖTERV Core 
Figures 3-13 and 3-14 show the effect of air Reynolds number on the effective deluge film coefficient, $h_{d}{ }^{*}$, and the effective deluge surface coefficient, $h_{s}{ }^{*}$, respectively. The increase in the effective deluge film coefficient with increased airflow is possibly due to the increased wetted surface area observed at higher airflow. Increased effective deluge surface coefficient is possibly due to increased surface area as well as to an increase in the local mass and heat transfer rates caused by the higher air velocity. It should be noted that the probable uncertainty in $h_{s}{ }^{*}$ is fairly large (particularly at higher Reynolds numbers) due to its derivation from the experimentally obtained values of $h_{s}{ }^{\prime}$ and $h_{d}{ }^{*}$ (see Section 4.1.1).

Limited tests were performed to evaluate the effect of deluge flow rate on performance. Figure 3-15 shows the effect of deluge flow on effective friction factor, $f_{0}$, at $3 \mathrm{ft} / \mathrm{sec}$ and $6 \mathrm{ft} / \mathrm{sec}$ air approach velocities. Friction factor increases as deluge flow increases from $3 \mathrm{gpm}$ to $6 \mathrm{gpm}$ at both air velocities. However, the increase is more dramatic at the $3 \mathrm{ft} / \mathrm{sec}$ air velocity than at the $6 \mathrm{ft} / \mathrm{sec}$ velocity. The higher air velocity may have the effect of inhibiting bridging of the deluge water between fins, thus minimizing the increase in pressure drop.

As shown in Figures 3-16 and 3-17, increased deluge flow increases both the effective overall deluged surface heat transfer coefficient, $h_{s}{ }^{\prime}$, and the effective deluge film coefficient, $h_{d}{ }^{*}$, for both $3 \mathrm{ft} / \mathrm{sec}$ and $6 \mathrm{ft} / \mathrm{sec}$ air approach velocities. However, Figure 3-18 indicates that the effective deluge surface coefficient, $h_{s}{ }^{*}$, increases as deluge flow is increased to $4.5 \mathrm{gpm}$ ( $2.25 \mathrm{gpm}$ per lineal $\mathrm{ft}$ of core) and then begins to decrease, possibly due to flooding of the core and a resulting reduction in deluge water/air interface area. Figure 3-19 looks at the net effect of increased deluge flow on surface performance by plotting the effective overall surface heat transfer coefficient per unit fan power (both based on frontal area) as a function of deluge flow rate at both $3 \mathrm{ft} / \mathrm{sec}$ and $6 \mathrm{ft} / \mathrm{sec}$ air approach velocities. For the $3 \mathrm{ft} / \mathrm{sec}$ tests, the overall effect of increased deluge flow is negligible. For the $6 \mathrm{ft} / \mathrm{sec}$ tests, slight increase in performance is seen up 


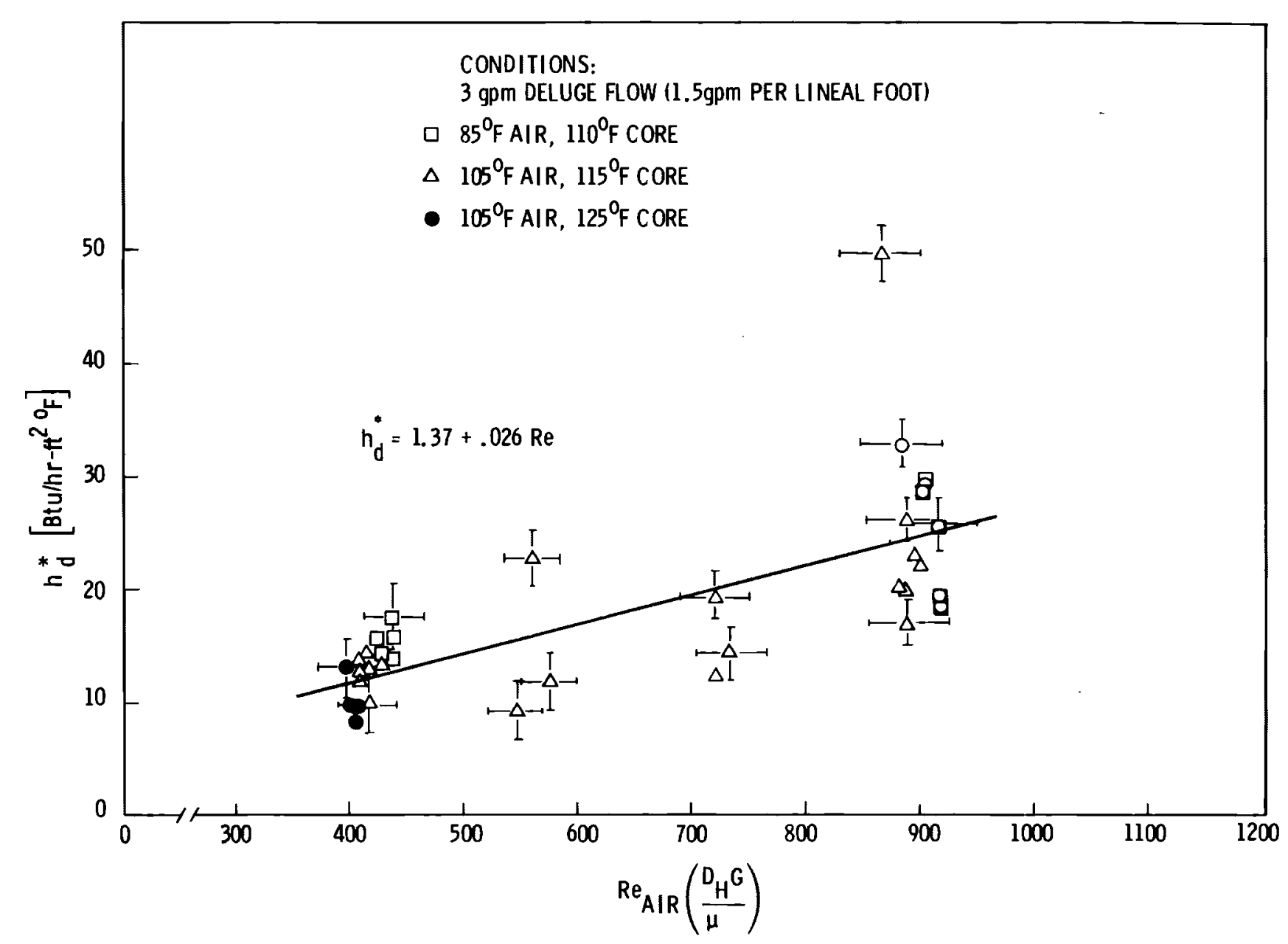

FIGURE 3-13. The Effect of Airflow on the Effective Deluge Film Coefficient, $h_{d}$ * 


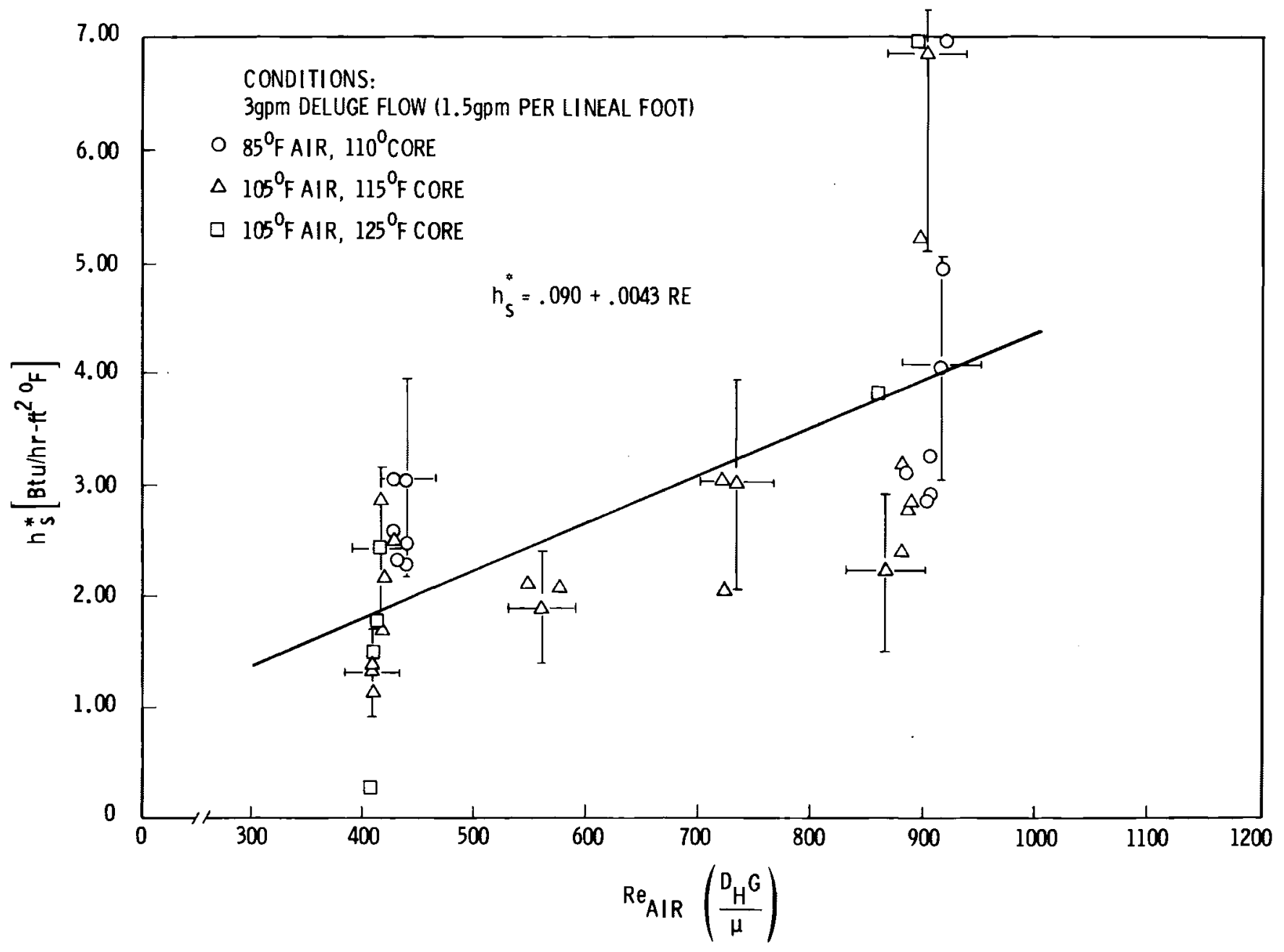

FIGURE 3-14. The Effect of Airflow on the Effective Deluge Surface Coefficient, $h_{s}$ * 


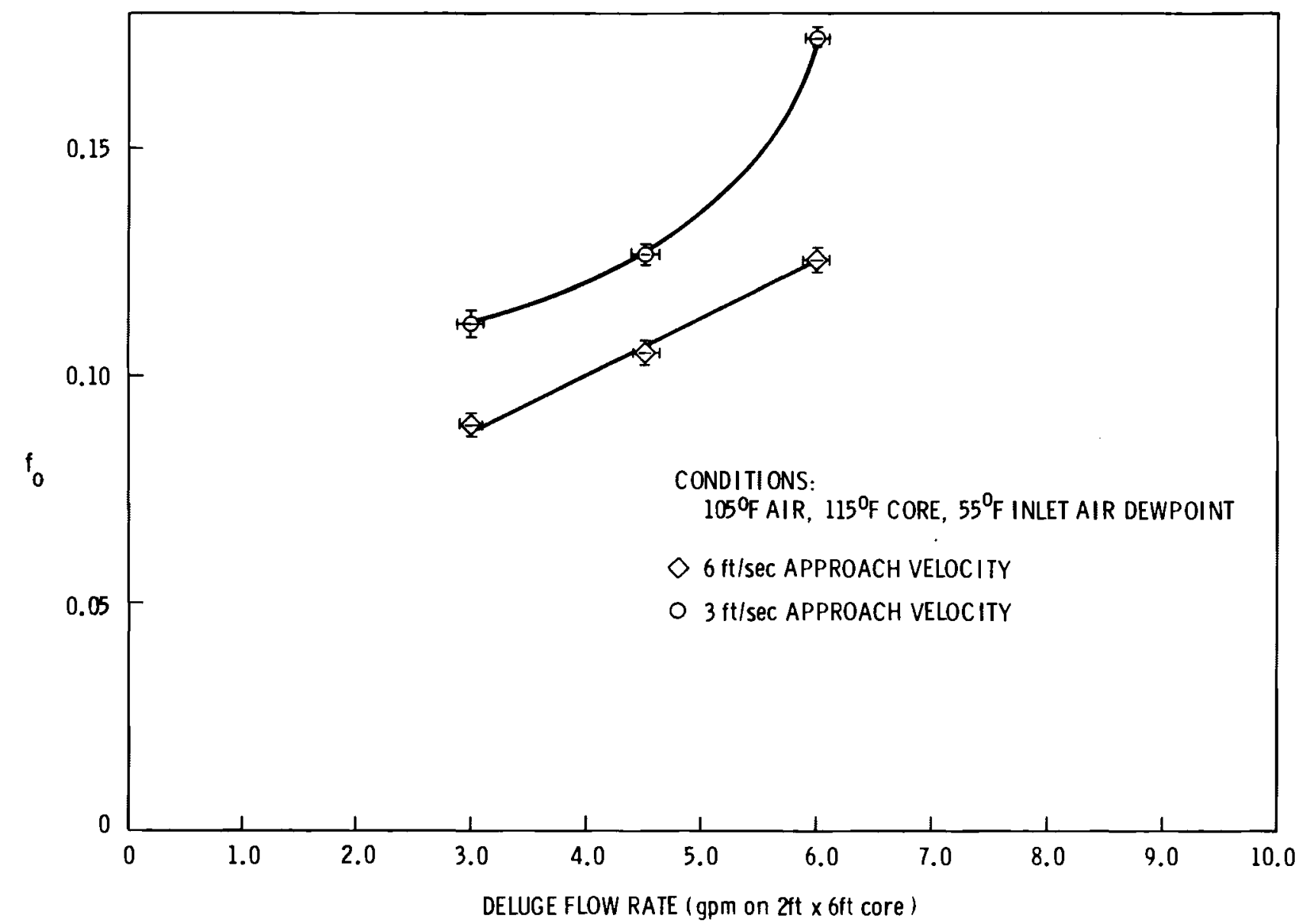

FIGURE 3-15. Effect of Deluge Flow Rate on Deluged Friction Factor, HÖTERV Core 


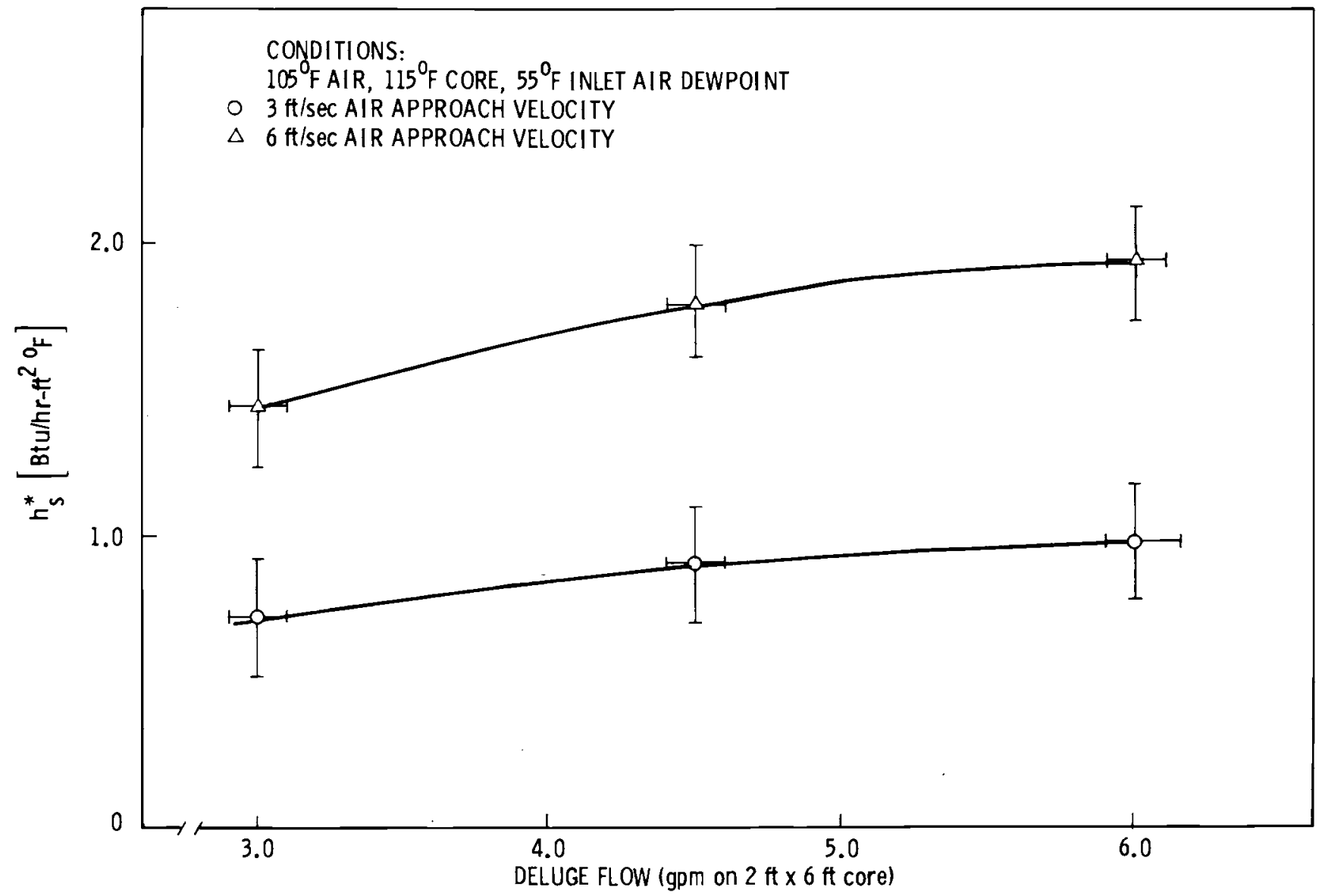

FIGURE 3-16. Effect of Deluge Flow Rate on Overa11 Deluged Surface Heat Transfer Performance, HÖTERV Core 


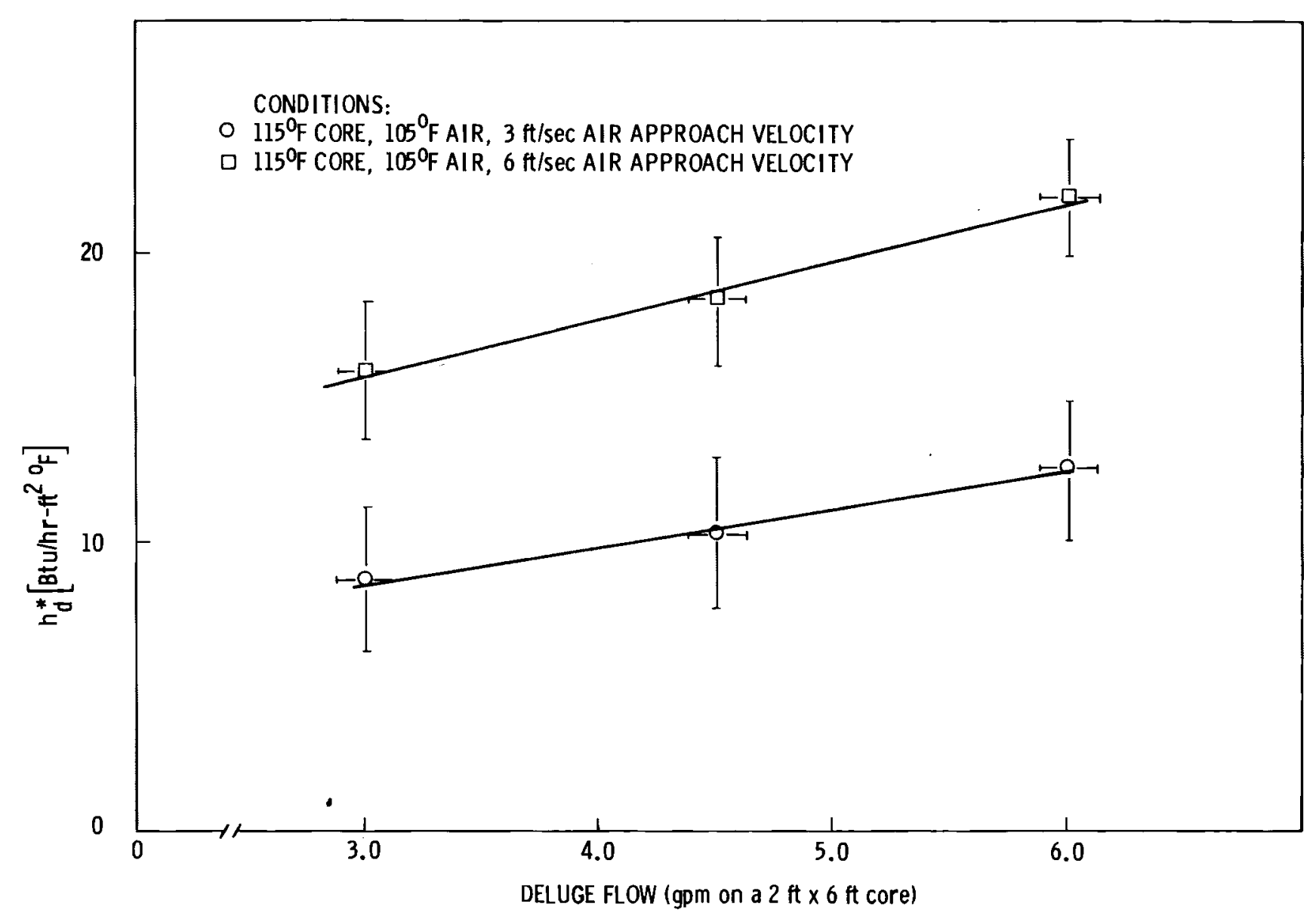

FIGURE 3-17. The Effect of Deluge Flow on Effective Deluge Film Coefficient, $h_{d}{ }^{\star}$ 


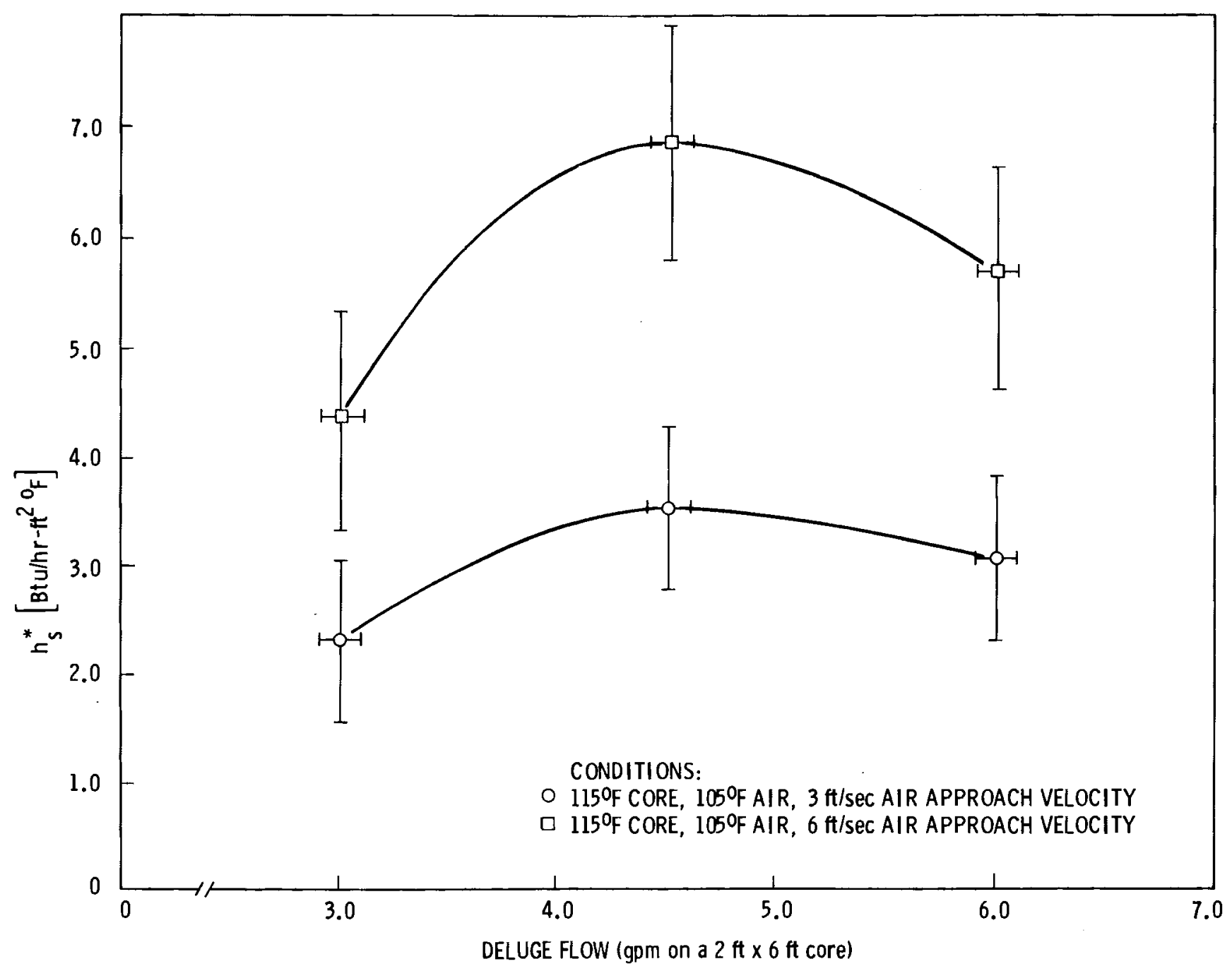

FIGURE 3-18. The Effect of Deluge Flow on Effective Deluge Surface Coefficient, $h_{s}$ * 


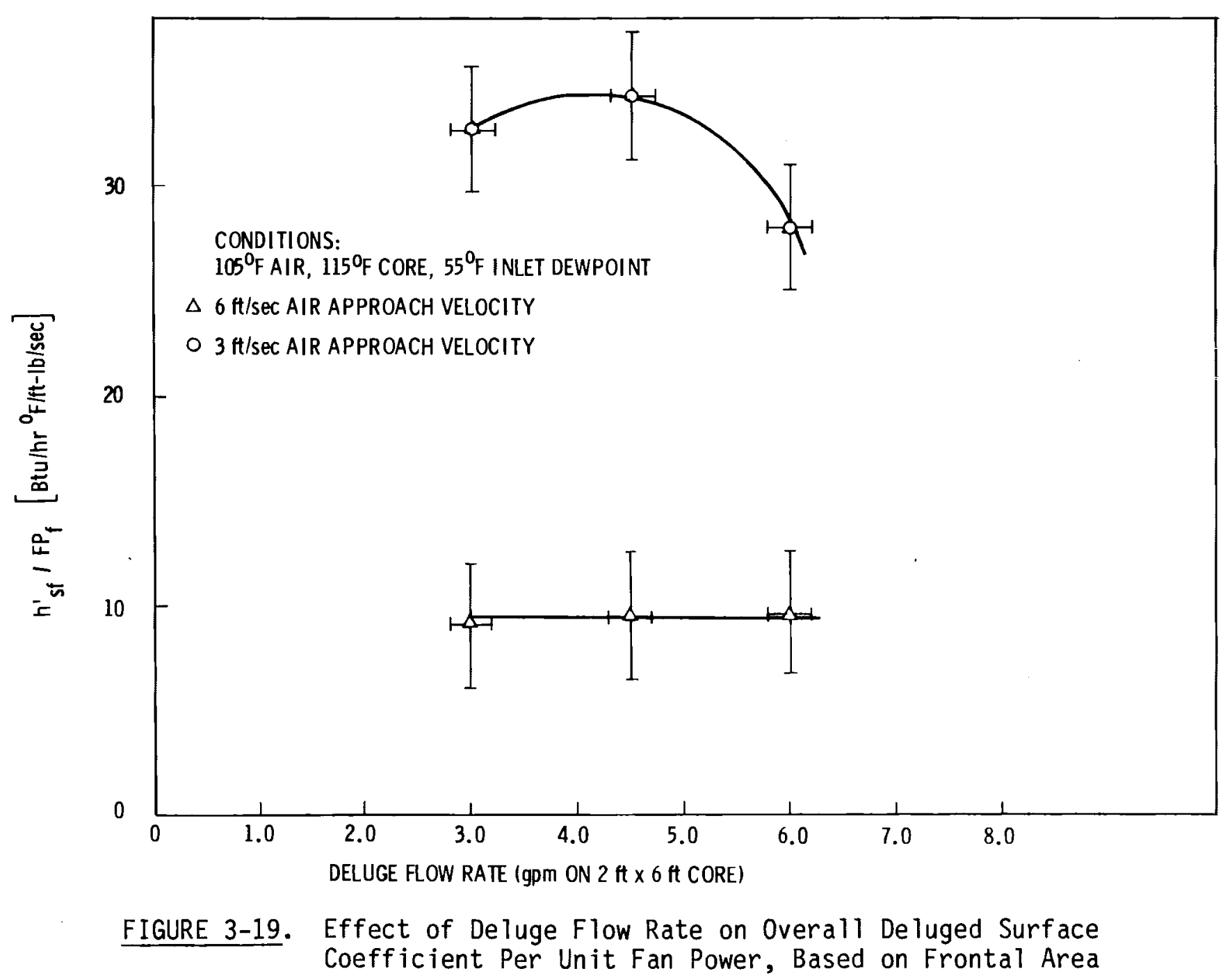


to a deluge flow of about $4.0 \mathrm{gpm}(2.0 \mathrm{gpm}$ per lineal ft of core), above which performance begins to degrade. Figure 3-19 does not in itself establish optimal deluge flow for the HÖTERV core. The actual optimal deluge flow is a complex function of design-dependent variables (such as piping costs and water availability), as well as heat rejection performance and must be evaluated for a specific design.

A short series of tests at $3 \mathrm{ft} / \mathrm{sec}$ air approach velocity was conducted to evaluate the effect of core tilt angle on the effective overall deluged surface heat transfer coefficient, $h_{s}{ }^{\prime}$. As shown in Figure 3-20, the effect of changing core tilt angle from vertical to $16^{\circ}$ from vertical is slight. Although the data indicate a tilt angle of $8^{0}$ may be optimal at the air velocity evaluated, a larger number of tests will be required to establish a statistically meaningful optimum. Physical layout of the cooling tower is probably the most important parameter in determining the optimal core tilt angle within the bounds investigated.

In an attempt to evaluate the effect of increasing the net surface wetted by the deluge water, limited tests were made with various amounts of a nonsudsing surfactant added to the deluge water. It was felt that dry areas might exist within the core since they were seen on the leading and trailing edges. Addition of a surfactant to the deluge water would reduce water surface tension and allow the water to more easily wet the surface.

The addition of even very small amounts of surfactant to the deluge water increased the visible wetting of the leading and trailing edges and presumably the inner surfaces. The effective overall deluged surface heat transfer coefficient, $h_{s}{ }^{\prime}$, was also greatly increased as shown in Figure 3-21. Figures 3-22 and 3-23 indicate that the increase in the overall surface coefficient was due to increases in both the effective deluge film coefficient, $h_{d}{ }^{*}$, and the effective deluge surface coefficient, $h_{s}{ }^{*}$. Unfortunately, the air-side pressure drop was also greatly increased by the addition of a surfactant, possibly due to the formation of bubbles in the core. The net effect of adding a surfactant to the deluge water is shown in Figure 3-24 which plots $h_{s}{ }^{\prime}$ per unit fan pressure (both on a frontal area basis) as 


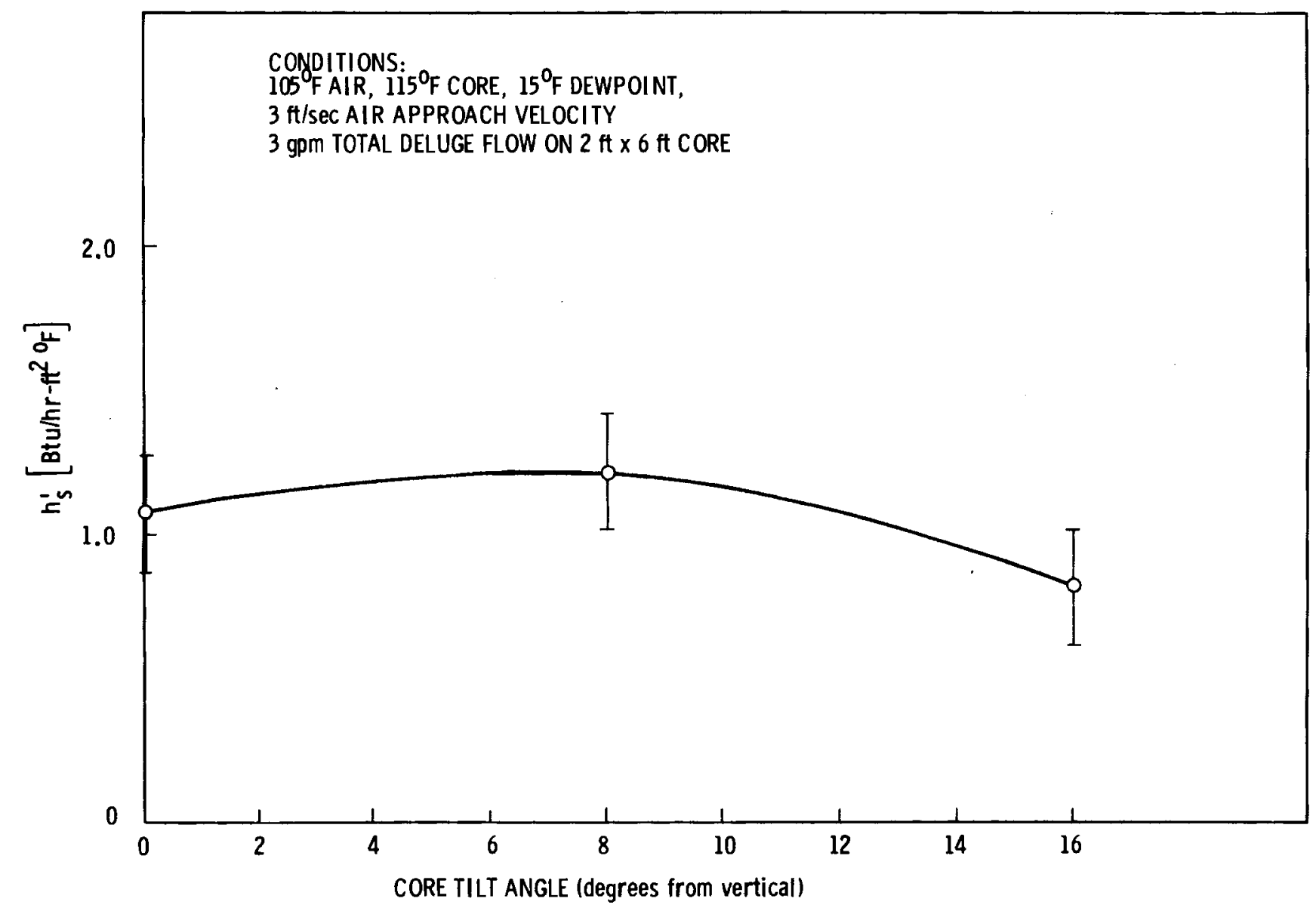

FIGURE 3-20. Effect of Core Tilt Angle on Effective Overa11 Deluged Surface Coefficient - HÖTERV Core 


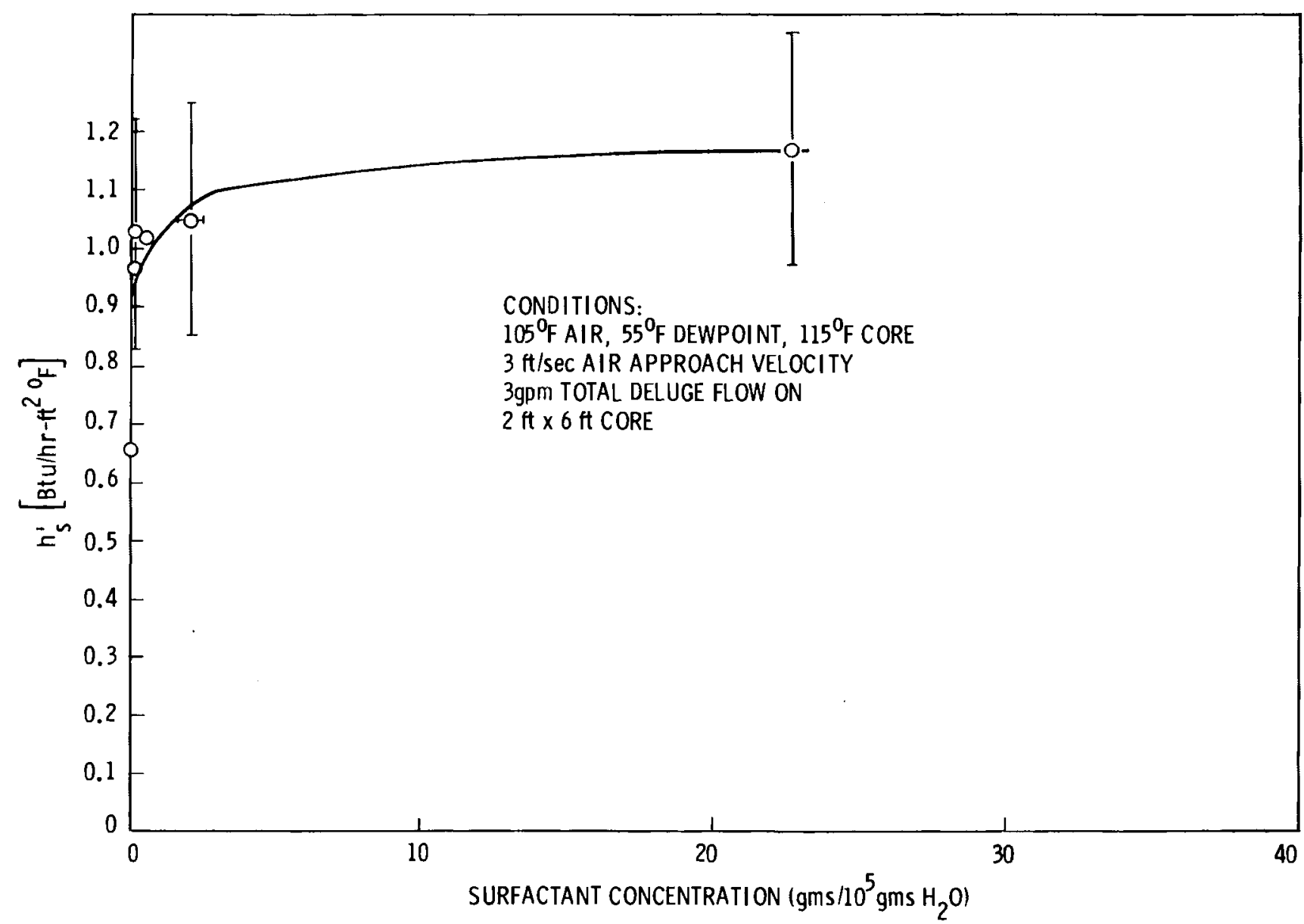

FIGURE 3-21. The Effect of Deluge Water Surfactant Concentration on Effective Overall Deluged Surface Coefficient, $h_{S}{ }^{\prime}$ 
G

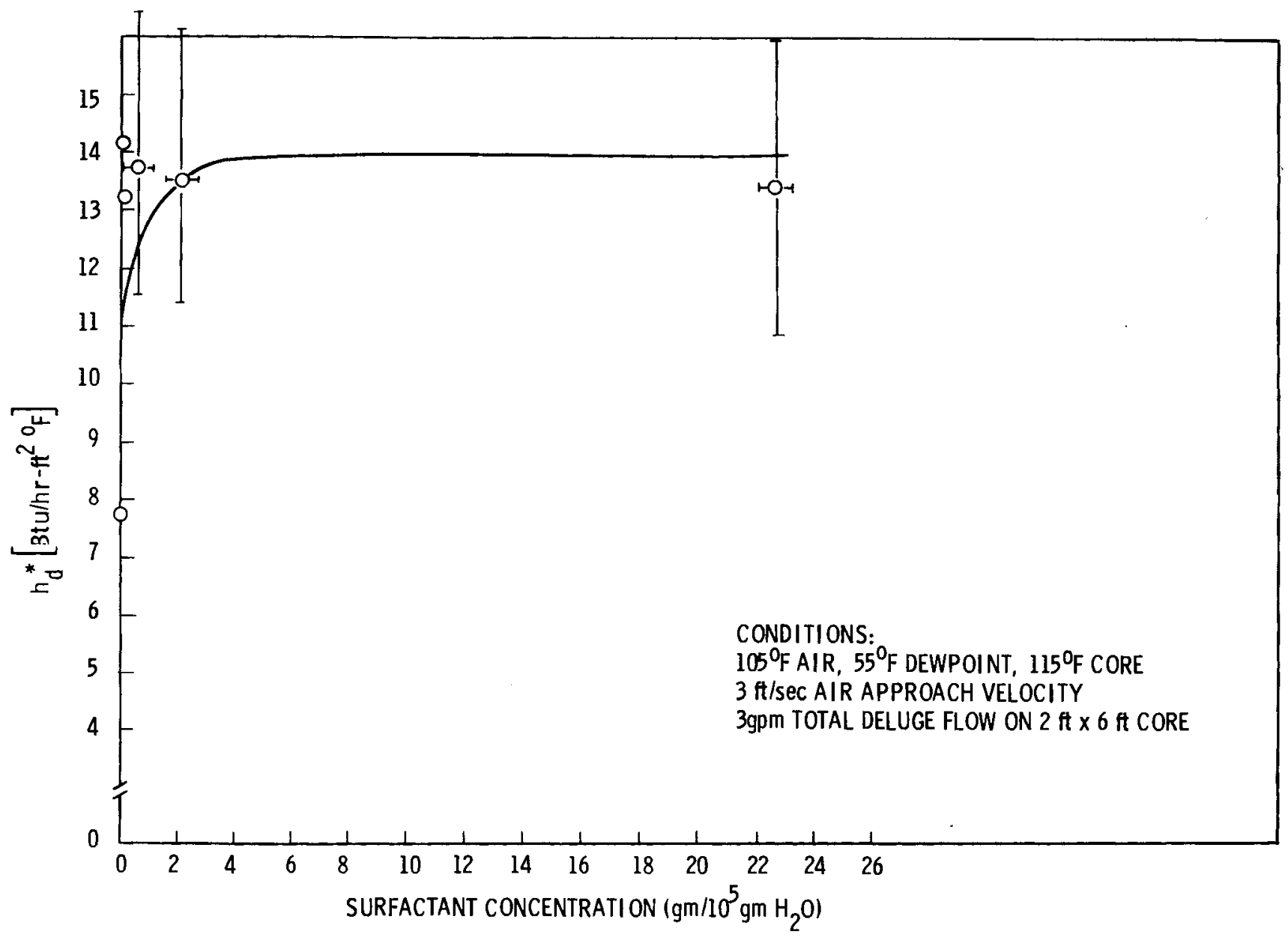

FIGURE 3-22. The Effect of Deluge Water Surfactant Concentration on Effective Deluge Film Coefficient, $h_{d^{*}}$ 


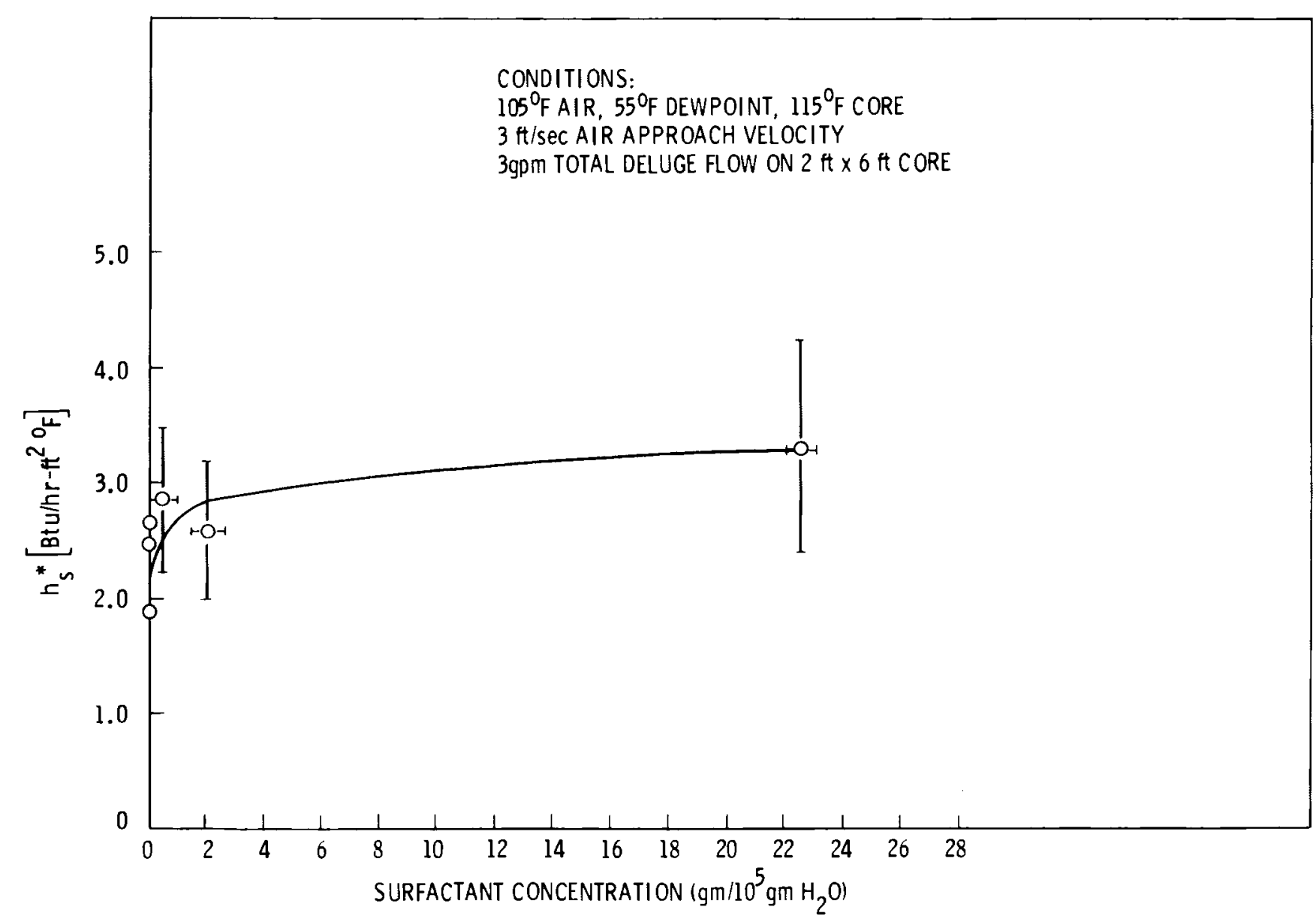

FIGURE 3-23. The Effect of Deluge Water Surfactant Concentration on Effective Deluge Surface Coefficient, $h_{s}$ * 


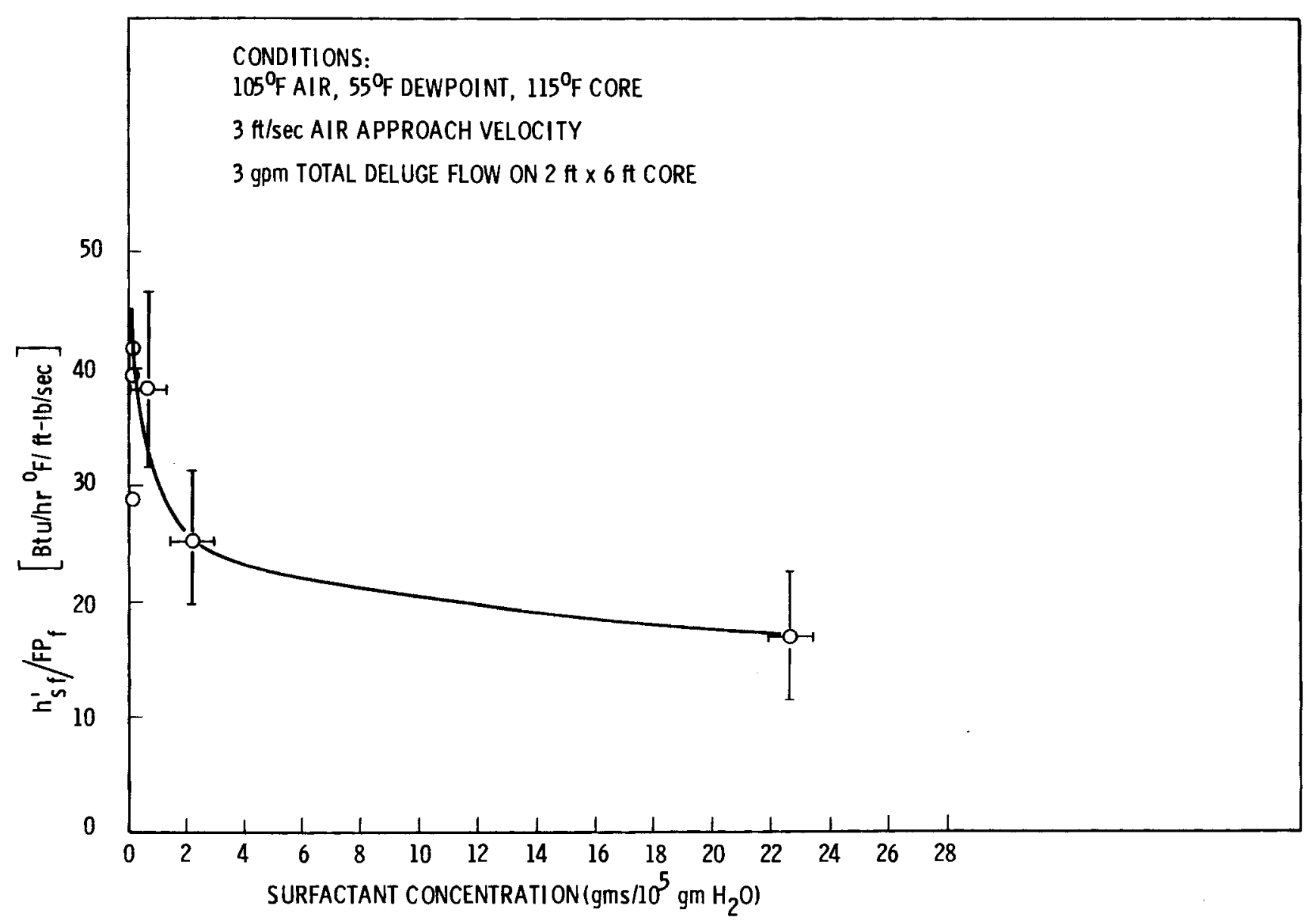

FIGURE 3-24. The Effect of Deluge Water Surfactant Concentration on Effective Overal1 Deluged Surface Coefficient Per Unit Fan Power, Based on Frontal Area 
a function of surfactant concentration. The figure indicates that the improvement in $h_{s}{ }^{\prime}$ is more than offset by the significant increase in required fan power and no net benefit is gained from the surfactant.

\subsection{SCAT TESTS}

Limited tests were performed on a Curtiss-Wright Surface "B" test core modified to allow the introduction of cool augmentation water into the third and sixth flow passage (counting from the leading edge) of each row of Curtiss-Wright tubes. This is the type of arrangement that might be used in the SCAT system mentioned in Section 1.0. Cool water was obtained directly from the building supply, passed through the selected passages in the core and then discharged. In a real SCAT system this water would be cooled evaporatively and recycled through the system. Heat rejected from the circulation water to the augmenting water was determined by measuring the augmentation water mass flow with the turbine flowmeter normally used for the deluge system and measuring its temperature $r$ ise across the core with thermocouples immersed in the flow. The primary goal of the tests was to evaluate the use of the HEATING5 computer code (see Appendix C) as a means of predicting SCAT system performance. Actual data from the SCAT tests were compared to predictions from a HEATING5 analysis performed using the geometry of Curtiss-Wright Surface "B" and the temperature conditions of the SCAT test. The same comparison was made for the simplified geometry of Surface "B" without slots. Results for SCAT Run \#8 are summarized in Table 3-1.

The HEATING5 code predicts total heat rejection of the SCAT system within an acceptable accuracy of $10 \%$, although the rate of heat rejection to the augmenting water is predicted high by up to $26 \%$. The additional analytical complexity of including the fin slots has little effect on the agreement between the prediction and the measured performance. 
TABLE 3-1. SCAT Test Data Compared to HEATING5 Predictions

HEATING5 Predictions

\begin{tabular}{|c|c|c|c|c|c|}
\hline & \multirow{2}{*}{ SCAT Test Data } & \multicolumn{4}{|c|}{ HEATING5 Predictions } \\
\hline & & Slotted S & $\frac{r f a c e}{\text { Frrar }}$ & Unslotted & $\frac{\text { Surface }}{\text { Frror }}$ \\
\hline Total Heat Rejected (Btu/hr) & 258,300 & 280,900 & $+9 \%$ & 278,000 & $+8 \%$ \\
\hline Heat Rejected to Air (Btu/hr) & 111,100 & 106,200 & $-10 \%$ & 102,200 & $-9 \%$ \\
\hline $\begin{array}{l}\text { Heat Reject to Augmenting } \\
\text { Water (Btu/hr) }\end{array}$ & 140,000 & 174,700 & $+25 \%$ & 175,800 & $+26 \%$ \\
\hline
\end{tabular}

A newly released PNL study ${ }^{(3)}$ comparing the cost of the SCAT system to the cost of a separate condenser system concludes that the separate condenser system has some cost advantages over the SCAT system. Consequently no further analytical or experimental work has been done to investigate the SCAT concept.

Complete details of the HEATING5 analysis and SCAT test conditions are presented in Appendix $C$. 


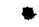

4

- 


\subsection{ANALYSIS}

The performance of evaporatively cooled heat exchangers (wet towers) can usually be predicted with acceptable accuracy using computational procedures and correlations that have evolved from years of experience. Similarly, the performance of all-dry heat exchangers (dry towers) can usually be predicted using semi-empirical correlations. However, the dry/wet or deluge mode of operation, in which a normally dry tower is periodically wetted to enhance heat transfer in hot weather, is not subject to either means of analys is. Thus, a new model has been developed ${ }^{(4-6)}$ to predict the heat transfer performance of a dry/wet tower when operated in the deluge mode.

The detailed development of the deluge models is provided in Appendixes $A$ and $B$. The purpose of this section is to provide a summary of that analysis and a comparison of the theory with experiment. The simple deluge model, assuming complete surface wetting, is developed first. The results of the simple theory are then briefly compared with the experimental results from WATA. The conclusion is reached that the simple deluge model is adequate when used with an empirical value for the deluge film coefficient $h_{d}$ which can be independently determined from the experimental data.

A modified deluge model was also developed (Appendix B) where in the effects of incomplete wetting are directly accounted for. An apparent degree of surface wetness is deduced by comparing the theory with the WATA data. Conclusions are reached regarding the usefulness and limitations of the models, and subjects requiring further research and analysis are identified.

\subsection{SUMMARY OF THE DELUGE HEAT TRANSFER MODELS}

The deluge model is based on the concept of the enthalpy driving potential, which originally appeared in the development of models for conventional wet cooling tower performance. (7) In this formulation, the separate effects of temperature and humidity are combined to produce a driving potential for heat transfer that is the difference between the enthalpies of moist air at the primary side and free stream conditions. 
The first case considered in the development of the deluge heat transfer model assumes that the heat exchanger surface is uniformly and completely wetted. This is in addition to the conventional assumption that $h_{S}$ is constant at all points on the surface. For these conditions, the governing equations and boundary conditions for deluge heat transfer (expressed in terms of the enthalpy difference driving potential) can be shown to be analogous to the corresponding equations for dry heat transfer from the same surface. (4) By analogy then, a transformation of variables is derived that allows the use of dry surface heat transfer correlations for predicting the performance of heat exchangers for wet operation.

\subsubsection{Derivation of the Enthalpy Driving Potential for Uniform Wetting}

Heat transfer from a dry surface to a cooler, flowing air stream is driven by convection where the driving potential for heat transfer is simply the surface-to-air temperature difference. When the surface is wet, the moist air at the surface may be assumed saturated at the surface temperature. A vapor concentration gradient (in addition to the temperature gradient) must then exist, resulting in a net diffusive motion of water vapor away from the surface. The latent heat of vaporization required for the liquid/vapor phase transition is provided by the cooled medium. Therefore, the rate of heat transfer to the surface is governed by the dual driving potentials of temperature and water vapor concentration.

Referring to Figure 4-1, it is shown in Appendix $A$ that a heat balance on the surface leads to the following expression:

$$
d Q=\sigma_{s}\left[C_{a}\left(T_{s}-T_{\infty}\right)\left(\frac{h_{s}}{C_{a} \sigma_{s}}\right)+\lambda_{s}\left(H_{s}^{\prime}-H_{\infty}\right)\right] d A_{s}
$$

The dimensionless grouping in Equation (4-1) is a convective or turbulent Lewis number

$$
L e=\frac{h_{s}}{c_{a} \sigma_{s}}
$$




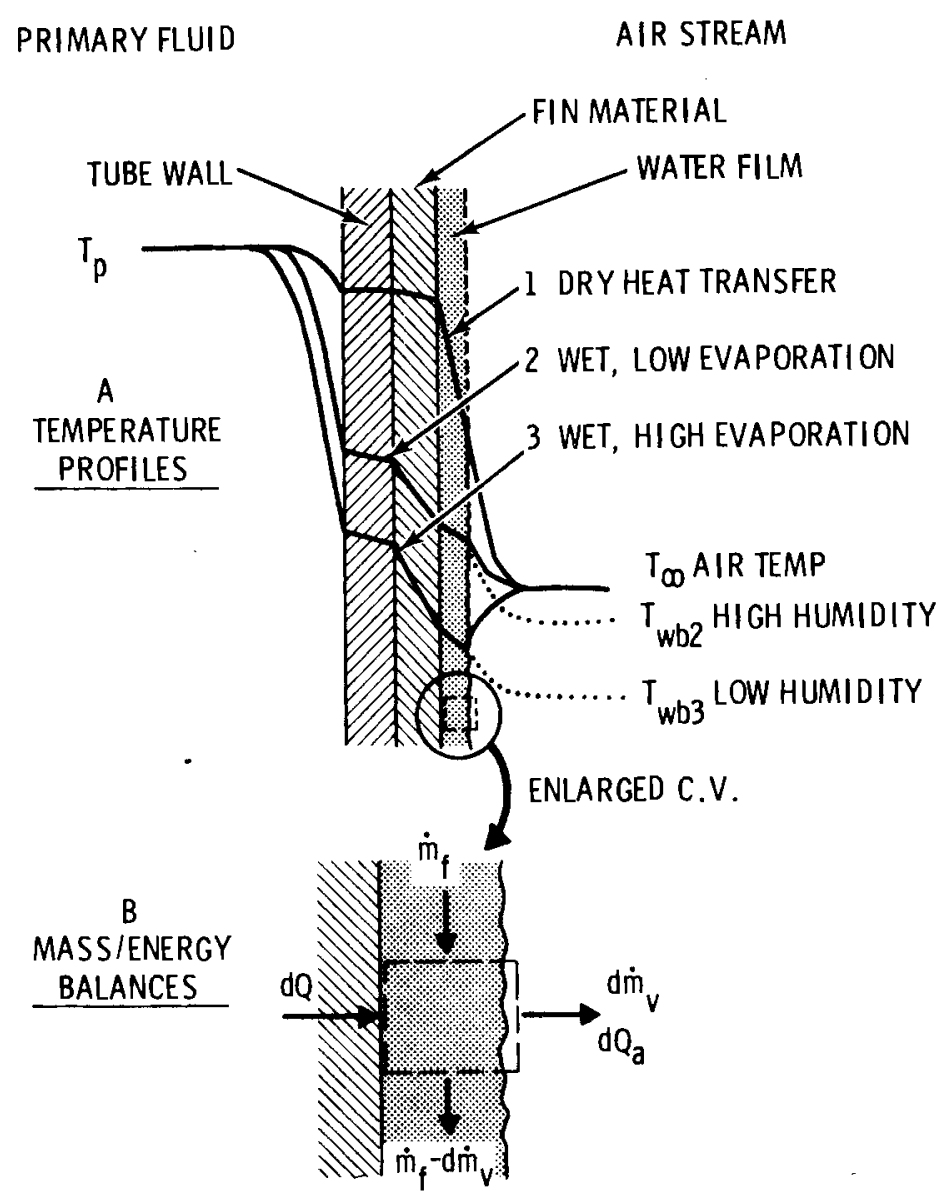

FIGURE 4-1. Temperature Distributions and Mass/Energy Balance for Deluge Heat Transfer Operation

which is frequently found to be very nearly equal to one for air/water vapor systems. $(8,9)$ In this case, Equation $4-1$ is closely approximated by

$$
\begin{aligned}
d Q & \simeq \sigma_{s}\left(i_{s}^{\prime}-i_{\infty}\right) d A_{s} \\
& \simeq h_{s}\left(\frac{i_{s}^{\prime}-i_{\infty}}{c_{a}}\right) d A_{s}
\end{aligned}
$$

The pseudo temperature difference $\left(i_{s}{ }^{\prime}-i_{\infty}\right) / C_{a}$ incorporates the dual driving potentials of temperature and water vapor concentration. 
Equation (4-4) is expressed in terms of the heat transfer coefficient and driving potential difference at the surface. We wish to express the heat flux in terms of an overall heat transfer coefficient and an overall enthalpy potential difference. To do so, it is necessary to develop an expression for the equivalent thermal resistance of the internal heat transfer path as illustrated in Figure 4-2. Because the same heat transfer $Q$ passes through all resistances, the overall resistance for dry operation may be given in terms of the respective temperature differences as follows:

$$
\begin{aligned}
& R_{0}=\frac{\left(T_{p}-T_{\infty}\right)}{Q / A_{s}}=\frac{\left(T_{p}-T_{t}\right)}{Q / A_{s}}+\frac{\left(T_{t}-T_{r}\right)}{0 / A_{s}}+\frac{\left(T_{r}-T_{\infty}\right)}{Q / A_{s}} \\
& R_{0}=\frac{1}{U_{0}}=\frac{A_{s}}{h_{p} A_{p}}+\frac{t_{t} A_{s}}{k_{t} A_{\bar{p}}}+\frac{A_{s}}{\left(A_{s t}+\eta_{f} A_{s f}\right) h_{s}}
\end{aligned}
$$

The net thermal resistance from the inside up to the root of the fin will be given for convenience as

$$
\frac{1}{U_{p r}}=\frac{1}{h_{p} a_{p}}+\frac{t_{t}}{k_{t} a_{\bar{p}}}
$$

where $a_{p}=A_{p} / A_{s}, a_{\bar{p}}=A_{\bar{p}} / A_{s}$. The dry surface fin efficiency $n_{f}$ may be given by an equation or graph (c.f. Figure 4-3) of the form

$$
n_{f}=f\left(\begin{array}{ll}
\frac{X_{e}}{X_{b}} & B i^{\frac{1}{2}}
\end{array}\right)
$$

where the dimensionless resistance of the finned surface is defined by a Biot number

$$
B i_{f}=\frac{l_{f}^{2} h_{s}}{k_{f} Y_{b}}
$$

The development of a model fin efficiency for the HÖTERV surface is discussed in Section 4.1.3. 

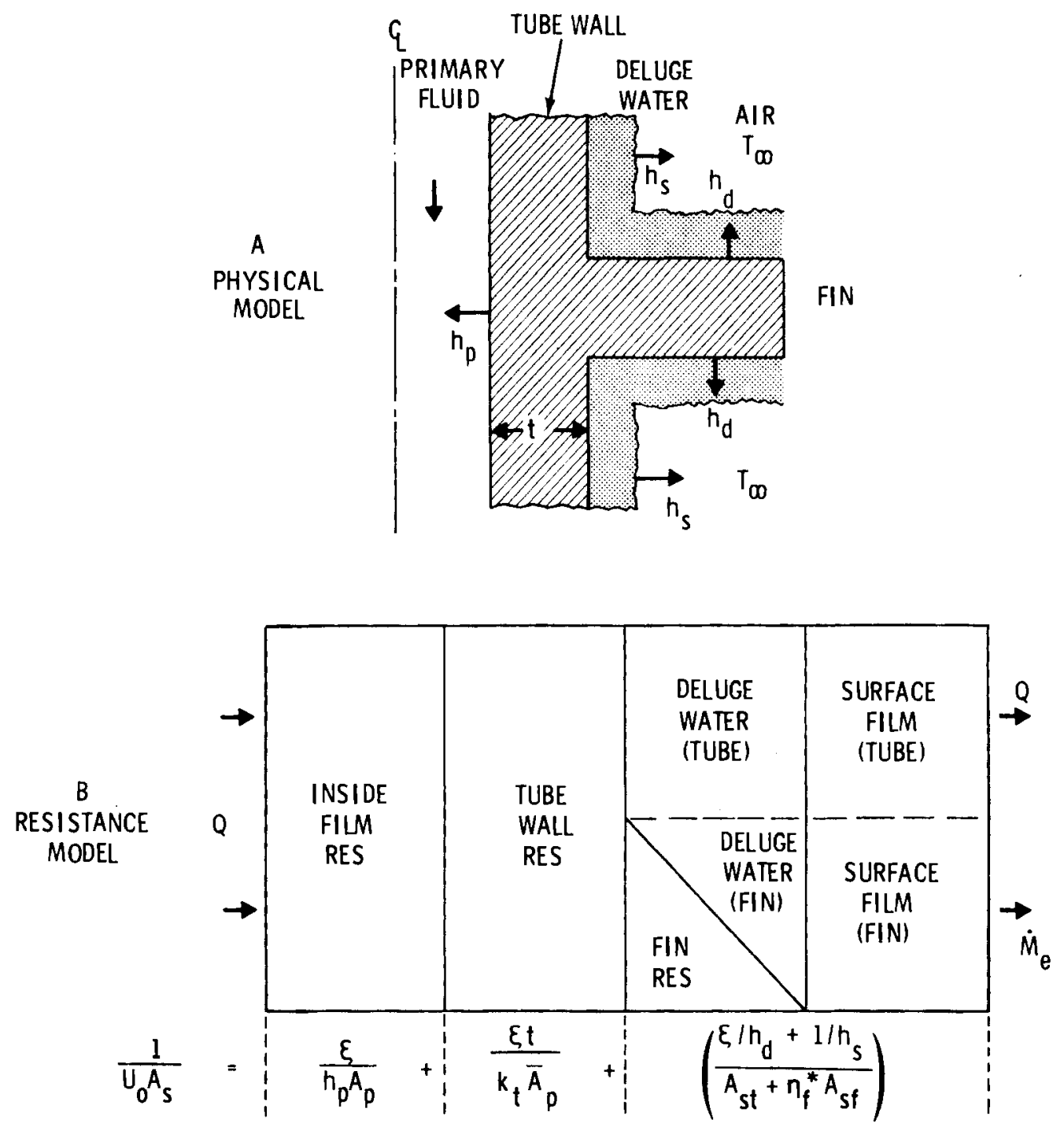

FIGURE 4-2. Heat Transfer Resistance Model for a Deluged Finned Surface

The analogous expression for the resistance to heat transfer in deluge operation is given in terms of the common $Q$ and the respective enthalpy differences by

$$
\begin{aligned}
R_{0}^{*}= & \frac{\left(i_{p}^{\prime}-i_{\infty}\right)}{C_{a} 0 / A_{s}}=\frac{\left(i p-i_{t}^{\prime}\right)}{C_{a} Q / A_{s}}+\frac{\left(i_{t}^{\prime}-i_{r}^{\prime}\right)}{C_{a} Q / A_{s}} \\
& +\frac{\left(i_{r}^{\prime}-i_{s}^{\prime}\right)}{C_{a} 0 / A_{s}}+\frac{\left(i_{s}^{\prime}-i_{\infty}\right)}{C_{a} \frac{0 / A_{s}}{d}}
\end{aligned}
$$




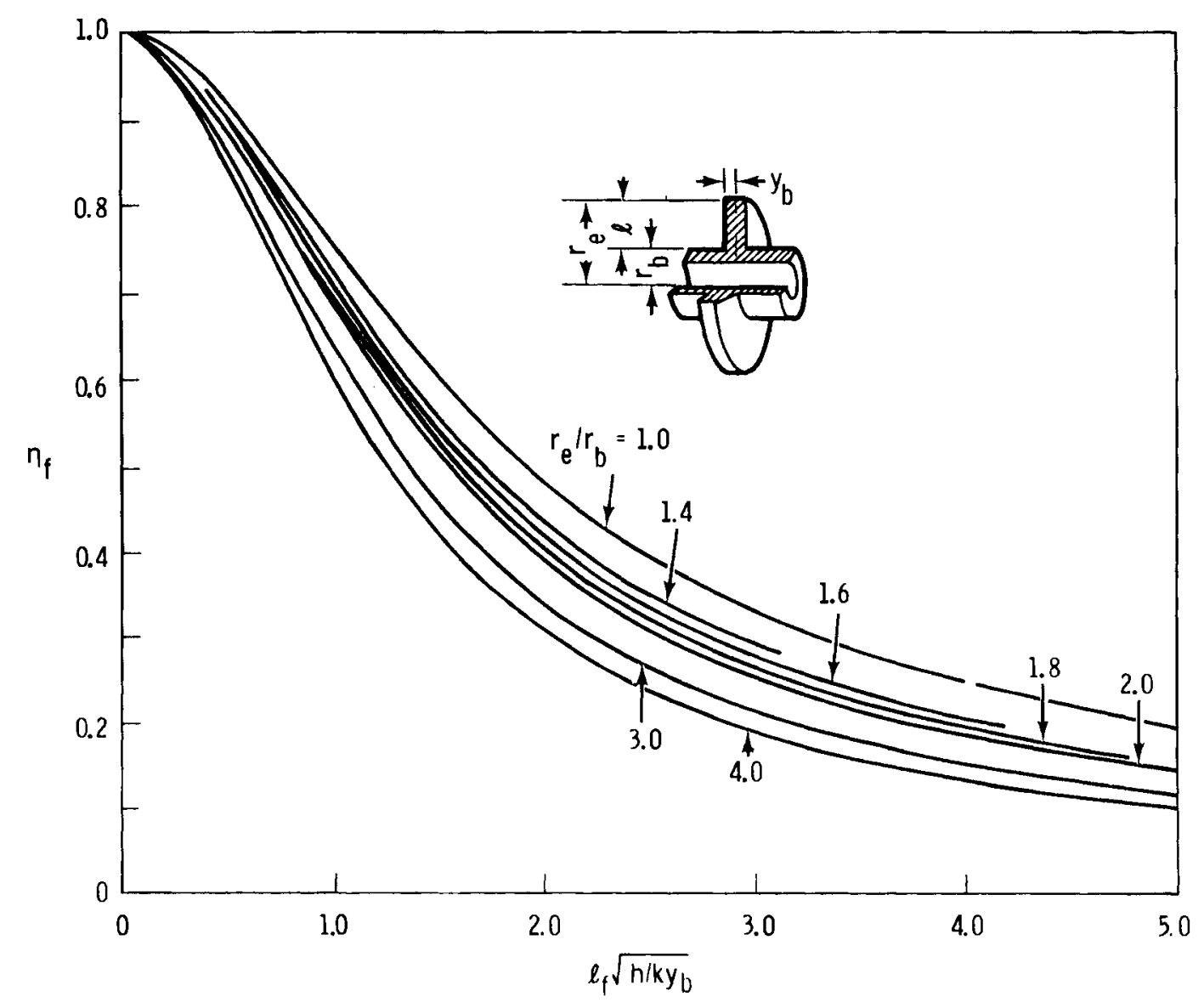

FIGURE 4-3. Fin Efficiency Solution for an Annular Fin (Also used to model plate fin with equivalent radius)

In this case an additional term must be included to account for the resistance of the delugeate film. The terms of Equation (4-10) will now be rearranged so that the simple thermal resistances in Equation (4-6) can be employed.

The overall and surface heat transfer rates may be given directly in terms of enthalpy potentials as

$$
\begin{aligned}
& Q=U_{0}^{*}\left(\frac{i_{p}^{\prime}-i_{\infty}}{c_{a}}\right) A_{s} \\
& Q=n_{s}\left(\frac{i_{s}^{\prime}-i_{\infty}}{C_{a}}\right)\left(A_{s t}+n_{f}^{*} A_{s f}\right)
\end{aligned}
$$


The wet fin efficiency $n_{f}$ is evaluated using the function derived for $n_{f}$, as discussed in more detail below.

The heat transfer across each of the internal resistances may be transformed from temperature to equivalent enthalpy potential form. For example, the heat transfer through the delugeate film resistance, assuming a delugeate film coefficient $h_{d}$, may be given as

$$
\begin{aligned}
Q & =h_{d}\left(T_{r}-T_{s}\right)\left(A_{s t}+n_{f}{ }^{*} A_{s f}\right) \\
& =\frac{h_{d}}{\xi_{r s}}\left(\frac{i_{r}^{\prime}-i_{s}^{\prime}}{c_{a}}\right)\left(A_{s t}+n_{f}{ }^{*} A_{s f}\right)
\end{aligned}
$$

where the enthalpy transformation for the delugeate resistance $\xi_{r s}$ is defined by

$$
\xi_{r s}=\frac{\left(i_{r}-i_{s}{ }^{\prime}\right)}{C_{a}\left(T_{r}-T_{s}\right)}
$$

Similar expressions could conceivably be derived for each resistance in the path. Alternatively, we may lump all of the internal resistances and define an overall resistance transformation as follows:

$$
\begin{aligned}
Q & =\left[\frac{1}{h_{p} A_{p}}+\frac{t_{t}}{k_{t} A_{\bar{p}}}+\frac{1}{h_{d}\left(A_{s t}+\eta_{f}^{\star} A_{s f}\right)}\right]^{-1}\left(T_{p}-T_{s}\right) \\
& =\frac{1}{\xi}\left[\frac{1}{U_{p r}}+\frac{1}{h_{d} a_{s}^{\star}}\right]^{-1}\left(\frac{i_{p}^{\prime}-i^{\prime} s}{C_{a}}\right) A_{s}
\end{aligned}
$$

where $a_{s}{ }^{*}=\left(A_{s t}+r_{f} * A_{s f}\right) / A_{s}$ is the reduced surface area. The overall enthalpy transformation parameter $\xi$ is defined as follows (see Figures $4-4$ and 4-5):

$$
\xi=\frac{\left(i p-i^{\prime}{ }_{s}\right)}{C_{a}\left(T_{p}-T_{s}\right)}
$$




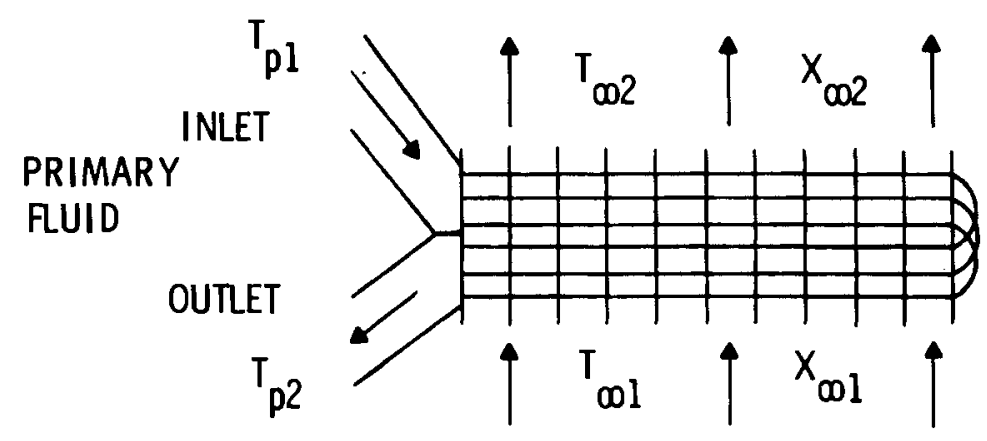

AIR

$$
\begin{aligned}
\xi & \left.=\frac{\left(i_{p}^{\prime}-i^{\prime} s^{\prime}\right.}{C_{a}\left(T_{p}^{-T_{s}}\right)} \sim \frac{1}{c_{a}} \frac{d i^{\prime}}{d T}\right)_{p} \\
\simeq & \frac{\left(i_{p l}^{\prime}-i^{\prime} \infty l\right)}{C_{a}\left(T_{p l}-T_{\infty l}^{\prime}\right)}
\end{aligned}
$$

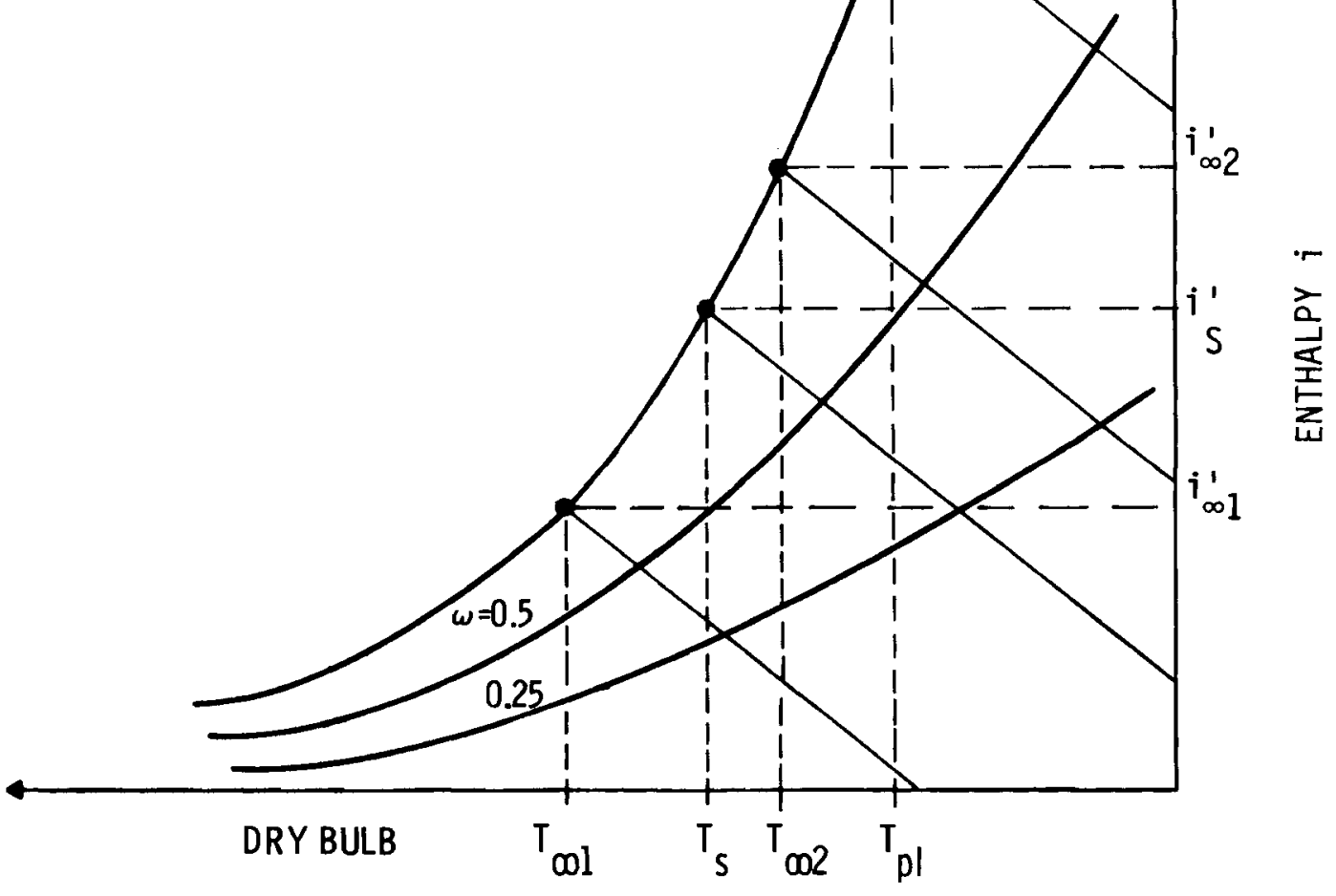

FIGURE 4-4. The Enthalpy Transformation 


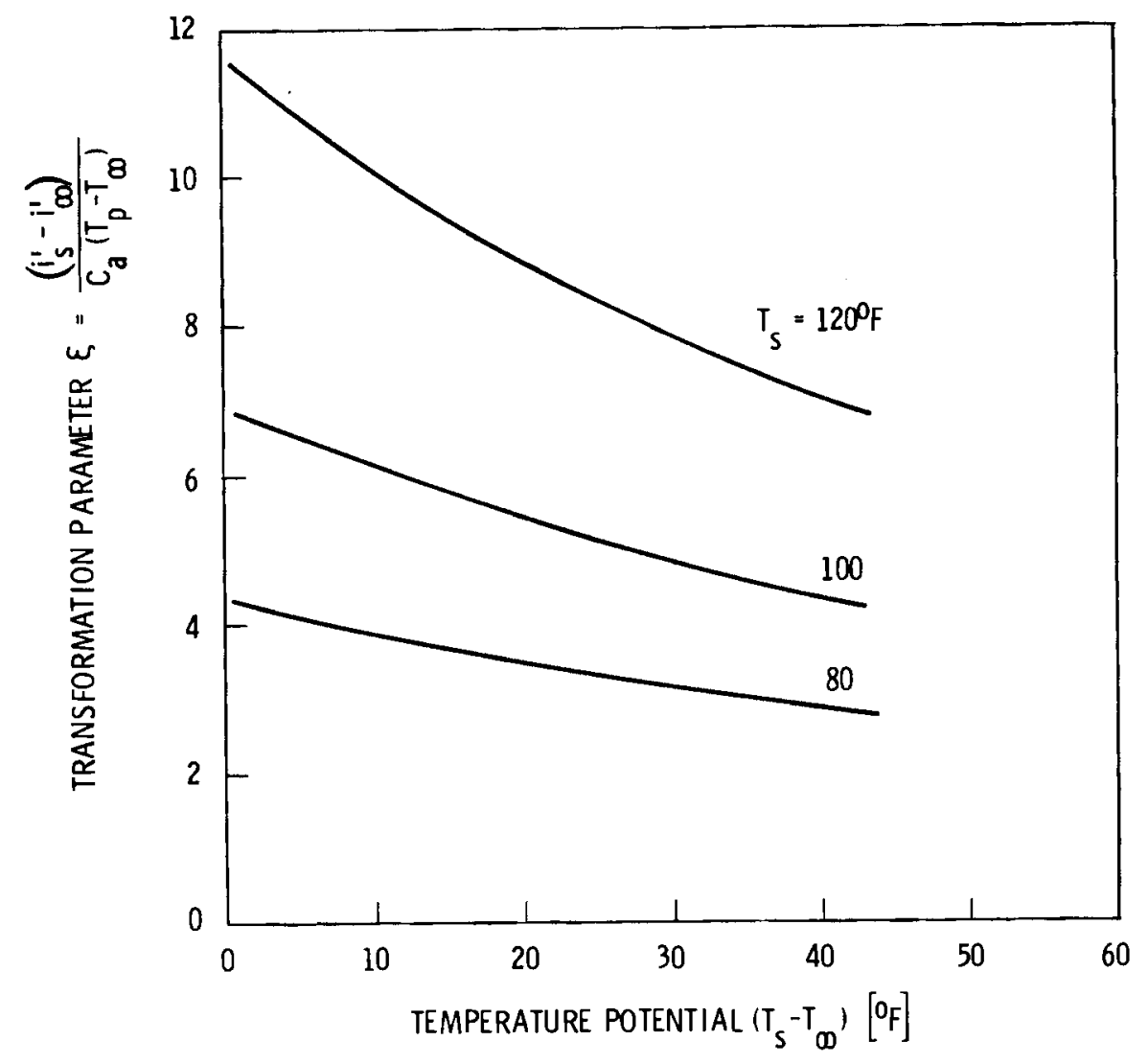

FIGURE 4-5. Temperature Dependence of the Transformation Parameter

The latter approach of lumping the internal resistances is preferable to the individual treatment because the apportioning of the enthalpy difference $\left(i_{p}{ }^{\prime}-i_{s}{ }^{\prime}\right)$ into separate elements is artificial and unnecessarily complicates the analysis.

The overall resistance for deluge operation may now be obtained by combining the results of Equations (4-10) through (4-12) and (4-17). The result is

$$
\mathrm{R}_{0}^{\star}=\frac{1}{U_{0}{ }^{\star}}=\frac{\xi}{U_{p r}}+\frac{\xi}{h_{d^{a} s^{*}}}+\frac{1}{h_{s^{a} s^{\star}}}
$$


Multiplying Equation $4-19$ by $\xi$ and rearranging then gives

$$
\frac{1}{\xi U_{0}{ }^{\star}}=\frac{1}{U_{p r}}+\frac{\left(1+B i_{d}\right)}{\xi h_{s}{ }^{{ }^{\star} s^{\star}}}
$$

where the dimensionless resistance of the delugeate $f i l m$ is given as a Biot number

$$
B i_{d}=\frac{\xi h_{s}}{h_{d}}
$$

An "effective" surface heat transfer coefficient may be defined by

$$
h_{e}^{\star}=\frac{\xi h_{s}}{\left(1+B i_{d}\right)}
$$

From Appendix $A$ and Section 4.1.2, it can be shown that $\eta_{f}$ may be given by the same function as $\eta_{f}$ if $B i_{f}$ * is evaluated with $h_{e}$ * substituted for $h_{s}$. Thus we obtain for $\eta_{f}{ }^{*}$,

$$
n_{f}^{\star}=f\left(\frac{r_{e}}{r_{b}}, B i_{f}^{\star \frac{1}{2}}\right)
$$

where $B i_{f} *$ is defined by

$$
B i_{f}^{*}=\frac{e_{f}^{2} h_{e}^{*}}{k_{f} Y_{b}}
$$

Thus, with the substitution of $\xi U_{0}{ }^{*}$ for $U_{0}$ and $h_{e}$ * for $h_{s}$, Equations (4-16) for dry heat transfer and (4-20) for deluge heat transfer are functionally identical. To use these results for predicting deluge heat transfer, all that is needed is an equation or graph of dry heat transfer data of the form 


$$
h_{s}=B R e^{n}
$$

and an equation or graph for the fin efficiency $n_{f}$. The computation of $Q$ is then completely analogous to the equivalent computation for dry surface heat transfer.

\subsubsection{Alternative Heat Transfer Formulations}

There are two fundamentally different, although equivalent, means for using the overall heat transfer coefficient for the prediction of heat transfer. These are:

- the log mean temperature difference (LMTD) and the analogous log mean enthalpy difference (LMED) approaches

- the NTU-effectiveness approach.

The analogous equations used in these two approaches are summarized in Table 4-1.

Calculation of the heat transfer by the LMTD (or LMED) technique requires a trial and error solution to determine the appropriate outlet stream conditions. In the NTU approach, $Q$ is computed using only the known inlet conditions. However, an equation for the effectiveness $\phi$ must be available for this calculation. In the WATA studies, the primary side flow rate was very high to simulate the operation of a condenser. For this case the HÖTERV core effectiveness can be modeled by Equation (4-30) or (4-37) (note that $\phi$ is not a function of $R$ for this particular example and that the crossflow correction has been neglected).

The above heat transfer calculational schemes provide alternative means for determining $U_{0}{ }^{*}$ from the data. From Equation 4-26 we obtain 
TABLE 4-1. Summary of Analogous Equations for Computation of Heat Transfer for Dry/Wet Performance

\begin{tabular}{|c|c|c|c|c|}
\hline Parameter & Dry Heat Transfer & $\begin{array}{c}\text { Equation } \\
\text { Number }\end{array}$ & Deluge Heat Transfer & $\begin{array}{c}\text { Equation } \\
\text { Number }\end{array}$ \\
\hline $\begin{array}{l}\text { Fundamental } \\
\text { Equation }\end{array}$ & $Q=U_{0} A_{s} \Delta T_{l m}$ & $4-26$ & $Q=U_{0}^{\star} A_{s} \Delta i_{\ell m}$ & $4-33$ \\
\hline $\begin{array}{l}\text { LMTD or LMED } \\
\text { Definition }\end{array}$ & $\Delta T_{\ell m}=\frac{\left(T_{p 1}-T_{\infty 1}\right)-\left(T_{p 2}-T_{\infty 2}\right)}{\ln \left|\frac{T_{p 1}-T_{\infty 1}}{T_{p 2}-T_{\infty 2}}\right|}$ & $4-27$ & $\Delta i_{\ell m}=\frac{\left(i_{p 1}^{1}-i_{\infty 1}\right)-\left(i_{p 2}^{1}-i_{\infty 2}\right)}{\ln \left|\begin{array}{ll}i_{p 1}^{1}-i_{\infty 1} \\
i_{p 2}^{1}-i_{\infty 2}^{1}\end{array}\right|}$ & $4-34$ \\
\hline $\begin{array}{l}\text { Fundamental } \\
\text { Equation }\end{array}$ & $Q=\phi \dot{m}_{a} C_{a}\left(T_{p l}-T_{\infty l}\right)$ & $4-28$ & $Q=\phi^{*} \dot{m}_{a}^{*}\left(i_{p}^{\prime}-i_{\infty}\right)$ & $4-35$ \\
\hline $\begin{array}{l}\text { Effectiveness } \\
\text { Definition }\end{array}$ & $\phi=\frac{T_{\infty 2}-T_{\infty 1}}{T_{p 1}-T_{\infty 1}}$ & $4-29$ & $\phi^{*}=\frac{i_{\infty 2}-i_{\infty 1}}{i_{p 1}^{\prime} i_{\infty 1}}$ & $4-36$ \\
\hline $\begin{array}{l}\phi \text { for a } \\
\text { Condenser }\end{array}$ & $\phi=1-e^{-N}$ & $4-30$ & $\phi^{*}=1-\mathrm{e}^{-N \star}$ & $4-37$ \\
\hline NTU Rating & $N=\frac{U_{0} A_{S}}{\dot{m}_{a} C_{a}}$ & $4-31$ & $N^{\star}=\frac{U_{0}^{*} A_{S}}{\dot{m}_{a}^{\star} C}$ & $4-38$ \\
\hline $\begin{array}{l}\text { Resistance } \\
\text { Ratio }\end{array}$ & $R=\frac{\dot{m}_{a} C_{a}}{\dot{m}_{p} C_{p}}=\frac{T_{p 2}-T_{p 1}}{T_{\infty 2}-T_{\infty 1}}$ & $4-32$ & $R^{*}=\frac{\xi \dot{m}_{a}^{*} C_{a}}{\dot{m}_{p} C_{p}}=\frac{-i_{1}-i_{p 2}^{\prime}}{i_{\infty}^{\prime}-i_{\infty 1}^{\prime}}$ & $4-39$ \\
\hline
\end{tabular}




$$
U_{0}^{*}=\frac{C_{a} Q_{h}}{A_{s} \Delta i_{\ell m}}
$$

where $Q_{h}$ is the heat input to the circulating water measured by the temperature $r$ ise and mass flow rate in the water heater bypass 1oop. Assuming negligible losses, the heat in is equal to the heat out, $Q=Q_{h}$.

The NTU technique provides two alternative means for determining $U_{0} *$. From Equations (4-35), (4-37) and (4-38) we obtain

$$
U_{0}^{*}=-\frac{\dot{m}_{a}^{*} c_{a}}{\bar{A}_{s}} \text { ln }\left|1-\frac{0}{\dot{m}_{a} \Delta i_{1}}\right|
$$

Or, by using the definition of $\phi *$ in Equation (4-36), we obtain

$$
U_{0}^{*}=-\frac{\dot{m}_{a}^{*} C_{a}}{A_{s}} \text { ln }\left|1-\frac{\Delta i_{\infty}}{\Delta i_{i}}\right|
$$

Equation (4-41) depends on measurement of the bypass heater input $\dot{Q}_{h}$ and the inlet enthalpy difference. Equation (4-42) depends on the air stream enthalpy rise which, in this study is not precisely measured. Thus, Equation (4-41) is likely to be most accurate. Theoretically, all three of the above determinations of $U_{0}{ }^{*}$ should give the same results. Thus, a comparison of the three results gives a good check on the internal consistency of the data.

Two different forms of an apparent surface heat transfer coefficient have been used to evaluate the WATA data. The first of these, $h_{s}$ ', is defined as

$$
\frac{1}{h_{s}^{1}}=\frac{1}{U_{0}^{\star}}-\frac{\xi}{U_{p r}}
$$


From Equation (4-19), the theoretical value of $h_{s}{ }^{\prime}$ is

$$
\begin{aligned}
\frac{1}{h_{s}^{\prime}} & =\frac{\xi}{h_{d^{a}} a^{\star}}+\frac{1}{h_{s} a_{s}^{\star}} \\
& =\frac{1}{h_{s} a_{s}^{\star}}\left(1+\frac{\xi h_{s}}{h_{d}}\right)
\end{aligned}
$$

Thus, from Equations (4-21) and (4-22) the theoretical expression for $h_{s}{ }^{\prime}$ may be given by

$$
\begin{aligned}
h_{s}^{\prime} & =\frac{h_{s}^{a} s}{\left(1+B i_{d}\right)} \quad \text { (theoretical value) } \\
& =\frac{h_{e}^{\star} a_{s}^{\star}}{\xi}
\end{aligned}
$$

The second form of the apparent surface heat transfer coefficient $h_{s}$ * is computed by subtracting out the delugeate resistance. The definition of $h_{S}{ }^{*}$ is then given by

$$
\begin{aligned}
\frac{1}{h_{\mathrm{s}}^{\star}} & =\frac{1}{U_{0}^{\star}}-\frac{\xi}{U_{p r}}-\frac{\xi}{h_{d}^{\star}} \text { (definition) } \\
& =\frac{1}{h_{s}^{\prime}}-\frac{\xi}{h_{d}^{\star}}
\end{aligned}
$$

where $h_{d}{ }^{*}=h_{d} a_{s}{ }^{*}$. From Equation (4-19), the theoretical value of $h_{s}$ * is thus given by

$$
h_{s}^{*}=h_{s}^{a *} \quad \text { (theoretical value) }
$$


Equations (4-43) and (4-48) are used to compute $h_{s}{ }^{\prime}$ and $h_{s}{ }^{*}$ from the WATA data. Equations (4-46) and (4-50) are used to compare theory with experiment. Computation of theoretical values of $U_{0}{ }^{*}, h_{s}{ }^{\prime}$ and $h_{s}{ }^{*}$ are provided in Section 4.2.

\subsubsection{Development of a Fin Efficiency Model for the HÖTERV Plate Fin Heat Exchanger}

Computation of fin efficiency for dry and wet performance was discussed briefly in Section 4.1.1. By transformation of variables, the relationship for $n_{f}$ based on dry operation, Equation (4-8), can be adapted to wet operation as given in a general form by Equation (4-23). These ideas were used to develop a specific fin efficiency model for the HÖTERV core.

The HÖTERV plate fin geometry is illustrated in Figure 4-6. The fin has a complex array of vertical slots parallel to the deluge flow and perpendicular to the airflow. The tube pitches in the vertical and horizontal

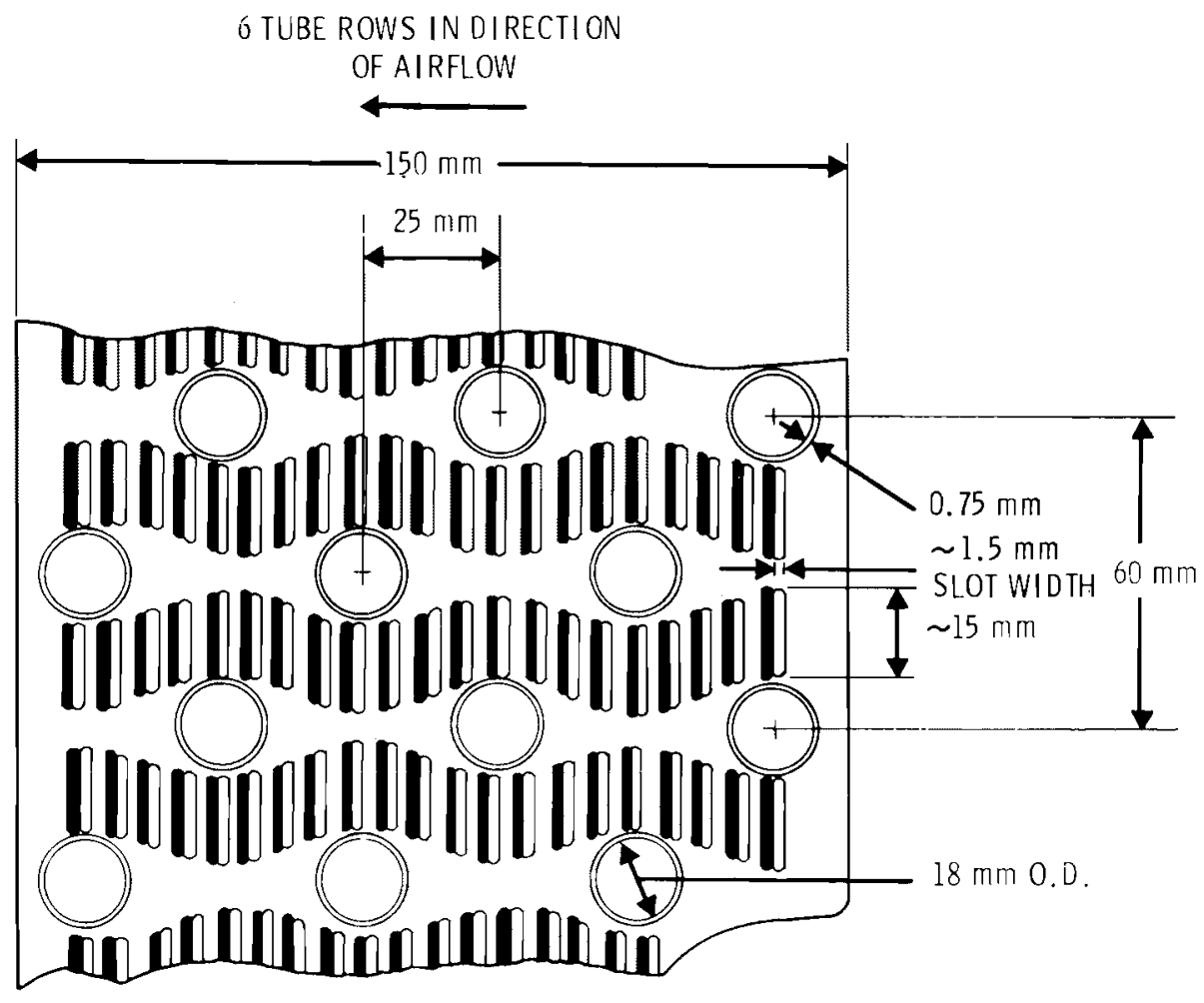

HOTERV SURFACE

FIGURE 4-6. HÖTERV Plate Fin Design 
directions are different as shown. Analytical prediction of fin efficiency for this surface is impractical, so a simple, approximate model was devised.

For the analysis, the plate fin was assumed to be equivalent to a set of annular fins with the same thickness and equivalent area, as illustrated in Figure 4-7. This is the same as the model used for predicting the heat exchanger cost and performance in the BNW-II computer code. (11) The question arises as to what equivalent area should be used: that which includes, or excludes, the area of the punchouts.

Because there is no basis for choosing either alternative, both alternatives were tested. Equivalent outer fin radii were computed for both alternatives and the data of Figure 4-3 were used to compute the efficiency curves plotted in Figure 4-8. The circles on Figure 4-8 are efficiencies computed for an approximation of the actual HÖTERV fin geometry using the HEATING5 computer code.

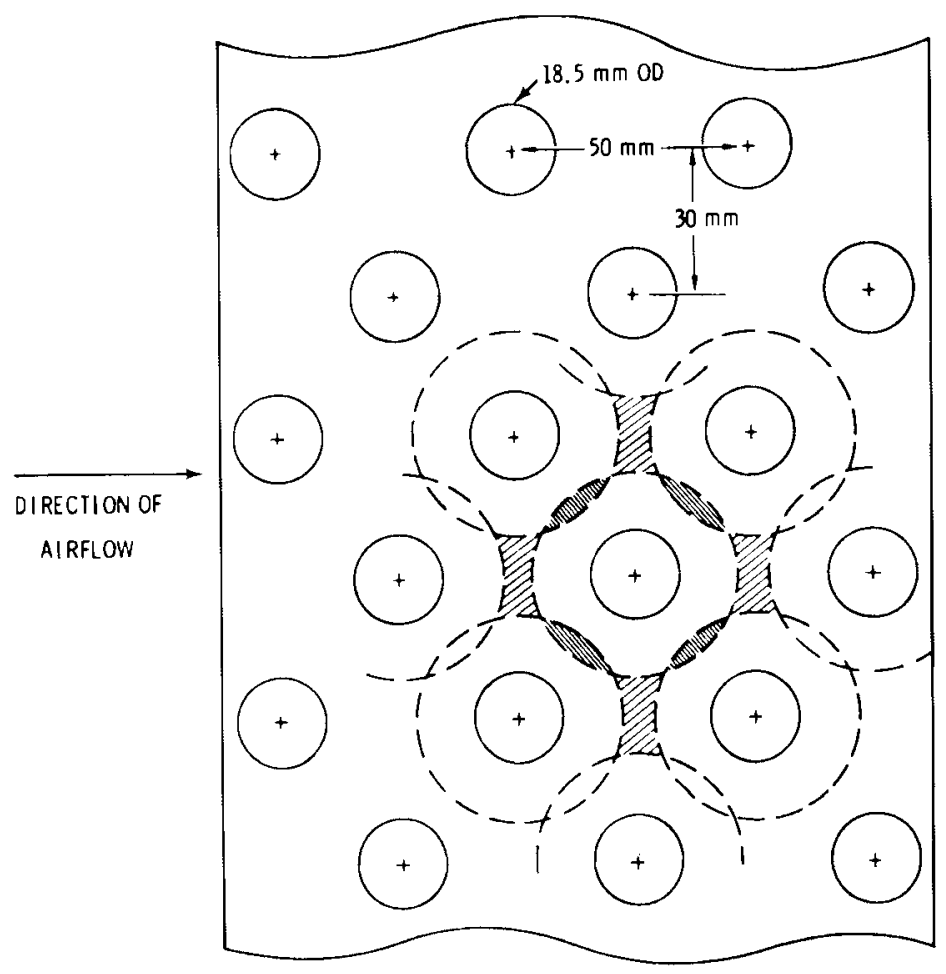

FIGURE 4-7. Equivalent Annular Fin for the HÖTERV Core 


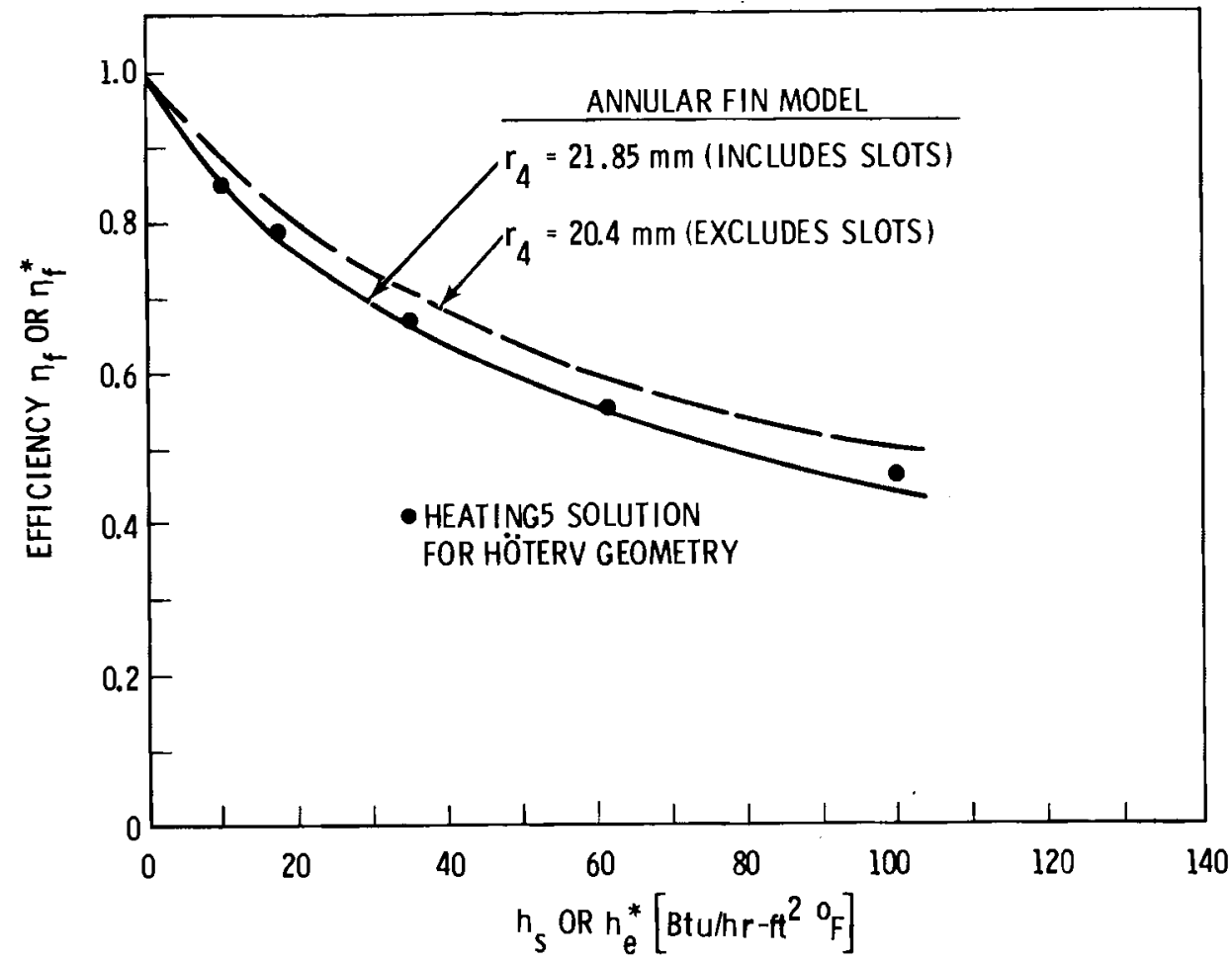

FIGURE 4-8. Comparison of the Annular Fin Model with Numerical Computations Using HEATING5 Code

The HEATING5 code $(12)$ is a versatile finite difference computer program for computing temperature distributions and heat transfer in systems of arbitrary geometry. The code has provisions to handle variable properties, variable geometry, transient or steady-state processes and variable boundary conditions. This includes constant temperature, constant heat flux, radiation and convection or any desired combination thereof. The code is set up to handle $r-\theta-Z$ or $X-Y-Z$ coordinates.

For the annular fin, the efficiencies computed using the $r-\theta-Z$ option of HEATING5 agreed almost exactly with the results of the exact theory shown in Figure 4-3. This illustrates that the code was functioning properly and that precision of computation was adequate. 
For the HÖTERV model shown in Figure $4-9$, the $X-Y-Z$ version of HEATING5 generated the fin efficiency predictions shown as solid circles on Figure 4-8. These results show that the annular fin model of the HÖTERV surface, using an equivalent area that includes the area of the slots, is completely satisfactory. The range of values of $h_{s}$ shown in Figure 4-8 is sufficient to represent the range of actual or effective heat transfer coefficients of interest for the HÖTERV deluge application.

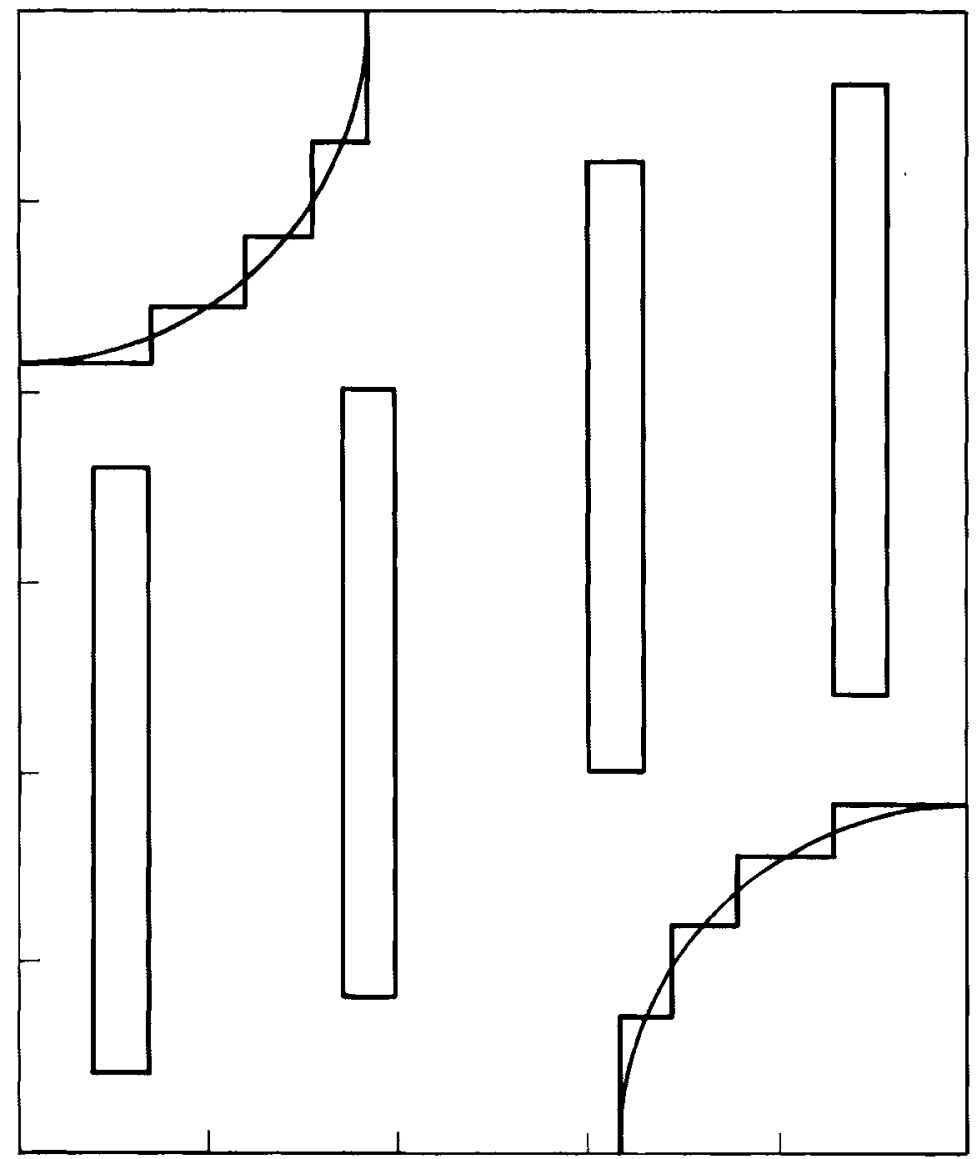

FIGURE 4-9. Rectilinear Approximation of the HÖTERV Plate Fin Used in the HEATING5 Efficiency Computations 


\subsubsection{Computation of the Deluge Film Coefficient $h_{d}$}

In the initial stages of the deluge heat transfer model development, it was assumed that the water film was very thin and uniform. For laminar film flow, the thermal resistance of the film could then be assumed to be due to simple thermal conduction. For films that are small relative to the fin spacing, the film resistances thus computed are negligible. If the film was turbulent, the thermal resistance would be even smaller. Thus, in the initial development of the deluge model it was assumed that the thermal resistance of the water film was negligible (i.e., $h_{d}+\infty$ or $B i_{d} \approx 0$ ).

When the simple model with $B i_{d}=0$ was compared with the results of the experiments, it was immediately found that the model overpredicted $U_{0}{ }^{*}$ by a factor of 2 or more in most cases. After considerable analys is and discussion it was concluded that the source of the discrepancy in the model was likely to be due primarily to incomplete wetting of the surface.

To assess the effects of incomplete wetting, a modified model was then developed wherein the distribution of water on the surface was accounted for. The details of this analysis are given in Appendix $B$ and a summary of the results is given in the next section. Unfortunately, the modified model also proved to be unsatisfactory because the surface wetness fraction $\alpha$ and certain other parameters including $B i_{d}$ could not be predicted.

Because neither of the above techniques was successful in predicting the deluge heat transfer data, numerous other means were investigated to bring the theory and the experiments into agreement. One of the first alternatives considered was the possibility that the resistance of the delugeate was nonnegligible $\left(B i_{d}>0\right)$. However, the values of $h_{d}$ predicted by all available correlations for film flow were much too large to account for the discrepancy in the theory. One of the alternatives considered was to use $h_{d}$ as a "fit parameter" whereby the theory could be "calibrated" to fit the data. However, there appeared to be no reasonable justification for this approach and it was abandoned. 
During the final preparation of this report, a series of telegrams exchanged with Dr. Forgo at the HÖTERV Institute in Hungary finally resulted in the solution of this dilemma. Dr. Forgo indicated that they computed a value of $h_{d}$ using the known heat rejection rate and the measured temperature difference between the tube wall and the deluge water. The values of $h_{d}$ thus computed brought the theory and experiment into good agreement for their experiments. As shown below, it worked equally well for this study in spite of the substantial differences in the values of $h_{d}$ obtained in the two studies.

A brief explanation of the technique used to compute $h_{d}$ will now be provided. The results are then used to compare with the data obtained in the experiments and with the results of the HÖTERV experiments.

The computation of $h_{d}$ can be illustrated by reference to Figure 4-1, which is a simplified depiction of the temperature profile through the heat exchanger. Temperature profiles are shown for dry surface heat transfer (Curve 1) and for deluge heat transfer for two cases where the air is warmed (Curve 2) and cooled (Curve 3). Either of the latter can (and does) occur, depending on the ITD, humidity, air flow rate and other conditions.

The heat rejection rate can be given in terms of the internal temperature differences by the alternative expressions

$$
\begin{aligned}
& Q=\left[\frac{1}{h_{p}^{a} p}+\frac{t}{k_{f}^{a} \bar{p}}\right]^{-1}\left(T_{p}-T_{r}\right) A_{s} \\
& Q=h_{d}\left(T_{r}-T_{d}\right)\left(A_{s t}+n_{f}^{*} A_{s f}\right)
\end{aligned}
$$

where $T_{r}$ is the fin root temperature and $T_{d}$ is the deluge water bulk temperature.

Solving Equation (4-51) for $T_{r}$, substituting for $T_{r}$ in Equation (4-52), and solving for $h_{d}$ then gives 


$$
\begin{aligned}
h_{d}^{*} & =h_{d}\left(\frac{A_{s t}+n_{f}^{\star} A_{s f}}{A_{s}}\right)=h_{d} a_{s}^{*} \\
& =\left[\frac{\left(T_{p}-T_{d}\right) A_{s}}{Q}-\left(\frac{1}{h_{p} a_{p}}+\frac{t}{k_{f} a_{\bar{p}}}\right)\right]^{-1}
\end{aligned}
$$

where $h_{d}{ }^{*}$, including the effects of fin efficiency, can be computed directly from the experimental data. The actual value of $h_{d}$, if needed, can be computed by first computing the efficiency $n_{f}$ (the latter, however, requires a trial and error solution). The results for $h_{d}{ }^{*}$ are given in Figures 3-13 and $3-17$.

\subsubsection{Summary of the Deluge Model for Incomplete Wetting}

The modified deluge model described below was developed in an early attempt to account for incomplete wetting of the surface. Although the simpler model with experimentally determined values of $h_{d}$ has subsequently been found to be the most useful approach, there is enough to be learned from the modified model to justify its inclusion here.

The approach taken in the analysis was to extend the annular fin model used for computing fin efficiency. The inner annulus of the fin, defined by $r_{2}<r<r_{3}$ and the contiguous portion of the tube were assumed wet with the outer annulus of the fin $\left(r_{3}<r<r_{4}\right)$ and the remainder of the tube was assumed dry (c.f. Figure 4-10). Equations were then written for the heat transfer from each of these surfaces. The total heat transfer was then obtained as the sum of the heat fluxes from the separate regions. The solution can be expressed in terms of an effective surface heat transfer coefficient $h_{s}{ }^{*}$, which, in this case, includes the effects of fin efficiency, delugeate resistance and partial wetting. The result is

$$
\varepsilon=\frac{h_{s}^{*}}{h_{s}}=(1-\alpha) n_{e} a_{f} \delta_{f}+\frac{\alpha\left(a_{t}+n_{e}^{*} a_{f}\right)}{\left(1+B i_{d}\right)}
$$



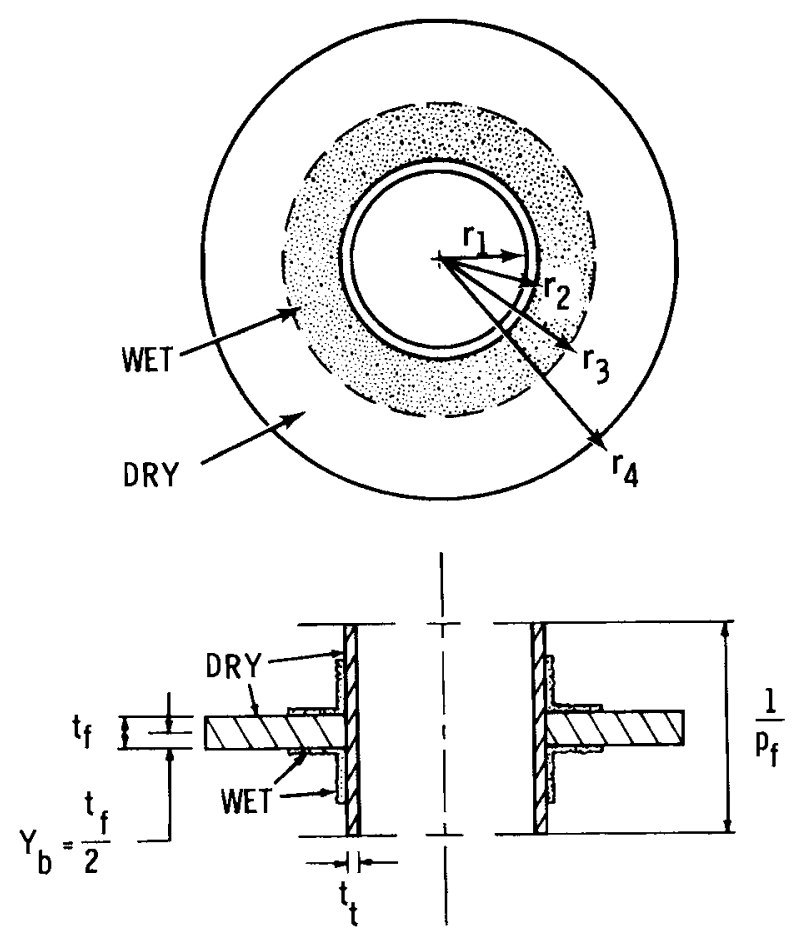

FIGURE 4-10. The Annular Fin/Annular Wetting Model for a Partially Wetted Finned Tube

where $a_{t}=A_{s t} / A_{s}$ and $a_{f}=A_{s f} / A_{f}$ are the total fractional surface areas of the exposed tubes and the fins and $\alpha$ is the fraction of the total surface wetted. The effective efficiencies of the dry area $n_{e}$ and wet area $n_{e}{ }^{*}$ are defined by

$$
\begin{aligned}
& \eta_{e}=f\left(\frac{r_{4}}{r_{3}}, B i_{f}^{\frac{1}{2}}\right) \quad \text { dry annulus, } r_{3}<r<r_{4} \\
& \eta_{e}^{\star}=f\left(\frac{r_{3}}{r_{2}}, B i_{f}^{\star \frac{1}{2}}\right) \quad \text { wet annulus, } r_{2}<r<r_{3}
\end{aligned}
$$

The parameter $\delta_{f}$ is a measure of the temperature depression at the outer edge of the wetted zone due to evaporation:

$$
\delta_{f}=\frac{c_{a}\left(T_{4}-T_{\infty}\right)}{\left(i_{r}^{1}-i_{\infty}\right)}
$$


This term arises in transforming the dry portion of the fin to the enthalpy potential formulation. Using the result in Equation (4-55), the overall heat transfer coefficient may then be computed using Equation (4-43):

$$
\frac{1}{U_{0}^{\star}}=\frac{\xi}{U_{p r}}+\frac{1}{\varepsilon h_{s}}
$$

The result in Equation (4-55) encompasses several approximations, including assumptions that the tube wall is isothermal and that the heat transfer through the dry portion of the tube is negligible. These assumptions are verified in Appendix B. The biggest difficulty in evaluating Equation (4-55) lies in predicting the values of $\delta_{f}$ and $B i_{d}$. Because no models have yet been devised for predicting these parameters, they are handled parametrically. The results are illustrated in Section 4.2.2.

\subsection{EVALUATION OF THE DELUGE MODELS}

This section provides detailed illustrations of the use of the two deluge models and compares the resulting predictions with experimental data. All of the design data and operating conditions used in the computations were drawn from the WATA experiments for deluge operation with the HÖTERV core. Because of the large number of variables involved, only a few representative cases were examined. Example calculations for each case are provided at the end of Appendixes $A$ and $B$.

\subsubsection{Application of the Deluge Model to Prediction of Heat Transfer for a Uniformly Wetted Core}

The HÖTERV heat exchanger used in the WATA experiments has a $2 \mathrm{ft}$ by $6 \mathrm{ft}$ effective frontal area. The design of the fins is illustrated in Figure 4-6 and the relevant design parameters are summarized in Table 4-2. Detailed descriptions of the core and related apparatus are provided in Section 3.0. For the present computations, the primary (tube side) surface heat transfer coefficient was assumed to be given by $h_{p}=625\left(B t u / \mathrm{ft}^{2} \mathrm{hr}{ }^{0} \mathrm{~F}\right)$.

The average values of $h_{d}{ }^{*}$ determined from the WATA experiments, from Figure $3-13$, may be summarized as 
TABLE 4-2. HÖTERV Core Design Parameters for WATA

Symbol

$A_{\text {st } \quad \text { Exposed tube surface area }}$

$A_{\text {sf }} \quad$ Total fin surface area

$A_{S} \quad$ Total exposed surface area

$A_{p} \quad$ Primary (tube-side) area

$A_{\bar{p}} \quad$ Mean tube wall area

$t_{t}$

$t_{f}$

$r_{1}$

$r_{3}$

$g_{f}$

$p_{f}$

$k_{t}$

$h_{p}$
Tube wal1 thickness

Fin thickness

Tube outer radius

Fin equivalent radius

Fin air gap

Fin pitch

Fin/tube thermal conductivity

Primary-side heat transfer coefficient
English Units

$56.9 \mathrm{ft}^{2}$

$942.3 \mathrm{ft}^{2}$

$999.2 \mathrm{ft}^{2}$

$59.1 \mathrm{ft}^{2}$

$61.7 \mathrm{ft}^{2}$

$0.00246 \mathrm{ft}$

$0.001083 \mathrm{ft}$

$0.03035 \mathrm{ft}$

$0.07169 \mathrm{ft}$

$0.00837 \mathrm{ft}$

$0.09945 \mathrm{ft}$

$111\left(\frac{\mathrm{Btu}}{\mathrm{hr} \mathrm{ft}^{\mathrm{O}} \mathrm{F}}\right)$

$500\left(\frac{}{h r \mathrm{ft}^{20} \mathrm{~F}}\right)$
Metric Units

$5.28 \mathrm{~m}^{2}$

$87.5 \mathrm{~m}^{2}$

$92.8 \mathrm{~m}^{2}$

$5.49 \mathrm{~m}^{2}$

$5.73 \mathrm{~m}^{2}$

$0.75 \mathrm{~mm}$

$0.33 \mathrm{~mm}$

$9.25 \mathrm{~mm}$

$21.85 \mathrm{~mm}$

$2.55 \mathrm{~mm}$

$2.88 \mathrm{~mm}$

$192\left(\frac{\text { watts }}{m^{0} \mathrm{C}}\right)$

$3550\left(\frac{\text { watts }}{\mathrm{m}^{20} \mathrm{C}}\right)$

at $\mathrm{Re}^{\star}=450$

$$
\begin{aligned}
& \bar{h}_{d}^{*}=h_{d} a_{s}^{*} \simeq 12 \\
& h_{e^{*} \simeq 12.5 \rightarrow h^{\star} \approx 0.84} \\
& a_{s}{ }^{*} \approx 0.85 \\
& h_{d} \approx \frac{12.5}{0.85} \simeq 15\left(\frac{\text { Btu }}{f t^{2} h^{0} \mathrm{~F}}\right)
\end{aligned}
$$


at $\operatorname{Re}^{\star}=900$

$$
\begin{aligned}
& \bar{h}_{\mathrm{d}^{*}}=\mathrm{h}_{\mathrm{d}} \mathrm{a}_{\mathrm{s}}{ }^{*} \simeq 23 \\
& \mathrm{~h}_{\mathrm{e}^{*}} \approx 23 \rightarrow \mathrm{n}_{\mathrm{f}} \approx \\
& \mathrm{a}_{\mathrm{s}} \approx 0.75 \\
& \mathrm{~h}_{\mathrm{d}} \approx \frac{23}{0.76} \approx 30\left(\frac{\mathrm{Btu}}{\mathrm{ft}^{2} \mathrm{hr}^{0} \mathrm{~F}}\right)
\end{aligned}
$$

For comparison, computations were also provided for $h_{d}=100\left(B t u / f t^{2} h r^{0} F\right)$, corresponding approximately to the value used by HÖTERV, and for $h_{d} \rightarrow \infty\left(B i_{d} \approx 0\right)$ corresponding to the ideal case where the resistance of the film is negligible (i.e., a thin uniform film of negligible thickness).

The surface heat transfer coefficient $h_{0}$ in Table 4-3 and Figure 4-11 was determined from the WATA experiments for dry heat transfer. This parameter incorporates the effect of fin efficiency. The actual surface heat transfer coefficient $h_{s}$ was extracted from $h_{0}$ by computing and backing out the fin efficiency. The results are also given in Table 4-3 and Figure 4-11. The coefficient and exponent in Equation 4-25 extracted by a curve fit are $B \simeq 1.07\left(B t u / h r f t^{20} F\right), n \simeq 0.34$.

The overall heat transfer coefficient $U_{0}$ corresponding to the range of $h_{s}$ in Figure 4-11 for dry heat transfer was computed using Equation 4-6. The result is given in Table 4-4 and as the solid portion of the curve on the left in Figure 4-12. Equation (4-20) for $\xi U_{0} *$ versus $h_{e}$ is identical with Equation (4-6) so the curve for wet heat transfer may be obtained by simply extending the calculations to large values of $h_{s}$. The results of these computations are also given in Table 4-4 and as the dashed portion of the curve on the right in Figure 4-12. The fin efficiency is also given in Figure 4-12 for convenience. Figure 4-12 may now be used to compute $U_{0}$ or $\xi U_{0} *$ for either dry or wet heat transfer. 
TABLE 4-3. HÖTERV Dry Heat Transfer

\begin{tabular}{|c|c|c|c|c|c|}
\hline $\mathrm{Re}$ & $\dot{\mathrm{m}} \operatorname{air}(1 \mathrm{~b} / \mathrm{hr})$ & $h_{0}\left(\frac{B t u}{f t^{2} h r^{0} F}\right)$ & $\mathrm{Bi}_{\mathrm{f}} \mathrm{I/2}$ & $\eta_{f}$ & $h_{s}\left(\frac{B t u}{f t^{2} h r^{0} F}\right)$ \\
\hline 591 & 12,161 & 8.166 & 0.482 & 0.88 & 9.3 \\
\hline 909 & 19,262 & 9.579 & 0.52 & 0.87 & 11.0 \\
\hline 958 & 19,608 & 9.193 & 0.51 & 0.87 & 10.6 \\
\hline 1280 & 26,014 & 10.725 & 0.55 & 0.86 & 12.5 \\
\hline 1616 & 32,636 & 10.468 & 0.55 & 0.86 & 12.2 \\
\hline 1940 & 39,271 & 12.118 & 0.59 & 0.84 & 14.4 \\
\hline 2266 & 45,855 & 11.874 & 0.58 & 0.84 & 14.1 \\
\hline 2567 & 51,947 & 12.703 & 0.60 & 0.83 & 15.3 \\
\hline
\end{tabular}

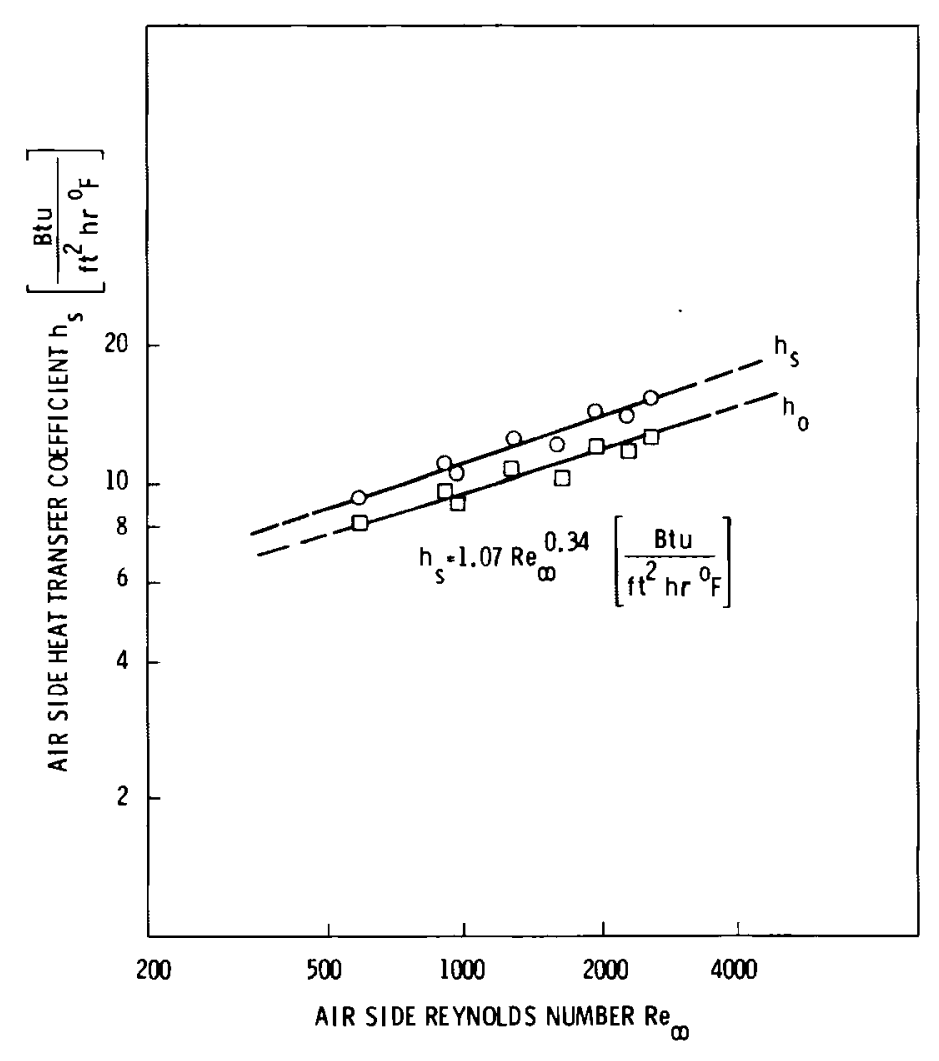

FIGURE 4-11. HÖTERV Surface Heat Transfer Correlation 
TABLE 4-4. Computations of $U_{0}$ Versus $h_{S}$ for the HÖTERV Plate Fin Heat Exchanger

$\left(\frac{h_{s} \text { or } h_{e^{*}}}{\mathrm{Bttu}}{ }^{2 t^{2} h r^{0} F}\right)$

10

15

20

40

80

160
$B i_{f}^{1 / 2}$ or $B i_{f}^{* 1 / 2}$

0.533

0.653

0.754

1.07

1.51

2.13

$$
\underline{n_{f} \text { or } n_{f}^{*}}
$$

0.86

0.82

0.77

0.64

0.48

0.35
$\left(\begin{array}{c}U_{0} \text { or } U_{0}^{*} \\ \frac{\mathrm{Btu}}{\mathrm{ft}^{2} \mathrm{hr}^{0} \mathrm{~F}}\end{array}\right)$

7.01

9.28

11.0

15.3

19.3

23.0

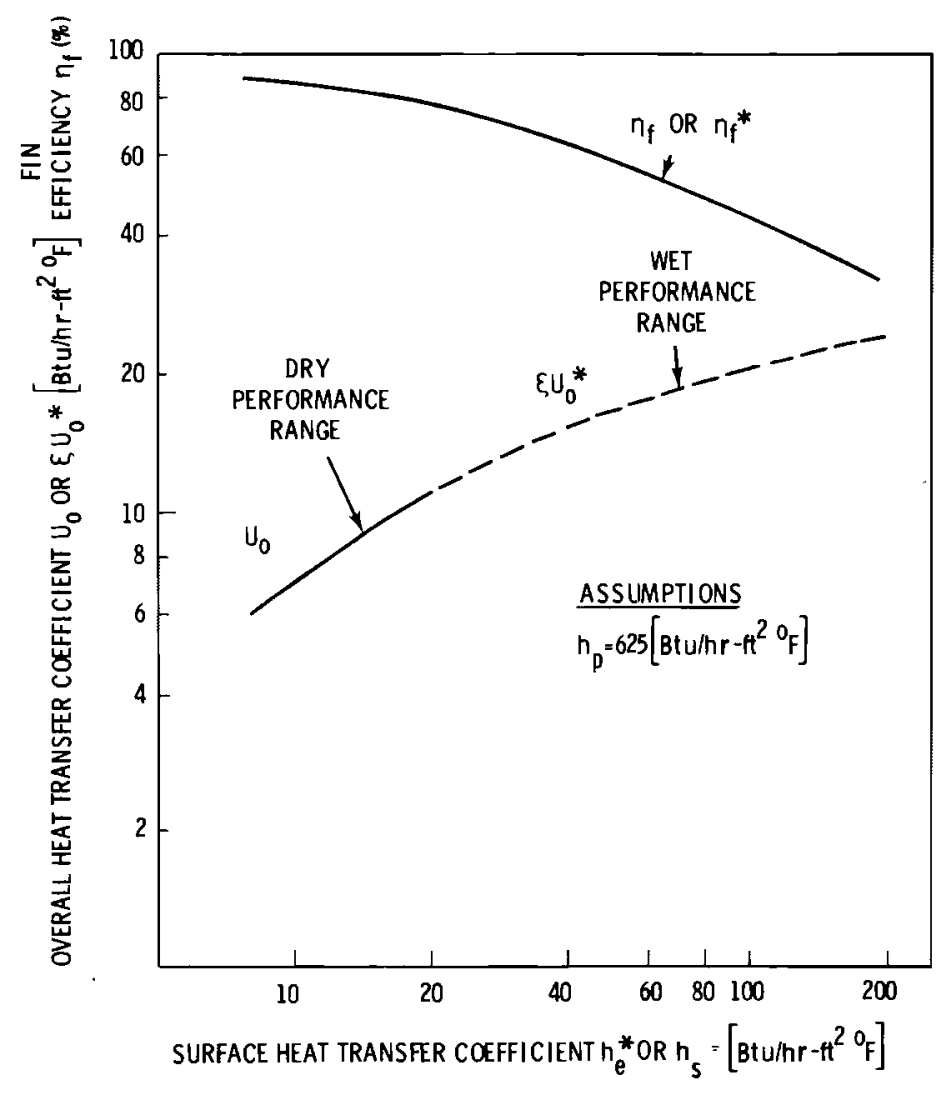

FIGURE 4-12. Correlation for Predicting the Overall Heat Transfer Coefficient for Wet or Dry Operation 
To compute the extent of heat transfer enhancement due to deluge, the basis for comparison must be established. A fair comparison should probably require equal airstream temperatures and equal primary fluid temperatures on the inlet side. However, the outlet conditions for both the air and the primary fluid are generally dependent upon their respective flow rates. Thus, it will be assumed that the primary fluid flow rate is sufficient to maintain the same outlet temperature and therefore about the same average temperature at all points on the primary side. For a condenser (and very nearly so for the WATA experiments) the primary-side temperature may be assumed constant.

The analogous requirement of equal out let temperatures for the air-side is also a possible basis for comparing heat transfer rates. However, the airstream outlet temperature depends on both the inlet relative humidity and flow rate. Comparison on the basis of equal outlet temperature would thus be arbitrary and meaningless.

Comparing on the basis of equal airflow rate may have some merit, but the pressure drop for a deluged core is substantially greater than for a dry core at the same airflow rate. In addition, substantial drift of droplets is likely to occur at the relatively high airflow rates used in dry operation. Therefore, comparing on the basis of equal airflow rates would not be very meaningful since it is highly likely that optimal performance in the deluge mode will be achieved at lower air velocities.

It is likely that dry and wet heat exchangers will operate side by side in a dry/wet tower where the deluge water will be turned on and off in selected banks of heat exchangers as the load and ambient conditions vary. In parallel operation, the dry cores and the wet cores will operate at the same overall pressure drop and the airflow rates will adjust accordingly. Therefore, the best comparison appears to be on the bas is of equal pressure drop, which implies a substantially lower airflow rate through the deluged core. Actual comparison based on equal pressure drop would be complex and tedious. Thus, for convenience, computations were made using the ratio of airflow rates $\beta=\dot{m}_{a} \star / \dot{m}_{a}$ as a parameter. 
For comparing dry/wet performance, the computations of heat transfer were done using the NTU approach, since this requires only that the inlet conditions be known. From Equations (4-28) and (4-35) the ratio of wet to dry heat transfer may be given by

$$
\begin{aligned}
\frac{Q_{S}^{*}}{Q_{S}} & =\frac{\dot{m}_{a}^{\star} \phi^{\star}\left(i_{p}^{\prime}-i_{\infty}\right)}{\dot{m}_{a} \phi C_{a}\left(T_{p}-T_{\infty}\right)} \\
& =\beta \frac{\phi^{\star}}{\phi} \Gamma
\end{aligned}
$$

where the driving potential ratio is defined by

$$
\Gamma=\frac{\left(i_{p}^{\prime}-i_{\infty}\right)}{C_{a}\left(T_{p}-T_{\infty}\right)}
$$

The effectiveness $\phi$ or $\phi^{*}$ [Equations (4-30) and (4-37)] is plotted in Figure 4-13 and values are tabulated in Table 4-5 for the range of conditions considered here. $\Gamma$ is the ratio of driving potentials based on enthalpy and temperature.

Computation of $U_{0}$ * from $F$ igure 4-12 requires that $\xi$ must be known. Precise computation of $\xi$ by Equation (4-18) would require that the average surface temperature and enthalpy must be known. In general, the actual surface conditions will not be known so that $\xi$ must be estimated. When the deluge water conditions are known, the average of the inlet and outlet temperatures may be used to evaluate $\xi$, and this is the approach used in analysis of the WATA data. For the present analysis, $\xi$ will be estimated with Equation (4-18) using the inlet conditions $t_{\infty 1}, i_{\infty 1}$ for $T_{s}, i_{s}$ '.

The ratio of driving potentials defined by Equation (4-62) can be evaluated using property tables. The moist air specific heat, $c_{a}$, was taken to be the average of the values evaluated in the free stream at the actual and fully saturated conditions. The results of the computations of $\xi$ and $\Gamma$ are summarized in Table 4-6 and plotted in Figure 4-14. (Note that $\xi$ is a special case of $\Gamma$ where the free stream saturation conditions are used.) 


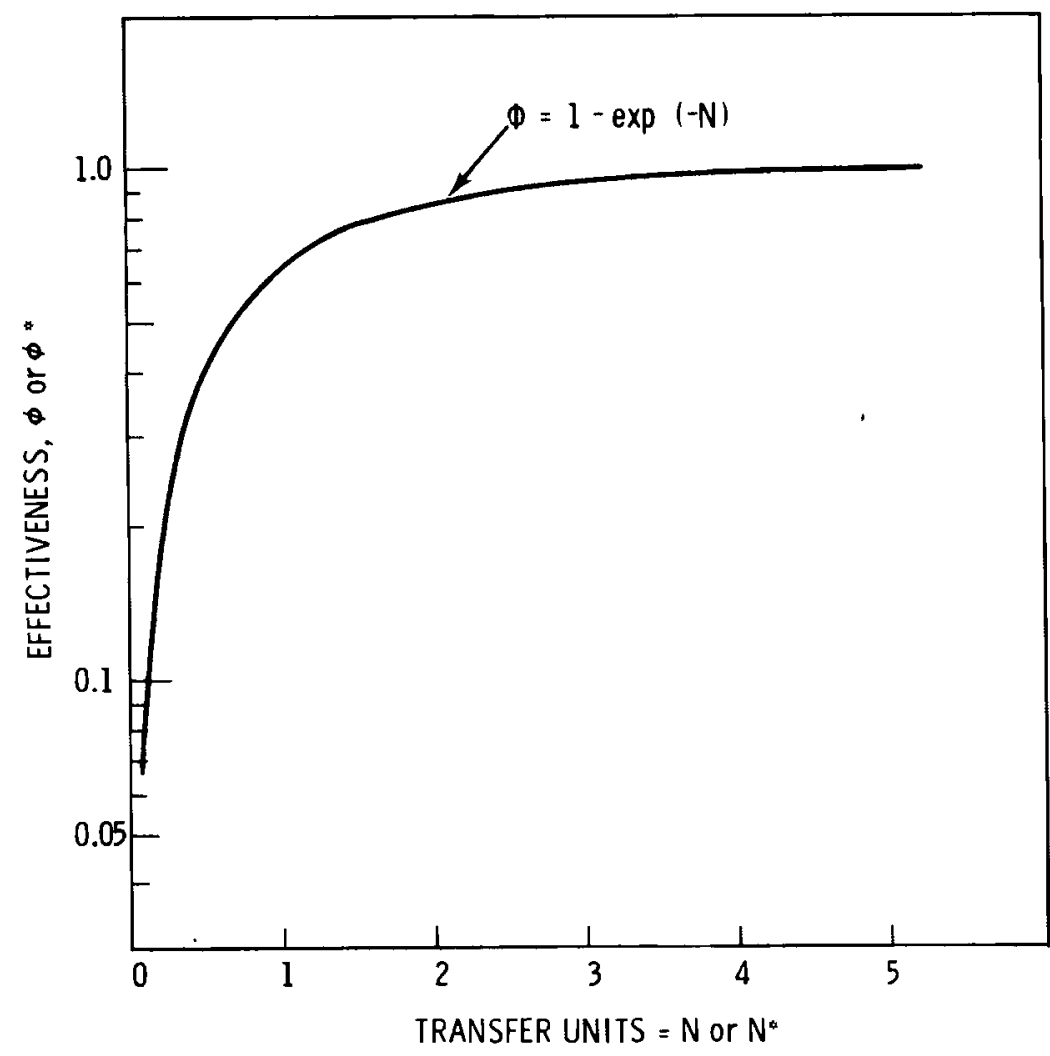

FIGURE 4-13. Plot of Fin Effectiveness $\phi$ for a Condenser (Model used for HÖTERV core)

For the present computations, the primary-side temperature was assumed to be constant at $120^{\circ} \mathrm{F}$ and only the free stream conditions were varied. For other values of $T_{p l}$ the curves will have the same general shape as in Figure 4-14, except shifted up or down approximately in proportion with the change in temperature.

The fin effectiveness $\phi$ and $\phi^{*}$ were computed using Equations (4-30) and (4-37), plotted in Figure 4-13. For a given airflow rate $\dot{m}_{a}$ and relative airflow rate $\beta$, the values of $\phi$ and $\phi^{*}$ were computed in the following sequence:

1) Compute $\operatorname{Re}_{\infty}$ and $\operatorname{Re}_{\infty}{ }^{*}=\beta \operatorname{Re}_{\infty}$.

2) Determine $h_{s}$ from Equation (4-25) and $h_{e}$ * from Equation (4-22), using appropriate values of $h_{d}$ and $\xi$. 
TABLE 4-5. Computation of the Overal1 Heat Transfer Coefficient and Fin Effectiveness for $\operatorname{Re}^{*}=450,900$ and $\beta=0.5,1$

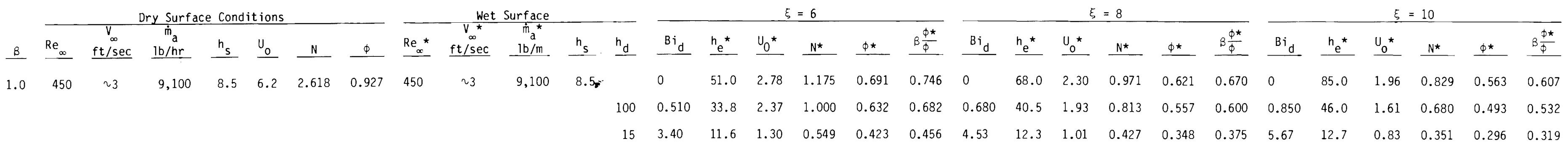

$\begin{array}{llllllllllll}1.0 & 900 & \sim 6 & 18,300 & 10.3 & 7.4 & 1.554 & 0.789 & 900 & \sim 6 & 18,300 & 10.3\end{array}$ $\begin{array}{llllllllllllllllllll}10.3 & & 0 & 61.8 & 2.97 & 0.623 & 0.436 & 0.588 & 0 & 82.4 & 2.43 & 0.509 & 0.399 & 0.506 & 0 & 103.0 & 2.06 & 0.433 & 0.351 & 0.445 \\ & 100 & 0.618 & 38.2 & 2.52 & 0.529 & 0.411 & 0.520 & 0.824 & 45.2 & 2.00 & 0.420 & 0.343 & 0.435 & 1.03 & 50.7 & 1.66 & 0.349 & 0.294 & 0.373\end{array}$

$\begin{array}{lllllllllllllllllll}30 & 2.06 & 20.2 & 1.83 & 0.385 & 0.320 & 0.405 & 2.75 & 22.0 & 1.46 & 0.307 & 0.264 & 0.335 & 3.43 & 23.3 & 1.19 & 0.250 & 0.221 & 0.280\end{array}$

\begin{abstract}
$\begin{array}{llllllllllll}0.5 & 900 & \sim 6 & 18,300 & 10.3 & 7.4 & 1.554 & 0.789 & 450 & \sim 3 & 9,100 & 8.5\end{array}$
$\begin{array}{llllllllllllllllll}0 & 51.0 & 2.78 & 1.175 & 0.691 & 0.438 & 0 & 68.0 & 2.30 & 0.971 & 0.621 & 0.394 & 0 & 85.0 & 1.96 & 0.829 & 0.563 & 0.357\end{array}$

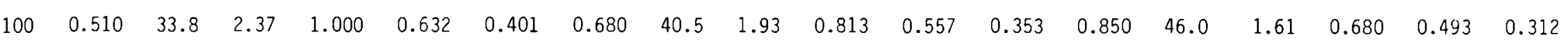

$\begin{array}{llllllllllllllllllll}15 & 3.40 & 11.6 & 1.30 & 0.549 & 0.423 & 0.268 & 4.53 & 12.3 & 1.01 & 0.427 & 0.348 & 0.221 & 5.67 & 12.7 & 0.83 & 0.351 & 0.296 & 0.188\end{array}$

$\begin{array}{lllllllllll}0.5 & 1800 & \sim 12 & 36,500 & 13.6 & 8.7 & 0.916 & 0.600 & 900 & \sim 6 & 18,300\end{array}$

$\begin{array}{llllllllllllllllll}0 & 61.8 & 2.97 & 0.623 & 0.436 & 0.386 & 0 & 82.4 & 2.43 & 0.509 & 0.399 & 0.333 & 0 & 103.0 & 2.06 & 0.433 & 0.351 & 0.293\end{array}$

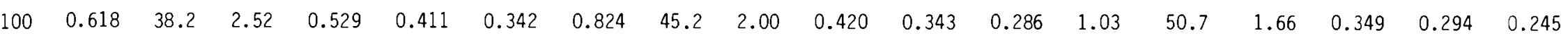

$\begin{array}{lllllllllllllllllll}30 & 2.06 & 20.2 & 1.83 & 0.385 & 0.320 & 0.266 & 2.75 & 22.0 & 1.46 & 0.307 & 0.264 & 0.220 & 3.43 & 23.3 & 1.19 & 0.250 & 0.221 & 0.184\end{array}$
\end{abstract}

Units of $U, h_{s}, h_{d}, h_{e}^{*} \operatorname{are}\left(\frac{B t u}{f t^{2} h r_{F}{ }_{F}}\right)$ 

TABLE 4-6. Computation of $\Gamma$ and $\xi$ for Varying Inlet Condition at a Core
Temperature of $120^{\circ} \mathrm{F}$

\begin{tabular}{|c|c|c|c|c|c|c|c|c|c|}
\hline$T_{p}-T_{\infty}$ & $T_{\infty}$ & $H_{\infty}{ }^{\prime}$ & $i_{\infty}{ }^{\prime}$ & $\omega_{\infty}$ & $H_{\infty}$ & $i_{\infty}$ & $\bar{c}_{a}$ & $\Gamma_{1}$ & $\xi_{1}$ \\
\hline$\left({ }^{0} \mathrm{~F}\right)$ & $\left({ }^{0} F\right)$ & $\left(1 b_{w} / 1 b_{a}\right)$ & $(B t u / l b)$ & & $\left(1 b_{w} / 1 b_{v}\right)$ & (Btu/lb) & $\left(\mathrm{Btu} / 1 \mathrm{~b}^{\circ} \mathrm{F}\right)$ & & \\
\hline \multirow[t]{3}{*}{5.} & 115 & 0.06962 & 104.98 & 1.0 & 0.06962 & 104.98 & 0.271 & 10.73 & 10.73 \\
\hline & & & & 0.5 & 0.03275 & 64.00 & 0.263 & 42.24 & \\
\hline & & & & 0 & 0 & 27.64 & 0.256 & 71.80 & \\
\hline \multirow[t]{3}{*}{10} & 110 & 0.05944 & 92.34 & 1.0 & 0.05944 & 92.34 & 0.267 & 10.20 & 10.20 \\
\hline & & & & 0.5 & 0.02825 & 57.7 & 0.260 & 23.78 & \\
\hline & & & & 0 & 0 & 26.43 & 0.253 & 36.80 & \\
\hline \multirow[t]{3}{*}{20} & 100 & 0.04319 & 71.73 & 1.0 & 0.04319 & 71.73 & 0.260 & 9.21 & 9.21 \\
\hline & & & & 0.5 & 0.0280 & 47.00 & 0.256 & 14.17 & \\
\hline & & & & 0 & 0 & 24.03 & 0.250 & 19.10 & \\
\hline \multirow[t]{3}{*}{30} & 90 & 0.03118 & 55.93 & 1.0 & 0.03118 & 55.93 & 0.254 & 8.35 & 8.35 \\
\hline & & & & 0.5 & 0.0152 & 38.35 & 0.250 & 10.83 & \\
\hline & & & & 0 & 0 & 21.63 & 0.247 & 13.21 & \\
\hline \multirow[t]{3}{*}{40} & 80 & 0.02233 & 43.69 & 1.0 & 0.02233 & 43.69 & 0.250 & 7.58 & 7.58 \\
\hline & & & & 0.5 & 0.0111 & 31.25 & 0.248 & 8.90 & \\
\hline & & & & 0 & 0 & 19.22 & 0.245 & 10.24 & \\
\hline
\end{tabular}




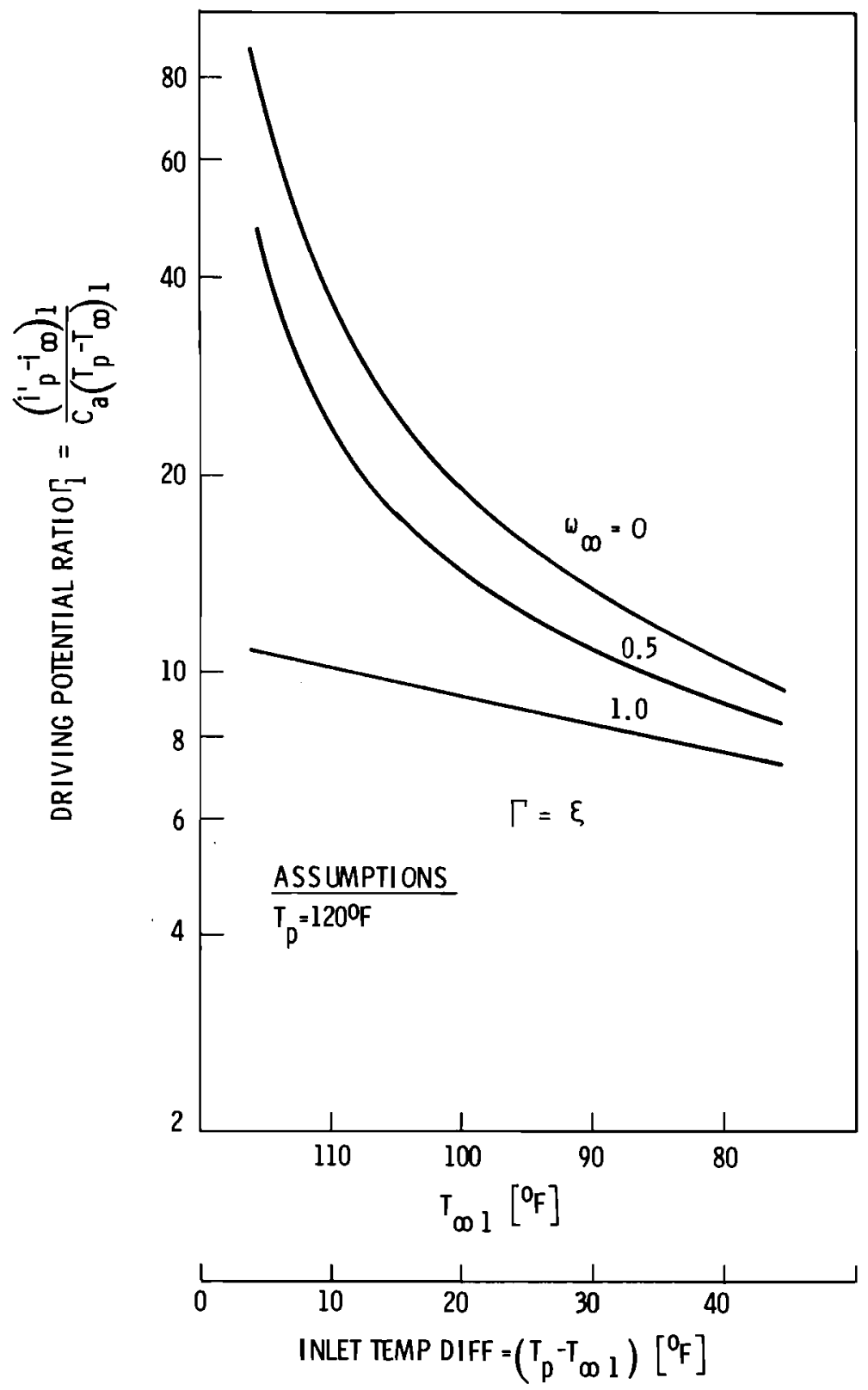

FIGURE 4-14. Computation of the Driving Potential Ratio $\Gamma$ 
3) Determine $U_{0}$ from Equation (4-6) and $\xi U_{0}{ }^{*}$ from Equation (4-20) (or use Figure 4-12).

4) Compute $N$ from Equation (4-31) and $N \star$ from Equation (4-38).

5) Compute $\phi$ from Equation (4-30) and $\phi^{\star}$ from Equation (4-37) (or use Figure 4-13).

Example calculations are given in Appendix A, Section A-5. The results of these computations are summarized in Table 4-5. $U_{0}{ }^{*}$ is plotted in Figure $4-15$ and $\beta \phi^{\star} / \phi$ is plotted in Figure $4-16$.

Finally, the heat transfer enhancement ratio $\dot{Q} * / \dot{Q}$ [Equation (4-61)] may be evaluated using Figure 4-14 for $\Gamma$ and Figure 4-16 for $\beta \frac{\phi^{*}}{\phi}$. Example calculations are given in Appendix A, Sections A-6 and A-7. The results are summarized in Tables 4-6 and 4-7 and plotted in Figures 4-17 and 4-18. Because of the large number of variables, computations of $\dot{Q} \star / \dot{Q}$ were done only for $T_{p}$ $=120^{\circ} \mathrm{F}$ at $\mathrm{Re}=450$ and 900 . These are representative of operating conditions in WATA. Computations for other temperatures and flow rates can easily be done using the calculational procedure outlined here.

The primary results of this section are the predictions of $U_{*}$ in Figure $4-15$ and the theoretical heat transfer enhancement ratio, $\frac{8^{\star}}{Q}$ in Figures 4-17 and 4-18. From Figure 4-15, it is apparent that the theoretical values of $U_{0}{ }^{*}$ (using measured values of $h_{d}$ ) are substantially less than would be predicted if a true, thin-film wetting condition were achieved (i.e., the curves for $\left.h_{d} \rightarrow \infty\right)$. In addition, it is apparent that the lower measured values of $h_{d}$ in the present experiment, as compared to the value obtained by HÖTERV, results in substantially lower predicted values of $U_{0}{ }^{*}$. As shown in Section 4.3, the measured values of $U_{0}{ }^{*}$ in this experiment are indeed lower than those obtained by HÖTERV. However, it is also shown in a subsequent analysis that when the experimental values of $h_{d}$ are used in the deluge theory, the agreement between the experimental and predicted values of $U_{0}$ * is quite good. 


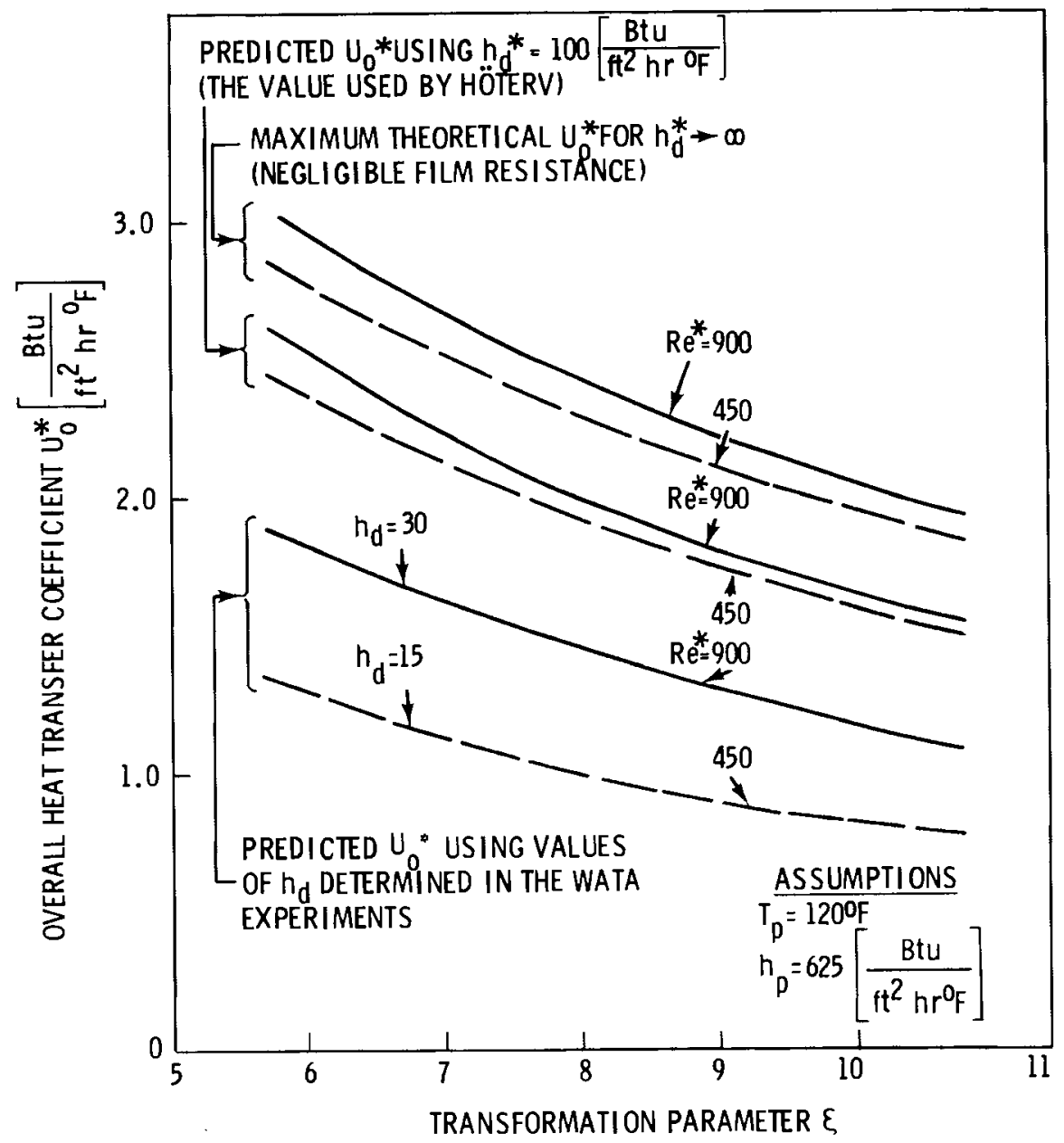

FIGURE 4-15.
Predicted Overal1 Heat Transfer Coefficients as
Function of Operating Conditions and Assumptions

From Figures 4-17 and 4-18 it can be seen that the deluge model predicts the potential for substantial enhancement in the heat transfer rate by use of the deluge concept. At a low ITD and low relative humidity, the predicted enhancement can be substantial even at low relative airflow rates. For example, assuming $\beta=0.5, \operatorname{Re}^{\star}=900(\mathrm{~V} \sim 6 \mathrm{ft} / \mathrm{sec})$, ITD $=\left(T_{p}-T_{\infty}\right)_{1}=10^{\circ} \mathrm{F}$ and $\omega_{\infty}=0.5$; from Figure $4-17, \dot{Q} * / \dot{Q} \simeq 4.3$. Thus, over four times as much heat is rejected from the wet core at only half the airflow rate of a dry core at the same conditions. For equal airflow rates, from Figure $4-18, \dot{Q} * / \dot{Q} \simeq 8.8$ for the same operating conditions. As shown in Section 4.3, these predicted

(a) See Table 4-5. 


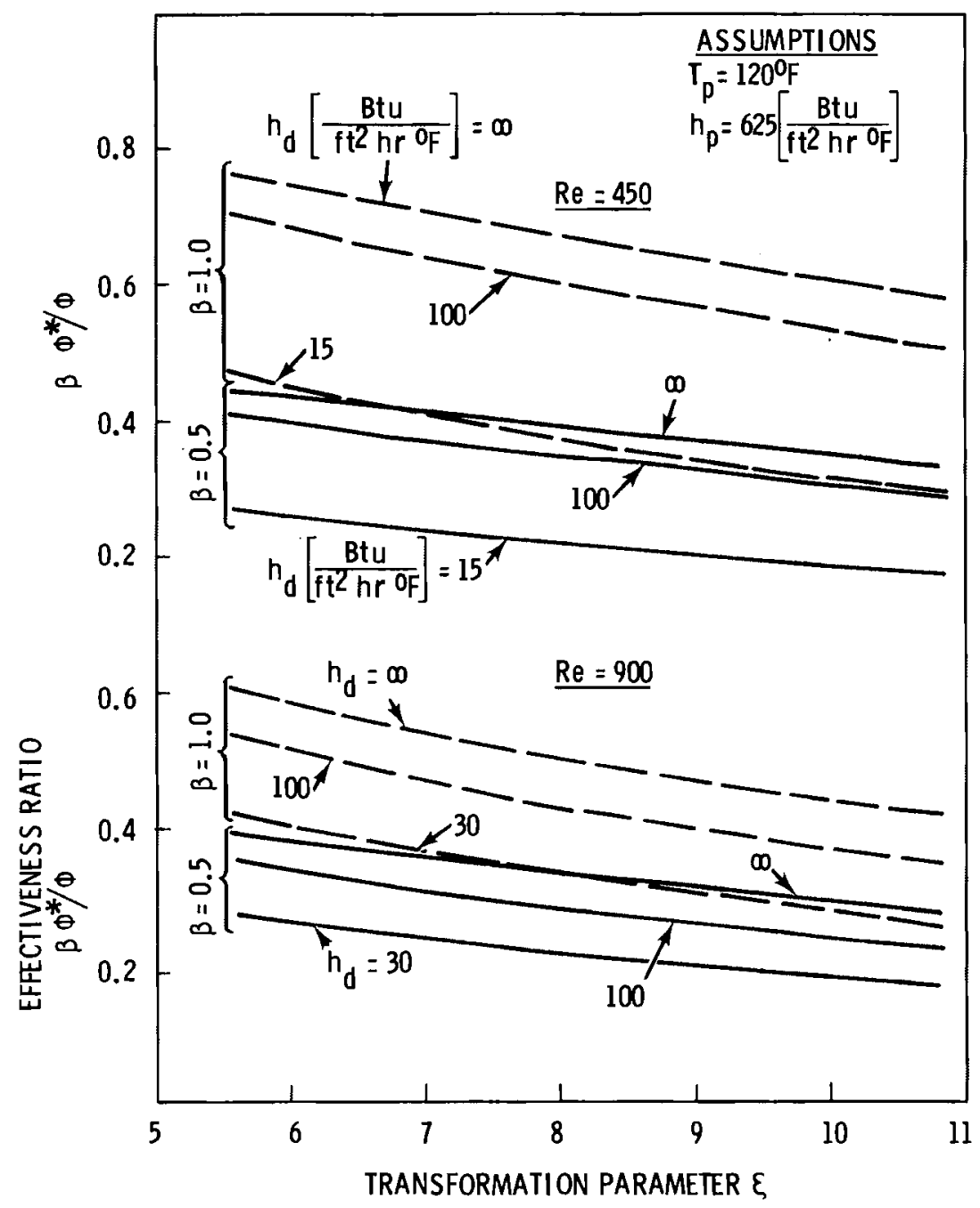

FIGURE 4-16. Computation of Effectiveness Ratio as a,Function
of Operating Conditions and Assumptions

enhancement ratios are in good agreement with the data. However, before going on to specific comparison of theory and data, an illustration will be given of the use of the alternative analys is where partial wetting can be accounted for.

(a) See Table 4-5. 
TABLE 4-7. Computation of Heat Transfer Enhancement Ratio for $\operatorname{Re}^{\star}=450$ at a Core Temperature of $1200 \mathrm{~F}$

\begin{tabular}{|c|c|c|c|c|c|c|c|c|c|c|c|c|c|c|c|}
\hline \multirow{3}{*}{$T_{p_{o_{F}}}-T_{\infty}$} & \multirow{3}{*}{$\begin{array}{l}T_{1} \\
0_{F} \\
\end{array}$} & \multirow[b]{3}{*}{$\underline{\omega_{\infty}}$} & \multirow{3}{*}{$\begin{aligned} h_{d}^{\beta} & = \\
\Gamma_{1} & =\end{aligned}$} & \multirow{2}{*}{\multicolumn{4}{|c|}{$\begin{array}{l}1.0 \\
100\end{array}$}} & \multirow{2}{*}{\multicolumn{2}{|c|}{15}} & \multicolumn{6}{|c|}{0.5} \\
\hline & & & & & & & & & & . & & & & & \\
\hline & & & & $\beta \frac{\phi^{\star}}{\phi}$ & $\frac{Q^{\star}}{Q}$ & $\beta \frac{\phi^{\star}}{\phi}$ & $\frac{Q^{*}}{Q}$ & $\beta \frac{\phi \hbar}{\phi}$ & $\frac{Q^{*}}{Q}$ & $\beta \frac{\phi \star}{\phi}$ & $\frac{Q^{\star}}{Q}$ & $\beta \frac{\phi \hbar}{\phi}$ & $\frac{Q^{\star}}{Q}$ & $\beta \frac{\phi \star}{\phi}$ & $\frac{Q^{\star}}{Q}$ \\
\hline \multirow[t]{3}{*}{5} & 115 & 1.0 & 10.73 & 0.586 & 6.29 & 0.512 & 5.49 & 0.305 & 3.27 & 0.340 & 3.65 & 0.295 & 3.17 & 0.178 & 1.91 \\
\hline & & 0.5 & 42.24 & & 24.8 & & 21.6 & & 12.9 & & 14.4 & & 12.5 & & 7.52 \\
\hline & & 0 & 71.80 & & 42.1 & & 36.8 & & 21.9 & & 24.4 & & 21.2 & & 12.8 \\
\hline \multirow[t]{3}{*}{10} & 110 & 1.0 & 10.20 & 0.602 & 6.14 & 0.528 & 5.39 & 0.317 & 3.23 & 0.351 & 3.58 & 0.308 & 3.14 & 0.184 & 1.88 \\
\hline & & 0.5 & 23.78 & & 14.3 & & 12.6 & & 7.54 & & 8.35 & & 7.32 & & 4.38 \\
\hline & & 0 & 36.80 & & 22.2 & & 19.4 & & 11.8 & & 12.9 & & 11.3 & & 6.77 \\
\hline \multirow[t]{3}{*}{20} & 100 & 1.0 & 9.21 & 0.632 & 5.82 & 0.561 & 5.17 & 0.342 & 3.15 & 0.371 & 3.42 & 0.328 & 3.02 & 0.200 & 1.84 \\
\hline & & 0.5 & 14.17 & & 8.96 & & 7.95 & & 4.85 & & 5.26 & & 4.65 & & 2.83 \\
\hline & & 0 & 19.10 & & 12.0 & & 10.7 & & 6.53 & & 7.09 & & 6.27 & & 3.82 \\
\hline \multirow[t]{3}{*}{30} & 90 & 1.0 & 8.35 & 0.660 & 5.51 & 0.589 & 4.92 & 0.367 & 3.06 & 0.391 & 3.27 & 0.350 & 2.92 & 0.218 & 1.82 \\
\hline & & 0.5 & 10.83 & & 7.15 & & 6.38 & & 3.98 & & 4.24 & & 3.79 & & 2.36 \\
\hline & & 0 & 13.21 & & 8.72 & & 7.78 & & 4.85 & & 5.17 & & 4.62 & & 2.88 \\
\hline \multirow[t]{3}{*}{40} & 80 & 1.0 & 7.58 & 0.687 & 5.21 & 0.618 & 3.22 & 0.390 & 2.96 & 0.402 & 3.05 & 0.363 & 2.75 & 0.231 & 1.75 \\
\hline & & 0.5 & 8.90 & & 6.11 & & 5.50 & & 3.47 & & 3.58 & & 3.23 & & 2.06 \\
\hline & & 0 & 10.24 & & 7.04 & & 6.33 & & 3.99 & & 4.12 & & 3.72 & & 2.37 \\
\hline
\end{tabular}




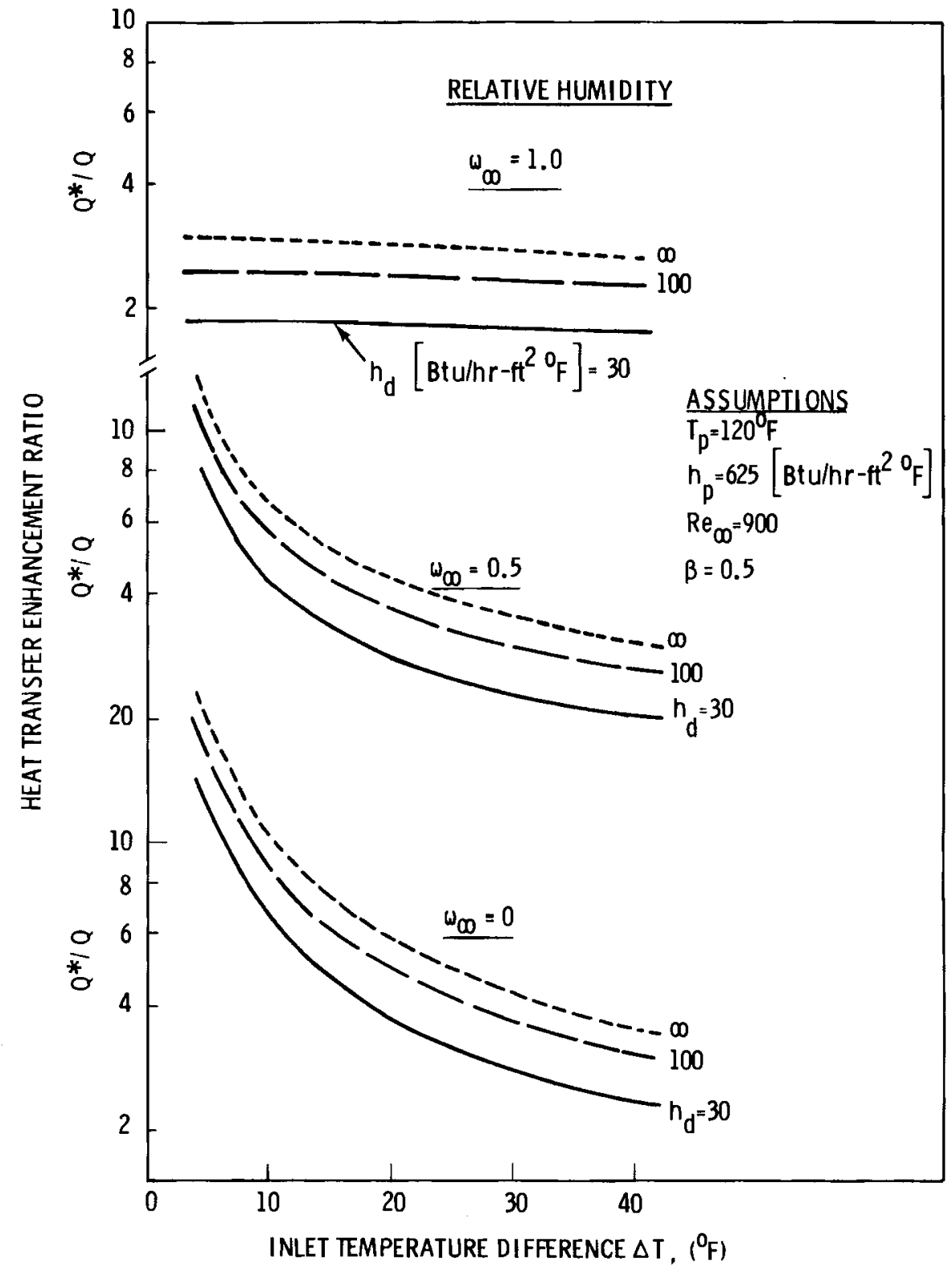

FIGURE 4-17. Prediction of the Heat Transfer Enhancement as a Function of Operating Conditions for $\mathrm{Re}^{\star}=900, \beta=0.5$ 


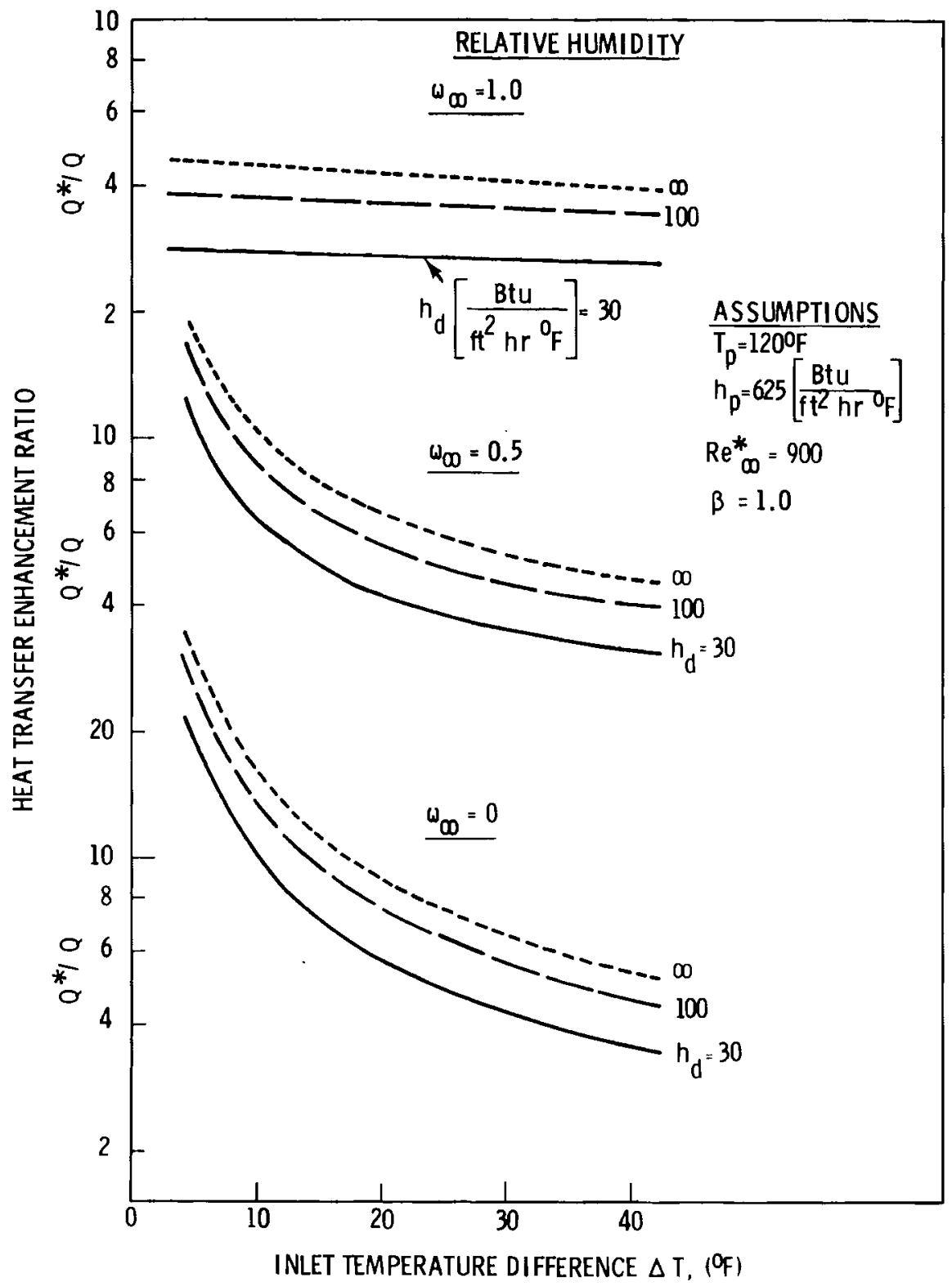

FIGURE 4-18. Prediction of the Heat Transfer Enhancement as a Function of Operating Conditions for $\operatorname{Re}^{\star}=900, \beta=1.0$ 


\subsubsection{Application of the Deluge Model to Prediction of Heat Transfer for Incomplete Wetting}

The modified deluge model developed in Appendix $B$ and summarized in Section 4.1 .5 contains a relatively large number of variables. However, computations to be provided here will be restricted to a limited number of cases that roughly encompass the range of variables investigated in the WATA experiments. All of the design data pertain to the HÖTERV core and operational variables as described in the previous section. Detailed example calculations are provided in Appendix $B$ and all computational results are summarized in Tables 4-8 and 4-9.

The computations were performed using Equation (4-55) for $\varepsilon$ and Equation (4-59) for $U_{0}{ }^{*}$. The primary independent variable is the surface wetness fraction $\alpha$. The delugeate resistance $B i_{d}$ and the temperature depression parameter $\delta_{f}$ (Equation (4-58)) are treated parametrically. The analys is assumes $h_{p}=625\left(B t u / f t^{2} h r^{0} F\right), h_{s}=10\left(B t u / f t^{2} h r^{0} F\right)$ and $\xi=7.0$ except in the HEATING5 computations where $h_{p}=500\left(B t u / f t^{2} h r^{0} F\right)$ was used.

The efficiencies of the dry and wet areas were computed with the annular fin model described in Section 4.1.3 using appropriate values of $r_{e} / r_{b}$ and $B i_{f}$ in each case. For the dry surface, $r_{e} / r_{b}=r_{4} / r_{3}$ and $\ell_{f}=\left(r_{4}-r_{3}\right)$, whereas for the wet surface, $r_{e} / r_{b}=r_{3} / r_{2}$ and $\ell_{f}=\left(r_{3}-r_{2}\right)$. The efficiency computations are summarized in Table 4-8.

Computations were performed for $B i_{d} \simeq 0$ and $B i_{d} \simeq 0.5$. This is thought to encompass the likely range for this variable, assuming a uniform film on the wetted areas. The temperature depression was treated for the range $-0.5<\delta_{f}<0.25$. Again, this is thought to more than encompass all possible values for this parameter. The analys is in Appendix B shows that the actual range of $\delta_{f}$ is likely to be somewhat more restrictive.

The results of the computations are summarized in Table 4-9 and plotted in Figure 4-19 where the overall heat transfer coefficient $U_{0}{ }^{\star}$ is plotted as a function of $\alpha$. For a given value of $B i_{d}$ it can be seen that $U_{0}$ * 
TABLE 4-8. Computation of Heat Transfer Enhancement Ratio for $\operatorname{Re}^{\star}=900$ at a Core Temperature of $120^{\circ} \mathrm{F}$

\begin{tabular}{|c|c|c|c|c|c|c|c|c|c|c|c|c|c|c|c|}
\hline \multirow{3}{*}{$T_{p_{o_{F}}}-T_{\infty}$} & \multirow{3}{*}{$\begin{array}{l}T^{\infty} \\
{ }^{0} \\
\end{array}$} & \multirow[b]{3}{*}{$\omega_{\infty}$} & \multirow{3}{*}{$\begin{array}{r}{ }^{\beta} \\
h_{d} \\
\Gamma_{1} \\
\end{array}$} & \multirow{2}{*}{\multicolumn{4}{|c|}{$\frac{1.0}{100}$}} & \multirow{2}{*}{\multicolumn{2}{|c|}{30}} & \multirow{2}{*}{\multicolumn{4}{|c|}{$\begin{array}{l}0.5 \\
100\end{array}$}} & \multirow{2}{*}{\multicolumn{2}{|c|}{30}} \\
\hline & & & & & & & & & & & & & & & \\
\hline & & & & $B \frac{\phi^{*}}{\phi}$ & $\frac{Q^{x}}{Q}$ & $\beta \frac{\phi^{x}}{\phi}$ & $\frac{Q^{*}}{Q}$ & $\beta \frac{\phi^{x}}{\phi}$ & $\frac{Q^{*}}{Q}$ & $\beta \frac{\phi^{*}}{\phi}$ & $\frac{Q^{x}}{Q}$ & $\beta \frac{\phi^{x}}{\phi}$ & $\frac{Q^{x}}{Q}$ & $\beta \frac{\phi^{*}}{\phi}$ & $\frac{Q^{*}}{0}$ \\
\hline \multirow[t]{3}{*}{5} & 115 & 1.0 & 10.73 & 0.428 & 4.59 & 0.355 & 3.81 & 0.262 & 2.81 & 0.278 & 2.98 & 0.228 & 2.45 & 0.173 & 1.86 \\
\hline & & 0.5 & 42.24 & & 18.1 & & 15.0 & & 11.1 & & 11.7 & & 9.63 & & 7.31 \\
\hline & & 0 & 71.80 & & 30.7 & & 25.5 & & 18.8 & & 20.0 & & 16.4 & & 12.4 \\
\hline \multirow[t]{3}{*}{10} & 110 & 1.0 & 10.20 & 0.440 & 4.49 & 0.368 & 3.75 & 0.275 & 2.81 & 0.288 & 2.94 & 0.241 & 2.46 & 0.181 & 1.85 \\
\hline & & 0.5 & 23.78 & & 10.5 & & 8.75 & & 6.54 & & 6.85 & & 5.73 & & 4.30 \\
\hline & & 0 & 36.80 & & 16.2 & & 13.5 & & 10.1 & & 10.6 & & 8.87 & & 6.66 \\
\hline \multirow[t]{3}{*}{20} & 100 & 1.0 & 9.21 & 0.468 & 4.31 & 0.395 & 3.64 & 0.300 & 2.76 & 0.307 & 2.83 & 0.258 & 2.38 & 0.198 & 1.82 \\
\hline & & 0.5 & 14.17 & & 6.63 & & 5.60 & & 4.25 & & 4.35 & & 3.66 & & 2.81 \\
\hline & & 0 & 19.10 & & 8.94 & & 7.55 & & 5.73 & & 5.86 & & 4.93 & & 3.78 \\
\hline \multirow[t]{3}{*}{30} & 90 & 1.0 & 8.35 & 0.494 & 4.13 & 0.423 & 3.53 & 0.323 & 2.70 & 0.326 & 2.72 & 0.278 & 2.32 & 0.212 & 1.77 \\
\hline & & 0.5 & 10.83 & & 5.35 & & 4.58 & & 3.50 & & 3.53 & & 3.01 & & 2.30 \\
\hline & & 0 & 13.21 & & 6.53 & & 5.59 & & 4.27 & & 4.31 & & 3.67 & & 2.80 \\
\hline \multirow[t]{3}{*}{40} & 80 & 1.0 & 7.58 & 0.521 & 3.95 & 0.450 & 3.41 & 0.348 & 2.64 & 0.343 & 2.60 & 0.296 & 2.24 & 0.229 & 1.74 \\
\hline & & 0.5 & 8.90 & & 4.64 & & 4.01 & & 3.10 & & 3.05 & & 2.63 & & 2.04 \\
\hline & & 0 & 10.24 & & 5.35 & & 4.61 & & 3.56 & & 3.51 & & 3.03 & & 2.35 \\
\hline
\end{tabular}


TABLE 4-9. Computation of $U_{0}$. and $h_{S} *$ Using the Deluge Theory Modified for Incomplete Wetting

$$
\xi=7.0, h_{s}=10\left(\frac{B t u}{f t^{2} h r^{0} F}\right), h_{p}=625\left(\frac{B t u}{f t^{2} h r^{0} F}\right)
$$

\begin{tabular}{|c|c|c|c|c|c|c|c|c|c|c|c|c|c|c|c|c|c|c|c|c|}
\hline \multirow[b]{2}{*}{$\underline{B i_{d}}$} & \multirow[b]{2}{*}{$\alpha$} & \multirow[b]{2}{*}{$r_{3}$} & \multirow[b]{2}{*}{$r_{3} / r_{2}$} & \multirow{2}{*}{$\left(B i_{f}^{\star}\right)^{1 / 2}$} & \multirow[b]{2}{*}{$\underline{n_{f}^{*}}$} & \multirow[b]{2}{*}{$r_{4} / r_{3}$} & \multirow{2}{*}{$\left(B_{f}\right)^{1 / 2}$} & \multirow{2}{*}{$\begin{array}{r}\delta_{f}= \\
n_{f}\end{array}$} & \multicolumn{2}{|c|}{-0.5} & \multicolumn{2}{|c|}{-0.25} & \multicolumn{2}{|c|}{-0.10} & \multicolumn{2}{|c|}{0} & \multicolumn{2}{|c|}{+0.10} & \multicolumn{2}{|c|}{+0.25} \\
\hline & & & & & & & & & $\varepsilon$ & $U_{0}^{*}$ & $\varepsilon$ & $U_{0}^{U^{*}}$ & $\varepsilon$ & $u_{0}{ }^{*}$ & $\varepsilon$ & $u_{0}^{*}$ & $E$ & $U_{0}^{*}$ & $\varepsilon$ & $U_{0}{ }^{*}$ \\
\hline \multirow[t]{6}{*}{0} & 1.0 & 0.07169 & 2.362 & 1.410 & 0.53 & 1.00 & 0 & 1.00 & 0.557 & 2.69 & 0.558 & 2.69 & 0.557 & 2.69 & 0.557 & 2.69 & 0.557 & 2.69 & 0.557 & 2.69 \\
\hline & 0.8 & 0.06554 & 2.159 & 1.200 & 0.60 & 1.094 & 0.079 & 0.99 & 0.405 & 2.28 & 0.452 & 2.42 & 0.480 & 2.50 & 0.498 & 2.55 & 0.517 & 2.60 & 0.545 & 2.67 \\
\hline & 0.6 & 0.05876 & 1.936 & 0.969 & 0.69 & 1.220 & 0.167 & 0.98 & 0.240 & 1.64 & 0.332 & 2.03 & 0.388 & 2.22 & 0.425 & 2.34 & 0.462 & 2.45 & 0.517 & 2.60 \\
\hline & 0.4 & 0.05107 & 1.683 & 0.707 & 0.81 & 1.404 & 0.266 & 0.96 & 0.0568 & 0.512 & 0.193 & 1.41 & 0.274 & 1.80 & 0.328 & 2.02 & 0.383 & 2.21 & 0.464 & 2.46 \\
\hline & 0.2 & 0.04201 & 1.384 & 0.398 & 0.93 & 1.706 & 0.383 & 0.93 & & & 0.011 & 0.112 & 0.117 & 0.953 & 0.187 & 1.38 & 0.257 & 1.72 & 0.362 & 2.14 \\
\hline & 0 & 0.03035 & 1.000 & 0 & 1.00 & 2.362 & 0.533 & 0.86 & & & & & & & 0 & 0 & 0.081 & 0.702 & 0.203 & 1.46 \\
\hline \multirow[t]{6}{*}{0.5} & 1.0 & 0.07169 & 2.362 & 1.151 & 0.62 & 1.00 & 0 & 1.00 & 0.428 & 2.35 & 0.428 & 2.35 & 0.428 & 2.35 & 0.428 & 2.35 & 0.428 & 2.35 & 0.428 & 2.35 \\
\hline & 0.8 & 0.06554 & 2.159 & 0.980 & 0.68 & 1.094 & 0.079 & 0.99 & 0.279 & 1.82 & 0.326 & 2.01 & 0.354 & 2.11 & 0.372 & 2.17 & 0.391 & 2.24 & 0.419 & 2.32 \\
\hline & 0.6 & 0.05876 & 1.936 & 0.791 & 0.77 & 1.220 & 0.167 & 0.98 & 0.128 & 1.03 & 0.221 & 1.55 & 0.276 & 1.81 & 0.313 & 1.96 & 0.350 & 2.10 & 0.406 & 2.28 \\
\hline & 0.4 & 0.05107 & 1.683 & 0.577 & 0.88 & 1.404 & 0.266 & 0.96 & & & 0.101 & 0.844 & 0.182 & 1.35 & 0.237 & 1.63 & 0.291 & 1.87 & 0.372 & 2.17 \\
\hline & 0.2 & 0.04201 & 1.384 & 0.325 & 0.95 & 1.706 & 0.383 & 0.93 & & & & & 0.0569 & 0.513 & 0.127 & 1.02 & 0.197 & 1.43 & 0.302 & 1.91 \\
\hline & 0 & 0.03035 & 1.000 & 0 & 1.00 & 2.362 & 0.533 & 0.86 & & & & & & & 0 & 0 & 0.0811 & 0.702 & 0.203 & 1.46 \\
\hline
\end{tabular}




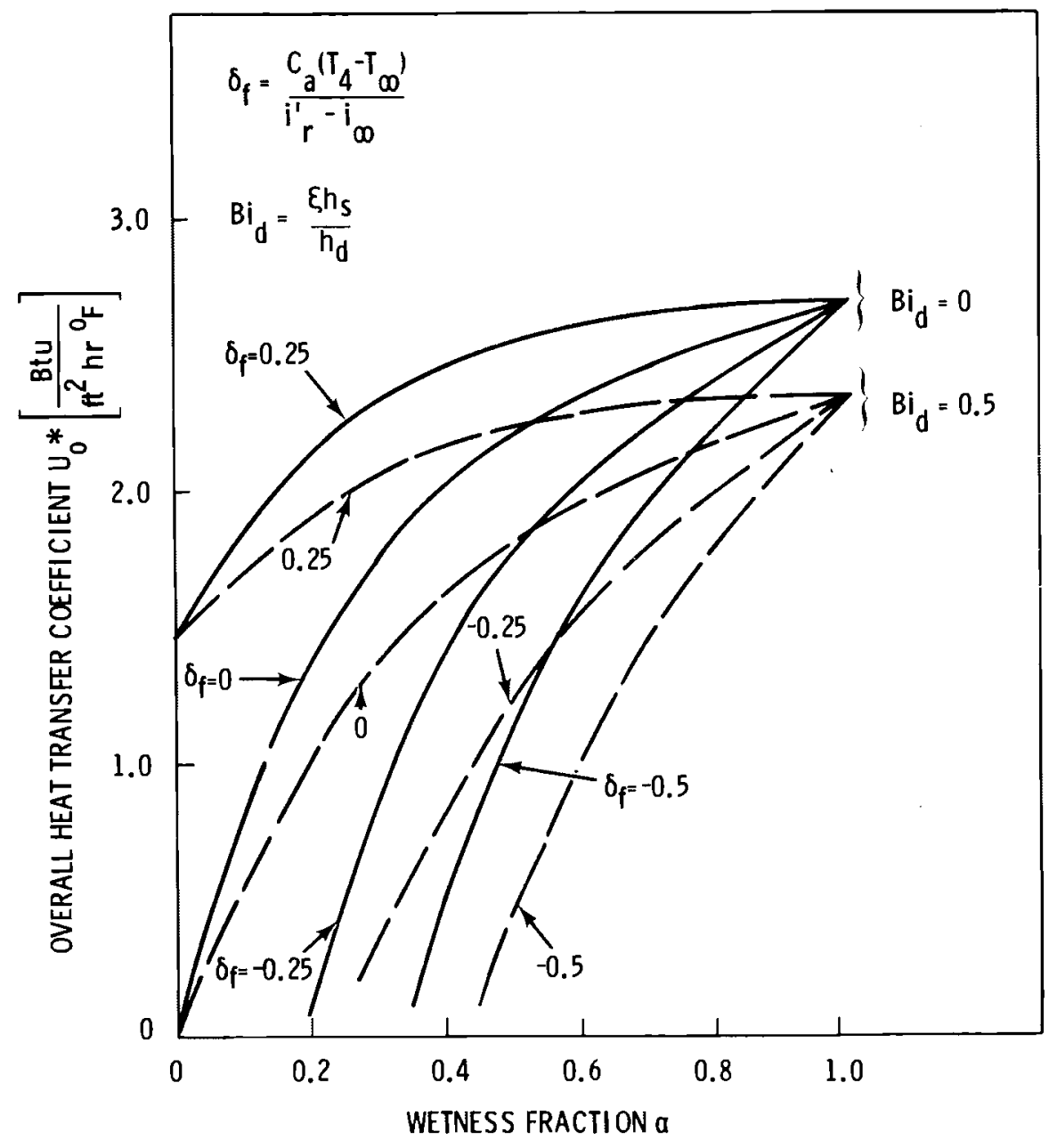

FIGURE 4-19. Computation of Heat Transfer Using the Partial Wetting Deluge Mode 1

decreases dramatically with a reduction in surface wetting $\alpha$, especially at large negative values of $\delta_{f}$. Negative values of $\delta_{f}$ arise because the evaporation process tends to drive the surface temperature toward the wet bulb temperature (i.e., see Figure 4-1). The greater the driving potential and/or the greater the effective surface heat transfer coefficient, the closer the surface will approach the wet bulb temperature. At large negative values of $\delta_{f}$, the air is actually cooled. To some extent this occurs due to convection of heat from the warmer air into the outer dry portion of the fin which 
is radially conducted backward into the wetted zone. Thus, in some cases the dry portion of the fin is actually detrimental to the dissipation of heat from the core and results in a decrease in the measured $U_{0}{ }^{*}$.

It is probably misleading to show the curves for large values of $\delta_{f}$ extending to small values of $\alpha$. For small $\alpha, r_{3}$ is small so that evaporation is restricted to areas on the fin very close to the tube where conduction is relatively efficient. Thus, for small $\alpha$, the degree of temperature depression should be significantly reduced so that attention should probably be restricted to the positive or slightly negative values of $\delta_{f}$. For large $\alpha$, the situation is reversed. Far out on the fin, conduction is relatively ineffective and the temperature at the surface will more closely approach the wet bulb. Thus, for large $\alpha$, attention should be on the more negative values . of $\delta_{f}$. Unfortunately, the actual relationship between $\alpha, \delta_{f}$ and operating conditions is still unknown.

The effect of the delugeate resistance, dealt with parametrically through $B i_{d}$, is seen to be relatively minor when the $f i l m$ is assumed thin as it is here. The value of $U_{0}{ }^{*}$ is generally reduced with increasing $B i_{d}$, but this dependence is much less pronounced than that due to $\alpha$ or $\delta_{f}$. Again, however, the actual relationship between $B i_{d}$ and the other variables is still unknown.

The results in Figure 4-19 show that nonuniform wetting can substantially reduce $U_{0}{ }^{*}$ from that predicted for uniform wetting. If most of the surface can be kept wet, i.e., $\alpha>0.8$, the reverse conduction on the dry fin areas is relatively small and $U_{0}{ }^{*}$ will be very nearly that predicted for uniform thin film wetting (i.e., for $B i_{d} \approx 0$ ). However, for relatively small wetting, i.e, $\alpha<0.5$, the effect of reverse conduction from the air due to the temperature depression effect can substantially reduce the effective heat transfer coefficient $U_{0}{ }^{*}$. It is currently believed that the latter effect is the explanation for the relatively low values of $U_{0}{ }^{*}$ obtained in the WATA experiments. 
As a check on the approximations used in developing the modified deluge model, a few computations were performed using the HEATING5 conduction code. For these computations, it was assumed that the core was at $120^{\circ} \mathrm{F}$ and the air was at $100^{\circ} \mathrm{F}$ and saturated. The calculation used $h_{p}=500\left(B t u / \mathrm{ft}^{2} \mathrm{hr}{ }^{0} \mathrm{~F}\right)$, $h_{s}=10\left(B t u / \mathrm{ft}^{2} \mathrm{hr}{ }^{0} \mathrm{~F}\right), B i_{d}=0$ and $=7.0$ such that the effective heat transfer coefficient was $h_{e}{ }^{*}=70\left(B t u / f^{2} h^{0} F\right)$. The computations were performed assuming first that the inner annulus was wet and then that the outer annulus was wet. The results are summarized in Table 4-10 and plotted in Figure 4-20.

TABLE 4-10. Computation of $\varepsilon+U_{0}$ * for Incomplete Wetting Using HEATING5 Code

\begin{tabular}{|c|c|c|c|c|c|c|c|}
\hline \multirow[b]{2}{*}{ HEATING5 Model } & \multirow[b]{2}{*}{$\frac{r_{3}}{r_{2}}$} & \multicolumn{3}{|c|}{ Inner Fin Surface Wet } & \multicolumn{3}{|c|}{ Outer Fin Surface Wet } \\
\hline & & $\alpha$ & $\varepsilon$ & $\frac{U_{0}^{\star}}{\left(\frac{B t u}{h r f t^{20} F}\right)}$ & $\alpha$ & 证 & $\frac{U_{0}^{\star}}{\frac{B t u}{h r f t^{20} F}}$ \\
\hline \multirow{6}{*}{$\begin{array}{l}\text { Annular-fin with } \\
\text { Annular Wetting }\end{array}$} & 1.00 & 0 & 0.129 & 0.989 & 1.0 & 0.540 & 2.36 \\
\hline & 1.384 & 0.2 & 0.267 & 1.63 & 0.8 & 0.427 & 2.11 \\
\hline & 1.683 & 0.4 & 0.376 & 1.98 & 0.6 & 0.359 & 1.93 \\
\hline & 1.936 & 0.6 & 0.457 & 2.19 & 0.4 & 0.291 & 1.72 \\
\hline & 2.160 & 0.8 & 0.503 & 2.28 & 0.2 & 0.226 & 1.46 \\
\hline & 2.362 & 1.0 & 0.540 & 2.36 & 0 & 0.129 & 0.989 \\
\hline \multirow{3}{*}{$\begin{array}{l}\text { HÖTERV Geometry } \\
\text { with Vertical } \\
\text { Strips Wetted }\end{array}$} & & 0.244 & 0.289 & 1.71 & 0.756 & 0.322 & 1.82 \\
\hline & & 0.374 & 0.335 & 1.86 & 0.626 & 0.379 & 1.99 \\
\hline & & 0.592 & 0.414 & 2.08 & 0.408 & 0.322 & 1.82 \\
\hline
\end{tabular}

Assumptions

$$
\begin{aligned}
\mathrm{Re}_{\infty} & =700 \\
\mathrm{~h}_{\mathrm{s}} & =10\left(\mathrm{Btu} / \mathrm{hrft}^{\left.20_{\mathrm{F}}\right)}\right. \\
\mathrm{h}_{\mathrm{p}} & =500\left(\mathrm{Btu} / \mathrm{hrft}^{20} \mathrm{~F}\right) \\
B i_{d} & =0 \\
\xi & =7.0 \\
\delta_{f} & \simeq 0.14
\end{aligned}
$$




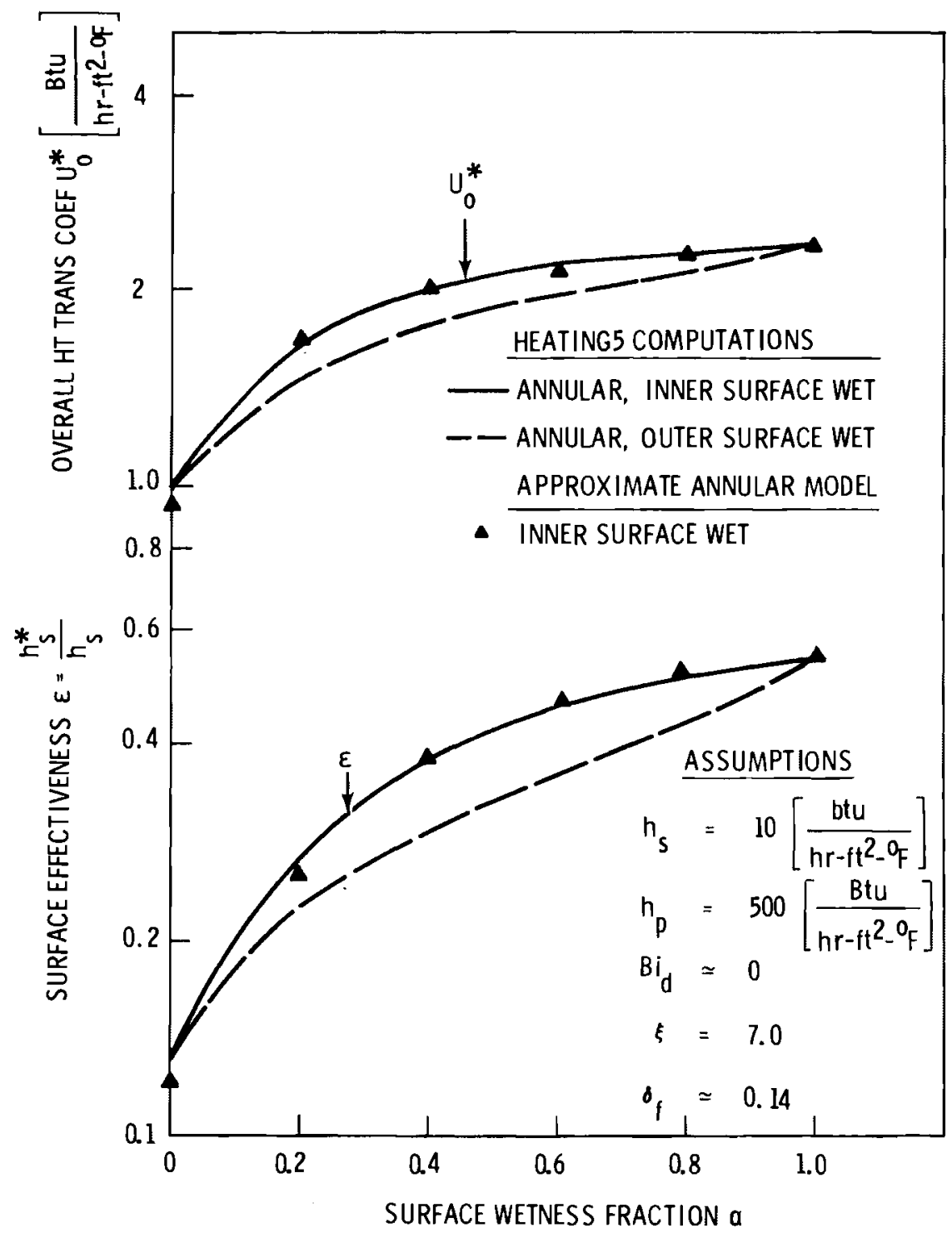

FIGURE 4-20. Comparison of Model for Partial Wetting with HEATING5 Computations for Annular Wetting

Also plotted in Figure 4-20 are the computations of $\varepsilon$ using the modified deluge model for the same conditions. Because the air was assumed saturated, there should be no temperature depression other than that due to the conductive resistance in the fin. Thus $\delta_{f} \leqslant 1 / \xi=0.14$. For these computations it was, therefore, assumed that $\delta_{f}=0.14$. 
From Figure 4-20 it can be seen that the predictions of $U_{0}$ * using HEATING5 and the modified deluge model are in good agreement. Even for the case where the outer annulus is wet, the value of $U_{0}{ }^{*}$ computed with HEATING5 does not differ substantially from that computed with the deluge model. It, therefore, appears that the modified deluge model is probably adequate, at least for the case where the humidity is relatively high. It is not currently possible to make additional comparisons due to the lack of a model for $\delta_{f}$.

Another check on the validity of the annular wetting model was performed using the HEATING5 code. The rectilinear model shown in Figure 4-9 was divided into wet and dry areas and $U_{0}{ }^{*}$ was computed for two cases. In the first case the wet area was a sinuous path that enveloped the tubes, leaving the interior portions of the fins dry. The percentage of wetted area was varied by widening the width of the wetted area for three different values of $\alpha$. The second case was just the inverse of the first case where the vertical strips of wetted fin wound their way through the interior of the fins, leaving dry the remaining strips enveloping the tubes. Of these, the case that assumes wetting surrounding the tubes is considered most representative of the actual situation.

The results of these computations are given in Figure 4-21. The results of the HEATING5 computation for the annular wetness model are also given in Figure 4-21 for comparison. The results for the case where the wet strip envelopes the tubes lie closest to the results for the annular fin model with the inner annulus wet. Similarly, the two computations for the case where the area around the tube is dry are in reasonable agreement. In any case, the agreement is sufficient to conclude that the annular fin model with annular wetting is probably adequate for the purposes of this analys is if $\delta_{f}$ can be properly accounted for.

\subsubsection{Comparison of the Analys is with the Results of the WATA Experiments}

The parametric analysis presented in the preceding sections was done for ranges of variables that approximate the conditions used in WATA. However, after final reduction of the data it was decided that to obtain a more direct comparison with the experimental results it was necessary to evaluate the 


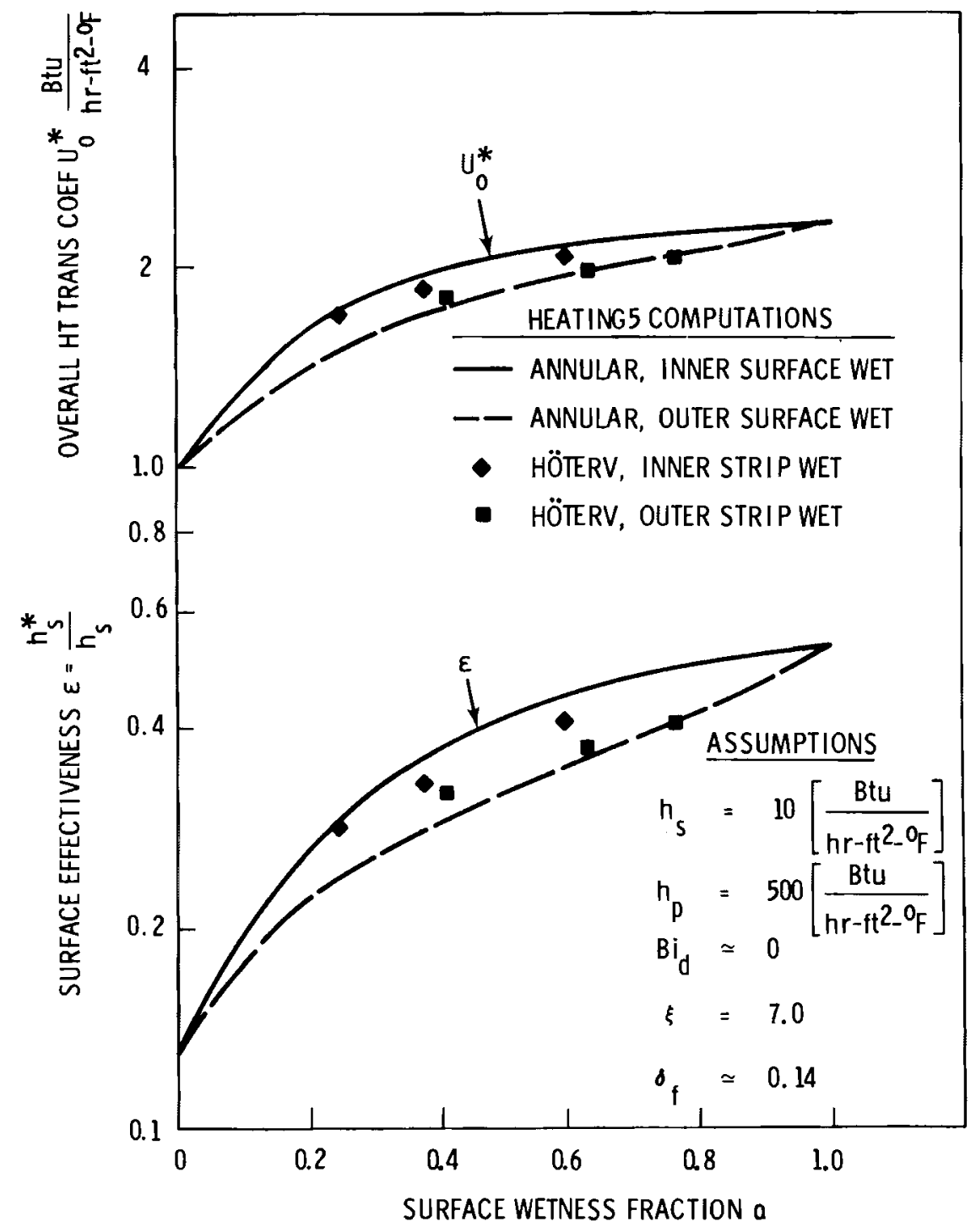

FIGURE 4-21. Comparison of HEATING5 Computations for Annular Model with Rectilinear Model with Nonannular Wetting

theory for the specific conditions used in the deluge tests. Thus, $U_{0}$ * was recomputed using appropriate values of all the parameters. Example calculations are provided in Appendix A, Section A-8. The results for $U_{0}{ }^{*}$ are tabulated in Table 4-11 and plotted in Figure 4-22, which also shows the experimental data for comparison. In all of these computations the resistance of the delugeate $f i 1 \mathrm{~m} h_{d}$ was computed from the data as discussed in Section 4.1 .4 . 
TABLE 4-11. Computation of the Heat Transfer Coefficients and Enhancement Ratio for Conditions Typical of the WATA Experiments (for $h_{p}=$
$625 \mathrm{Btu} / \mathrm{ft}^{2} \mathrm{hr} \mathrm{O}^{0} \mathrm{~F}$ )
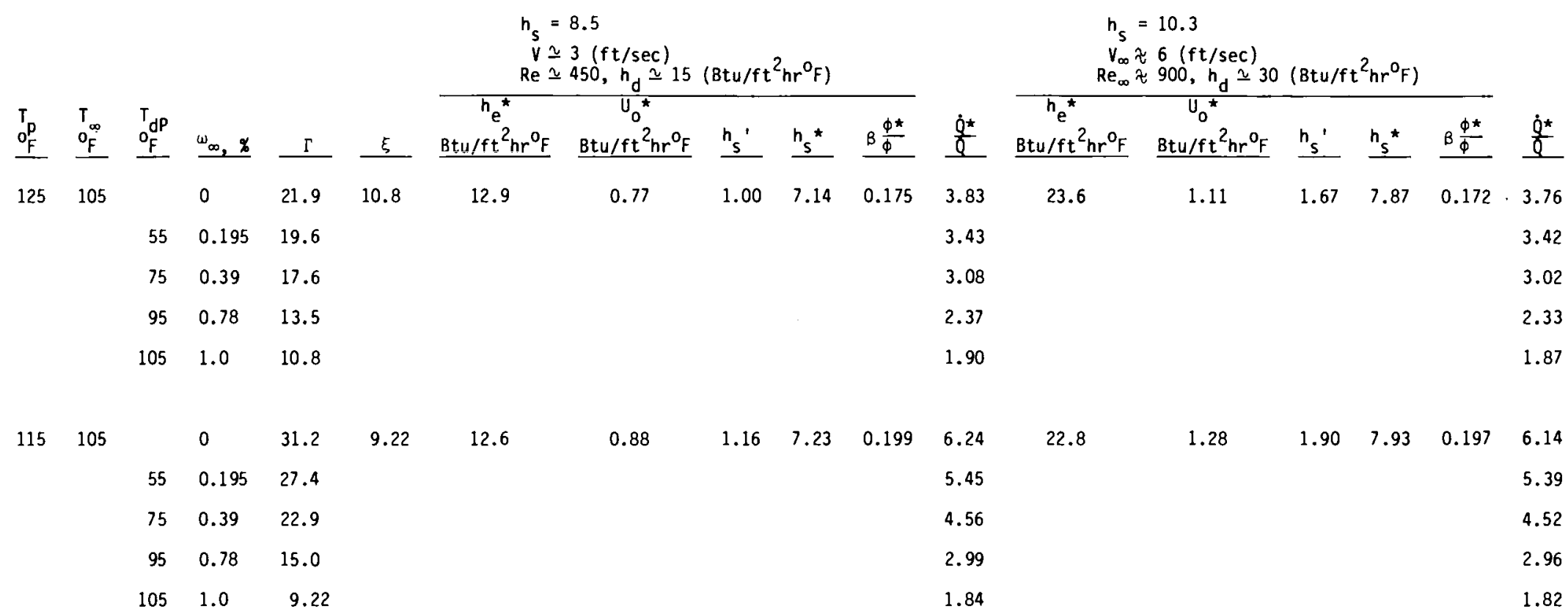

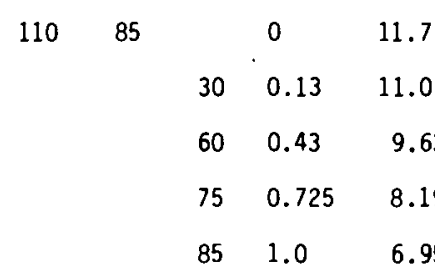

$6.95 \quad 12.0$

$\begin{array}{lllll}1.13 \quad 0.48 & 7.31 & 0.243 & 2.83 \\ & & & 2.68 \\ & & & 2.34 \\ & & & 1.99 \\ & & & 1.69\end{array}$

21.1

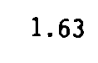

2.

$\begin{array}{rrr}9.06 \quad 0.241 & 2.81 \\ & 2.65 \\ & 2.32 \\ & 1.97 \\ & 1.68\end{array}$




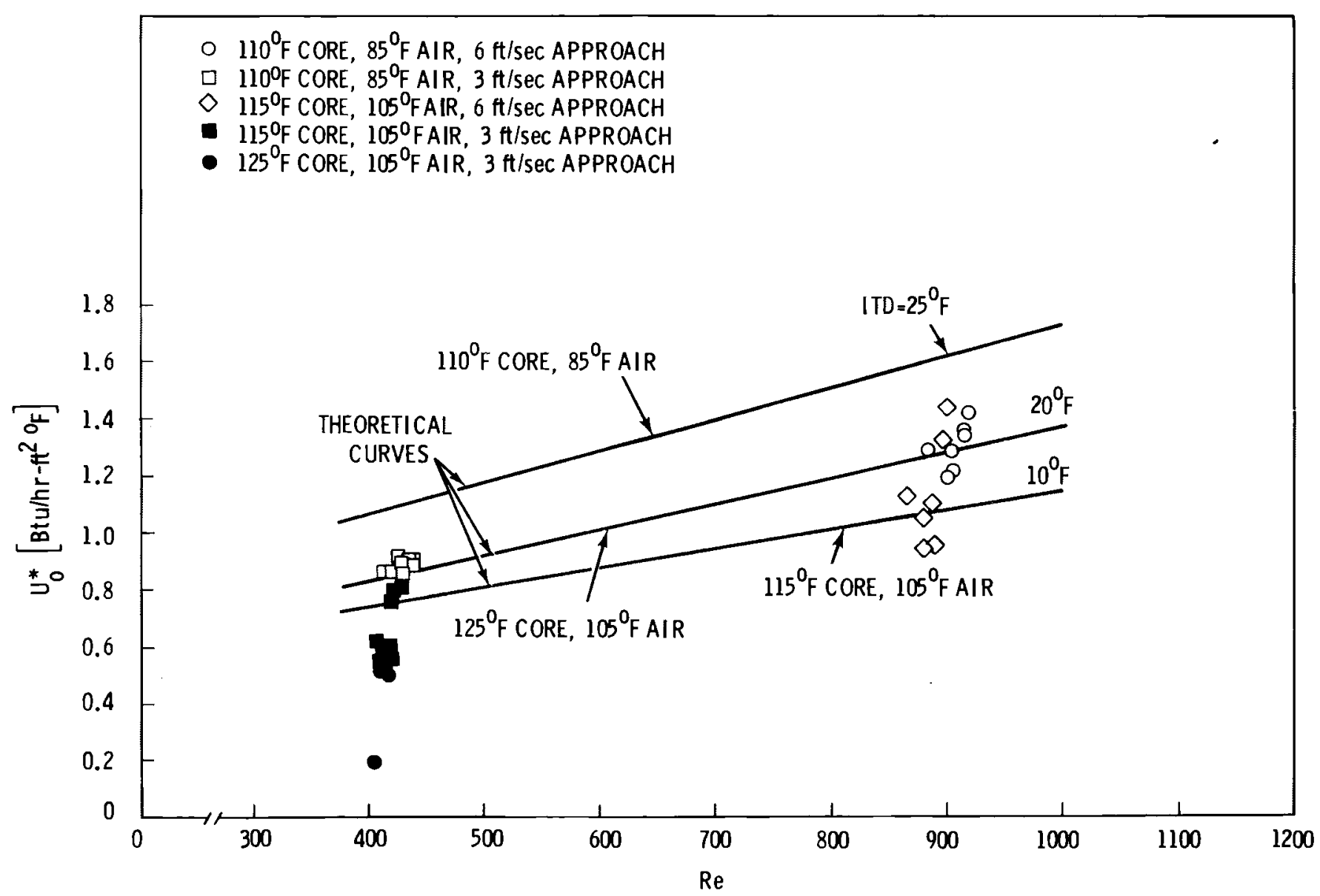

FIGURE 4-22. Comparison of Predicted and Measured Values of $U_{0}$ * 
The experiments were run at three primary combinations of core temperature and free stream temperature using varying values of inlet dew-point temperature. The operating conditions varied slightly from run to run within each data set because of limited repeatability in the establishment of equilibrium flows, humidities and temperatures. For comparison with the data, the model has been evaluated at conditions that approximate the nominal conditions chosen for each data set.

For the WATA measurements, the core temperature varied from about $110^{\circ} \mathrm{F}$ to $125^{\circ} \mathrm{F}$ and the air temperature varied from about $85^{\circ} \mathrm{F}$ to $105^{\circ} \mathrm{F}$ with relative humidities of about $10 \%$ to $80 \%$ at the inlet. The chosen range of core temperatures is representative of conditions relevant to operation of an ammonia condenser. Air temperatures of $105^{\circ} \mathrm{F}$ represent an adverse operating condition for an all-dry heat exchanger, especially at a core temperature of only $115^{\circ} \mathrm{F}$. This illustrates the sort of conditions in which deluge augmentation is needed and for which the degree of heat transfer enhancement is expected to be greatest. Thus, most of the data were obtained at $T_{p}=115^{\circ} \mathrm{F}, T_{\infty}=$ $105^{\circ} \mathrm{F}$ and these are the results that will be emphasized for comparison with the theory.

Example calculations for this section are in Section A-8. The results of the computations of $U_{0}{ }^{*}, h_{S}{ }^{*}$ and $\dot{Q} * / \dot{Q}$ are summarized in Table $4-11$. Computations are included for $V \approx 3(\mathrm{ft} / \mathrm{sec})$, for which $\operatorname{Re}^{\star} \simeq 450$ and $\bar{h}_{\mathrm{d}} \approx$ $15\left(\mathrm{Btu} / \mathrm{ft}^{2} \mathrm{hr}{ }^{0} \mathrm{~F}\right)$ and at $V \approx 6(\mathrm{ft} / \mathrm{sec})$ for which $\mathrm{Re}^{\star} \approx 900$ and $\bar{h}_{\mathrm{d}} \approx$ $30\left(\mathrm{Btu} / \mathrm{ft}^{2} \mathrm{hr}{ }^{\mathrm{O}} \mathrm{F}\right)$. The results of these computations are given graphically in Figure 4-22 for $U_{0} *$ and Figure 4-23 for $\dot{Q} * / \dot{Q}$. The experimental results are also shown in the figures for comparison.

From Figure 4-22 it is apparent that the deluge model predicts $U_{0}$ * best at the high velocity, low ITD and high core temperature. At $\operatorname{Re}^{\star}=900$, the data are in good agreement with the theory except at an ITD of $25^{\circ} \mathrm{F}$ where the theory appears to predict too high by about 20 to $25 \%$. At $\operatorname{Re}^{\star}=450$, the theory generally predicts $U_{0}{ }^{*}$ too high, especially at the higher ITD. However, considering the nature of the approximations in the deluge model and the uncertainty in the data, the agreement in Figure 4-22 can be considered quite 


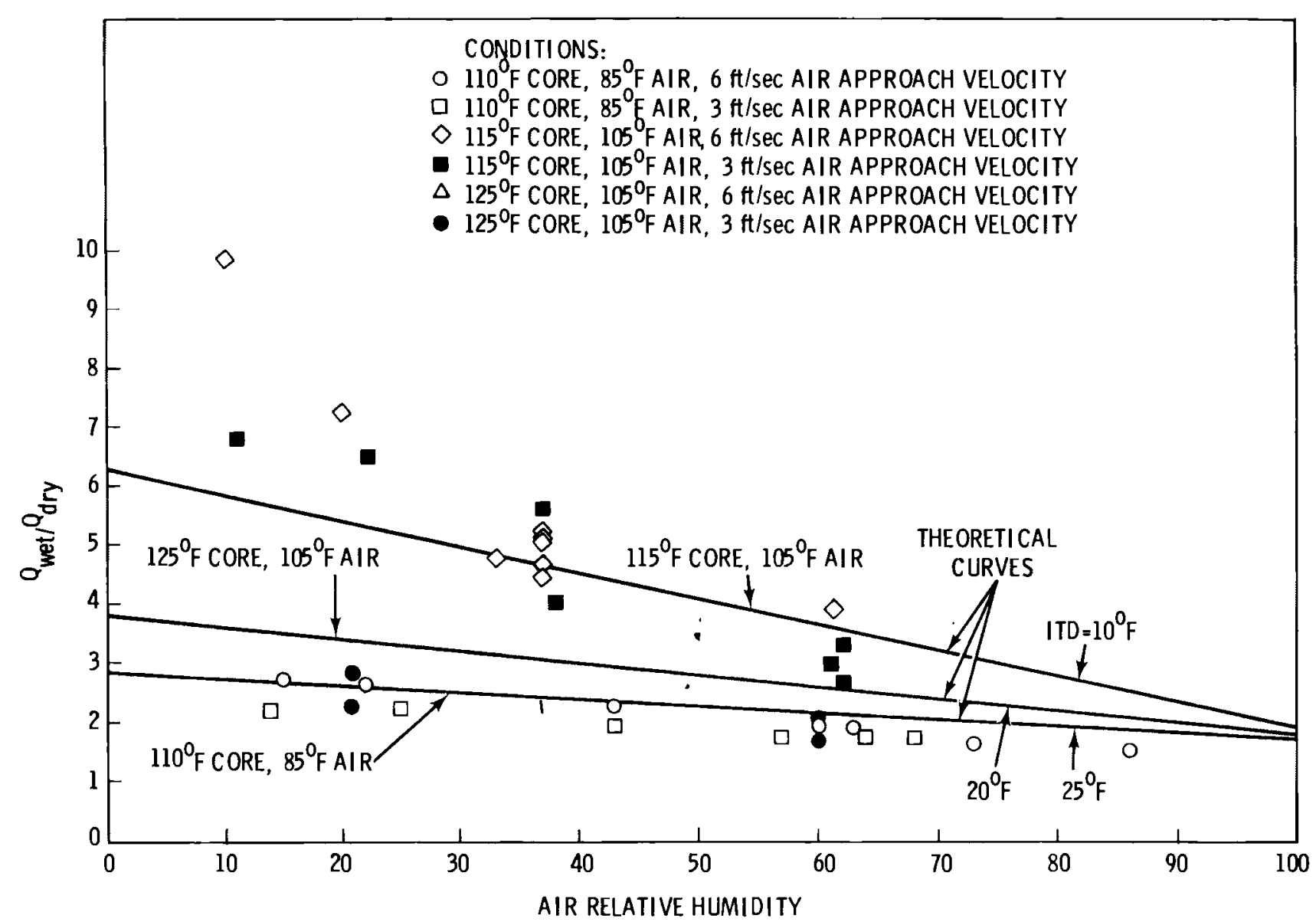

FIGURE 4-23. Comparison of Predicted and Measured Values of the Heat Transfer Enhancement Ratio for Equal Pressure Drop Operation 
good. Fortunately, the conditions where the theory appears most accurate (high core temperature, low ITD) are those conditions of primary interest in the use of deluge heat transfer.

The results for $\dot{Q} \star / \dot{Q}$ from theory and experiment are plotted together for comparison in Figure 4-23. From Table 4-11 it can be seen that the curves of $\dot{Q} \star / \dot{Q}$ for different values of ITD and $\omega_{\infty}$ are essentially independent of Re* for these conditions. Thus, only one line is plotted in each case. It was found that the enhancement increases with decreasing relative humidity and decreasing ITD. Theory and experiment are in good agreement except at very low relative humidities where the experimental enhancement exceeds the predicted value. Again, the degree of agreement is quite acceptable in light of the assumptions and approximations made in development of the theory.

The above theoretical results were obtained using experimentally determined values of $h_{d}$. Thus, $h_{d}$ incorporates thermal resistance due to nonuniform and incomplete wetting and the resultant increase in thermal resistance. The modified deluge model provides an alternative means of treating nonuniform wetting by directly accounting for the surface wetness fraction $\alpha$. Unfortunately, we cannot quantitatively predict $\alpha, \delta_{f}$ or $B i_{d}$ in this model so it is of qualitative value only. However, we will now attempt to interpret the data in terms of a deduced wetness $\alpha$ that explains the apparent reduction in $U_{0}{ }^{*}$ due to incomplete wetting.

For the low velocity data, $V \sim 3 \mathrm{ft} / \mathrm{sec}$, the apparent. $U_{0}{ }^{*}$ values are relatively low, being in the range of 0.29 to 0.36 of the value predicted by the optimal deluge model. Thus, it is likely that the degree of wetting in this case was relatively poor. As noted above, when $\alpha$ is small, $\delta_{f}$ is likely to be on the positive side because of efficient conduction of heat into the evaporation zone. Using $\delta_{\mathrm{f}} \approx 0$ and $B i_{\mathrm{d}} \approx 0$, the results in Figure 4-19 would give $0.05 飞 \alpha \approx 0.11$ for $0.4<U_{0}{ }^{*} \approx 0.9$ (Btu/ft ${ }^{2} \mathrm{hr}^{0} \mathrm{~F}$ ). Using $\delta_{f}=-0.25$ would give $0.23 ₹ \alpha \prec 0.33$ for the same range of $U_{0}{ }^{*}$. It is likely that $\delta_{f}$ would lie somewhere in this range, so from this analysis it would appear that the wetting was probably in the range of only about $5 \%$ to $30 \%$ for these data runs. Based on visual observations of the core faces and 
the limited view into the core interior, surface wetting on the order of $30 \%$ is believable but $5 \%$ seems much too low.

For the data taken at $6 \mathrm{ft} / \mathrm{sec}, 0.94<\mathrm{U}_{0} *<1.4\left(\mathrm{Btu} / \mathrm{ft}^{2} \mathrm{hr} \mathrm{O}^{\mathrm{O}} \mathrm{F}\right)$. Using $\delta_{f}=0$, Figure $4-19$ gives $0.10 \approx \alpha \approx 0.20$. Using $\delta_{f}=-0.25$ gives $0.30 \approx$ $\alpha<0.40$. Wetting of 30 to $40 \%$ seems reasonable in view of the observations but $10 \%$ wetting again seems unrealistically low.

In both cases, the delugeate resistance was neglected. If $B i_{d}>0$, this would tend to give larger values of $\alpha$ for a given value of $U_{0}{ }^{*}$. However, without models for predicting $\mathrm{Bi}_{d}$ and $\delta_{f}$, no further comparisons can reasonably be made at this time.

\subsubsection{Summary and Discussion of Results}

The analysis in this section has summarized the development of the deluge models for combined heat and mass transfer from an evaporatively cooled finned heat exchanger. The analysis includes development of a simple model that uses an empirical deluge surface film coefficient $h_{d}$ and a more complex model wherein the degree of surface wetness is directly accounted for. The mechanics of using these models, their accuracy, and ultimate usefulness are demonstrated by applying the models to prediction of the results of the WATA experiments using the deluged HÖTERV core. The principal results of this section are shown in Figure 4-22, which compares theoretical and measured overall heat transfer coefficient $U_{0}{ }^{*}$ and in Figure 4-23, which compares theoretical and measured values of the wet/dry heat transfer enhancement ratio.

Very early in the development of the deluge'model it became apparent that the deluge surface film coefficient $h_{d}$ could not be predicted by conventional means. The thermal resistance of a thin uniform water $f i 1 m$, whether laminar or turbulent, would be negligible compared to the other path resistances and it was so assumed in the initial analyses. However, predictions of $U_{0}{ }^{*}$ based on the simple deluge theory with $1 / h_{d} \sim 0$ were too high by a factor of two or more compared to the data from WATA. From literature provided by HÖTERV, it was learned that they used $h_{d}{ }^{*} \simeq 100\left(B t u / \mathrm{ft}^{2} h r^{0} F\right)$. Although this value of $h_{d}$ apparently provided adequate agreement between the 
HÖTERV data and their version of the deluge theory, it was still much too large to account for the discrepancy between the theory and the data for the present experiments.

To explain the discrepancy between theory and experiment, a modified deluge model was developed that directly accounted for incomplete wetting by assuming the core to be made up of wet and dry regions. Although some insight was gained from this model, it was not very useful in a quantitative sense because it contains functions that cannot be quantitatively evaluated.

The fraction of surface wetted, as deduced from the data using the modified deluge model, is somewhat lower than was expected. However, intuition may be biased in this case by the concept of $f i l m$ wetting that was invoked in both of the deluge models. The thin film assumption was adopted primarily to make the mathematics manageable although it was originally believed that film flow could actually be achieved. Subsequent observations indicated that true film flow was rarely (if ever) achieved in these experiments.

The flow of the deluge water, as observed by looking into the core from the front and the back, can best be described as an intermittent rivulet, slug-like flow. It is observed that water frequently bridges the fin gap and that rivulets wander about to some extent because of localized flow instabilities. For most of the operating conditions, the back and especially the front surfaces often appear dry or nearly so. The visibility into the core is extremely limited so it is not possible to see beyond the first few rows of turbulators. However, it is expected that the rivulet-like flow persists throughout the interior of the core. If so, the relatively small fraction of surface wetness (i.e., 5 to $30 \%$ at $3 \mathrm{ft} / \mathrm{sec}$ and 10 to $40 \%$ at $6 \mathrm{ft} / \mathrm{sec}$ ) is plausible. However, this conclusion is subjective and cannot be verified at this time. Qualitatively it is probably safe to conclude that relatively little of the surface was wetted on the average. However, no claim can be made for the accuracy of the actual values of the wetness fraction that were extracted from the data using the deluge model. 
Some aspects of the WATA tests indicate that the partial wetting model is at least qualitatively correct. As mentioned above, doubling of the air velocity from $3 \mathrm{ft} / \mathrm{sec}$ to $6 \mathrm{ft} / \mathrm{sec}$ substantially increased the apparent surface wetness. This result is supported by visual observation where the degree of wetness, at least on the back face, appears to increase at the higher air velocity. The mechanism that is suggested to account for the increased wetness is a smearing out of the rivulets due to higher shear forces, resulting in a more film-like and uniform wetting of the surface. Visual observation tends to confirm this hypothesis, although very little can be seen beyond the actual faces of the core.

Another brief test of the effect of surface wetness was performed by adding a surfactant to the deluge water. Addition of the surfactant resulted in extreme foaming and bubbling of the deluge water, even at substantially lower dilution than recommended by the manufacturer. However, at a dilution that gave manageable foaming rates, the heat transfer was increased by only about 20 to $30 \%$, whereas the pressure drop was about doubled. In addition, meaningful results could only be obtained at $3 \mathrm{ft} / \mathrm{sec}$, because higher velocities caused substantial drift downstream of the core. At $3 \mathrm{ft} / \mathrm{sec}$, the surface wetness was increased substantially (by visual observation) on the front, but especially on the back. However, looking into the core, it appeared to be primarily full of foam.

The modified deluge model was used with the measured heat transfer data to estimate a value for the apparent wetness, $\alpha$, for the runs with the surfactant. The result indicated that the increased rate of heat transfer due to the surfactant could be explained by approximately doubling the wetness fraction as compared to data taken at the same conditions without surfactant. In this case, the wetness was estimated at about 20 to $30 \%$. The apparent wetted area was still much smaller than would be visually estimated. However, the effect of the bubbles is difficult to predict. It is hypothesized that the area touching a bubble may be effectively insulated and thus transfers no heat. The large pressure drop would indicate that a substantial blockage is in fact experienced. 
Because of the relative lack of success with the modified model, attention was again directed at devising a means for predicting or measuring $h_{d}$. During the final writing and editing of this report, communications were held with $D r$. Forgo that subsequently led to empirical means for computing $h_{d}$ (described in Section 4.1 .4 above). The values of $h_{d}$ thus obtained were found to provide good agreement between theory and experiment, as shown in Figures 4-22 and 4-23. Although the theory still tends to overpredict $U_{0}$ * by as much as $25 \%$, agreement must still be considered good in light of the extent of the approximations, assumptions and analogies used to develop the theory and the relatively large uncertainty in the data.

At first glance it might appear that $h_{d}$ is merely used as a "fit parameter" to force agreement with the theory. However, this is not the case at all. The computation of $h_{d}$ from the experimental data uses the measured heat transfer $\dot{Q}^{\star}$, the metal/water interface temperature (computed from the known primary fluid temperature $T_{p}$ and the inside film resistance) and the measured average deluge water temperature $T_{d}$. None of these measurements or computations requires any knowledge of the air-side temperature, humidity, flow rate or other conditions. Thus, the average deluge water film coefficient $\bar{h}_{d}$ is measured directly and independently of the measurement of $U_{0}{ }^{*}$. The value of $\bar{h}_{d}$ so determined incorporates in some average way the effects of nonuniform wetting. The effects of fin efficiency were factored out to get the values of $\bar{h}_{d}$ used in the analysis.

The big question that remains to be answered is why there is such a large difference between the values of $\bar{h}_{\hat{g}}$ determined from the data in these experiments, $h_{d} \sim 15$ to $30\left(B t u / f t^{2} h r^{0} F\right)$, as compared to those obtained by HÖTERV in their experiments with a very similar core, $h_{d} \sim 100\left(B t u / \mathrm{ft}^{2} \mathrm{hr}^{\mathrm{O}} \mathrm{F}\right)$. Although the different values of $h_{d}$ are adequately accounted for in the model, there is a substantial difference in the experimentally determined rates of heat transfer for similar conditions (see Figures 4-15 and 4-17). The most likely explanation would be that the surface in the HÖTERV experiments was more completely wetted. This may have been due to different deluge flow rates (theirs was only slightly greater), different water distribution 
techniques, core angulation, core geometry, surface preparation, water treatment, or other conditions of which we are not yet aware.

Although the heat transfer enhancement obtained in this study was substantially lower than that predicted for thin film wetting and also lower than that obtained by HÖTERV, it is still apparent from the results in Figure 4-23 that deluge heat transfer is potentially of great value. At low ITD (where enhancement is needed most) factors of improvement of about 4 at $50 \%$ R.H. to as much as 10 at very low R.H. were obtained. Even at high ITD and high humidity, enhancement factors of no less than 1.5 were obtained. With improved wetting and optimized performance, these ratios can probably be increased even more, as evidenced by the apparently better performance obtained by HÖTERV. Thus, the potential value of deluge operation appears very promising based on these results.

\subsubsection{Conclusions and Recommendations}

The primary conclusions of this study relate to the usefulness and accuracy of the deluge model and the potential of the deluge technique for peaking duty in cooling tower applications.

- The deluge model has been found to be functionally and quantitatively adequate for predicting the heat transfer due to combined heat and mass transfer on a deluged finned heat exchanger.

- The enhancement of heat transfer due to deluge was found to be substantial for conditions that could be expected in most power plant cycles. With the development of optimized designs and operational strategies, even better performance can be expected.

Pursuant to the above conclusions, a number of specific recommendations are made concerning further work. Additional studies should include tests to more fully investigate the following,

- optimal deluge flow rate

- improved deluge water distribution systems

- effects of airflow rate

- effects of core tilt angle

- alternative core designs

- water composition, wetting agents. 
In the course of these studies other factors to be considered should include effects of meteorological conditions, problems related to excess pressure drop and droplet drift, fouling, corrosion and environmental impacts.

\subsection{COST OF DRY/WET COOLING BASED ON THE WATA DELUGE DATA}

Previous reports $(4,5)$ have dealt with the projected cost of an optimized deluge dry/wet system using ammonia as the heat transport fluid. In this section the results of these earlier studies, based on heat exchanger performance data provided by the manufacturer, HÖTERV, are reexamined in light of the heat transfer characteristics obtained in WATA. As might be anticipated, the measured performance of the HÖTERV test core was not identical to either the manufacturer's data or the theoretical projections. To obtain a measure of the effects these differences in performance would have on the cost of electricity, the BNW-II computer code was used to obtain incremental costs of electricity at the San Juan, New Mexico site using the data from Reference 2, and the current data obtained in WATA.

The inputs to the code are summarized in Table 4-12. These inputs are similar to those used in Reference 5.

The BNW-II code computes the wet performance with the aid of an input variable, the ratio of air velocity under wet operation to that under dry operation (see Table 4-12). This ratio is primarily a function of the relationship between the dry and the wet friction factors, so it can vary from core to core. Extending the calculations of Reference 2, computations were carried out with the manufacturer's data to determine the air velocity ratio as a function of the fraction of wet cooling duty. A ratio of 0.77 was chosen as an average value. For the WATA core, a value of 0.5 was chosen for this ratio, because it was consistent with the observed ratio of air velocities under wet and dry conditions at the same pressure drop.

The results obtained with these inputs in the BNW-II code provided designs and incremental costs that permit a comparison for power plants equipped with deluged heat exchangers having WATA performance characteristics with those having characteristics used in Reference 2. 
TABLE 4-12. Input Parameters

Parameters

\section{Plant Parameters}

Plant Type

Design Net Power

Conventional Turbine (a)

Capacity Factor

Cost Parameters

Fixed Charge Rate

Fuel

Base Plant Capital

Base Plant Steam Supply System

Gas Turbine Capital

Power Cost for Gas Turbines

Design Parameters

Cooling System Type

HÖTERV Plate-Fin Heat Exchanger

Tower Configuration

Velocity Recovery Stacks

Intermediate Heat Transfer Fluid

Ammonia Vapor Design Velocity

Ammonia Liquid Design Velocity

Deluge Water Design Velocity

Deluge Flow/Evaporation

Distance from Condenser to Tower

Condenser Type

Condenser Tubes
Values

\section{Fossi 1}

1000 MWe

$4.92 \times 10^{9} \mathrm{Btu} / \mathrm{hr}$

0.758

0.180

$66.9 \phi / 10^{6}$ Btu

$\$ 571 / \mathrm{kWe}$

$\$ 190 / \mathrm{kWe}$

$\$ 121 / \mathrm{kWe}$

$24.0 \mathrm{mills} / \mathrm{kWh}$

Indirect mechanical draft

Yes

Symmetric polygon ( 8 sides), horizontal tube

Yes

Ammonia

$150 \mathrm{ft} / \mathrm{sec}$

$15 \mathrm{ft} / \mathrm{sec}$

$10 \mathrm{ft} / \mathrm{sec}$

5

$500 \mathrm{ft}$

Single-pressure, one-pass, two-she 11 surface condenser

Linde AL12, 1.00-in. OD, 50-ft length

(a) The heat rate versus exhaust pressure curve is given in Reference 2 . 
TABLE 4-12. (contd)

\begin{tabular}{|c|c|}
\hline Parameters & Values \\
\hline \multicolumn{2}{|l|}{ Deluge Parameters } \\
\hline Water Cost & $\$ 0 / 1000 \mathrm{gal}$ \\
\hline Design Temperature & $33^{\circ} \mathrm{F}$ \\
\hline Meteorology Site & San Juan, New Mexico \\
\hline $\begin{array}{l}\text { Relative Humidity of Air at Heat } \\
\text { Exchanger Exit }\end{array}$ & 1.00 \\
\hline $\begin{array}{l}\text { Ratio of Air Velocity through } \\
\text { Deluge Section to Air Velocity } \\
\text { through Dry Section }\end{array}$ & $\begin{array}{l}0.77 \text { (Babcock \& Wilcox) } \\
0.50 \text { (WATA) }\end{array}$ \\
\hline \multicolumn{2}{|l|}{ ry Parameters } \\
\hline Tube Length & Optimized \\
\hline Tube Rows in Direction of Airflow & Optimized \\
\hline Number of Towers & Optimized \\
\hline Number of Tower Sides & 8 \\
\hline Tower Roof Area/Fan-Swept Area & 3.0 \\
\hline Fan Diameter & $28 \mathrm{ft}$ \\
\hline Air Velocity & Optimized \\
\hline Turbine & Conventiona 1 \\
\hline
\end{tabular}

Optimized designs were obtained for 1000-MWe power plants having 0 to 5000 acre-feet per year of water available for evaporation which corresponds to 0 to $50 \%$ of the water needed for total evaporative cooling (Tables 4-13 and 4-14). The incremental cost using the WATA data is lower than previously calculated for the all-dry case, is equal at 4\% evaporative cooled, and becomes somewhat higher than the previous calculation as water availability increases (Figure 4-24).

Considerable scatter was observed in the value of the deluge mass transfer coefficient, $\sigma$. To account for this, correlations bracketing the experimental data were developed. These upper bound and lower bound correlations 
TABLE 4-13. Optimized Designs Using WATA Data

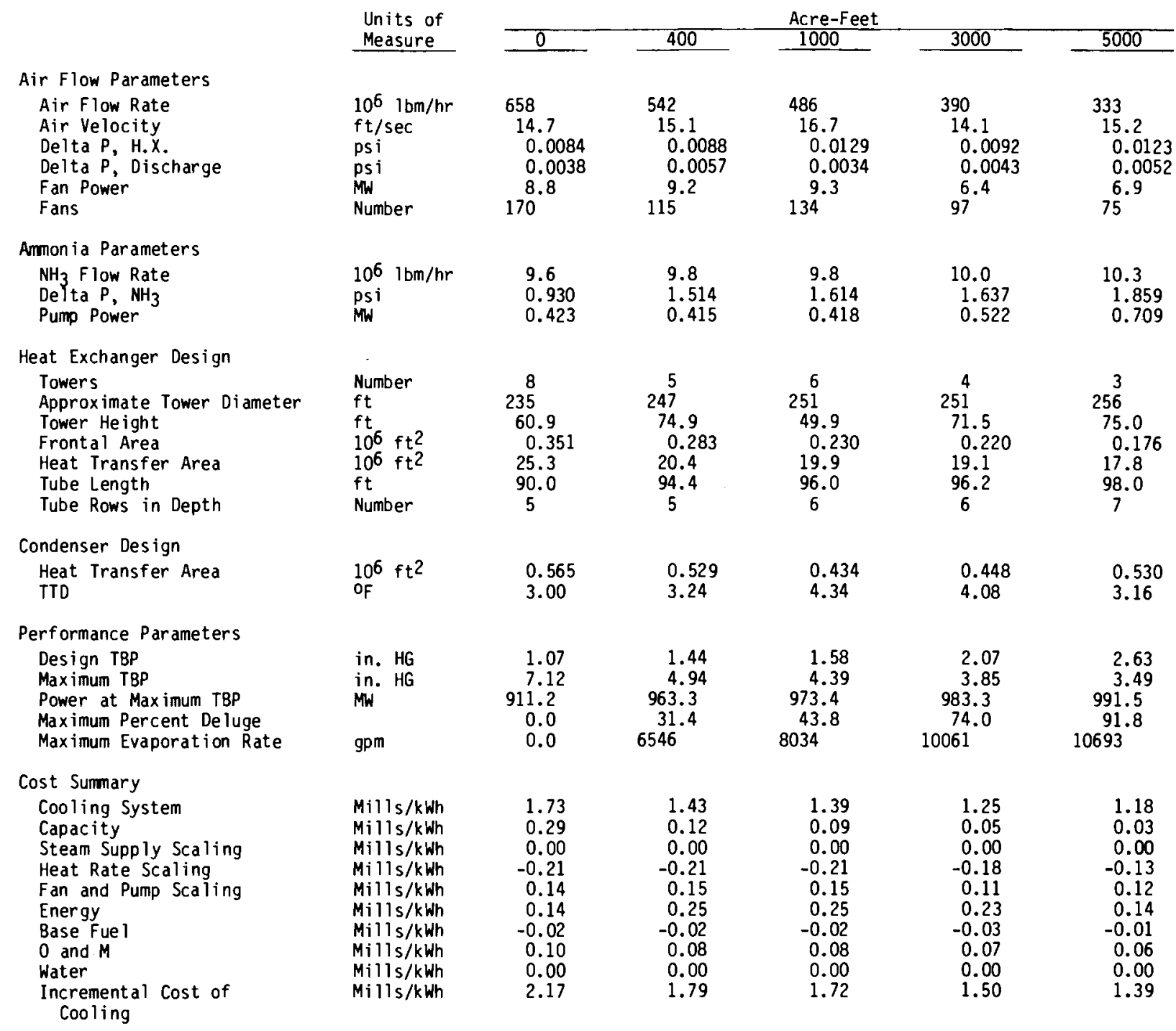

were then used in BNW-II to obtain upper and lower bounds of incremental costs at the $4 \%$ and 0 to $30 \%$ all-wet cases. These are shown by the vertical bars on Figure 4-24. It is clear the differences in incremental costs exceed those that would be caused by just experimental scatter. 
TABLE 4-14. Optimized Designs Using Correlations Based on Manufacturer's Data

\begin{tabular}{|c|c|c|c|c|c|c|}
\hline & \multirow{2}{*}{$\begin{array}{l}\text { Units of } \\
\text { Measure }\end{array}$} & \multicolumn{5}{|c|}{ Acre-Feet } \\
\hline & & 0 & 400 & 1000 & 3000 & 5000 \\
\hline \multicolumn{7}{|l|}{ Air Flow Parameters } \\
\hline $\begin{array}{l}\text { Air Flow Rate } \\
\text { Air Velocity } \\
\text { Delta P, H.X. } \\
\text { Delta P, Discharge } \\
\text { Fan Power } \\
\text { Fans }\end{array}$ & $\begin{array}{l}10^{6} 1 \mathrm{bm} / \mathrm{hr} \\
\mathrm{ft} / \mathrm{sec} \\
\mathrm{psi} \\
\text { psi } \\
\text { MN } \\
\text { Number }\end{array}$ & $\begin{array}{l}822 \\
11.4 \\
0.0051 \\
0.0048 \\
8.8 \\
188\end{array}$ & $\begin{array}{l}566 \\
13.4 \\
0.0113 \\
0.0049 \\
10.7 \\
130\end{array}$ & $\begin{array}{l}473 \\
13.8 \\
0.0142 \\
0.0048 \\
10.4 \\
110\end{array}$ & $\begin{array}{l}409 \\
14.2 \\
0.0150 \\
0.0054 \\
9.7 \\
90\end{array}$ & $\begin{array}{l}351 \\
13.5 \\
0.0136 \\
0.0058 \\
8.0 \\
75\end{array}$ \\
\hline \multicolumn{7}{|l|}{ Amon ia Parameters } \\
\hline $\begin{array}{l}\mathrm{NH}_{3} \text { Flow Rate } \\
\text { Delta } \mathrm{P}, \mathrm{NH}_{3} \\
\text { Pump Power }\end{array}$ & $\begin{array}{l}10^{6} \mathrm{Ibm} / \mathrm{hr} \\
\mathrm{psi} \\
\mathrm{MW}\end{array}$ & $\begin{array}{l}9.6 \\
0.701 \\
0.465\end{array}$ & $\begin{array}{l}9.7 \\
1.095 \\
0.381\end{array}$ & $\begin{array}{l}9.8 \\
1.693 \\
0.417\end{array}$ & $\begin{array}{l}10.1 \\
1.485 \\
0.482\end{array}$ & $\begin{array}{l}10.5 \\
1.303 \\
0.700\end{array}$ \\
\hline \multicolumn{7}{|l|}{ Heat Exchanger Design } \\
\hline $\begin{array}{l}\text { Towers } \\
\text { Approximate Tower Diameter } \\
\text { Tower Height } \\
\text { Front al Area } \\
\text { Heat Transfer Area } \\
\text { Tube Length } \\
\text { Tube Rows in Depth }\end{array}$ & $\begin{array}{l}\text { Number } \\
\mathrm{ft} \\
\mathrm{ft} \\
10^{6} \mathrm{ft}^{2} \\
10^{6} \mathrm{ft}^{2} \\
\mathrm{ft} \\
\text { Number }\end{array}$ & $\begin{array}{l}12 \\
203 \\
70.4 \\
0.524 \\
23.5 \\
77.6 \\
3\end{array}$ & $\begin{array}{c}6 \\
239 \\
70.4 \\
0.309 \\
23.1 \\
91.6 \\
5\end{array}$ & $\begin{array}{c}4 \\
277 \\
74.7 \\
0.253 \\
22.7 \\
106.0 \\
6\end{array}$ & $\begin{array}{l}4 \\
242 \\
72.0 \\
0.213 \\
19.1 \\
92.6 \\
6\end{array}$ & $\begin{array}{l}4 \\
222 \\
71.8 \\
0.195 \\
17.4 \\
84.8 \\
6\end{array}$ \\
\hline \multicolumn{7}{|l|}{ Condenser Design } \\
\hline $\begin{array}{l}\text { Heat Transfer Area } \\
\text { TTD }\end{array}$ & $\begin{array}{l}10^{6} \mathrm{ft}^{2} \\
\text { of }\end{array}$ & $\begin{array}{l}0.532 \\
3.24\end{array}$ & $\begin{array}{l}0.413 \\
4.72\end{array}$ & $\begin{array}{l}0.424 \\
4.50\end{array}$ & $\begin{array}{l}0.404 \\
4.84\end{array}$ & $\begin{array}{l}0.379 \\
5.40\end{array}$ \\
\hline \multicolumn{7}{|l|}{ Performance Parameters } \\
\hline $\begin{array}{l}\text { Design TBP } \\
\text { Maximum TBP } \\
\text { Power at Maximum TBP } \\
\text { Maximum Percent Deluge } \\
\text { Maximum Evaporation Rate }\end{array}$ & $\begin{array}{l}\text { in. } H G \\
\text { in. } H G \\
M W \\
\text { gpm }\end{array}$ & $\begin{array}{r}1.22 \\
7.89 \\
888.9 \\
0.0 \\
0.0\end{array}$ & $\begin{array}{c}1.44 \\
4.70 \\
967.8 \\
14.2 \\
5585\end{array}$ & $\begin{array}{c}1.66 \\
4.10 \\
978.3 \\
20.7 \\
6872\end{array}$ & $\begin{array}{l}2.17 \\
3.24 \\
991.5 \\
43.3 \\
9528\end{array}$ & $\begin{array}{c}3.02 \\
3.02 \\
999.9 \\
63.0 \\
10764\end{array}$ \\
\hline \multicolumn{7}{|l|}{ Cost Summary } \\
\hline $\begin{array}{l}\text { Cooling System } \\
\text { Capacity } \\
\text { Steam Supply Scaling } \\
\text { Heat Rate Scaling } \\
\text { Fan and Pump Scaling } \\
\text { Energy } \\
\text { Base Fue } 1 \\
0 \text { and } M \\
\text { Water } \\
\text { Incremental Cost of } \\
\text { Cooling }\end{array}$ & $\begin{array}{l}\text { Mills/kWh } \\
M i l l s / k W h \\
M i l l s / k W h \\
M i l l s / k W h \\
M i l l s / k W h \\
M i l l s / k W h \\
M i l l s / k W h \\
M i l l s / k W h \\
M i l l s / k W h \\
M i l l s / k W h\end{array}$ & $\begin{array}{r}1.75 \\
0.36 \\
0.00 \\
-0.21 \\
0.14 \\
0.19 \\
-0.02 \\
0.10 \\
0.00 \\
2.31\end{array}$ & $\begin{array}{r}1.42 \\
0.11 \\
0.00 \\
-0.21 \\
0.17 \\
0.24 \\
-0.01 \\
0.08 \\
0.00 \\
1.79\end{array}$ & $\begin{array}{r}1.33 \\
0.07 \\
0.00 \\
-0.20 \\
0.17 \\
0.23 \\
-0.01 \\
0.07 \\
0.00 \\
1.65\end{array}$ & $\begin{array}{r}1.17 \\
0.03 \\
0.00 \\
-0.18 \\
0.16 \\
0.14 \\
-0.01 \\
0.06 \\
0.00 \\
1.37\end{array}$ & $\begin{array}{r}1.07 \\
0.00 \\
0.00 \\
-0.08 \\
0.13 \\
0.00 \\
-0.02 \\
0.06 \\
0.00 \\
1.20\end{array}$ \\
\hline
\end{tabular}

The WATA core shows a better dry performance than does the previous design information received from HÖTERV, which explains the lower incremental cost at zero water availability. However, the deluge performance of the WATA core is poorer, which explains the higher incremental costs at higher levels of water availability (see Appendix $F$ for these comparisons). 


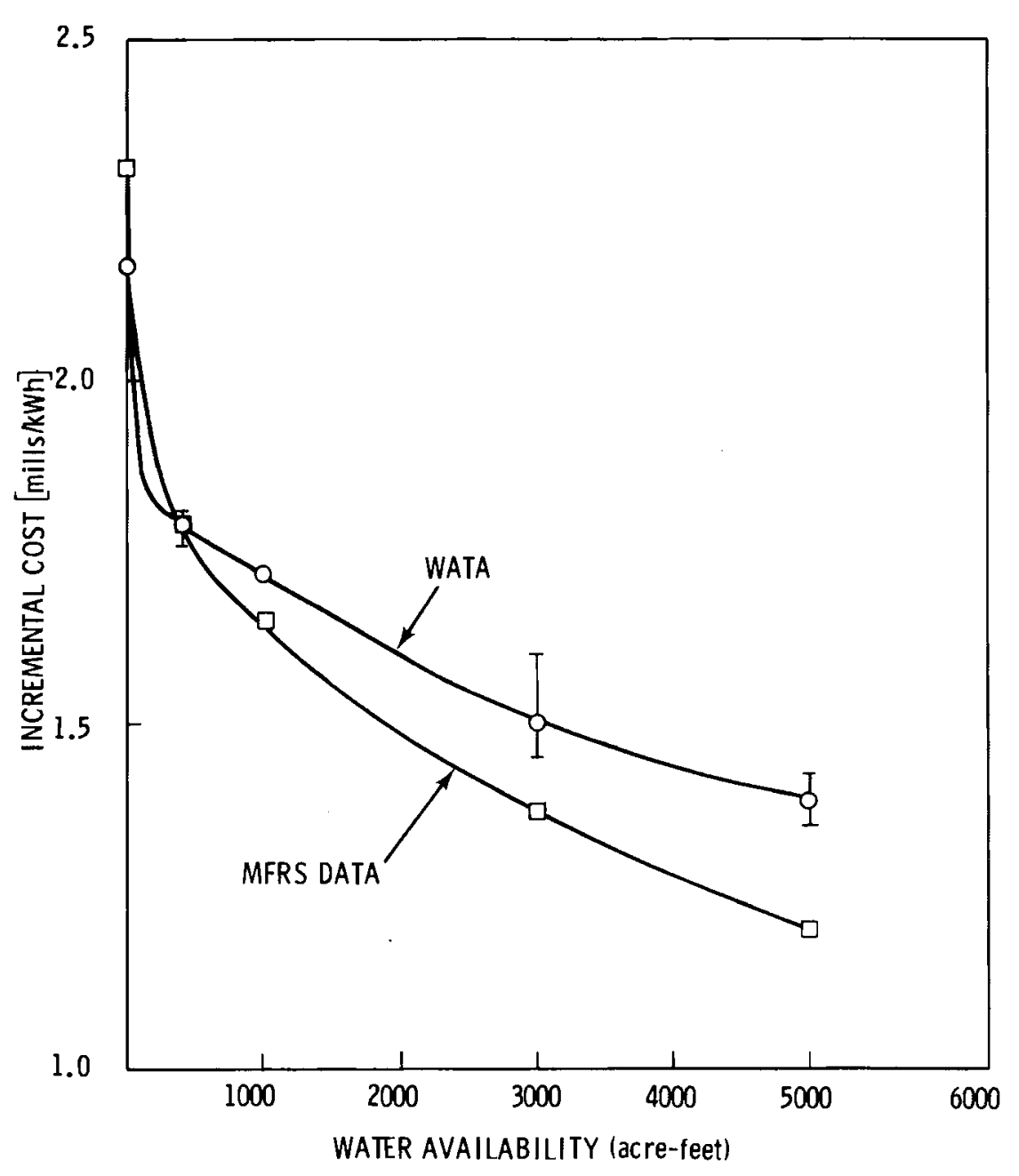

FIGURE 4-24. Incremental Costs for Plants with Heat Exchangers with Performance Predicted from WATA Data and from Manufacturer's Information

The differences in incremental costs can be put into perspective by discussing them as a function of the fraction of an all-wet plant's water requirements. If a utility can allocate $50 \%$ of an all-wet plant's water to a dry/wet plant, the electricity from the dry/wet plant would cost about $0.2 \mathrm{mills} / \mathrm{kWh}$ more and a significant difference is seen between the results from two test data sources. This difference is more than just scatter due to code accuracy. At $30 \%$ of an all-wet power plant's allocation, however, this 
difference is near $0.1 \mathrm{mill} / \mathrm{kWh}$, a difference of borderline significance. The interpolated difference between the results from two test sources is negligible for lower water availabilities except for zero water availability where borderline significance is again observed. To the extent that these differences in heat exchanger core performance are due to random changes, within tolerance, in heat exchanger dimensions they are more a matter of quality control and engineering judgement in selecting adequate safety factors than of differences in heat transfer behavior.

The computer results were examined for trends in design which may have resulted from differences in heat exchanger performance, both wet and dry. This type of analysis is difficult to do because of the large number of tradeoffs exercised by BNW-II. It is important to understand that BNW-II attempts to determine the best system to do the job and that the heat exchanger is only one component of that system. The code considers such things as the size of the gas turbine contingent, size of the condenser/reboiler, and optimal number of towers. A consequence of the many variables that can be adjusted to provide a minimum cost is that the optimum is relatively flat but the discrete nature of the values used in the computations results in a response surface pocked by local optima. As a result, slight changes in stipulated heat exchanger performance may yield quite different, noncomparable "optimal" designs. For example, plants with:

- a larger condenser/reboiler

- a smaller heat exchanger

- a larger gas turbine contingent

- a higher air velocity

may satisfy the optimization criteria and yet show similar incremental costs. Such different variations make heuristic comparison difficult.

Nevertheless, several trends consistent with the differences in dry and wet heat transfer performance were observed. Use of the WATA data gave designs: 
- with higher air velocities in four out of five cases; the fifth case had essentially the same air velocity

- designs with lower pressure drops per row in four out of five cases; the fifth case showed essentially the same pressure drop per row

- with heat exchangers with the same or greater number of rows in the direction of airflow

- in which a larger fraction of the heat exchanger was deluged on the hottest day.

The first three observations are in line with the lower value of friction factor and higher heat transfer coefficients found with the WATA data. A lower friction factor would be expected to permit a higher velocity for a given pressure drop and fan power; a higher heat transfer coefficient would permit the design to optimize at a lower fan power.

The fourth observation, that the percent of the cooling tower deluged on the hottest day was larger for the WATA data, is consistent with the much lower value of deluge mass transfer coefficient observed and with the lower ratio of air velocity during deluge to that of dry operation observed with the WATA core ( 0.5 instead of 0.77 used previously). In essence, poorer deluge performance of the WATA core was compensated for by deluging a greater percent of the heat-exchanger surface. An alternative hypothesis, that the heat exchangers designed by BNW-II with the WATA data have less heat rejection capability, therefore requiring more deluging, is proven false by the fact that the design turbine back pressure (the back pressure at the $33^{\circ} \mathrm{F}$ design temperature, where no deluging occurs) is equal or lower in all cases for the WATA designs. The picture that emerges is one of a better dry exchanger which has its overall performance during deluging degraded by the poor wet performance.

Deluging a larger amount of the surface has a direct cost (deluge piping), which is relatively small, plus a larger cost--that of removing more of the heat exchanger from service on the hottest day. This increases the maximum turbine back pressure in all four of the deluged cases using the WATA data (compare Tables 4-13 and 4-14). Consequently, the size of the gas turbine 
contingent is larger, yielding increased costs for "capacity" and "energy." Indeed, the increases in these two costs account for much of the increased cost of the WATA system at higher water availabilities.

\subsection{SUMMARY}

The WATA data predict a heat exchanger with better dry performance but poorer wet performance. As a result, the incremental costs based on WATA data are (barely significantly) lower for all-dry operation and slightly higher for a system using half of the annual water requirements of an all-wet system than those costs based on Reference 2 data. The cost differentials do not appear to alter the economic feasibility of the ammonia deluged ammonia system from that determined from earlier studies. 


\section{REFERENCES}

1. S. J. Kline and F. A. McClintock, "Describing Uncertainties in Single Sample Experiments," Mechanical Engineering. January 1953, p. 3.

2. B. Cox and P. A. Jallouk, "Methods for Evaluating the Performances of Compact Heat Transfer Surfaces." ASME Paper No. 72-WA/HT-56. 1972. ASME Winter Annual Meeting.

3. R. D. Tokarz et al., Comparative Cost Study of Four Wet/Dry Cooling Concerns That Use Ammonia as the Intermediate Heat Exchange Fluid. PNL-2661, Pacific Northwest Laboratory, Richland, Wash., September 1978.

4. D. K. Kreid, B. M. Johnson, and D. W. Faletti, "Approximate Analys is of Evaporative Heat Transfer from a Finned Surface," PNL-SA-6422, ASME Paper No. 78-HT-26, AIAA/ASME Joint Thermophysics and Heat Transfer Conf., Palo Alto, CA (May 25-26, 1978).

5. W. Kals, "Wet Surface Air Coolers: Characteristics and Usefulness, " ASME Paper No. 72-HT-28, 1972.

6. C. Tasnadi, "Calculation of Heat Transport Combined with Material Transfer by Analogy to Heat Exchanger Dimensioning," Energia Es Atomtechnia, vol. 25 , no. 6, 1972, pp. 252-257.

7. F. Merkel, "Verdunstungskühlung Zeitschrift des Vereines Deutscher Ingen ieure," vol. 70, 1926, pp. 123-128.

8. D. G. Kern, Process Heat Transfer, 1st ed., McGraw-Hi11, New York, 1950, p. 607 .

9. G. Yadigaroglu and E. J. Pastor, "An Investigation of the Accuracy of the Merkel Equation for Evaporative Cooling Tower Calculations," ASME Paper No. 74-HT-59, 1974.

10. K. A. Gardner, "Performance of Circumferential Fins of Circular Cross Section," Trans ASME. vol. 67, pp. 621-631 (1945).

11. "A User's Manual for the BNW-II Optimization Code for Dry/Wet Cooled Power Plants," PNL-2674, vol. 1 (May 1978).

12. W. D. Turner, D. C. Elrod and I. I. Simon-Tov, HEATING5 - an IBM Heat Conduction Program, Oak Ridge National Laboratory, Oak Ridge, TN, March 1977.

13. W. M. Kays and A. L. London, Compact Heat Exchangers, The National Press, Palo Alto, CA, 1955, second ed., McGraw-Hill, New York, 1964. 

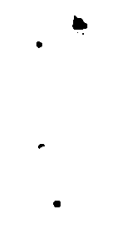
APPENDIX A

DEVELOPMENT OF THE DELUGE MODEL FOR A UNIFORMLY WETTED HEAT EXCHANGER 
APPENDIX A

DEVELOPMENT OF THE DELUGE MODEL FOR A

UNIFORMLY WETTED HEAT EXCHANGER

The following analysis summarizes the development of the deluge theory for uniform wetting. Techniques are developed for computing the overall heat transfer coefficient using surface and overall heat transfer correlations for dry operation. Numerical computations of deluge performance predictions are provided based on a correlation obtained for the HÖTERV plate $f$ in heat exchanger for normal dry operation.

\section{A-1 Derivation of the Enthalpy Driving Potential}

Heat transfer from a dry surface to a flowing air stream is driven by convection and the driving potential for heat transfer is simply the surface-to-air temperature difference. When the surace is wet, the moist air at the surface may be assumed saturated at the surface temperature because the rate of evaporation is diffusion limited (i.e., the random exchange of water molecules between liquid and vapor states occurs infinitely faster than the rate of removal of water molecules from the surface by diffusion). If the surface is warmer than the air in the free stream, a concentration gradient must exist resulting in a net diffusive motion of water vapor away from the surface. The latent heat of vaporization that is required for the liquid/ vapor phase transition is provided by the cooled surface. Therefore, the rate of heat transfer from the surface is governed by the dual driving potentials of temperature and water vapor concentration.

The governing equation for heat transfer from a wet surface can be obtained by a simple mass and energy balance that incorporates the effects of convection and diffusion.

The heat balance will be performed on a control volume of wetted area $d A_{s}$ extending from the metal surface to just beyond the delugeate film (see Figure 4-1). The analys is assumes steady, one-dimensional, incompressible flow. The vertical transport of heat by the delugeate and the energy content 
of the makeup water are neglected. For these conditions the heat flux from the metal into the water dQ may be given as:

$$
\begin{aligned}
d Q & =d Q_{a}+\left(\dot{m}_{w}-\dot{d m}_{v}\right) i_{w}-\dot{m}_{w} \dot{i}_{w}+\dot{d m}_{v} i_{v} \\
& =d Q_{a}+\left(i_{v}-i_{w}\right) \dot{d m}_{v}
\end{aligned}
$$

The convection of sensible heat into the air may be given in terms of the surface heat transfer coefficient $h_{s}$ by

$$
d Q_{a}=h_{s}\left(T_{s}-T_{\infty}\right) d A_{s}
$$

The rate of evaporation at the surface may be given by an analogous form of Fick's law of diffusion,

$$
\dot{d m_{v}}=\sigma_{s}\left(H_{s}^{\prime}-H_{\infty}\right) d A_{s}
$$

where $\sigma_{S}$ is the surface mass transfer coefficient and $H_{\infty}$ is the absolute humidity of the air in $\left(1 b_{v} / 1 b_{a}\right)$. The superscript on $H_{s}$ ' denotes the saturation enthalpy at the surface conditions. The difference in enthalpy of the liquid and vapor phases is the heat of vaporization, denoted $\lambda_{S}=\left(i_{v}-i_{w}\right)$. With these substitutions, Equation (A-2) becomes

$$
\begin{aligned}
d Q & =h_{s}\left(T_{s}-T_{\infty}\right) d A_{s}+\lambda_{s} \sigma_{s}\left(H_{s}^{\prime}-H_{\infty}\right) d A_{s} \\
& =\sigma_{s}\left[C_{a}\left(T_{s}-T_{\infty}\right)\left(\frac{h_{s}}{\sigma_{s} C_{a}}\right)+\lambda_{s}\left(H_{s}^{\prime}-H_{\infty}\right) d A_{s}\right]
\end{aligned}
$$


The dimensionless parameter that appears in the first term of Equation (A-6) is designated the convective or turbulent Lewis number,

$$
L e=\frac{h_{s}}{\sigma_{s} c_{a}}
$$

For air-water vapor processes, it is frequently found that Le is very nearly equal to one. $(8,9)$ In this case, the quantity on the right in Equation (A-6) is very nearly equal to the difference between the moist air enthalpies at the surface and in the free stream. Thus, we may write for Equation (A-6),

$$
d Q \simeq \sigma_{S}\left(i_{S}^{\prime}-i_{\infty}\right) d A_{S}
$$

or, from Equation (A-7) with Le $=1$ we obtain the equivalent result,

$$
d Q \simeq h_{s}\left(\frac{i_{s}-i_{\infty}}{C_{a}}\right) d A_{s}
$$

where $\left(i_{s}{ }^{\prime}-i_{\infty}\right) / C_{a}$ is now a "pseudo temperature" that incorporates the dual driving potentials of temperature and concentration.

There are several approximations inherent in using these results. To estimate the magnitude of the errors involved, the result of Equation (A-6) may be arranged by adding and subtracting equal terms to generate the required enthalpy difference. After considerable manipulation, ${ }^{(1)}$ the result is

$$
\begin{aligned}
\frac{d Q}{d A_{s}} & =\sigma_{s}\left\{\left(i_{s}^{\prime}-i_{\infty}\right)+C_{a}\left(T_{s}-T_{\infty}\right)(L e-1)\right. \\
& \left.-\left[C_{v}\left(\dot{T}-T_{0}\right)+\left(\lambda_{0}-\lambda_{s}\right)\right]\left(H_{s}^{\prime}-H_{\infty}\right)\right\}
\end{aligned}
$$


where $\lambda_{0}$ is the heat of vaporization at the reference condition $T_{0}, C_{v}$ and $C_{a}$ are the specific heats of water vapor and moist air at the film average conditions, and $\bar{T}=1 / 2\left(T_{S}+T_{\infty}\right)$ is the film average temperature.

Expressed as a percentage, the error $\frac{\Delta Q}{Q}$ in using Equation $(A-8)$ may be computed by subtracting Equation $(A-8)$ and $(A-10)$ and then dividing by Equation $(A-9)$. The result may be given as follows: ${ }^{(1)}$

$$
\frac{\Delta Q}{Q} \simeq\left[\frac{C_{a}\left(T_{s}-T_{\infty}\right)}{\left(i_{s}^{\prime}-i_{\infty}\right)}\right]\left\{(L e-1)+\left(H_{s}^{\prime}-H_{\infty}\right)\left[\frac{C_{v}\left(\bar{T}-T_{0}\right)+\left(\lambda_{s}-\lambda_{0}\right)}{C_{a}\left(T_{s}-T_{\infty}\right)}\right]\right\}
$$

The ratio of driving potentials at the surface is denoted by $\Gamma$.

$$
F=\frac{\left(i_{s}^{\prime}-i_{\infty}\right)}{C_{a}\left(T_{s}-T_{\infty}\right)}
$$

Finally, in terms of $\Gamma$, the error due to neglected terms in going from Equation $(A-10)$ to Equation (A-8) may be now given by

$$
\frac{\Delta Q}{Q}=\frac{1}{\Gamma}\left\{(L e-1)+\left(H_{s}^{\prime}-H_{\infty}\right)\left[\frac{C_{v}\left(\bar{T}-T_{0}\right)+\left(\lambda_{s}-\lambda_{0}\right)}{C_{a}\left(T_{s}-T_{\infty}\right)}\right]\right\}
$$

The quantity (Le -1$) / \Gamma$ in Equation $(A-13)$ is the percentage error in Equation $(A-8)$ due to incomplete similarity between the convective and diffusive heat transfer mechanisms. If similarity is complete, Le $\simeq 1$ and this term vanishes. For air/water vapor systems, it is believed ${ }^{(5,6)}$ that Le is in the approximate range $1.2<$ Le $<1.4$.

The second grouping of terms on the right of Equation (A-13) is due to the neglect of a portion of the energy content of the evaporated water. This introduces a dependence on the "arbitrary" reference conditions with respect 
to which all properties are defined. This is because Equation (A-8) is not conservative of the mass of water vapor (i.e., $i_{s}{ }^{\prime}$ and $i_{\infty}$ refer to unit masses of air that contain different quantities of water vapor). The result of Equation (A-6) and its equivalent form, Equation (A-10), are mass conservative and contain no dependence on $T_{0}$. It is only when the terms of Equation (A-10) are neglected to obtain the approximate result of Equation $(A-8)$ that the dependence of the reference state is introduced.

\section{A-2 Extension of the Deluge Model to Overall Heat Transfer Correlations}

The result in Equation (A-9) is expressed in terms of the heat transfer from the surface and, as such, involves only the air-side coefficient $h_{s}$. However, the heat flux is governed by the sum of all the resistances in the heat flow path, including convective resistance on the primary (inside) surface, the conductive resistance of the tube wall and the fins, fouling of either surface, and the resistance of the delugeate film. These heat flow resistances are illustrated schematically in Figure 4-2 for a simple finned heat exchanger.

For a dry heat exchanger with negligible fouling, the sum of the path resistances, in terms of the relevant area ratios, may be given as:

$$
\frac{1}{U_{0}}=\frac{A_{s}}{h_{p} \bar{A}_{p}}+\frac{t A_{s}}{k_{t} A_{\bar{p}}}+\frac{A_{s}}{\left(A_{s t}+n_{f} A_{s f}\right) h_{s}}
$$

where the heat transfer is given by

$$
Q=U_{0} A_{S} \Delta T_{1 m}
$$

The terminology in Equation (A-15) is defined in the Nomenclature and illustrated in Figure 4-2. The fin resistance is given in the usual form through use of a fin efficiency. 
The fin efficiency for a given heat exchanger geometry can usually be given by a function of a dimensionless parameter of the following general form. (10)

$$
\begin{aligned}
n_{f} & =f_{\eta}\left(1_{f} \sqrt{\frac{h_{s}}{k_{f} y_{b}}}\right) \\
& =f_{\eta}\left(B i_{f}^{1 / 2}\right)
\end{aligned}
$$

where the Biot number for the fin is defined by

$$
B i_{f}=\frac{1_{f}^{2} h_{s}}{k_{f} y_{b}}
$$

Solutions for $n_{f}$ are normally given in graphical form (see Figure $4-3^{(7)}$ ) since analytical solutions are impractical for complex heat exchanger geometries. The variable parameter on the graphs would normally be a geometrical function, such as the ratio of inner and outer radii in Figure 4-3.

For deluge heat transfer where the entire surface is assumed to be wet, the overall resistance to heat flow is again simply the sum of the path resistances. In this case, however, it is necessary to add an additional resistance for the delugeate film. In addition, it is necessary to modify all of the resistances in the path leading up to the surface to compensate for the switch from temperature to enthalpy as the driving potential.

The enthalpy transformation that is required for the resistances may be derived quite simply by considering the definition of the thermal resistance. In the normal formulation, the resistance is the ratio of the temperature drop (the driving potential) to the heat flux, 


$$
R_{j}=\frac{\Delta T_{j}}{Q}
$$

where the same heat flux, Q, flows through all resistances in the series path. This equation may be converted to enthalpy potential by multiplying and dividing by $\left(\Delta i_{j} / C_{a}\right)$

$$
\begin{aligned}
Q & =\frac{\Delta T_{j}}{R_{j}} \cdot \frac{\left(\Delta i_{j} / C_{a}\right)}{\left(\Delta i_{j} / C_{a}\right)} \\
& =\frac{\left(\Delta i_{j} / C_{a}\right)}{R_{j}\left(\Delta i_{j} / C_{a} \Delta T_{j}\right)} \\
& =\frac{\left(\Delta i_{j} / C_{a}\right)}{\xi_{j} R_{j}}
\end{aligned}
$$

Thus, the resistance that must be used with the enthalpy driving potential formulation is $\xi_{j} R_{j}$, where the enthalpy transformation parameter $\xi_{j}$ is defined by

$$
\xi_{j}=\frac{\Delta i_{j}}{C_{a} \Delta T_{j}}=\frac{\left(i_{2}-i_{j}\right)_{j}}{C_{a}\left(T_{2}-T_{1}\right)_{j}}
$$

The transformation parameter $\xi$ is a fundamental parameter in the implementation of the deluge heat transfer model. Unfortunately, in practice, $\xi$ is difficult to evaluate precisely since the conditions at the intermediate surfaces will seldom, if ever, be known. Thus, an approximation for $\xi$ is defined that uses the overall conditions across the heat exchanger, 


$$
\xi \simeq \frac{\left(i_{p}^{\prime}-i_{\infty}^{\prime}\right)}{C_{a}\left(T_{p}-T_{\infty}\right)}
$$

where $i_{\infty}$ ' is the saturated air enthalpy in the free stream and $i_{p}$ ' is the saturated enthalpy of moist air evaluated at the primary fluid temperature $T_{p}$. To evaluate $\xi$, the fluid properties should be evaluated at the average conditions on the primary fluid and air sides, respectively.

There is a rather simple interpretation for $\xi$. From Figure 4-4 it can be seen that $\xi$ is $1 / C_{a}$ times the average slope of the saturation line on an enthalpy-temperature diagram for moist air. Note that the slope of the saturation line increases with increasing temperature as illustrated by Figures 4-4 and 4-5. This effect can be important in computing the thermal resistances and the ultimate heat transfer enhancement due to deluge.

With the above transformation the series resistance of the wetted heat exchanger can now be given by direct analogy to Equation (A-14). The result is

$$
\frac{1}{U_{0}^{\star}}=\frac{\xi A_{s}}{h_{p} A_{p}}=\frac{\xi t_{s} A_{s}}{k_{t} A_{\bar{p}}^{A}}+\left(\frac{A_{s}}{A_{s t}+\eta_{f}{ }^{\star} A_{s f}}\right)\left(\frac{1}{h_{s}}+\frac{\xi}{h_{d}}\right)
$$

where $h_{d}$ is the convection coefficient in the delugeate film. With a slight rearrangement Equation $(A-25)$ can be given in a more convenient form as:

$$
\frac{1}{\xi U_{0}^{\star}}=\frac{A_{s}}{h_{p} A_{p}}+\frac{t A_{s}}{k_{t} A_{\bar{p}}}+\left(\frac{A_{s}}{A_{s t}+\eta_{f}^{\star} A_{s f}}\right)\left(\frac{1+B i}{h^{\prime}}\right)
$$

where the Biot number in the delugeate film is defined by

$$
B i_{d}=\frac{\xi h_{s}}{h_{d}}=\frac{\text { resistance of delugeate film }}{\text { resistance of the surface }}
$$


The fin efficiency for a uniformly wetted heat exchanger, $\eta_{f}{ }^{*}$, can also be obtained by analogy, using the result for $n_{f}$ for dry heat transfer from the same surface. To do so, it is only necessary to use a value for the effective surface heat transfer coefficient, which accounts for resistance of the film and enhancement due to evaporation. In this case, the effective surface heat transfer coefficient is given by

$$
\begin{aligned}
h_{e}^{\star} & =\left(\frac{1}{\xi h_{s}}+\frac{1}{h_{d}}\right)^{-1} \\
& =\frac{\xi h_{s}}{1+B i_{d}}
\end{aligned}
$$

such that $\eta_{f}$ * may be given by

$$
\eta_{f}^{\star}=f_{\eta}\left(B i_{f}^{\star 1 / 2}\right)
$$

where the Biot number for the wet surface is given by

$$
\left(B i_{f}^{*}\right)^{2}=\frac{1_{f}^{2} h_{e}}{k_{f} y_{b}}
$$

The function $f_{\eta}$ is the same for both dry and wet heat transfer from a given surface.

The result expressed by Equation (A-26) for deluge heat transfer is identical with Equation (A-14) for dry heat transfer if the following substitutions are made: 


$$
\begin{aligned}
& \xi U_{0}^{\star} \text { for } U_{0} \\
& h_{e}^{\star} \text { for } h_{s} \\
& n_{f}^{\star} \text { for } n_{f}
\end{aligned}
$$

where as noted, $n_{f}{ }^{*}$ and $\eta_{f}$ are computed with the same function. The significance of these results is that a graph or equation of $U_{0} v s h_{s}$ can be prepared from dry heat transfer data that will also represent overall wet heat transfer performance by use of the simple substitutions given above. The use of this result is illustrated in Section 4.1 and in Figure 4-12.

\section{A-3 Application to Alternative Heat Exchanger Formulations}

The overall heat transfer coefficient, $U_{0}$, can be used to compute the performance of a heat exchanger using either of two fundamentally different formulations. These are

- the log mean temperature difference (LMTD) formulation, and

- the NTU-effectiveness approach.

Both of these techniques are based on the same differential equations and boundary equations and ultimately yield the same theoretical results. However, the mechanics of applying these techniques to prediction of heat exchanger performance differ substantially.

In the LMTD approach, the heat transfer is given by

$$
Q=F U_{0} A_{s} \Delta T 1 m
$$

where the LMTD is given by

$$
\Delta T_{1 m} \simeq \frac{\left(T_{p}-T_{\infty}\right)_{1}-\left(T_{p}-T_{\infty}\right)_{2}}{\ln \left|\frac{\left(T_{p}-T_{\infty}\right)}{\left(T_{p}-T_{\infty}\right)_{2}}\right|}
$$


State points "1" and "2" indicate the inlet and outlet conditions for a counterflow geometry. The cross flow correction $F$ is typically very close to one and will subsequently be neglected.

For a deluged heat exchanger, the analogous equation for $Q$ is given in terms of a log mean enthalpy difference (LMED)

$$
Q=F * U_{0}^{\star} A s\left(\frac{\Delta i}{C_{a}}\right)
$$

where the LMED is defined by

$$
{ }^{\Delta i_{1 m}}=\frac{\left(i_{p}^{1}-i_{\infty}\right)-\left(i_{p}^{\prime}-i_{\infty}\right)_{2}}{\ln \left|\frac{\left(i_{p}^{1}-i_{\infty}\right)_{1}}{\left(i_{p}^{1}-i_{\infty}\right)_{2}}\right|}
$$

In this case, $i_{p}$ ' is the enthalpy of saturated air evaluated at the tubeside temperature and $i_{\infty}$ is the actual enthalpy of the air. Variation of $c_{a}$ has been neglected and $F^{*}$ is assumed equal to one.

In the NTU-effectiveness formulation, the heat transfer for dry operation is given by $(13)$

$$
Q=\phi_{\phi}(\dot{m} c)_{\min }\left(T_{p 1}-T_{\infty 1}\right)
$$

where the effectiveness $\phi$ is defined by

$$
\phi=\frac{(\dot{m} c)_{a i r}\left(T_{\infty 2}-T_{\infty 1}\right)}{(\dot{m c})_{\min }\left(T_{p 1}-T_{\infty 1}\right)}
$$


For the air-cooled system, air has the minimum capacity; thus

$$
\phi=\frac{T_{\infty 2}-T_{\infty 1}}{T_{p 1}-T_{\infty 1}}=\frac{\text { Air Range }}{\text { ITD }}
$$

The ITD is the inlet temperature difference and the range is the temperature rise in the air from inlet to outlet.

For a given heat exchanger, the effectiveness, $\phi$, can be given by an equation or a graph of the form

$$
\phi=f_{\phi}(R, N)
$$

where the capacity ratio is defined by

$$
R=\frac{(\dot{m} c)_{\min }}{(\dot{m} c)_{\max }}=\frac{m_{a} c_{a}}{m_{p} c_{p}}=\frac{T_{p l}-T_{p 2}}{T_{\infty 2}-T_{\infty 1}}
$$

Thus, $R$ is also the ratio of the fluid stream temperature ranges.

The NTU rating of the heat exchanger, $N$, is defined by

$$
N=\frac{U_{0} A_{S}}{m_{a} C_{a}}
$$

$N$ is a measure of the "size" of the heat exchanger system.

Many different types of heat exchangers have been analyzed by this approach and solutions for $\phi$ in analytical or graphical form are available from numerous sources. (13) For the WATA experiments with the HÖTERV core, the heat exchanger may best be described as a single-pass, plate fin design with 
the air and water in cross flow and with essentially isothermal conditions on the primary side. For these conditions, the heat exchanger may be modeled as a condenser in cross flow for which may be given as follows:

$$
\phi=1-e^{-N}
$$

where the effect of the capacity ratio, R, vanishes. This result is used for interpretation of the WATA data for the HÖTERV core for both dry and wet heat transfer.

For deluge heat transfer, the analogous equation for $Q$ in the NTU form is given by

$$
Q=\phi *(\dot{m} c)_{\min }\left(\frac{i_{p l}^{\prime}-i_{\infty l}}{C_{a}}\right)
$$

where the wet effectiveness, $\phi^{*}$, is defined by

$$
\phi^{*}=\frac{i_{\infty 2}-i_{\infty 1}}{i_{p 1}^{\prime}-i_{\infty 1}}=\frac{\text { Air Range }}{\text { IED }}
$$

where variations in $C_{a}$ have been neglected. Air again has the minimum capacity such that $Q$ may be given by

$$
Q=\phi * \dot{m}_{a}\left(i_{p 1}^{\prime}-i_{\infty 1}\right)
$$

By analogy, the solutions for $\phi^{*}$ may be given in the same form as $\phi$, 


$$
\phi \star=f_{\phi}\left(R^{\star}, N^{\star}\right)
$$

where $f_{\phi}$ is the same function as was used for dry heat transfer if $R^{\star}$ and $N^{\star}$ are properly defined for the deluge conditions.

The definitions of $R$ for dry heat transfer from Equation (A-43) shows that $R$ is equal to the ratio of the primary range to the air range. For wet heat transfer, using the latter result, we obtain for $R^{*}$

$$
R *=\frac{\left(i_{p 1}^{1}-i_{p 2}^{\prime}\right)}{\left(1_{\infty 2}-i_{\infty 1}\right)}=\frac{\dot{m}_{a}}{\dot{m}_{p}^{*}}
$$

where the ratio of ranges here employs the enthalpy driving potentials. The quantity $\dot{\mathrm{m}}_{\mathrm{a}}{ }^{*}$ is the actual mass flow rate of air through the heat exchanger. However, $\dot{m}_{p}{ }^{*}$ is the equivalent flow rate of saturated air that is required to absorb the system heat load. Thus, $\dot{\mathrm{m}}_{\mathrm{p}}{ }^{*}$ is given by

$$
\begin{aligned}
C_{p} \dot{m}_{p}\left(T_{p 1}\right. & \left.=T_{p 2}\right)=\dot{m}_{p}^{*}\left(i_{p 1}^{\prime}-i_{p 2}^{\prime}\right) \\
\dot{m}_{p}^{*} & =\dot{m}_{p} \frac{c_{p}}{C_{a}}\left[\frac{C_{a}\left(T_{p l}-T_{p 2}\right)}{\left(i_{p 1}^{\prime}-i_{p 2}^{\prime}\right)}\right] \simeq \frac{\dot{m}_{p} c_{p}}{\xi C_{a}}
\end{aligned}
$$

Where the latter result follows from the following approximation,

$$
\frac{c_{a}\left(T_{p 1}-T_{p 2}\right)}{\left(i_{p 1}^{\prime}-i_{p 2}^{\prime}\right)} \simeq \frac{C_{a}\left(T_{p}-T_{\infty}\right)}{\left(i_{p}^{\prime}-i_{\infty}^{\prime}\right)}=\frac{1}{\xi}
$$

$R^{*}$ can then be given by

$$
R^{*}=\frac{\dot{\mathrm{m}}_{a}}{\left(\frac{\dot{\mathrm{m}}_{\mathrm{p}} C_{p}}{\xi C_{a}}\right)}=\frac{\dot{\mathrm{m}}_{\mathrm{a}} C_{a}}{\dot{\mathrm{m}}_{\mathrm{p}} \mathrm{C}_{\mathrm{p}}}
$$


The transformation of $N^{\star}$ is accomplished by simply substituting $U_{0}^{*}$ for $U_{0}$

$$
N *=\frac{U_{0}^{\star} A s}{\dot{m}_{a} C_{a}}
$$

For the special case of a condenser in cross flow, $\phi^{*}$ may be given by

$$
\phi \star=1-e^{-N \star}
$$

where the effect of $R^{\star}$ again cancels out, just as it did for dry heat transfer with the same geometry.

A-4 Example Calculations for Table 4-4, Computation of $U_{0}$ Versus $h_{S}$ (or $U_{0}^{*}$ Versus $h_{e}^{*}$ ) for the HÖTERV Core

The data relevant to the WATA measurements for the HÖTERV core are summarized in Table 4-1. An example calculation will be done for $h_{s}=10$ (Btu/ $\mathrm{ft}^{2} \mathrm{hr}^{\circ} \mathrm{F}$ ). Other values in the table are computed in a similar fashion. The results are tabulated in Table 4-3 and plotted in Figure 4-11. The computations are:

$$
\begin{aligned}
& { }^{B 1 / 2} f=\left[\frac{1^{2} f_{s}^{h_{s}}}{k_{f} y_{b}}\right]=\left[\frac{(.07169-.03035)^{2}(10)}{111(.000542)}\right]^{1 / 2}=\underline{.533} \\
& \frac{r_{3}}{r_{2}}=\frac{r_{e}}{r_{b}}=\frac{.07169}{.03035}=\underline{2.362}
\end{aligned}
$$

From Figure 4-3,

$$
\left.\begin{array}{l}
B_{f}^{1 / 2}=.533 \\
\frac{r_{e}}{r_{b}}=2.362
\end{array}\right\} \rightarrow n_{f} \simeq \underline{0.86}
$$




$$
\begin{aligned}
a_{s} & =\frac{A_{s t}+\eta_{f} A_{s f}}{A_{s t}+A_{s f}}=\frac{56.9+.86(942.3)}{999.2}=\frac{.868}{n_{s}} \\
U_{0} & =\left[\frac{1}{h_{p} a_{p}}+\frac{1}{k_{t} a_{\vec{p}}}+\frac{1}{h_{s} a_{s}}\right]^{-1} \\
& =\left[\frac{1}{625(.0592)}+\frac{.00246}{111(.0618)}+\frac{1}{10(.868)}\right]^{-1}=7.01\left(\frac{\mathrm{Btu}}{\mathrm{ft}^{2} \mathrm{hr}^{\circ} \mathrm{F}}\right)
\end{aligned}
$$

\section{A-5 Example Calculations for Table 4-5, Computation of Overall Heat}

\section{Transfer Coefficients}

The data are again as in Table 4-1. An example calculation will be provided for the last line in the table at $\xi=6$. The data in columns 2 through 7 are for the dry surface performance against which the computation of heat transfer enhancement is made. For this data set, we assume that the air flowrate in the wet core is half that in the dry core; $\beta=0.5$. The computations are done as follows,

$$
\text { Re } \simeq 1800 \text { corresponds to } \dot{\mathrm{m}}_{\mathrm{a}} \simeq 36,500 \mathrm{lb} / \mathrm{hr} \text { and } \mathrm{V}_{\infty} \simeq 12 \mathrm{ft} / \mathrm{sec}
$$

for average conditions in the experiment. From Figures 4-11 and 4-12 at $\operatorname{Re}=(800)$

$$
h_{s} \simeq 13.6 \frac{B t u}{f t^{2} h r^{\circ} \mathrm{F}}
$$




$$
U_{0} \simeq 8.7\left(\frac{B t u}{f t^{2} h r^{\circ} F}\right)
$$

From Equation (A-43),

$$
N=\frac{U_{0} A_{s}}{\dot{m}_{a} C_{a}}=\frac{8.7(999.2)}{36.500(.26)}=.916
$$

From Equation (A-45),

$$
\phi=1-\mathrm{e}^{-\mathrm{N}}=1-\mathrm{e}^{-.916}=\underline{.600}
$$

for $\beta=0.5, \operatorname{Re}_{\infty}{ }^{*}=900 ; V \approx 6 \mathrm{ft} / \mathrm{sec}, \mathrm{m}_{\mathrm{a}}{ }^{*} \simeq 18,300 \mathrm{lb} / \mathrm{hr}$. At $\operatorname{Re}_{\infty}{ }^{*} \simeq 900$ we obtain

$$
h_{s}=10.3\left(\frac{B t u}{f t^{2} h r^{\circ} \mathrm{F}}\right)
$$

with $h_{d}=30\left(B t u / f t^{2} h r^{0} F\right), \xi=6$, we obtain

$$
\begin{aligned}
& B i_{d}=\frac{\xi h_{s}}{h_{d}}=\frac{6(10.3)}{30}=2.06 \\
& h_{e}^{*}=\frac{\xi h_{s}}{1+B i_{d}}=\frac{6(10.3)}{1+206}=20.2\left(\frac{B t u}{f t^{2} h r^{\circ} F}\right)
\end{aligned}
$$

then, from Figure $4-12$ at $h_{e}^{*}=20.2$,

$$
U_{0}^{*}=1.83\left(\frac{B t u}{f t^{2} h r^{\circ} F}\right)
$$


(Note that an alternative to use of Figures $4-11$ and $4-12$ is to use the equations from which the figures were computed).

Then from Equation (A-55)

$$
N^{*}=\frac{U_{0}^{*} A S}{\dot{m}_{a}^{*} C}=\frac{1.83(999.2)}{18,300(.26)}=\underline{.385}
$$

From Equation $(A-56)$

$$
\phi *=1-e^{-N *}=1-e^{-.385}=\underline{.320}
$$

The ratio of effectivenesses is then

$$
\beta \frac{\phi \star}{\phi}=.5 \frac{.320}{.600}=.266
$$

The other entries in the table are computed in an analogous manner.

A-6 Example Computations for Table 4-6, $\Gamma$ and $\xi$ for Varying Inlet Conditions

These computations are all relevant for a core temperature of $T_{p}=$ $120^{\circ} \mathrm{F}$. The first two columns are the ITD and air side temperature. The humidity $H_{\infty}$ and the enthalpies $i_{p}{ }^{\prime}, i_{\infty}{ }^{\prime}$ and $i_{\infty}$ come from air psychometric tables. $C_{a}$ is the moist specific heat, computed for each assumed condition. For the second line in the table, $\Gamma$ and $\xi$ are computed as follows:

$$
\Gamma=\frac{i_{p}^{\prime}-i_{\infty}}{C_{a}\left(T_{p}-T_{\infty}\right)}=\frac{119.54-64.0}{.263(120-115)}=\underline{42.24}
$$




$$
\xi=\frac{i_{p}^{\prime}-i_{\infty}^{\prime}}{C_{a}\left(t_{p}-T_{\infty}\right)}=\frac{119.54-104.98}{.271(120-115)}=10.73
$$

The other values in the table are computed in an analogous manner.

A-7 Example Computations for Tables 4-7, and 4-8 Computation of the Heat Transfer Enhancement Ratio

This table combines Table 4-5 and 4-6 to compute the enhancement ratio $Q \star / Q$ for varying operating conditions. The computations for the second 1 ine and last column in Table 4-7 are as follows:

From Table 4-5, at $h_{d}=15, \beta=0.5, \operatorname{Re}=450$; we obtain;

$$
\beta \frac{\phi^{*}}{\phi}=\underline{.178}
$$

From Table 4-7 at ITD $=5^{\circ} \mathrm{F}, \omega_{\infty}=0.5$, we obtain;

$$
\Gamma=\underline{42.24}
$$

The enhancement ratio for this case is then

$$
\frac{Q^{*}}{Q}=\beta_{\phi}^{\phi^{*}} \Gamma=.178(42.24)=\underline{7.52}
$$

The computations in Table 4-8 are done in exactly the same manner. 


\section{A-8 Example Calculations for Table 4-11 Computation of Heat Transfer Terms}

\section{for the WATA Experimental Conditions}

This table was evaluated very much like Tables 4-5 through 4-8 except it was done for the specific conditions used in the WATA experiments. The computations of the data in the second row at $\mathrm{Re}^{\star}=450$ will be given here for illustration.

$\Gamma$ and $\xi$ are computed from the operating conditions as follows; at $T_{p}=$ $125^{\circ} \mathrm{F}, \mathrm{T}_{\infty}=105^{\circ} \mathrm{F}, \mathrm{T}_{\mathrm{a} 1}=55^{\circ} \mathrm{F}$,

$$
\begin{aligned}
& \Gamma=\frac{i_{p}^{\prime}-i_{\infty}}{C_{a}\left(T_{p}-T_{\infty}\right)} \frac{(136.4-35.5)}{.254(125-105)}=19.86 \\
& \xi=\frac{i_{p}^{\prime}-i_{\infty}^{\prime}}{C_{a}\left(T_{p}-T_{\infty}\right)}=\frac{(136.4-81.34)}{.254(125-105)}=10.84
\end{aligned}
$$

The dry surface heat transfer coefficient at $\operatorname{Re}=450$ is $h_{s} \simeq 8.5$ $B t u / h r f t^{20} F$ from Figure 4-11. The average value for the deluge coefficient is $h_{d} \simeq 15 \mathrm{Btu} \mathrm{ft}^{2} \mathrm{hr}^{0} \mathrm{~F}$ at $\mathrm{Re}^{\star}=450$ as computed from the data in Figure 3-13.

The effective heat transfer coefficient $h_{e}{ }^{*}$ is then computed from Equation 4-22.

$$
h_{e}^{*}=\frac{\xi h_{s}}{1+B i_{d}}=\frac{10.8(8.5)}{1+\frac{10.8(8.5)}{15}}=12.9\left(\frac{B t u}{f t^{2} h^{\circ}{ }^{\circ}}\right)
$$


The Biot number for the wet fin is

$$
\begin{aligned}
& \left(B i_{f}^{*}\right)^{1 / 2}=\left[\frac{1_{f}^{2} h_{e}^{*}}{k y_{b}}\right]^{1 / 2}=\left[\frac{(.07169-.03035)^{2}(12.9)}{111\left(\frac{.001083}{2}\right)}\right]^{1 / 2}=\underline{.606} \\
& \frac{r_{e}}{r_{b}}=\frac{.07169}{.03035}=\underline{2.362}
\end{aligned}
$$

From Figure $4-3, n_{f}$ * is,

$$
\begin{aligned}
& \eta_{f}^{\star} \simeq \underline{0.83} \\
& a_{s}^{\star}=\left(A_{s t}+\eta_{f}^{*} A_{s f}\right) / A_{s}=[56.9+.83(9.42 .3)] / 999.2=\underline{0.840}
\end{aligned}
$$

The overall heat transfer coefficient is then computed as:

$$
\begin{aligned}
U_{0}^{*} & =\frac{1}{\xi}\left\{\frac{1}{U_{p r}}+\frac{1}{h_{e}^{*} \mathrm{a}_{\mathrm{s}}}\right\}^{-1}=\frac{1}{10.8}\left\{.0274+\frac{1}{12.9(.84)}\right\}^{-1} \\
& =\underline{0.774}\left(\frac{\mathrm{Btu}}{\mathrm{ft}^{2} \mathrm{hr}^{\circ} \mathrm{F}}\right)
\end{aligned}
$$

Note that $\eta_{f}{ }^{*}$ and $U_{o}{ }^{*}$ could have been determined from Figure 4-12 with the same results.

The apparent heat transfer coefficient $h_{s}{ }^{\prime}$ can now be computed from Equation (5-46),

$$
\begin{aligned}
& h_{s}^{\prime}=\frac{h_{s} a_{s}^{*}}{1+B i_{d}}=\frac{8.5(.84)}{1+\frac{10.8(8.5)}{15}}=1.00\left(\frac{B t u}{f t^{2} h r^{\circ} F}\right) \\
& \varepsilon=\frac{h_{s}^{\prime}}{h_{s}}=\frac{1.00}{8.5}=.118
\end{aligned}
$$


The second apparent heat transfer coefficient $h_{s}{ }^{*}$ can now be computed from Equation (5-50),

$$
\begin{aligned}
& h_{S}^{*}=h_{s} a_{S}^{*}=8.5(.84)=7.14\left(\frac{B t u}{{f t^{2} h r^{\circ} \mathrm{F}}^{2}}\right) \\
& \varepsilon=\frac{h_{S}^{*}}{h_{s}}=a_{s}^{*}=\underline{0.84}
\end{aligned}
$$

The factor $\beta \frac{\phi^{\star}}{\phi}$ can be determined from Figure $4-5$ at $\xi=10.9, \operatorname{Re}_{\infty}{ }^{*}=450$, $\beta=0.5$ and $h_{d}=15$,

$$
\beta \frac{\phi \star}{\phi}=\underline{0.175}
$$

The heat transfer enhancement is then computed from

$$
\frac{Q^{\star}}{Q}=\Gamma \beta \frac{\phi^{\star}}{\phi}=(19.6)(.175)=\underline{3.43}
$$

The computations for all other values in the table are done in the same manner as outlined above. 
APPENDIX B

DEVELOPMENT OF THE DELUGE MODEL FOR NONUNIFORM WETTING 
APPENDIX B

DEVELOPMENT OF THE DELUGE MODEL FOR NONUNIFORM WETTING

\section{B-1 Analysis}

The analysis in Section 4.1.1 illustrates how the effective surface heat transfer coefficient, $h_{s}{ }^{\prime}$, is extracted from the measured value of $U_{0}{ }^{*}$ (see Equation 4-43). To nondimensionalize these results and to further facilitate correlation of data for different operating conditions, a surface effectiveness is defined by $\varepsilon=h_{s}{ }^{\prime} / h_{s}$. The heat flux at the surface can then be given by

$$
Q_{s}=\varepsilon h_{s} A_{s}\left(\frac{i_{r}{ }^{\prime}-i_{\infty}}{c_{s}}\right)
$$

where $i_{r}$ ' is the air saturated enthalpy at the fin root (tube surface) temperature and $A_{s}$ is the total air-side. surface area. An attempt will now be made to predict $\varepsilon$ for comparison with the data.

The effects of nonuniform distributions of surface wetness and temperature and the effect of the delugeate film thermal resistance are inseparably lumped into the parameter $\varepsilon$. Prediction of $\varepsilon$ requires that the distribution of wetness and the delugeate film coefficient, $h_{d}$, must be specified at all points on the heat exchanger surface. For a typical heat exchanger geometry and water distribution, numerical solution is required. In practice, unfortunately, neither the distribution of water nor the local surface film resistance can be measured or predicted with any degree of confidence.

As a consequence of the above considerations, an approximate technique for computing $\varepsilon$ has been derived. The HÖTERV surface is modeled by an annular fin of equivalent area since this technique was found to be adequate for 
predicting fin efficiency. Extending this result, the wetness distribution on the fins is also assumed annular with the wet area extending from the fin root at $r_{2}$ to an intermediate radius $r_{3}$ as illustrated by Figure 4-10. (The alternative configuration where the inner annulus is dry and the outer annulus is wet was also considered briefly.) The predicted results for $\varepsilon$, based on these simple models, will be compared with a limited number of numerical computations for the same geometry and with results computed from the experiments.

The rate of heat transfer from the partially wetted finned tube will be computed as the sum of the heat fluxes from four distinct regions on the surface,

$$
Q_{s}=Q_{1}+Q_{2}+Q_{3}+Q_{4}
$$

Here $Q_{1}$ and $Q_{2}$ denote heat fluxes from the dry and wet areas of the tubes and $Q_{3}$ and $Q_{4}$ denote heat fluxes from the wet and dry areas of the $f$ in, respectively. Each of these will be computed separately and then summed. The resulting equation for $Q_{S}$ will then be reduced to yield an expression for $\varepsilon$.

The heat transfer from the dry portion of the tube may be given by a surface integral,

$$
\begin{aligned}
Q_{1} & =\int_{A_{1}} h_{s}\left(T_{s}-T_{\infty}\right) d A \\
& \simeq h_{s}\left(T_{r}-T_{\infty}\right)\left(1-\alpha_{t}\right) A_{s t}
\end{aligned}
$$

This is obtained by assuming that the dry area of the tube is uniformly at the "root" temperature, $T_{r}$, and that the fraction of the tube wetted is given by $\alpha_{t}$. We convert this result to an enthalpy driving potential as in Equation B-1 by use of an enthalpy/temperature potential ratio 


$$
\Gamma_{r}=\frac{\left(i_{r}^{\prime}-i_{\infty}\right)}{C_{a}\left(T_{r}-T_{\infty}\right)}
$$

The heat flux from the dry tube surface can then be given by

$$
Q_{1}=\frac{h_{s}}{\Gamma_{r}} A_{s t}\left(1-\alpha_{t}\right)\left(\frac{i_{r}{ }^{\prime}-i_{\infty}}{c_{a}}\right)
$$

An interpretation of $\Gamma_{r}$ and the relative contribution of this turn to the overall rate of heat transfer are discussed at the conclusion of this section.

The heat flux from the wet portion of the tube, $Q_{2}$, may be given directly, by the deluge model. In this case, the surface thermal resistance is the sum of the delugeate resistance $\frac{\xi}{h_{g}}$ and the air-water surface resistance $\frac{1}{h_{s}}$. The heat flux is then given by a surface integral

$$
\begin{aligned}
Q_{2} & =\int_{A_{2}} \frac{1}{\left(\frac{1}{h_{s}}+\frac{\xi}{h_{d}}\right)}\left(\frac{i_{s}^{\prime}-i_{\infty}}{c_{a}}\right) d A \\
& =\frac{h_{s} A_{s t} \alpha_{t}}{\left(1+\frac{\xi h_{s}}{h_{d}}\right)}\left(\frac{i_{2}-i_{\infty}}{c_{a}}\right)
\end{aligned}
$$

where $B i_{d}=\frac{\xi h_{s}}{h_{d}}$ is the Biot number in the delugeate film. 
In the latter result it is assumed that the wet portion of the tube surface is uniformly at a temperature $T_{2}$ and that the thermal resistance of the surface is constant. We introduce a correction factor to express Equation B-8 in terms of the fin root condition $i_{r}$ ',

$$
\begin{aligned}
\delta_{2} & =\left(\frac{i_{2}{ }^{\prime}-i_{\infty}}{i_{r}-i_{\infty}}\right) \\
& \simeq\left(\frac{T_{2}-T_{\infty}}{T_{r}-T_{\infty}}\right) \approx 1
\end{aligned}
$$

where variations in $\xi$ and $C_{a}$ are neglected. Equation $B-8$ may then be expressed in the required form,

$$
Q_{2} \simeq \frac{h_{s} A_{s t} t_{t} \delta_{2}}{\left(1+B i_{d}\right)}\left(\frac{i_{r}{ }^{\prime}-i_{\infty}}{c_{a}}\right)
$$

The parameter $\delta_{2}$ is a measure of the temperature depression on the wet surface of the tube (relative to the temperature of the dry tube) due to enhanced heat transfer created by evaporation. In most cases, the thermal resistance of the tube wall will be sufficiently low that the tube may be assumed isothermal such that $\delta_{2} \approx 1$. This approximation will be adopted from this point on in the analysis. The validity of this and other similar approximations used in the analysis are examined at. the conclusion of this discussion.

For the annular fin model with the inner annulus wet, the heat transfer from the wet surface can be given by the surface integral,

$$
Q_{3}=\int_{A_{3}} \frac{1}{\left(\frac{1}{h_{s}}+\frac{\xi}{h_{d}}\right)}\left(\frac{i_{s}{ }^{\prime}-i_{\infty}}{c_{a}}\right) d A
$$


In this case, the thermal resistances are again assumed constant, but $i_{s}$ ' must be treated as a variable. We proceed by defining a fin efficiency analogous to that for a dry fin,

$$
n_{f} *=\frac{1}{A_{3}} \int_{A_{3}}\left(\frac{i_{s}^{\prime}-i_{\infty}}{i_{3}^{\prime}-i_{\infty}}\right) d A
$$

where $i_{3}$ ' is the enthalpy at the true fin root temperature $T_{3}$ and $A_{3}=$ $\alpha_{f} A_{s f}$ is the wet portion of the fin surface. Equation B-12 may now be given by

$$
Q_{3} \simeq \frac{h_{s} \alpha_{f} A_{s f} n_{f}^{*}}{\left(1+\frac{\xi h_{s}}{h_{d}}\right)}\left(\frac{i_{3}{ }^{\prime}-i_{\infty}}{c_{a}}\right)
$$

This result must also be expressed in terms of $i_{r}{ }^{\prime}$. To do so we define a second correction factor,

$$
\delta_{3}=\frac{i_{3}^{\prime}-i_{\infty}}{i_{r}^{\prime}-i_{\infty}} \simeq \frac{T_{3}-T_{\infty}}{T_{r}-T_{\infty}} \approx 1
$$

such that Equation B-14 can now be given by

$$
Q_{3} \simeq \frac{h_{s} \alpha_{f} A_{s f} n_{f} \delta_{3}}{\left(1+B i_{d}\right)}\left(\frac{i_{r}{ }^{\prime}-i_{\infty}}{c_{a}}\right)
$$

We again assume that the tube wall is isothermal such that $\delta_{3} \approx \delta_{2} \approx 1$. The computation of $n_{f}{ }^{*}$ is discussed below. 
The heat transfer from the dry annular surface at the outer end of the fin may be given by

$$
\begin{aligned}
Q_{4} & =\int_{A_{4}} h_{S}\left(T_{s}-T_{\infty}\right) d A \\
& =h_{s}\left(1-\alpha_{f}\right) A_{s f} n_{f}\left(T_{4}-T_{\infty}\right)
\end{aligned}
$$

where we assume that the "root" temperature of the outer annulus is uniform at $\mathrm{T}_{4}$. The efficiency of this surface is defined by

$$
n_{f}=\frac{1}{A_{4}} \int\left(\frac{T_{s}-T_{\infty}}{T_{4}-T_{\infty}}\right) d A
$$

We define another correction factor to convert Equation A-18 to dependence on $T_{r}$.

$$
\delta_{4}=\left(\frac{T_{4}-T_{\infty}}{T_{r}-T_{\infty}}\right)
$$

We also employ the enthalpy transformation to convert to enthalpy driving potential. The result for Equation B-18 is then

$$
\begin{aligned}
& Q_{4}=h_{s}\left(1-\alpha_{f}\right) A_{s f} n_{f}\left(\frac{T_{4}-T_{\infty}}{T_{r}-T_{\infty}}\right) \frac{C a}{\left(T_{r}-T_{\infty}\right)}\left(\frac{i_{r}{ }^{\prime}-i_{\infty}}{\left.C_{a}-i_{\infty}\right)}\right) \\
& \simeq h_{s}\left(1-\alpha_{f}\right) A_{s f} \eta_{f} \frac{\delta_{4}}{\Gamma_{r}}\left(\frac{i_{r}{ }^{\prime}-i_{\infty}}{c_{a}}\right)
\end{aligned}
$$


In this case, the temperature depression, $\delta_{4}$, cannot generally be assumed equal to one.

The total heat transfer from the partially wetted finned tube surface may now be given as the sum of Equations B-6, B-11, B-16 and B-22.

$$
\begin{aligned}
Q_{s}= & \frac{h_{s}\left(1-\alpha_{t}\right) A_{s t}}{\Gamma_{r}}\left(\frac{i_{r}{ }^{\prime}-i_{\infty}}{c_{a}}\right)+\frac{h_{s} \alpha_{t} A_{s t}}{\left(1+B i_{d}\right)}\left(\frac{i_{r}{ }^{\prime}-i_{\infty}}{c_{a}}\right) \\
& +\frac{h_{s} \alpha_{f} A_{s f} n_{f}{ }^{\star}}{\left(1+B i_{d}\right)}\left(\frac{i_{r}{ }^{\prime}-i_{\infty}}{c_{a}}\right)+\frac{h_{s}\left(1-\alpha_{f}\right) A_{s f} n_{f} \delta_{4}}{\Gamma_{r}}\left(\frac{i_{r}{ }^{\prime}-i_{\infty}}{c_{a}}\right)
\end{aligned}
$$

This can be expressed in the form of Equation B-1 by collecting terms and factoring out the common parameters. The result is

$$
\begin{aligned}
Q_{s}= & h_{s} A_{s}\left\{\frac{\alpha_{t} a_{t}+\alpha_{f} n_{f}^{*} a_{f}}{\left(1+B i_{d}\right)}\right. \\
& \left.+\frac{1}{\Gamma_{r}}\left[\left(1-\alpha_{t}\right) a_{t}+\left(1-\alpha_{f}\right) n_{f} \delta_{4} a_{f}\right]\right\}\left(\frac{i_{r}^{\prime}-i_{\infty}}{c_{a}}\right)
\end{aligned}
$$

where $a_{t}=A_{s t} / A_{s}$ and $\alpha_{f}=A_{s t} / A_{s}$ are the tube and fin areas per unit total surface area, $A_{s}$. An expression for the surface effectiveness, $\varepsilon$, can now be deduced by comparing Equation B-24 with Equation B-1. The result is

$$
\varepsilon=\frac{\alpha_{t} a_{t}+\alpha_{f} n_{f}{ }^{\star} a_{f}}{\left(1+B i_{d}\right)}+\frac{1}{\Gamma_{r}}\left[\left(1-\alpha_{t}\right) a_{t}+\left(1-\alpha_{f}\right) n_{f} \delta_{4} a_{f}\right]
$$


The first term on the right in Equation B-25 is the contribution due to the wet surfaces and the term on the far right is the contribution of the dry surfaces. For the case where the fins and tubes are wetted in the same proportion, $\alpha_{t}=\alpha_{f}=\alpha$, Equation B-25 may be given in the following simplified form,

$$
\varepsilon=\left(\frac{a}{\Gamma+B i_{d}}\right)\left(a_{t}+n_{f} a_{f}\right)+\left(\frac{1-\alpha}{\Gamma_{r}}\right)\left(a_{t}+n_{f} \delta_{4} a_{f}\right)
$$

Alternatively, this may be rearranged in terms of the contributions of fins and the tubes,

$$
\varepsilon=\varepsilon_{t} a_{t}+\varepsilon_{f} a_{f}
$$

where tube and fin effectivenesses are now defined separately by

$$
\begin{aligned}
& \varepsilon_{t}=\frac{\alpha_{t}}{\left(1+B i_{d}\right)}+\frac{\left(1-\alpha_{t}\right)}{\Gamma_{r}} \\
& \varepsilon_{f}=\frac{\alpha_{f} n_{f}^{*}}{\left(1+B i_{d}\right)}+\frac{\left(1-\alpha_{f}\right) n_{f} \delta_{4}}{\Gamma_{r}}
\end{aligned}
$$

If the wet and dry areas of the fin are reversed, where the inner annulus is dry and the outer annulus is wet, the analysis is essentially the same. The result for $\varepsilon_{t}$ in this case is the same as before, but $\varepsilon_{f}$ is slightly different. Since this model is not considered as realistic as the previous model with the inner annulus wet it will not be discussed further here.

Before evaluating the general solution for $\varepsilon$, it is instructive to first examine the extreme cases for totally wet and totally dry operation. For a totally wetted surface, $\alpha \rightarrow 1$, the effectiveness as given by Equation B-26 reduces to the following form, 


$$
\left.\begin{array}{l}
\varepsilon_{t}=\left(\frac{1}{1+B i_{d}}\right) \\
\varepsilon_{f}=\left(\frac{1}{1+B i_{d}}\right) n_{f} \\
\varepsilon=\left(\frac{1}{1+B i_{d}}\right)\left(a_{t}+n_{f} a_{f}\right)
\end{array}\right\} \begin{aligned}
& \text { for } \\
& \alpha \rightarrow 1
\end{aligned}
$$

This result is consistent with the result in Equation 4-20 for $\alpha=1$.

Similarly, for a dry surface, $\alpha \rightarrow 0$, the effectiveness may be given by

$$
\left.\begin{array}{l}
\varepsilon_{t}+1 / \Gamma_{r} \\
\varepsilon_{t} \rightarrow n_{f} / \Gamma_{r} \\
\varepsilon+\left(a_{t}+n_{f} a_{f}\right) / \Gamma_{r}
\end{array}\right\} \begin{aligned}
& \text { for } \\
& \alpha \rightarrow 0
\end{aligned}
$$

For $\alpha=0$ (the surface is dry), the heat transfer may be given by Equation B-1, substituting Equation B-31 for $\varepsilon$ and Equation B-5 for $\Gamma_{r}$. We then obtain,

$$
\begin{aligned}
Q & =h_{s}\left(\frac{A_{s t}}{A_{s}}+n_{f} \frac{A_{s f}}{A_{s}}\right)\left(\frac{C_{a}\left(T_{r}-T_{\infty}\right)}{{ }_{r}{ }^{\prime}-i_{\infty}}\right)\left(\frac{i_{r}{ }^{\prime}-i_{\infty}}{C_{a}}\right) A_{s} \\
& =h_{s}\left(T_{r}-T_{\infty}\right)\left(A_{s t}+n_{f} A_{s f}\right)
\end{aligned}
$$


This result is, of course, equivalent to the definition of the heat transfer from a dry surface, Equation A-3. Thus, we have shown that Equation B-26 has the correct limiting values at $\alpha=0$ and $\alpha=1$.

\section{B-2 Evaluation of $\delta_{4} \frac{/ \Gamma_{r}}{r}$}

The above equations can be used to predict $\varepsilon$ for a given operating condition if suitable models are available for predicting $n_{f}, n_{f}{ }^{\star}, \Gamma_{r}$ and $\delta_{4}$. In the case of $\eta_{f}$ and $\eta_{f}{ }^{\star}$ we can use the annular fin model with the appropriate value for $\mathrm{Bi}_{f}$ in each case. However, the parameters denoted $\Gamma_{r}$ and $\delta_{4}$ depend on the meteorological conditions and other operating conditions in a manner that cannot presently be predicted. For the present, these parameter will, thus, have to be dealt with parametrically.

The equations can be simplified somewhat by using some additional approximations. The area of the tubes is relatively small, the dry portion is even smaller and the rate of heat transfer on the dry surface is small compared to that on the wet surface. Consequently, the contribution of the dry part of the tube can safely be neglected. The equation for may, thus, be given in a slightly simpler form as follows,

$$
\varepsilon \simeq \frac{\alpha\left(a_{t}+\eta_{f} \star^{\star} a_{f}\right.}{\left(1+B i_{d}\right)}+(1-\alpha) n_{f} \delta_{f} a_{f}
$$

where $\delta_{f}$ is defined by

$$
\delta_{f}=\frac{\delta_{4}}{\Gamma_{r}}=\frac{c_{a}\left(T_{4}-T_{\infty}\right)}{\left(i_{r}{ }^{\prime}-i_{\infty}\right)}
$$

The complex relationships encompassed by $\delta_{f}$ will be handled parametrically.

The temperature of the fin at the limit of the wet surface $T_{4}$ will tend to be driven toward the wet bulb temperature of the free stream. In many cases, the temperature at the evaporating surface, and thus, $T_{4}$, will be 
below $T_{\infty}$ resulting in cooling of the air (this has actually been observed in the experiments). In this case, $\mathrm{T}_{4}$ is determined by a heat balance due to transfer of heat radially outward from the core and radially inward due to convection of heat from the air into the dry portion of the fin. $T_{4}$ is, thus, very difficult to predict even under the best of conditions.

In order to examine the effects due to $\delta_{f}$ parametrically we must determine bounds on its value. In the case where the ambient air is humid, evaporation is relatively slow, $T_{4}$ would be close to $T_{r}$ so that the upper bound on $\delta_{f}$ can be given as follows,

$$
\begin{aligned}
& \delta_{f}=\frac{c_{a}\left(T_{4}-T_{\infty}\right)}{\left(i_{r}{ }^{\prime}-\dot{i}_{\infty}\right)} \leqslant \frac{C_{a}\left(T_{r}-T_{\infty}\right)}{\left(\dot{i}_{r}{ }^{\prime}-\dot{i}_{\infty}\right)} \\
& \left(\delta_{f}\right)_{\max } \simeq \frac{1}{\xi}
\end{aligned}
$$

In the other extreme, where the air is dry and the surface heat transfer is vigorous, $\mathrm{T}_{4}$ would approach the wet bulb. A reasonable extreme might be as follows,

$$
\begin{aligned}
& \left.T_{p}=120^{\circ} \mathrm{F}\right\} \quad i_{p}{ }^{\prime}=119.54 \frac{\mathrm{Btu}}{\mathrm{Tb}} \\
& \left.\begin{array}{rl}
\mathrm{T}_{\infty} & =100^{\circ} \mathrm{F} \\
\omega_{\infty} & =25 \% \\
T_{W B} & =71.5^{\circ} \mathrm{F}
\end{array}\right\} \quad \begin{array}{l}
i_{\infty}{ }^{\prime}=71.73 \frac{\mathrm{Btu}}{\mathrm{Tb}} \\
i_{\infty}=35.2 \quad \frac{\mathrm{Btu}}{\mathrm{lb}}
\end{array} \\
& \xi \simeq \frac{(119.54-71.73)}{0.26(120-100)} \simeq 9.2 \\
& \frac{1}{\xi} \simeq 0.11
\end{aligned}
$$


Assuming a heat transfer rate of 6500 (Btu/ft ${ }^{2} \mathrm{hr}$ ) and an inside convection coefficient of 625 (Btu/ $\mathrm{ft}^{2} \mathrm{hr}{ }^{0} \mathrm{~F}$ ) (these are representative of maximum heat rejection rates obtained in WATA experiments), the temperature drop on the inside is about $10.5^{\circ} \mathrm{F}$. Thus, allowing for the loss in the tube wall, $T_{r} \simeq 109^{0} \mathrm{~F}, i_{r}{ }^{\prime}=63.82(\mathrm{Btu} / \mathrm{lb})$. For these conditions then, the lower bound on $\delta_{f}$ may be estimated as follows,

$$
\delta_{f} \simeq \frac{0.26(71.5-100)}{(63.82-35.2)} \simeq-0.26
$$

Thus, by this estimate it appears that reasonable bounds on $\delta_{f}$ would be as follows,

$$
-0.26 \approx \delta_{f} \approx 0.11
$$

The range that will be examined parametrically will be exponded slightly for completeness. We will use,

$$
-0.5<\delta_{f}<0.25
$$

\section{B-3 Computation of Efficiencies}

The efficiencies employed in the above results may be estimated using available solutions. For the case where the outer $f$ in is assumed dry, the exact solution for heat transfer from an annular fin of inner radius $r_{3}$ and outer radius $r_{4}$ may be given in the form

$$
n_{f}=f\left(\frac{r_{4}}{r_{3}}, B i_{f}^{1 / 2}\right)
$$


where

$$
\begin{aligned}
& B i_{f}=\frac{h_{s} l_{f}^{2}}{k_{f} y_{b}}=\text { Biot number for the fin } \\
& k_{f}=\text { fin conductivity } \\
& 1_{f}=\text { fin length }=\left(r_{4}-r_{3}\right) \\
& y_{b}=\text { fin semithickness }=t_{f} / 2
\end{aligned}
$$

A graph of $\eta_{f}$ taken from Gardner $(10)$ is shown in Figure 4-3.

The same results can be used for estimating $\eta_{f}$ f for the inner wet portion of the fin, although this involves some degree of approximation. The derivation of the efficiency for an annular fin assumes that the outer end of the fin is adiabatic, which is not the case here. However, most of the heat is dissipated on the inner wet surface so that the relative proportion of the heat passing from the inner wetted annulus to the outer dry annulus is small. Therefore, the assumption of an adiabatic fin tip should not be too bad in this case. We thus assume that the efficiency of the wet area may be given approximately by the annular fin solution transformed to wet variables,

$$
n_{f} \approx f\left(\frac{r_{3}}{r_{2}},\left(B i_{f}\right)^{1 / 2}\right)
$$

where $B i_{f}$ * is the Biot number transformed to the wet surface conditions,

$$
B i_{f}{ }^{*}=\frac{\xi h_{s} l_{f}^{2}}{k_{f} y_{b}\left(1+B i_{d}^{*}\right)}
$$

In this case, $1_{f}=\left(r_{3}-r_{2}\right)$ is the effective length of the wetted annular region. With this value of $\mathrm{Bi}_{f}{ }^{*}$, the graph of Figure 4-3 may be used to compute $n_{f}$. 
The present analysis assumes that the temperature depression parameters $\delta_{2}$ and $\delta_{3}$ may be assumed equal to one. This is equivalent to the assumption that the entire tube wall, including the dry area, the wet area, and the fin root, may be treated as an isothermal surface in computing the heat transfer. At this time, a test will be devised to evaluate the validity of this assumption.

The surface temperature of the wet and dry areas of the tube may be assumed constant if the resistance to lateral conduction in the tube is small compared to the convective resistances on the inside or outside surfaces. In this case, it is known that the inside resistance is less than the outside resistance for either wet or dry heat transfer. For the isothermal wall assumption to be valid, it is thus sufficient that the ratio of the resistance to lateral conduction to the resistance of the inside surface must be small. This gives

$$
\frac{R(\text { cond })}{R(\text { inside })}=\frac{\frac{1 / 2 P_{f}}{k_{t} t_{t} d_{t}}}{\frac{1}{h_{p} \pi d_{t} / 2 P_{f}}} \ll 1
$$

This requirement reduces to

$$
\frac{h_{p}}{4 P_{f}^{2} k_{t} t_{t}} \ll 1
$$

where $P_{f}$ is the fin pitch and $\pi d_{t}$ is the tube circumference.

To extend the isothermal wall assumption to include the fin root, it is also necessary that the resistance to lateral conduction must be less than the effective resistance of the fin. This requirement may be given by 


$$
\frac{R(\text { cond })}{R(\text { fin })} \leqslant \frac{\frac{1 / 2 P_{f}}{k_{t} t_{t} \pi d_{t}}}{\left(\frac{1+B \dot{i}_{d}}{\xi h_{s} \eta_{s} \star 2 \pi\left(r_{f}^{2}-r_{t}^{2}\right)}\right)}<<1
$$

where the fin area used is both sides of an annular fin of equivalent area. In this expression the fin is assumed to be totally wet with efficiency $n_{f}{ }^{*}$. Neglecting the $f i l m$ resistance $\left(B i_{d} \approx 0\right)$, this requirement may be given by

$$
\frac{\xi_{s} n_{f}\left(r_{f}^{2}-r_{t}^{2}\right)}{p_{f} k_{t} t_{t} d_{t}} \ll 1
$$

For conditions representative of the WATA tests with the HÖTERV surface, Equation B-43 may be given quantitatively as follows:

$$
\begin{aligned}
\frac{h_{p}}{4 P_{f}^{2} k_{t} t_{t}} & \left.=\frac{625\left[\frac{B t u}{h r t^{2}{ }^{O} F}\right]}{4(106)^{2}\left[\frac{f i n}{f t}\right]^{2} 110\left[\frac{B t u}{h r f t^{O_{F} F}}\right]}\right] \frac{0.00246[\mathrm{ft}]}{} \\
& =0.051
\end{aligned}
$$

Thus, it appears that the first half of the isothermal wall test is satisfied.

The test of Equation B-45 may be given quantitatively as follows:

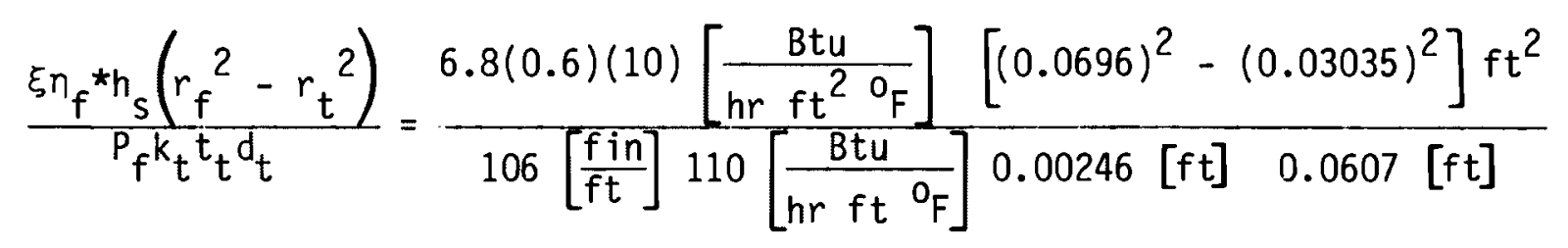


Thus, the test of Equation B-45 is satisfied, although not as we 11 as that of Equation B-43.

In conclusion, it appears that the isothermal tube wall approximation is probably sufficiently accurate for the purpose of this analysis. However, the latter result shows that the resistance of the fin is only one order of magnitude larger than the resistance due to lateral conduction in the tube. Therefore, the temperature depression at the root of the fin could be significant if any of the relevant parameters are changed appreciably.

\section{B-4 Example Calculations for Table 4-9}

The values in Table 4-9 are the results of a parametric analysis of Equation $B-33$. The computations were performed for $B i_{d}=0$ (ideal thin film wetting) and $B i_{d}=0.5$ (corresponding to an approximate upper bound on this parameter for film wetting). The wetness fraction was varied from 0 to 1 for values of $r_{3}$ (the outer limit of the wetted area) between the tube outer radius $r_{2}$ and the equivalent annular fin radius $r_{4}$. The data in the table are for the case $h_{p}=625\left(B t u / f t^{2} h r^{0} F\right), h_{s}=10\left(B t u / \mathrm{ft}^{2} h r^{0} F\right)$ and $\xi=7.0$ the following example calculations are for the second row, $\alpha=0.8$, for $\delta_{S}=-0.10$.

The Biot number on the inner wet region is given by

$$
\begin{aligned}
& B i_{f} \star^{1 / 2}=\left[\frac{l_{f}^{2} h_{e}^{*}}{k y_{b}}\right]^{1 / 2}=\left[\frac{(0.06554-0.03035)^{2}(10)(7)}{111 \frac{0.001083}{2}}\right]^{1 / 2}=\underline{1.20} \\
& \frac{r_{3}}{r_{2}}=\frac{x_{e}}{x_{b}}=\frac{0.06554}{0.03035}=\underline{2.159}
\end{aligned}
$$


From Figure 4-3, at $r_{e} / r_{b}=2.159$ and $\left(B i_{f}^{*}\right)^{1 / 2}=1.20$, we obtain

$$
n_{f}^{*}=\underline{0.60}
$$

The computation of $n_{f}$ for the outer dry annulus of the fin is done in a similar manner.

$$
\begin{aligned}
& B i_{f}^{1 / 2}=\left[\frac{1_{f}^{2} h_{s}}{k y_{b}}\right]^{1 / 2}=\left[\frac{(0.07169-0.06554)^{2}(10)}{111 \frac{0.001083}{2}}\right]^{1 / 2}=\underline{0.079} \\
& \frac{r_{4}}{r_{3}}=\frac{r_{e}}{r_{b}}=\frac{0.07169}{0.06554}=\underline{1.094}
\end{aligned}
$$

From Figure 4-3 then,

$$
\eta_{f} \simeq \underline{0.99}
$$

From Equation B-33 for the above conditions we then obtain for $\delta_{f}=-0.10$,

$$
\begin{aligned}
\varepsilon & =\left(\frac{\alpha}{1+B i_{d}}\right)\left(a_{t}+\eta_{f} * a_{f}\right)+(1-\alpha) \eta_{f} \delta_{f} a_{f} \\
& =\left(\frac{0.8}{1+0}\right)\left[\frac{56.9}{999.2}+0.6\left(\frac{942.3}{999.2}\right)\right]+(0.2)(-0.1)\left(\frac{942.3}{999.2}\right) \\
& =\underline{0.480}
\end{aligned}
$$


The overall heat transfer coefficient in this case can be calculated from Equation B-25 where $h_{s}{ }^{*}=\varepsilon h_{s}$ is substituted for the product of term on the $r$ ight hand side of this equation.

$$
\begin{aligned}
U_{0}^{*} & =\left\{\left(\frac{1}{h_{p} a_{p}}+\frac{t}{k \frac{a}{p}}\right)+\frac{1}{h_{s}^{\star}}\right\}^{-1} \\
& =\left\{7\left[\frac{999.2}{625(59.1)}+\frac{(0.00246)(999.2)}{111(61.7)}\right]+\frac{1}{0.48(10)}\right\}^{-1} \\
& =2.50\left(B t u / \mathrm{ft}^{2} \mathrm{hr}^{0} \mathrm{~F}\right)
\end{aligned}
$$

Other entries in the table are calculated in an analogous manner. 
APPENDIX C

HEATING5 ANALYSIS OF A SCAT CORE 


\section{APPENDIX $C$ \\ HEATING5 ANALYSIS OF A SCAT CORE}

A computer code was used to analyze the performance of the Curtiss-Wright surface used in the WATA experiments. A calculated heat balance between the core and SCAT fluids and the air was found to agree fairly closely with the experimentally determined heat balance. It was thereby concluded that the code could be used to assist the analysis and verification of experimental data. Also, changes to the structure of the Curtiss-Wright surface can be conveniently evaluated at relatively low cost using computer simulation.

The computer code used in the analysis is entitled HEATING5. (a) The purpose of the code is to deal with problems involving heat transfer by conduction. While the code has many additional options, it was used in this analys is to determine the steady-state temperature distributions in the Curtiss-Wright surface.

To use HEATING5 in a cost effective manner it is necessary to consider any $\mathrm{planes}$ of symmetry that may exist in the system. The Curtiss-Wright surface used in the WATA system included two sections in the direction of airflow. The two sections are geometrically identical, each having eight flow channels. As shown in Figure $\mathrm{C}-1$, the third and sixth channel from the leading edge of the first section were designated as SCAT channels. The other

(a) HEATING5 is a multi-dimensional transient or steady-state heat conduction code with temperature-dependent thermal properties, nonlinear and surface-to-surface boundary conditions and change-of-phase capabilities. The version of the code used in this analys is is entitled HEATING5 and is described in the following reference: W. D. Turner, D. C. Elrod and I. I. Siman-Tov, HEATING5 - An IBM 360 Heat Conduction Program. ORN/CSD/TM-15, Computer Sciences Division, Union Carbide Corporation, Nuclear Division, Oak Ridge, TN 37830, March 1977. 


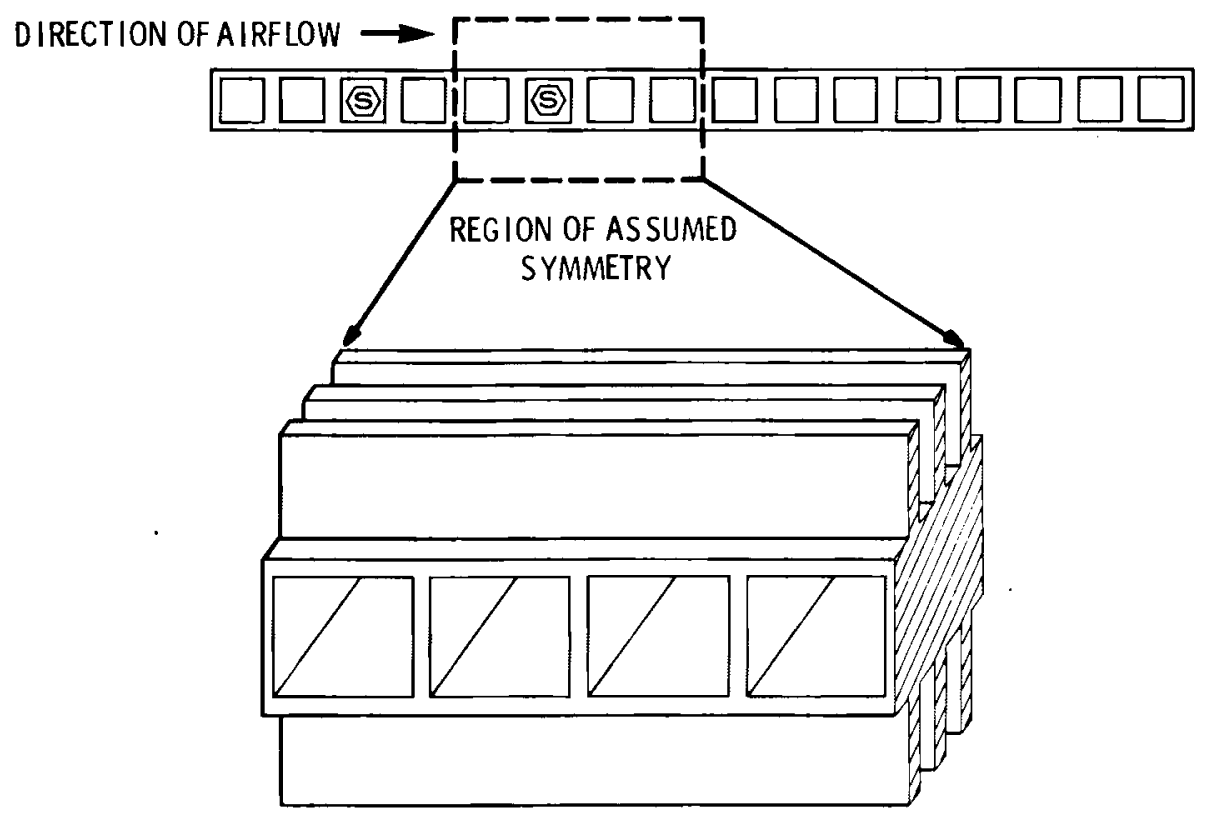

(5) SCAT CHANNEL

FIGURE $\mathrm{C}-1$.

14 channels carried the core fluid. There are 12 rows of channels perpendicular to the direction of airflow. Thus, there are a total of 24 SCAT channels and 168 core channels. The channels were considered to be $6 \mathrm{ft}$ long.

A region of symmetry was chosen to include groups of 4 channels. Dimensions of the symmetrical region are given in Figure C-2. Symmetry of a quarter section of the surface is shown in Figure $\mathrm{C}-3$. Two analyses were performed on this quarter section; one case with an unslotted fin and one case with the slots included. (The actual test core had slots.) The temperatures, heat transfer coefficients, etc., were identical in both analyses.

The analysis was based on bulk temperature data taken from a WATA run (SCAT8). This data included:
- $\mathrm{T}_{\text {AIR, IN }}=80.6^{\circ} \mathrm{F}$
- $\mathrm{T}_{\mathrm{AIR}, \text { OUT }}=94.9^{\circ} \mathrm{F}$
- ${ }^{\mathrm{T}}$ CORE, IN $=100.3^{0} \mathrm{~F}$
- ${ }^{\mathrm{T}}$ CORE, OUT $=99.1^{\circ} \mathrm{F}$
- $\mathrm{T}_{\text {SCAT, IN }}=66.4^{\circ} \mathrm{F}$
- $\mathrm{T}_{\text {SCAT, OUT }}=83.9^{\circ} \mathrm{F}$ 

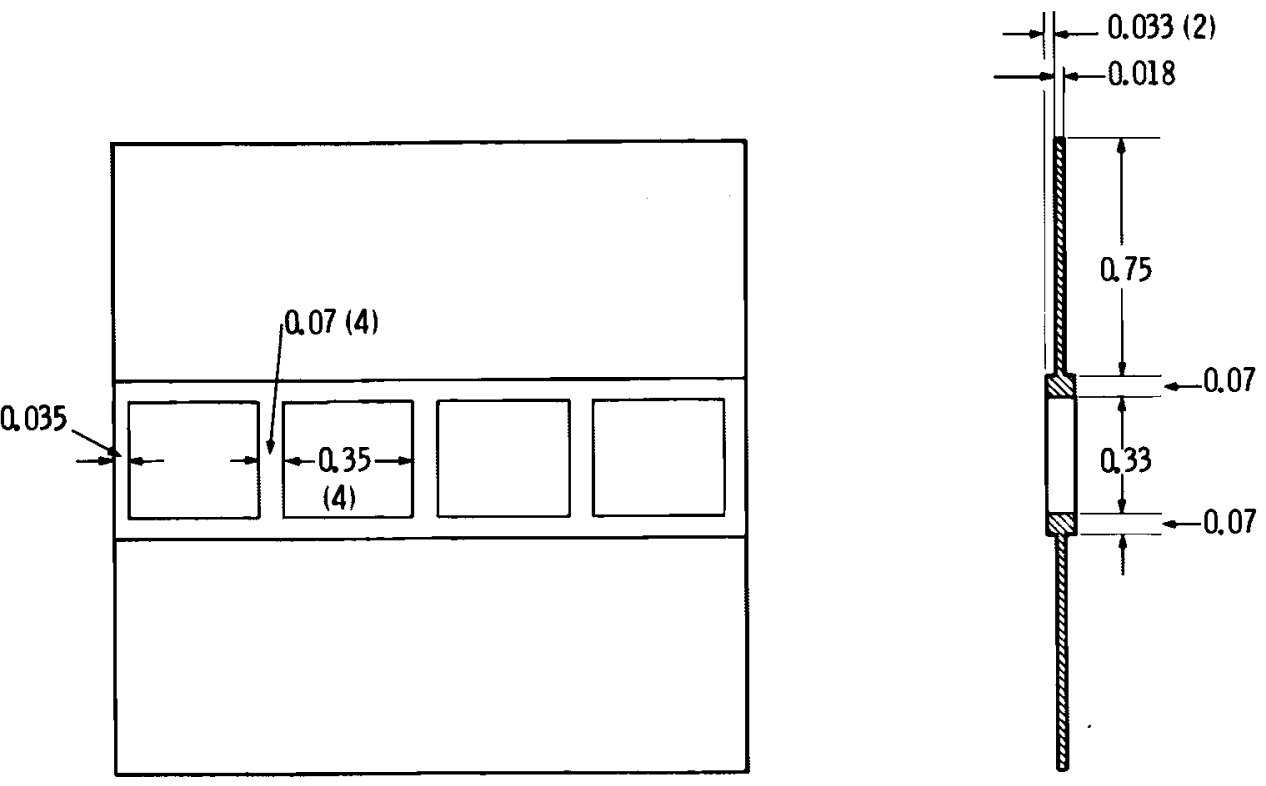

FIGURE C-2. Dimensions in Inches
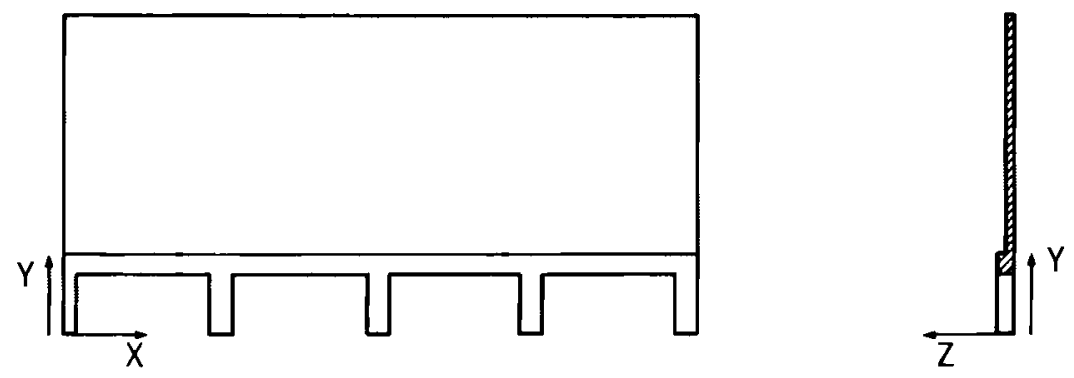

FIGURE C-3. Symmetric Quarter Section

The air temperature applied to the analysis was the average of the inlet and out let measurements: $T_{A I R, A V G}=87.8^{\circ} \mathrm{F}$. Water properties were based on average temperatures. The tube-side heat transfer coefficients were based on a SCAT flow of $16.0 \mathrm{gal} / \mathrm{min}$ through 24 channels, and a core flow of $334 \mathrm{gal} /$ min through 168 channels. The Von Karman analogy was used to compute the coefficients. Data obtained from tests of the Curtiss-Wright core indicated that the air-side heat transfer coefficient is independent of air velocity over the range considered. Details of the evaluation of the heat transfer coefficients are given in the following: 


\section{COEFFICIENTS FOR SCAT8 DATA}

Properties of Water

$\begin{array}{lccc}\text { SCAT Temperature } & =(66.4+83.9) / 2=75^{\circ} \mathrm{F} \\ \text { CORE Temperature }= & (100.3+99.1) / 2=100^{\circ} \mathrm{F} \\ \text { Property } & 75^{0} \mathrm{~F} & 100^{\circ} \mathrm{F} & \\ \rho & 62.2 & 62.1 & 1 \mathrm{bm} / \mathrm{ft}^{3} \\ \mathrm{C}_{\mathrm{p}} & 1.0 & 1.0 & \mathrm{Btu} / 1 \mathrm{bm}{ }^{0} \mathrm{R} \\ \nu & 1.002 & 0.736 & \star 10^{-5} \mathrm{ft}^{2} / \mathrm{sec} \\ \mathrm{Pr} & 6.44 & 4.51 & \text { dimensionless }\end{array}$

Tube-side Hydraulic Diameter

$$
D=\frac{4 A}{P}=\frac{4(0.330 .35) i n .^{2}}{2.033+2.035 \text { in. }} \frac{\mathrm{ft}}{12 \mathrm{in.}}=0.028 \mathrm{ft}
$$

Velocities

$$
\begin{aligned}
& \text { SCAT: } \quad v_{s}=16.0 \frac{\mathrm{gal}}{\min } \frac{\mathrm{min}}{60 \mathrm{sec}} \frac{144 \frac{\mathrm{in.}^{2}}{\mathrm{ft}^{2}}}{\frac{0.33 \mathrm{0.35} \mathrm{in.}^{2}}{\text { tube }}} \frac{\mathrm{ft}^{3}}{7.48 \mathrm{gat}} \frac{1}{24 \text { tubes }} \\
& v_{s}=2.037 \frac{\mathrm{ft}}{\mathrm{sec}}
\end{aligned}
$$

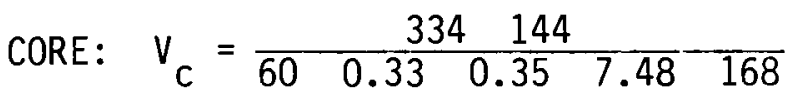

$$
\begin{aligned}
& v_{c}=5.523 \frac{\mathrm{ft}}{\mathrm{sec}}
\end{aligned}
$$

Reynolds Numbers

$$
\text { SCAT: } \quad \operatorname{Re}_{S}=\frac{D V S}{V_{S}}
$$




$$
\begin{aligned}
& =\frac{0.028 \mathrm{ft} 2.037 \frac{\mathrm{ft}}{\mathrm{sec}}}{1.00210^{-5} \frac{\mathrm{ft}^{2}}{\mathrm{sec}}} \cong 5700 . \\
C_{f, s} & =0.0087 \\
\text { CORE: } \operatorname{Re}_{c} & =\frac{0.028 \quad 5.523}{0.73610^{-5} \cong 21000 .} \\
C_{f, c} & =0.0063
\end{aligned}
$$

Von Karman Analogy

$$
\begin{aligned}
S t & =\frac{h}{\rho V C_{p}}=\frac{C_{f / 2}}{1+5 \sqrt{C_{f} / 2}\left\{\operatorname{Pr}-1+\ln \left[1+\frac{5}{6}(\operatorname{Pr}-1)\right]\right\}} \\
h_{S} & =\frac{62.2 \frac{\mathrm{lbm}}{\mathrm{ft}^{2}} 2.037 \frac{\mathrm{ft}}{\mathrm{sec}} 1.0 \frac{\mathrm{Btu}}{1 \mathrm{bm}^{\mathrm{O}_{\mathrm{R}}}} \frac{0.0087}{2} 3600 \frac{\mathrm{sec}}{\mathrm{hr}}}{1+5 \sqrt{\frac{0.0087}{2}\left\{6.44-1+\ln \left[1+\frac{5}{6}(6.44-1)\right]\right\}}} \\
& =591 \frac{\mathrm{Btu}}{\mathrm{hr} \mathrm{ft}^{2} \mathrm{O}_{\mathrm{R}}}=3.3510^{-3} \frac{\omega}{\mathrm{mm}^{2}{ }^{\circ} \mathrm{C}} \\
\mathrm{h}_{\mathrm{C}} & =\frac{-62.1}{1+5 \sqrt{\frac{0.0063}{2}}\left\{4.51-1+\ln \left[1+\frac{5}{6}(4.51-1)\right]\right\}}
\end{aligned}
$$




$$
=1640 \frac{\mathrm{Btu}}{\mathrm{hr} \mathrm{ft}^{2} \mathrm{O}_{\mathrm{R}}}=9.32 \quad 10^{-3} \frac{\omega}{\mathrm{mm}^{2}{ }^{\circ} \mathrm{C}}
$$

\section{Air-side Coefficient}

Based on data obtained from baseline dry tests

$$
\begin{aligned}
h_{0} & =8 \cdot \frac{B t u}{h r^{f t^{2}{ }^{\circ}}} \\
& =4.5 \quad 10^{-5} \frac{\omega}{\mathrm{mm}^{2}{ }^{\circ} \mathrm{C}}
\end{aligned}
$$

For both the slotted and unslotted models, four steady-state solutions were computed. These included:

1. region of symmetry with a SCAT channel; inlet temperatures applied,

2. region of symmetry without a SCAT channel; inlet temperatures applied,

3. region of symmetry with a SCAT channel; outlet temperatures applied, and

4. region of symmetry without a SCAT channel; out let temperatures applied. In all cases the average air temperature, $T_{A I R, A V G}$, was used.

The heat transfer between the three fluids was computed for each case from the temperature distributions. The total heat transfer was computed as an average of the heat transfers computed for the inlet and outlet conditions.

Isotherms are shown for the unslotted and slotted fins in Figures C-4 and C-5. These plots are based on the analys is of the SCAT region with the inlet temperatures. 


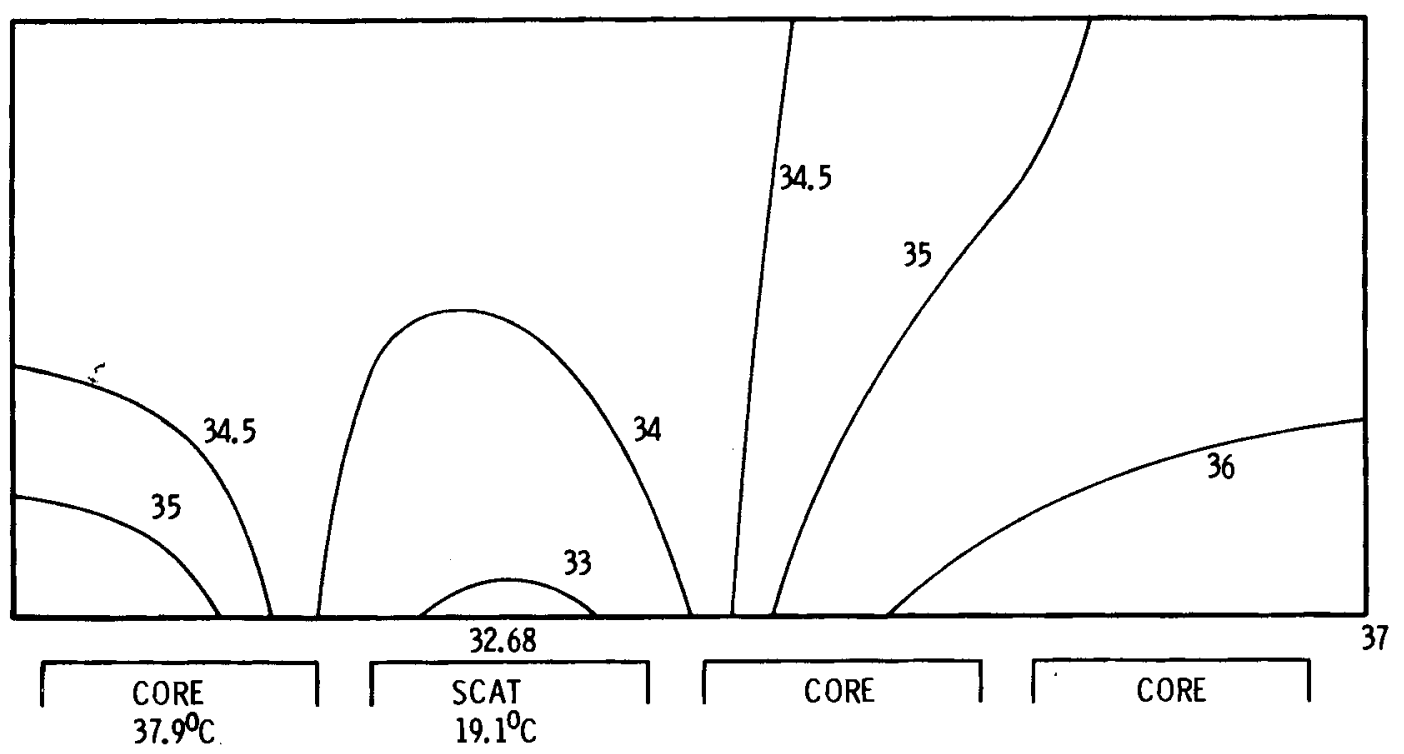

FIGURE C-4. Uns lotted Fin Isotherm

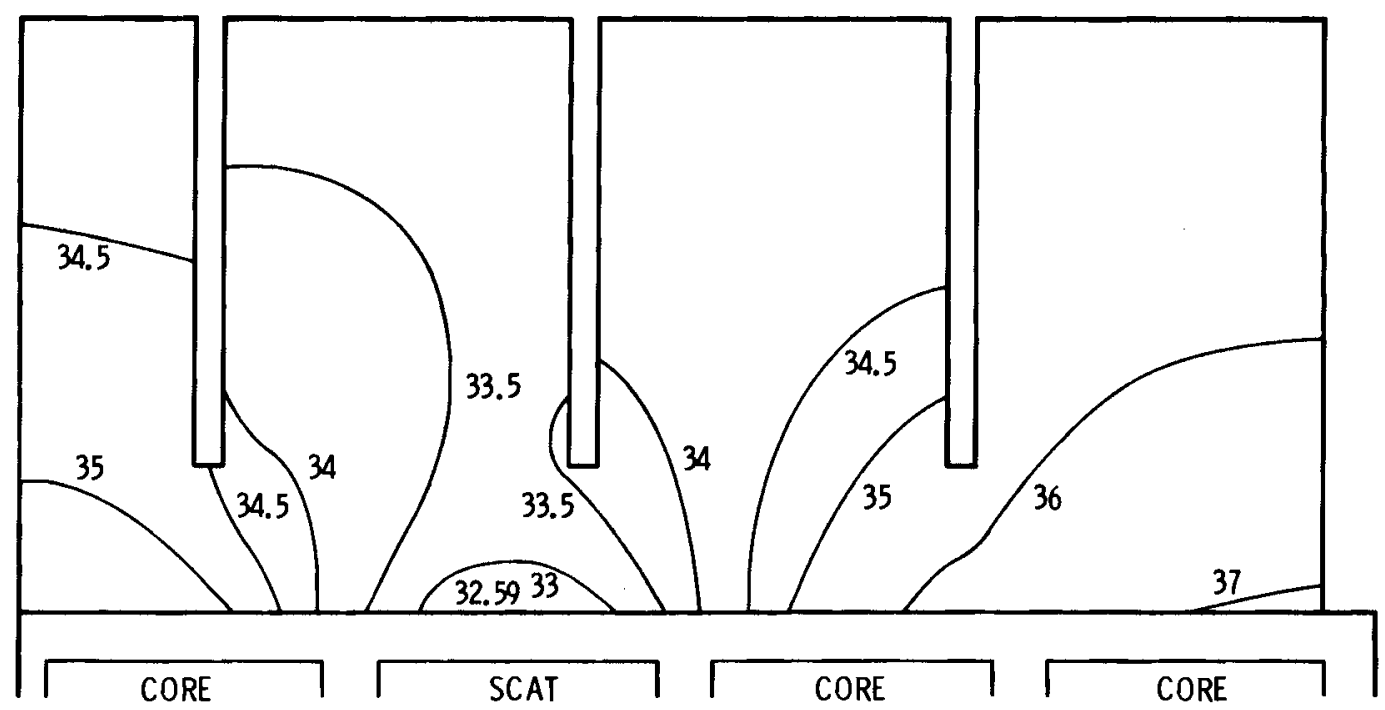

FIGURE C-5. Slotted fin Isotherm 
The following heat transfers weris computed:

\begin{tabular}{|c|c|c|c|}
\hline & SCAT8 Data & Uns lotted & Slotted \\
\hline $\begin{array}{l}\text { Heat Transfer } \\
\text { to Air }\end{array}$ & 111,100 & 102,200 & 106,200 \\
\hline $\begin{array}{l}\text { Heat Transfer } \\
\text { to SCAT }\end{array}$ & 140,000 & 175,800 & 174,700 \\
\hline $\begin{array}{l}\text { Heat Transfer } \\
\text { from CORE }\end{array}$ & 258,300 & 278,000 & $280,900^{\prime}$ \\
\hline
\end{tabular}

The results indicate that little benefit in accuracy is obtained by using the more complicated geometry of the slotted fin. The dominant result, however, is that the computed heat transfers are very close to the experimental values. Considering the approximations that were made involving the averaging of temperaiures, the agreement is surprising. If a more accurate temperature distribution in the three fluids could be obtained experimentally, it is likely that the agreement would improve.

This result shows that HEATING5 can be used to analyze the experimental data. It should also be possible to change the model to compare other geometries. However, this analysis has shown the dependence of the calculations on experimentally defined temperatures. Thus, caution would be advised in using results obtained by merely changing the geometry in the HEATING5 analysis as the temperatures available would no longer directly apply. 
APPENDIX D

CALCULATION OF DIMENSIONAL PARAMETERS OF SURFACES INVESTIGATED 


\author{
APPENDIX D \\ CALCULATION OF DIMENSIONAL PARAMETERS \\ OF SURFACES INVESTIGATED
}

\title{
CURTISS-WRIGHT CORE "A"
}

The Curtiss-Wright Core "A" is an extruded chipped fin heat exchanger. The dimensional information and geometric calculations for this core are shown below:

Dimensional Information:

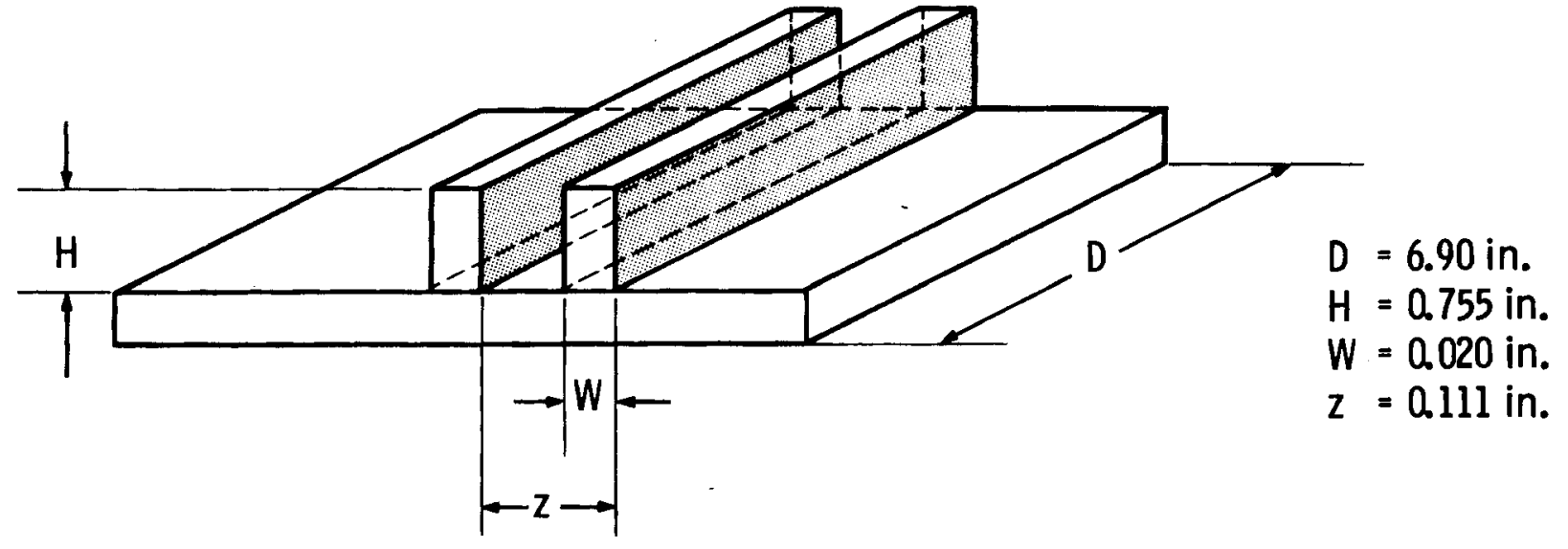

FIGURE D-1.

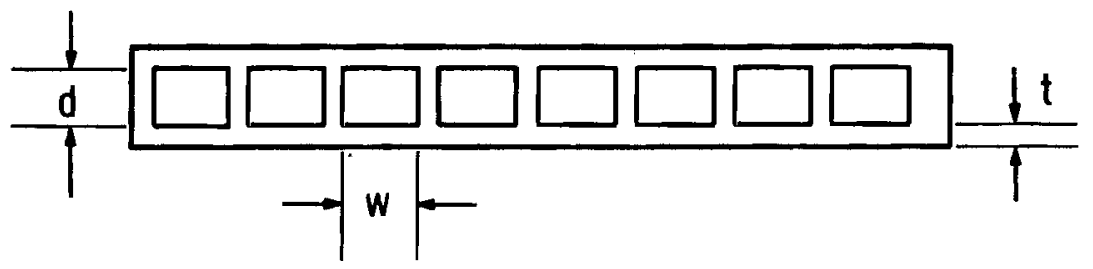

$d=0.327 \mathrm{in}$.

$w=0.348 \mathrm{in}$.

$\mathrm{t}=0.065 \mathrm{in}$.

FIGURE D-2. 


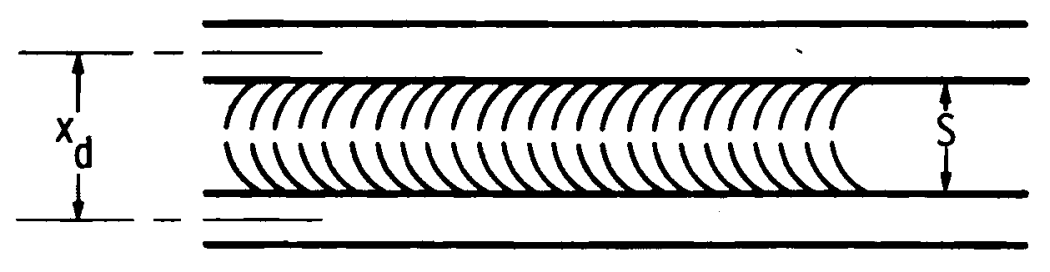

$$
\begin{aligned}
& x_{d}=2.00 \mathrm{in} . \\
& S=1.53 \mathrm{in} .
\end{aligned}
$$

FIGURE D-3.

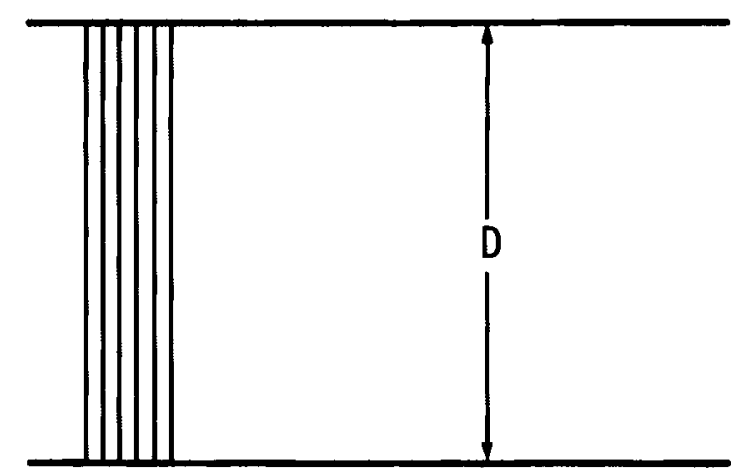

$$
D=6.90 \mathrm{in} .
$$

\section{FIGURE D-4.}

From Figures $D-1$ through $D-4$, geometric quantities can be determined: Minimum Cross-Sectional Flow Area/in. Length:

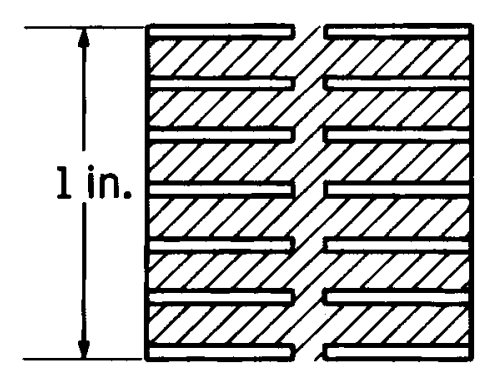

$\nabla A_{\min }$

$$
\begin{aligned}
A_{\text {min/in. }}= & \begin{array}{l}
\text { (area between channels) }- \\
(\text { cross sectional area of fins) }
\end{array} \\
A_{\text {min/in. }} & =\mathrm{S}-2 \mathrm{PHW} \\
= & 1.53-(2)(9)(0.755)(0.020) \\
= & 1.2582 \mathrm{in}^{2} / \mathrm{in} . \\
A_{\text {min }} \text { TOTAL CORE } & =(1.2582)(12 \text { channe } 1 \mathrm{~s})(72 \mathrm{in.}) \\
& =1087.1 \mathrm{in}^{2} \\
& =\underline{7.5492 \mathrm{ft}^{2}}
\end{aligned}
$$

FIGURE D-5. 
Area for Heat Transfer/in. Length:

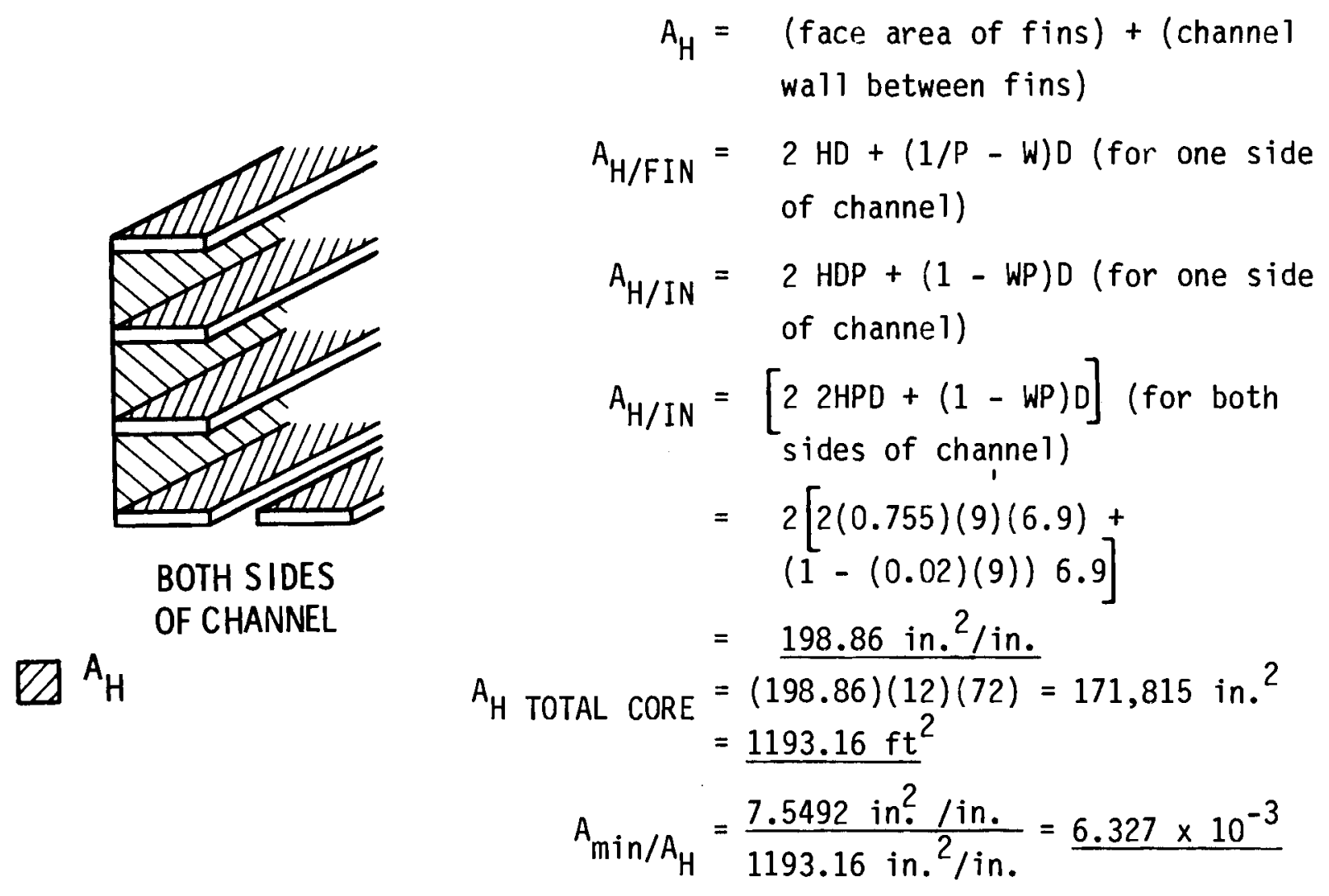

FIGURE D-6.

Ratio of Free Flow Area to Frontal Area:

$$
\sigma=A_{\min } \text { tot. } /_{A_{C S}}=\frac{7.5492 \mathrm{ft}^{2}}{12 \mathrm{ft}^{2}}=\underline{0.629}
$$

Hydraulic Diameter (Air-side):

$$
D_{H}=\frac{4\left(A_{\min } / A_{H}\right) D}{12}=4\left(6.327 \times 10^{-3}\right) \frac{6.9}{12}=1.4552 \times 10^{-2} \mathrm{ft}
$$


The Curtiss-Wright Core "B" differs from the previously discussed CW core as shown in Figure $D-7$ below.

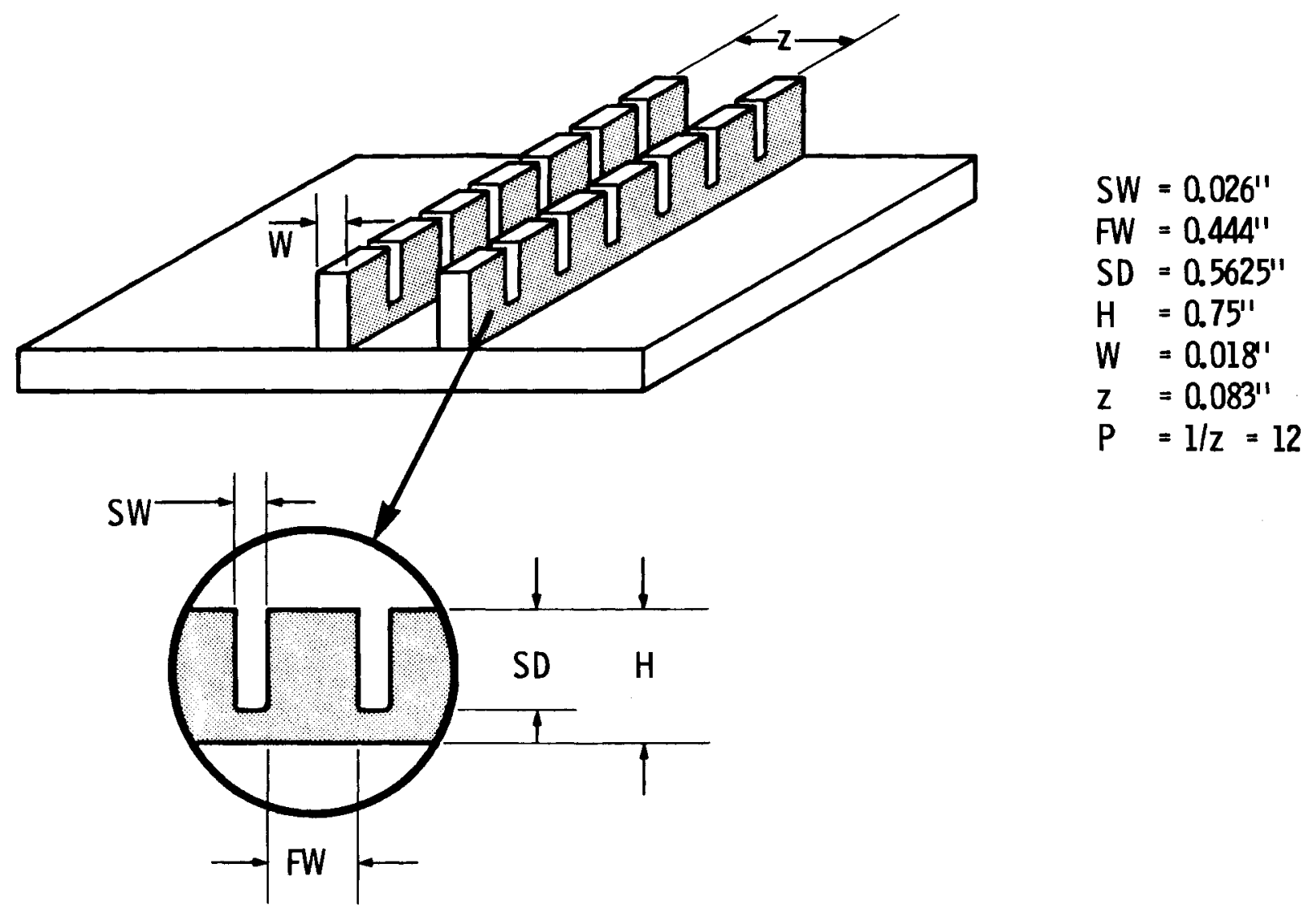

FIGURE D-7.

From these dimensions, we can calculate the geometric quantities:

$$
\begin{aligned}
& \left.A_{\text {min/in. }}=S-2 \text { PHW (see figure for uns lotted } \mathrm{CW}\right)=1.206 \mathrm{in.}^{2} / \mathrm{in} . \\
& A_{\text {min tot. }}=(1.206)(72 \text { in. })(12 \text { channels })=7.236 \mathrm{ft}^{2}
\end{aligned}
$$




$$
\begin{aligned}
& A_{H / \text { in. }}=\left[\begin{array}{r}
2(f \text { ace area of fins }- \text { area of slots }) \frac{f i n s}{\text { in. }} \\
\text { (both sides of } f \text { in })
\end{array}\right. \\
& + \text { area between fins }] 2 \\
& \text { (both sides of air channel) } \\
& A_{H / \text { in. }}=\left[\begin{array}{l}
2(H D-6 \text { - } S H \cdot S W) P \\
\begin{array}{l}
\text { (both sides } \\
\text { of fins })
\end{array}
\end{array}\right. \\
& \begin{aligned}
= & {[2((0.75 \cdot 6.9)-(6 \cdot 0.5625 \cdot 0.026)) 12+} \\
& (1-0.018 \cdot 12) 6.9] 2
\end{aligned} \\
& =[2 \cdot 12(5.175-0.0878)+5.410] 2 \\
& \text { (face area (area of (area of channel } \\
& \text { fins) slots) walls) } \\
& =255.00 \mathrm{in} .^{2} / \mathrm{in} . \\
& A_{H \text { TOT }}=(255)(72 \text { in. })(12 \text { channels })=1530 \mathrm{ft}^{2} \\
& A_{\min / A_{H}}=\frac{1.206}{255.00}=4.729 \times 10^{-3}
\end{aligned}
$$

Ratio of Free Flow Area to Total Face Area:

$$
\sigma=\frac{A_{\min }}{X_{d}}=\frac{1.206}{2.00}=\underline{0.603}
$$


Hydraulic Diameter (Air-side):

$$
\begin{aligned}
D_{H}=4\left(A_{\min / A_{H}}\right) \frac{D}{12} & \\
=4\left(4.729 \times 10^{-3}\right) \frac{6.9}{12} & =0.01088 \\
& =1.088 \times 10^{-2} \mathrm{ft}
\end{aligned}
$$




\section{HÖTERV CORE}

The HÖTERV core is a tubular plate fin heat exchanger.

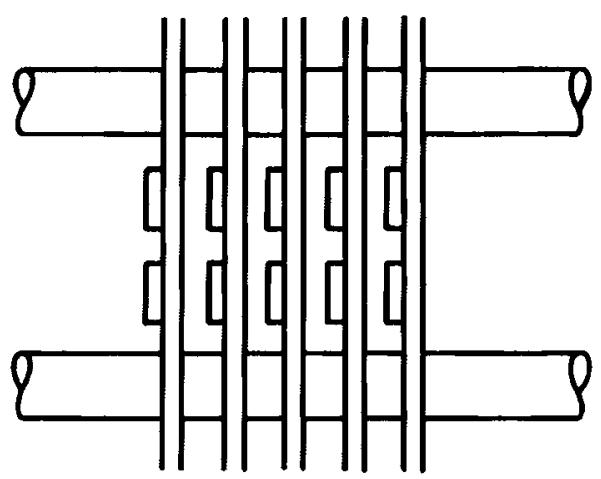

EXPANDED VIEW:

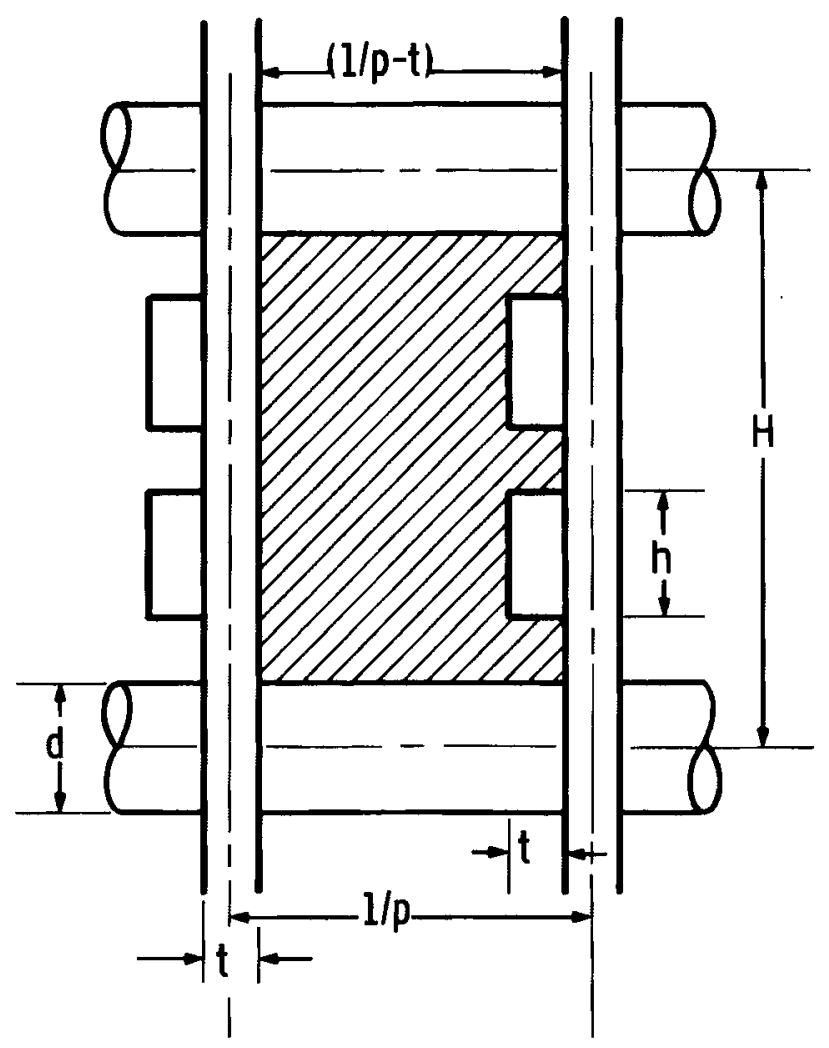

FIGURE D-8.

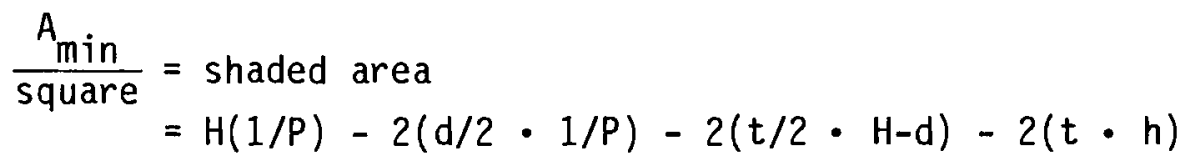

$$
\text { where } \quad \begin{aligned}
H & =60 \mathrm{~mm} \\
P & =0.345 \text { fins } / \mathrm{mm} \\
d & =19.4 \mathrm{~mm} \\
t & =0.44 \mathrm{~mm} \\
\mathrm{~h} & =16 \mathrm{~mm}
\end{aligned}
$$


$\frac{A_{\min }}{\text { square }}=(60)(1 / 0.345)-2(19.4 / 2)(1 / 0.345)-2(0.44 / 2)(60-19.4)-2(0.44)(16)$ $=\underline{85.74 \mathrm{~mm}^{2}}$ for 1 fin wide

$A_{\min }$ TOTAL CORE $=\left(85.74 \mathrm{~mm}^{2} / \mathrm{fin}, 60 \mathrm{~mm}\right.$ high)(211 fins) $\frac{1828.8 \mathrm{~mm} \text { total height }}{60 \mathrm{~mm}}$

$=551,418 \mathrm{~mm}^{2}$

$=5.9354 \mathrm{ft}^{2}$

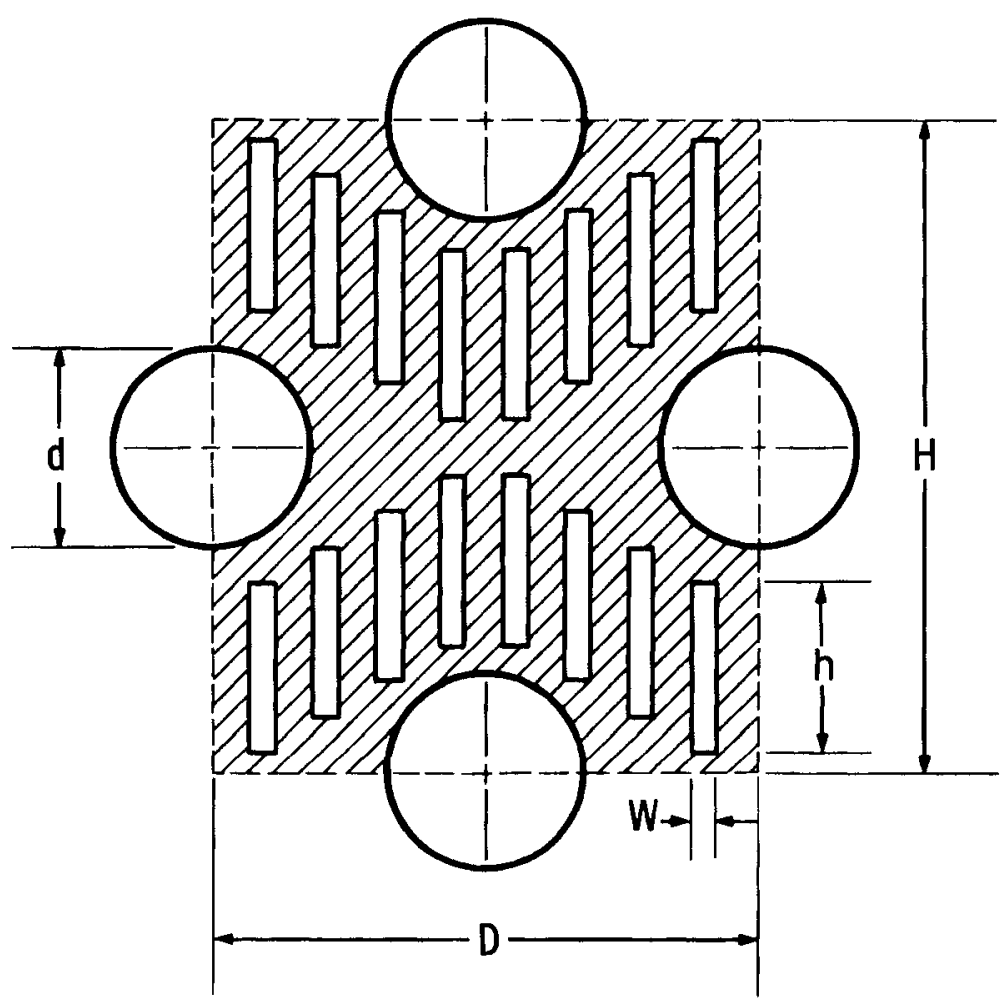

FIGURE D-9. 
Al1 variables are defined the same.

New Ones:

$$
\begin{aligned}
D & =50 \mathrm{~mm} \\
w & =1.5 \mathrm{~mm} \\
A_{H} & =\text { shaded areas }
\end{aligned}
$$

$\frac{A_{H}}{\text { square }}=$ area fin - area slots $-A_{C S}$ tubes + tube wall area

$$
=2\left[H D-16 h w-4\left(\frac{\pi d^{2}}{4} \cdot \frac{1}{2}\right)\right]+4\left[\frac{\pi d}{2} \cdot\left(\frac{1}{p}-t\right)\right]
$$

(for both sides of air channel)

$$
\begin{aligned}
\frac{A_{H}}{\text { square }}= & 2\left[(60)(50)-16(16)(1.5)-4 \frac{\pi(18.5)^{2}}{(4)(2)}\right] \\
& +4\left[\frac{\pi(18.5)}{2}\left(\frac{1}{0 . \overline{345}}-0.44\right)\right]
\end{aligned}
$$

$\frac{A_{H}}{\text { square }}=4156.79 \mathrm{~mm}^{2}+285.78 \mathrm{~mm}^{2}$

$$
=4442.57 \mathrm{~mm}^{2}
$$

$$
\frac{A_{\min }}{A_{H}}=\frac{85.74}{4442.57}=\underline{0.0193}
$$




$$
\begin{aligned}
D_{H} & =4 \cdot \frac{A_{\min }}{A_{H}} \cdot D \\
& =\frac{4(85.74)}{(4442.57)}(50)=\underline{3.86 \mathrm{~mm}}=0.0127 \mathrm{ft} \\
\sigma & =\frac{A_{\min }}{A_{\text {face }}}=\frac{85.74 \mathrm{~mm}^{2}}{60(1 / 0.345)}=0.493=\sigma
\end{aligned}
$$

Total Heat Transfer Area for $2 \mathrm{ft} \times 6 \mathrm{ft}$ Core:

$$
\mathrm{A}_{\mathrm{H}_{\text {TOTAL }}}=\# \text { sheets }\left[\left(\frac{\mathrm{A}_{\mathrm{H}}}{\text { square }} \cdot \frac{\# \text { squares }}{\text { sheet }}\right)+\frac{\text { edge areas }}{\text { sheet }}\right]
$$

Middle Area:

$$
\begin{gathered}
A_{H} \text { /square }=4.442 .57 \mathrm{~mm}^{2} \\
\# \text { squares/sheet, } 1 / 3 \text { core length }=(2.5 \text { deep })(9.5 \text { long })=23.75 \text { squares } \\
A_{H} \text { middle/sheet }=\left(4442.57 \mathrm{~mm}^{2} / \text { square }\right)(23.75 \text { squares })=105,511 \mathrm{~mm}^{2}
\end{gathered}
$$

\section{Edge Areas:}

We will use the same density ratio for slots in edges as in square areas:

$$
R=\frac{A_{H^{w} / \text { s lots }}}{A_{H} \text { w/o slots }}=\frac{(50 \times 60)-16(1.5 \times 16)}{50 \times 60}=0.872
$$




$$
\begin{aligned}
& A_{H} \text {, edge/sheet, } 1 / 3 \text { core length }= \\
& {\left[2(160)(14)-\frac{6}{2}\left(\pi \cdot 9.25^{2}\right) \quad 0.872\right] \quad \begin{array}{l}
\text { For top and } \\
\text { bottom edge }
\end{array}} \\
& +\left[2(570)(17: 5)-\frac{19}{2}\left(\pi \cdot 9.25^{2}\right)\right] 0.872 \begin{array}{l}
\text { For side } \\
\text { edges }
\end{array} \\
& +24 \pi \cdot \frac{18.5}{2} \cdot\left(\frac{1}{0.345}-0.44\right) \quad \begin{array}{l}
\text { For tube-side } \\
\text { areas }
\end{array} \\
& =20,567 \mathrm{~mm}^{2} \text { for } 1 \text { side, } 1 \text { sheet } \\
& =41,134 \mathrm{~mm}^{2} \text { for both sides }
\end{aligned}
$$

Total

$A_{H \text { TOTAL } / 1 \text { sheet, } 1 / 3 \text { core }}=105,511+41,134=146,645 \mathrm{~mm}^{2}$

$A_{H \text { TOTAL/1 sheet, full core }}=3(145,686)=439,935 \mathrm{~mm}^{2}$

$$
A_{H \text { TOTAL }}=211(437,056)=92,826,285 \mathrm{~mm}^{2}=\frac{999.18 \mathrm{ft}^{2}}{=A_{H} \text { TOTAL }}
$$


. 
APPENDIX E

SAMPLE CALCULATIONS 


\section{APPENDIX E \\ SAMPLE CALCULATIONS}

\section{FRICTION FACTOR}

The following calculations are an example of the reduction of the pressure drop data to friction factors, $f$, and effective friction factor, $f_{0}$. The example is for Curtiss-Wright surface "B" Run \#3.

\section{Raw Data:}

$$
\begin{aligned}
& \Delta \mathrm{p} \text { over core } \\
& \mathrm{T} \text { air in } \\
& D P_{\text {in }} \\
& P_{\text {in }} \\
& T_{\text {air out }} \\
& \text { DP out } \\
& P_{\text {out }} \\
& \text { TAnnubar } \\
& \text { DP ann } \\
& P \text { ann } \\
& \text { h ( } \triangle \mathrm{P} \text { over Annubar) } \\
& 0.26 \text { in. } \mathrm{H}_{2} \mathrm{O} \\
& 90.13^{\circ} \mathrm{F} \\
& 28.0^{\circ} \mathrm{F} \\
& \rho_{1}=0.0712 \mathrm{lb} / \mathrm{ft}^{3} \\
& 29.67 \text { in. } \mathrm{Hg} \\
& 89.40^{\circ} \mathrm{F} \\
& 28.0^{\circ} \mathrm{F} \\
& \rho_{2}=0.0713 \mathrm{lb} / \mathrm{ft}^{3} \\
& 29.655 \mathrm{in} . \mathrm{Hg} \quad \rho_{\mathrm{m}}=0.07122 \mathrm{lb} / \mathrm{ft}^{3} \\
& 88.3^{\circ} \\
& 28.0^{\circ} \mathrm{F} \\
& 29.44 \text { in. } \mathrm{Hg} \\
& 1.38 \text { in. } \mathrm{H}_{2} \mathrm{O} \\
& \dot{\mathrm{m}}_{\mathrm{air}}=90326 \sqrt{\rho_{\mathrm{ann}} \mathrm{h}} \text { (Annubar calibration) } \\
& \rho_{\mathrm{ann}}=0.0720 \text { (from psychometric chart) } 1 \mathrm{~b} / \mathrm{ft}^{3} \\
& \text { Pressure corrected: } \quad \rho_{\mathrm{ann}}=(0.0720) \frac{(29.44)}{(29.921)}=0.0709 \frac{\mathrm{lb}}{\mathrm{ft}^{3}} \\
& \dot{\mathrm{m}}_{\mathrm{air}}=90326 \sqrt{0.0709} \sqrt{1.38}=28,251 \frac{\mathrm{lb}}{\mathrm{hr}}
\end{aligned}
$$




$$
G_{\text {air }}=\frac{\dot{m}_{\text {air }}}{A_{\text {min total }}}=\frac{28,251 \frac{\mathrm{lb}}{\mathrm{hr}}}{7.236 \mathrm{ft}^{2}}=3904.3 \frac{\mathrm{lb}}{\mathrm{hr} \mathrm{ft}^{2}}
$$

From Appendix $D$, geometric quantities were found to be:

$$
\begin{aligned}
A_{\text {min total }} & =7.236 \mathrm{ft}^{2} \\
A_{H \text { total }} & =1530 \mathrm{ft}^{2} \\
\frac{A_{\text {min }}}{A_{H}} & =4.729 \times 10^{-3} \\
\sigma & =0.603 \\
\left(1+\sigma^{2}\right) & =1.3636
\end{aligned}
$$

Entrance and exit coefficients were found to be: ${ }^{(1)(a)}$

$$
\begin{array}{ll}
K_{e}=0.06 & \text { (assuming average } R e=2000 \text { multiple } \\
K_{c}=0.44 & \text { square tube-plate fin system) }
\end{array}
$$

for the Curtiss-Wright Surface "B". Now a friction factor can be calculated using the following equation:

$$
\begin{aligned}
& f=\left(\frac{A_{\min }}{A_{H}}\right)\left(\frac{\rho_{m}}{\rho_{1}}\right)\left[\frac{2 g_{c} \Delta P \rho_{1}}{G^{2}}(N)-\left(1+\sigma^{2}\right)\left(\frac{\rho_{1}}{\rho_{2}}-1\right)\right. \\
&\left.-K_{c}-K_{e}\left(\frac{\rho_{1}}{\rho_{2}}\right)\right]
\end{aligned}
$$

(a) Note that $K_{e}=0.03$ and $K_{c}=0.41$ for both the HÖTERV and CurtissWright Surfăce " $A$ " core. 
where $\mathrm{N}=$ units conversion factor

$$
=6.7418 \times 10^{7} \frac{\mathrm{lb} \mathrm{sec}}{2} \frac{\left.\mathrm{ft}^{2}\right)\left(\text { in. } \mathrm{H}_{2} \mathrm{O}\right) \mathrm{hr}^{2}}{}
$$

Therefore

$$
\begin{aligned}
f= & \left(4.729 \times 10^{-3}\right) \frac{(0.07122)}{(0.0712)}\left[\frac{2(32.2)(0.26)(0.0712)}{(3904.27)^{2}}\left(6.7418 \times 10^{7}\right)\right. \\
& \left.-(1.3636)\left(\frac{0.0712}{0.0713}-1\right)-0.44-0.06\left(\frac{0.0712}{0.0713}\right)\right] \\
= & \underline{0.0226}
\end{aligned}
$$

A loss coefficient, $f_{0}$, can be calculated with the following equation:

$$
\begin{aligned}
& f_{0}=\left(\frac{A_{\min }}{A H}\right)\left(\frac{\rho_{m}}{\rho_{1}}\right)\left[\frac{2 g_{C} \Delta P \rho_{1}}{G^{2}}(N)\right] \\
& =\left(4.729 \times 10^{-3}\right) \frac{(0.07122)}{(0.0712)}\left[\frac{2(32.2)(0.26)(0.0712)}{(3904.27)^{2}}\left(6.7418 \times 10^{7}\right)\right] \\
& =\underline{0.0249}
\end{aligned}
$$




\section{HÖTERV CURTISS-WRIGHT, SLOTTED CURTISS-WRIGHT}

DRY HEAT TRANSFER CALCULATIONS

As an example of the dry heat transfer calculations, Run \#2 on the HÖTERV core is shown below.

$$
\begin{aligned}
T_{\text {air in }} & =t_{1}=42.5^{\circ} \mathrm{F} \\
T_{\text {air out }} & =t_{2}=91.3^{\circ} \mathrm{F} \\
T_{\text {water in }} & =T_{1}=104.9^{\circ} \mathrm{F} \\
T_{\text {water out }} & =T_{2}=102.5^{\circ} \mathrm{F} \\
\text { The LMTD } & =\frac{\left(T_{1}-t_{1}\right)-\left(T_{2}-t_{2}\right)}{\operatorname{Tn}\left(T_{1}-t_{1}\right) /\left(T_{2}-t_{2}\right)}=29.79^{\circ} \mathrm{F}
\end{aligned}
$$

The area for heat transfer $=A_{H}=999.18 \mathrm{ft}^{2}$

$$
\begin{aligned}
Q_{\text {TOTAL }} & =Q_{\text {heater }}+Q_{\text {pump }} \\
Q_{\text {heatr }} & =\dot{\mathrm{m}}_{\substack{\text { heater } \\
\text { water }}} C_{p_{\text {water }}} T_{\text {heater }} \\
\dot{\mathrm{m}}_{\text {heater }} & =\dot{\mathrm{v}}_{\text {heater }} \rho 8.02 \\
& =(40.2 \mathrm{gpm})\left(61.96 \frac{\mathrm{lb}}{\mathrm{ft}^{3}}\right)\left(0.1337 \frac{\mathrm{ft}^{3}}{\mathrm{gat}}\right)\left(60 \frac{\mathrm{min}}{\mathrm{hr}}\right) \\
& =19,976 \frac{\mathrm{lb}}{\mathrm{hr}} \\
\Delta T_{\text {heater }} & =9.7^{0} \mathrm{~F} \\
\dot{Q}_{\text {heater }} & =(19,976)(1.00)(9.7)=193,766 \frac{\mathrm{Btu}}{\mathrm{hr}}
\end{aligned}
$$




$$
\begin{aligned}
\dot{Q}_{\text {pump }} & =16,200 \mathrm{Btu} / \mathrm{hr} \text { (from graph) } \\
\therefore & \dot{Q}_{\text {total }}=193,766+16,200=\underline{209,966} \frac{\mathrm{Btu}}{\mathrm{hr}}=Q_{\text {total }}
\end{aligned}
$$

Overall heat transfer coefficient, $U$ is then calculated:

$$
\begin{aligned}
& U=\frac{\dot{Q}}{A_{H} \times L M T D}=\frac{209,966}{(999.18)(29.79)} \\
& U=7.054 \frac{\mathrm{Btu}}{\mathrm{hrft}^{20} \mathrm{~F}}
\end{aligned}
$$

Next, the Reynolds number of air is calculated:

$$
\operatorname{Re}_{\text {air }}=\frac{\mathrm{GD}_{H}}{\mu}
$$

where $G$ is the flow through the minimum cross-sectional area $=\frac{\dot{\mathrm{m}}_{\text {air }}}{A_{\min , \text { total }}}$

$$
\begin{aligned}
\dot{\mathrm{m}}_{\mathrm{air}} & =19608.2 \mathrm{lb} / \mathrm{hr} \\
A_{\min } & =5.9354 \mathrm{ft}^{2} \\
\therefore G & =\frac{19608.2}{5.9354}=3303.6 \frac{\mathrm{lb}}{\mathrm{hrft}^{2}} \\
D_{H} & =0.0127 \mathrm{ft} \\
\mu & =0.0438 \frac{\mathrm{lbm}}{\mathrm{fthr}}
\end{aligned}
$$




$$
\operatorname{Re}_{\text {air }}=\frac{(3303.6)}{(0.0: 438)} \frac{0.0127)}{957.9=\operatorname{Re}_{\text {air }}}
$$

The following calculations show the computation of the effective inside and outside heat transfer coefficients.

The inside heat transfer coefficient is calculated from the DittusBoelter equation:

$$
\begin{aligned}
& h_{i}=0.023 \frac{K_{\text {water }}}{D_{h}} \operatorname{Re}_{d}^{0.8} \operatorname{Pr} 0.333 \\
& K_{\text {water }}=0.3647 \frac{\mathrm{Btu}}{\mathrm{hrft}^{0} \mathrm{~F}} \\
& D_{h_{\text {tube }}}=0.0558 \mathrm{ft} \\
& \operatorname{Re}_{\mathrm{d}} \text { of the tube }=\frac{G_{w} D_{h}}{\mu_{w}} \text { tube }
\end{aligned}
$$

where $G_{W}$ is the flow through the minimum cross-sectional area

$$
\begin{aligned}
& =\frac{\dot{\mathrm{m}}_{\text {water, core }}}{\mathrm{A}_{\text {cross section }}} \\
& \text { total tubes }
\end{aligned}
$$




$$
\begin{aligned}
& =406,748 \frac{1 \mathrm{~b}}{\mathrm{hrft}^{2}} \\
& \mu_{w}=1.58 \frac{1 \mathrm{bm}}{\mathrm{fthr}} \\
& \therefore \operatorname{Re}_{d}=\frac{(406,748)(0.0558)}{1.58}=14365 \\
& \operatorname{Pr}_{\text {water }}=\frac{C_{p_{w} \mu_{w}}}{k_{w}}=\frac{(1.00)(1.58)}{(0.3647)}=4.332 \\
& \therefore h_{i}=0.023 \frac{(0.3647)}{(0.0558)}(14365)^{0.8}(4.332)^{0.333} \\
& =518.7 \frac{\mathrm{Btu}}{\mathrm{hrft}^{2 \mathrm{O}_{\mathrm{F}}}}
\end{aligned}
$$

The outside heat transfer coefficient which includes the fin efficiency is given by the following equation:

$$
\begin{aligned}
h_{0} & =\frac{1}{\frac{1}{U}-\frac{t}{k_{\text {wall }}} \frac{A_{H}}{A_{\text {mid }}}-\frac{1}{h_{i}} \frac{A_{H}}{A_{i}}} \\
t & =\text { thickness of tube wall }=0.00246 \mathrm{ft} \\
k_{\text {wall }} & =111 \frac{\text { Btu }}{\mathrm{hr}-\mathrm{ft}^{2}}
\end{aligned}
$$




$$
\begin{aligned}
& A_{H} / \text { square }=4442.57 \mathrm{~mm}^{2} \\
& A_{j} / \text { square }=\text { tube inside area } \\
& =4 \frac{\pi D i}{2}\left(\frac{1}{P}-t\right) \\
& D i=17.0 \mathrm{~mm} \\
& A_{i} / \text { square }=4\left(\begin{array}{ll}
\frac{\pi(17.0)}{2} & \frac{1}{0.345}-0.44
\end{array}\right) \\
& =262.61 \mathrm{~mm}^{2} \\
& A_{\text {mid }} / \text { square }=\text { midtube area } \\
& =4\left(\frac{\pi \operatorname{Dmid}}{2}\left(\frac{1}{p}-t\right)\right) \\
& D_{\text {mid }}=\frac{D_{C}+D_{i}}{2}=\frac{18.5+17.0}{2}=17.75 \mathrm{~mm} \\
& \begin{aligned}
A_{\text {mid }} \text { square } & =4 \frac{\pi(17.75)}{2}\left(\frac{1}{0.345}-0.44\right) \\
& =274.19 \mathrm{~mm}^{2}
\end{aligned} \\
& \therefore \frac{A_{H}}{A_{j}}=\frac{4442.57}{262.61}=16.92 \\
& \frac{A_{H}}{A_{\text {mid }}}=\frac{4442.57}{274.19}=16.20
\end{aligned}
$$




$$
\therefore h_{0}=\frac{1}{\left(\frac{1}{7.054}-\frac{0.00246}{111}(16.20)-\frac{1}{518.7}(16.92)\right)}=9.192 \frac{\mathrm{Btu}}{\mathrm{hr} \mathrm{ft}^{20_{\mathrm{F}}}}
$$

The Colburn $j$ factor can then be calculated on the basis of this heat transfer coefficient by using the equation:

$$
\begin{aligned}
& j_{0}=\frac{h_{0}}{C_{\text {pair }} G_{\text {air }}} \operatorname{Pr}^{2 / 3} \\
& C_{\text {pair }}=0.2424 \mathrm{Btu} / 1 \mathrm{bm}^{0} \mathrm{~F} \\
& G_{\text {air }}=3303.6 \frac{\mathrm{lb}}{\mathrm{hrft}^{2}} \\
& \operatorname{Pr}_{\text {air }}=\frac{C_{\text {pair }} \mu_{\text {air }}}{k_{\text {air }}} \\
& \mu_{\text {air }}=0.0438 \frac{\mathrm{lbm}}{\mathrm{fthr}} \\
& k_{\text {air }}=0.01484 \frac{B t u}{h_{r f t}{ }^{2} F} \\
& \operatorname{Pr}_{\text {air }}=\frac{(0.2424)(0.0438)}{0.01484}=0.7154 \\
& \therefore j_{0}=\left(\frac{9.192}{(0.2424)(3303.6)}\right)\left(0.7154^{0.6667}\right) \\
& j_{0}=9.182 \times 10^{-3}
\end{aligned}
$$




\section{SAMPLE CALCULATIONS FOR DELUGED DATA}

As an example of the calculations used to reduce the deluged data, HÖTERV $R$ in No. 39 will be used.

Data:

$$
\begin{aligned}
& j *=83,388 \mathrm{Btu} / \mathrm{hr} \\
& \dot{m}_{\mathrm{a}}=8898.4 \mathrm{lb} / \mathrm{hr} \\
& \operatorname{Re}_{n_{\text {iin }}}=410 \\
& \mu_{\mathrm{a}}=0.0464 \\
& \rho_{\mathrm{a}}=0.0647 \mathrm{lb} / \mathrm{ft}^{3} \\
& \overline{\mathrm{C}}_{\mathrm{a}}^{\mathrm{a}}=0.265 \mathrm{Btu} / 1 \mathrm{~b}^{\circ} \mathrm{F} \\
& \mathrm{T}_{\text {air in }}=106.4^{\circ} \mathrm{F} \\
& T_{p}=113.8^{\circ} \mathrm{F} \\
& \mathrm{T}_{\mathrm{d}}=104.6^{\circ} \mathrm{F} \\
& i^{\prime} \text { core in }=103.65 \mathrm{Btu} / \mathrm{lb} \\
& i_{\text {air in }}=59.9 \mathrm{Btu} / \mathrm{lb} \\
& i_{p}^{\prime}=101.79 \mathrm{Btu} / 1 \mathrm{~b} \\
& { }^{i}{ }_{d}^{\prime}=80.54 \mathrm{Btu} / \mathrm{lb} \\
& \Delta p=0.12 \text { in. } \mathrm{H}_{2} \mathrm{O} \\
& \dot{\mathrm{m}}_{\mathrm{p}}=175,016 \mathrm{lb} / \mathrm{hr} \\
& \mu_{p}=1.4038 \mathrm{lb} / \mathrm{hrft} \\
& k_{p}=0.366 \mathrm{Btu} / \mathrm{hrft}^{0} \mathrm{~F} \\
& \operatorname{Pr}_{p}=3.804
\end{aligned}
$$

Core Data:

$$
\begin{aligned}
A_{s} & =999.18 \mathrm{ft}^{2} \\
A_{p} & =63.08 \mathrm{ft}^{2} \\
A_{\min } & =5.9354 \mathrm{ft}^{2} \\
a_{p} & =0.063 \\
\bar{a}_{p} & =0.062 \\
a_{s}{ }^{*} & =1.00 \\
t_{t} & =0.00246 \mathrm{ft} \\
k_{t} & =111 \mathrm{Btu} / \mathrm{hrft}^{2} \\
D_{H} & =0.0127 \mathrm{ft} \\
D_{H_{p}} & =0.0541 \mathrm{ft} \\
\text { A cross sec } & =0.414 \mathrm{ft}^{2} \\
\text { tubes } &
\end{aligned}
$$

1. $U_{02}{ }^{*}$ is the overall heat transfer coefficient for wet operation based on $Q_{\text {rejected. }}$

$$
U_{02}{ }^{*}=-\frac{\dot{m}_{a} C_{a}}{A_{s}} \ln \left|1-\frac{\dot{Q}}{\dot{m}_{a} \Delta \dot{i}_{i n}}\right|
$$




$$
\begin{aligned}
U_{02} & =\frac{(8898.4 \mathrm{lb} / \mathrm{hr})\left(0.265 \mathrm{Btu} / 1 \mathrm{~b}^{0} \mathrm{~F}\right)}{999.18 \mathrm{ft}^{2}} \ln \left|1-\frac{83388 \mathrm{Btu} / \mathrm{hr}}{(8898.4 \mathrm{lb} / \mathrm{hr}(43.75 \mathrm{Btu} / \mathrm{lb})}\right| \\
& =0.57
\end{aligned}
$$

2. $h_{p}$ is the heat transfer coefficient on the primary (tube) side and is calculated from the Dittus-Boelter equation.

$$
\begin{aligned}
h_{p} & =0.023 \operatorname{Re}_{p}^{0.8} \operatorname{Pr}_{p}^{0.4} \frac{k_{p}}{D_{H_{p}}} \\
h_{p} & =0.023\left[\frac{\dot{m}_{p}{ }_{H_{p}}}{A_{\text {cross sec. } \mu_{p}}}\right]^{0.8} \operatorname{Pr}_{p}^{0.4} \frac{k_{p}}{D_{H_{p}}} \\
& =0.023\left[\frac{(175016)(0.0541)}{(0.414)(1.4038)}\right]^{0.8} 3.804^{0.4} \frac{(0.366)}{(0.0541)} \\
& =622 \mathrm{Btu/ \textrm {hr } ^ { 0 } \mathrm { Fft }}
\end{aligned}
$$

3. $h_{d}{ }^{*}$ is the average heat transfer coefficient in the delugeate and it is calculated from the data as follows:

$$
h_{d} *=\frac{\frac{\dot{Q}}{A_{s}}}{T_{p}-T_{d}-\frac{Q}{h_{p} A_{p}}-\frac{Q}{k_{t} A_{p} / t}}
$$




$$
\begin{aligned}
h_{d}{ }^{*} & =\frac{83388 / 999.18}{113.8-104.6-83388 /(602)(63.08)} \\
& =11.80 \mathrm{Btu} / \mathrm{hrft}^{20_{F}}
\end{aligned}
$$

4. $h_{S}{ }^{\prime}$ is the lumped apparent heat transfer coefficient uilder wet conditions, includes the effects of nonuniform wetness and fin efficiency.

$$
h_{s^{\prime}}{ }^{\prime}=\left[\frac{1}{U_{02}{ }^{\star}}-\xi\left(\frac{1}{h_{p} a_{p}}+\frac{t_{t}}{k_{t} \bar{s}_{p}}\right)\right]^{-1}
$$

where $\xi$ is the transformation parameter from a temperature driving force to a enthalpy driving force and is given by:

$$
\xi=\frac{i_{p}^{\prime}-i_{\infty}^{\prime}}{C_{a}\left(T_{p}-T_{\infty}\right)}
$$

and can be approximated by:

$$
\begin{aligned}
\xi & =\frac{i_{p}^{\prime}-i_{d}^{\prime}}{C_{a}\left(T_{p}-T_{d}\right)} \\
\xi & =\frac{101.79-80.54}{0.265(113.8-104.6)} \\
& =\underline{8.72} \\
h_{s}{ }^{\prime} & =\left[\frac{1}{0.57}-8.72\left(\frac{1}{(622)(0.063)}+\frac{0.00246}{(111)(0.062)}\right)\right]^{-1} \\
& =\underline{0.65 \mathrm{Btu} / \mathrm{hrft}^{20} \mathrm{~F}}
\end{aligned}
$$


5. $h_{s}{ }^{*}$ is the apparent surface heat transfer coefficient that includes effects of fin efficiency.

$$
\begin{aligned}
h_{s^{*}} & =\left\{a_{s}^{\star}\left[\frac{1}{U_{02}^{\star}}-\xi\left(\frac{1}{h_{p} a_{p}}+\frac{t_{t}}{k_{t} \bar{a}_{p}}+\frac{1}{h_{d^{\star} a_{s}^{\star}}}\right)\right]\right\}^{-1} \\
h_{s} * & =\left\{1.00\left[\frac{1}{0.57}-8.72\left(\frac{1}{(622)(0.063)}+\frac{0.00246}{(111)(0.062)}+\frac{1}{(11.30)(1)}\right)\right]\right\}^{-1} \\
& =1.27 \text { Btu/hrft }{ }^{20} F
\end{aligned}
$$

6. $P_{f}$ is the fan power, calculated by:

$$
\begin{aligned}
P_{f} & =\frac{\Delta p A_{\min } \operatorname{Re} \mu_{a} / \rho_{a}}{D_{H_{a}}} \\
& =\frac{(0.12)(5.9354)(410)(0.0464 / 0.0647)}{(0.0127)} \frac{i n . H_{2} 0 \mathrm{ft}^{2} \mathrm{ft}^{2} / \mathrm{hr}}{\mathrm{ft}} \\
& =16490 \frac{\text { in. } \mathrm{H}_{2} 0 \mathrm{ft}^{3}}{\mathrm{hr}} \times \frac{5.202}{12 \mathrm{ft}^{2} \mathrm{face}} \frac{1 \mathrm{~b} / \mathrm{ft}^{2}}{\mathrm{in.} \mathrm{H}_{2} 0} \times \frac{1 \mathrm{hr}}{3600 \mathrm{sec}} \\
& =1.99 \mathrm{ft} \mathrm{lb/sec} \mathrm{ft}{ }^{2} \mathrm{face}
\end{aligned}
$$

7. The methods for calculating the enhancement ratios, $Q_{\text {wet HöTERV }} / Q_{\text {dry HÖTERV }}$ and $Q_{\text {wet HÖTERV }} / Q_{\text {dry }}$ Curtiss-Wright are as follows:

a. The HÖTERV-HÖTERV comparison was done at a constant pressure drop. 
1) $\Delta p_{\text {wet }}=0.12$ in. $\mathrm{H}_{2} \mathrm{O}$

2) $R e_{\text {dry }} \propto \Delta p_{\text {wet }}=890$ (from data curve)

3) $U_{o_{d r y}}{ }^{\circ R e_{d r y}}=6.83$ ( $f$ rom data curve)

4) $\dot{m}_{\text {a ir dry }}=\frac{\operatorname{Re}_{d r y} A_{m i n}{ }^{\mu}}{D_{H}}$

$$
\begin{aligned}
& =\frac{(890)(5.9354)(0.0464)}{0.0127} \\
& =19,300 \mathrm{lb} / \mathrm{hr}
\end{aligned}
$$

5) $Q_{d r y}=\dot{m}_{a i r d r y} \bar{C}_{a i r}\left(T_{p}-T_{\text {air in }}\right)\left(1-e\left(\frac{-U_{o_{d r y} A_{s}}}{\dot{m}_{\text {air dry }} \bar{C}_{\text {air }}}\right)\right.$ $=(19300)(0.265)(1138-106.4)\left(1-\mathrm{e}\left(\frac{-6}{19} \cdot \frac{83}{300} \frac{999.18}{0.265}\right)\right.$

$=27881 \mathrm{Btu} / \mathrm{hr}$

6) $\frac{Q_{\text {wet }}}{Q_{d r y}}=\frac{83388}{27881}=\underline{2.99}$

b. The HÖTERV-Curtiss Wright enhancement comparison was done on the basis of constant $f$ an power, because the two cores have different pressure drop characteristics.

1) $P_{f \text { wet }}=1.99$

2) $R e_{d r y}{ }^{\circ} P_{f \text { wet }}=780$ (from data curve)

3) $h_{0} \odot \operatorname{Re} \frac{d r y}{}=6.90$

4) $U_{0}=\left[\frac{A_{s}}{A_{p} h_{p}}+\frac{A_{s} t_{t}}{k_{t} \bar{A}_{w a 11}}+\frac{1}{h_{0}}\right]^{-1}$

$$
\begin{aligned}
& =\left[\frac{1193}{(129.6)(622)}+\frac{(1193)(0.0054)}{(111)(129.6)}+\frac{1}{6.9}\right]^{-1} \\
& =6.24
\end{aligned}
$$


5) $\dot{\mathrm{m}}_{\mathrm{air} d r y}=\frac{\operatorname{Re}_{d r y}{ }^{A_{\min }{ }^{\mu} a}}{D_{H}}$

$$
\begin{aligned}
& =\frac{(780)(7.549)(0.0464)}{0.0146} \\
& =18713 \mathrm{lb} / \mathrm{hr}
\end{aligned}
$$

6) $\dot{Q}_{d r y}=\dot{m}_{a i r \text { dry }} \bar{C}_{a i r}\left(T_{p}-T_{a i r \text { in }}\right)\left(1-e\left(\frac{-U_{0} A_{s}}{\tilde{m}_{\text {air dry }} \tau_{a}}\right)\right.$

$$
\begin{aligned}
& =(18713)(0.265)(113.8-106.4)\left(1-\mathrm{e}\left(\frac{-6.24}{18713} \frac{1193.16}{0.265}\right)\right. \\
& =28518 \mathrm{Btu} / \mathrm{hr}
\end{aligned}
$$

7) $Q_{\text {wet }} / Q_{\text {dry }}=\frac{83388}{28518}=\underline{2.92}$ 


\section{UNCERTAINTY ANALYSIS TECHNIQUE}

To illustrate the uncertainty analys is technique, Curtiss-Wright "A" dry heat trans er Run \#8 was used. The results are shown in Table E-1. The major variables in the calculation of $j_{0}$ were examined for their expected error (due to instrument and reading) and then as to their affect on the final $j_{0}$. Error in varidbles such as dinensional parameters, $C_{p a i r}$ and $\operatorname{Pr}_{a i r}$ was considired negligible. The expected error is then calculated as a root sum square of all the individual error percentages.

\section{REFERENCE - APPENDIX E}

E-1 W. M. Kays, "Loss Coefficients for Abrupt Changes in Flow Cross Section with Low Reynolds Number in Single and Multiple Tube Systems," Transactions of ASME. November 1950. 
TABLE E-1. Curtiss-Wright "A" Dry Heat Transfer Run \#8

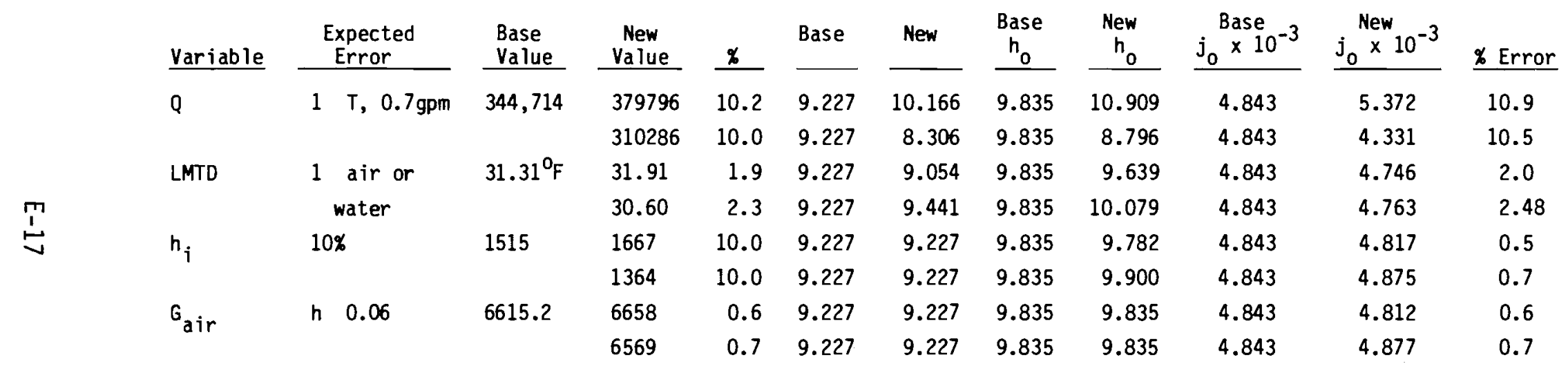

Expected error $\%=$ root sum square $=11.22 \%$

Maximum error $=15.4 \%$ 
$-4$ 
APPENDIX $F$

COMPARISON OF HÖTERV SURFACE PERFORMANCE AS MEASURED IN WATA TO THAT PREDICTED BY HÖTERV 


\section{APPENDIX $F$ \\ COMPARISON OF HÖTERV SURFACE PERFORMANCE \\ AS MEASURED IN WATA TO THAT PREDICTED BY HÖTERV}

HÖTERV has provided correlations for the HÖTERV plate fin surface which may be used to predict both dry and deluged performance. These correlations describe the following parameters as functions of the air mass flow rate per unit frontal area, $G_{f}$ :

1. Dry air-side pressure drop

$$
\begin{aligned}
\Delta P= & 0.165\left(G_{f}\right)^{1.76} \\
& G_{f}-\left(\text { metric tons } / h r m_{f}^{2}\right. \\
& \Delta P-\left(\mathrm{mm} \mathrm{H}_{2} 0\right)
\end{aligned}
$$

In English units

$$
\begin{aligned}
\Delta P= & 5.55 \times 10^{-7}\left(G_{f}\right)^{1.76} \\
& G_{f}-\left(1 b_{m} / h r-f t_{f}^{2}\right) \\
& \Delta P-\left(\text { in. }_{2} H_{2}\right)
\end{aligned}
$$

2. Deluged air-side pressure drop

$\Delta P=0.260 G_{f}{ }^{1.76}$ (units as in item 1 )

In English units

$\Delta P=8.75 \times 10^{-7} G_{f} 1.76$ 
3. Dry effective air-side heat transfer coefficient based upon frontal area

$$
\begin{aligned}
& h_{\text {of }}= 1200\left(G_{f}\right)^{0.515} \\
& G_{f}-\left(\text { metric tons } / \mathrm{hr} \cdot \mathrm{m}_{\mathrm{f}}^{2}\right) \\
& h_{\text {of }}=\left(\mathrm{Kcal} / \mathrm{hr} \cdot{ }^{0} \mathrm{C} \cdot \mathrm{m}_{\mathrm{f}}^{2}\right)
\end{aligned}
$$

In English units

$$
\begin{aligned}
& h_{\text {of }}= 15.86\left(G_{f}\right)^{0.515} \\
& G_{f}-\left(1 b_{m} / h r \cdot f t_{f}^{2}\right) \\
& h_{\text {of }}-\left(B t u / h r \cdot{ }^{0} F \cdot f t_{f}^{2}\right)
\end{aligned}
$$

4. Deluged mass transfer coefficient, $\sigma_{f}$, based upon frontal area

$$
\begin{aligned}
\sigma_{f}= & 1970\left(G_{f}\right) 0.615 \\
& G_{f}-\left(\text { metric tons } / \mathrm{hr} \cdot \mathrm{m}_{f}^{2}\right) \\
& \sigma_{f}-\left(\mathrm{kg} / \mathrm{m}_{f}^{2} \mathrm{hr}\right)
\end{aligned}
$$

In English units

$$
\begin{array}{r}
\sigma_{f}=15.29\left(G_{f}\right)^{0.615} \\
G_{f}-\left(1 b_{m} / h r \cdot f t_{f}^{2}\right) \\
\sigma_{f}-\left(1 b_{m} / h r \cdot f t_{f}^{2}\right)
\end{array}
$$


The HÖTERV correlations are based on data from a $0.48 \times 1.0 \times 0.15 \mathrm{~m}$ $\left(1.57 \times 3.28 \mathrm{ft} \times 5.9 \mathrm{in}\right.$.) test core. Air temperature was held at $20^{\circ} \mathrm{C}$, and deluged tests were run at $560 \mathrm{~kg} / \mathrm{m}_{\mathrm{f}}$ deluge flow based on a $2.4 \mathrm{~m}$ core fin length (this corresponds to $1.8 \mathrm{gpm}$ per lineal ft). Test core primary fluid temperature has not been given.

For comparison, data from the WATA dry and deluged tests may be reduced to the same parameters as the HÖTERV correlations. Figure F-1 compares the WATA pressure drop data to HÖTERV pressure drop data for both dry and deluged operation. It is interesting to note that the WATA tests show a lower pressure drop than claimed by HÖTERV for a dry core, but a higher pressure drop than claimed by HÖTERV for a deluged core. No specific reason for this has been identified. Manufacturing tolerances may make the two test cores slightly different. The WATA test core has a calculated hydraulic diameter based on measured dimensions of $0.0127 \mathrm{ft}$ (see Appendix $\mathrm{C}$ ), while core dimensions from HÖTERV blueprints would result in a hydraulic diameter of $0.0133 \mathrm{ft}$. Such a small difference (ca 5\%) certainly does not account for the large difference in pressure drop seen in Figure F-1. One would expect the difference in core dimensions to result in consistently higher pressure drops in the WATA regardless of whether the core is wet or dry. Furthermore, differences in deluge flow between the two sets of data do not account for the difference in pressure drop. HOTERV tests were run at higher deluge flow than WATA tests ( $1.8 \mathrm{gpm}$ per lineal $\mathrm{ft}$ versus $1.5 \mathrm{gpm}$ per lineal $\mathrm{ft}$ for WATA), and hence, we expected a higher pressure drop from HÖTERV rather than a lower one.

Figure F-2 compares the dry effective surface heat transfer coefficient supplied by HÖTERV to a best fit curve from the WATA dry tests. The WATA results indicate slightly higher performance at air mass flows below 2200 $\mathrm{lb} / \mathrm{hr} \mathrm{ft}_{\mathrm{f}}$ and slightly lower performance at higher airflow rates. No information has been provided regarding the estimated uncertainty of the HÖTERV data. However, if the HÖTERV data has the same order of uncertainty a the WATA data (about $10 \%$ at low airflows), the two curves can be regarded as being in agreement within the uncertainty of the data. 


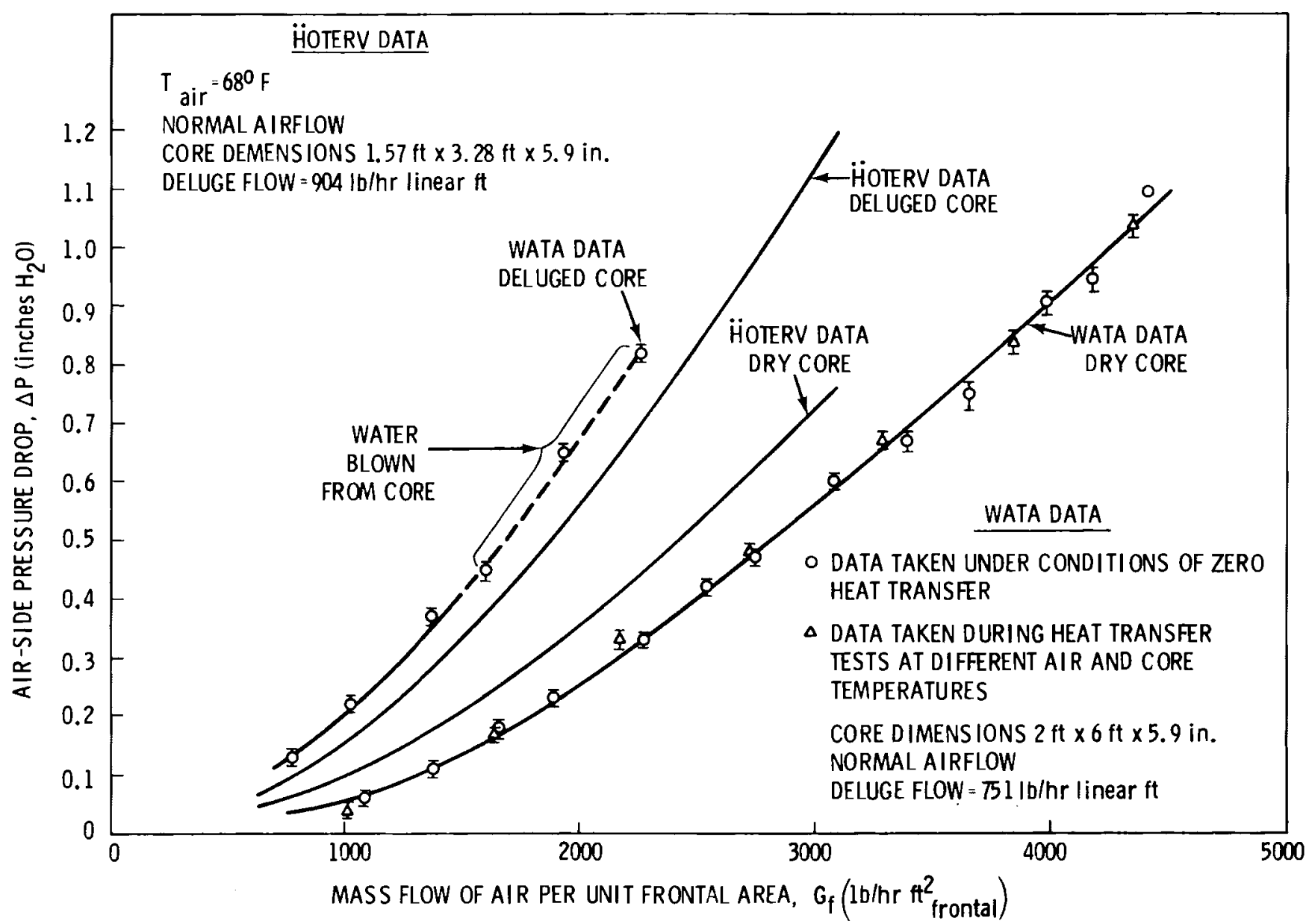

FIGURE F-1. Comparison of Pressure Drop Test Results 


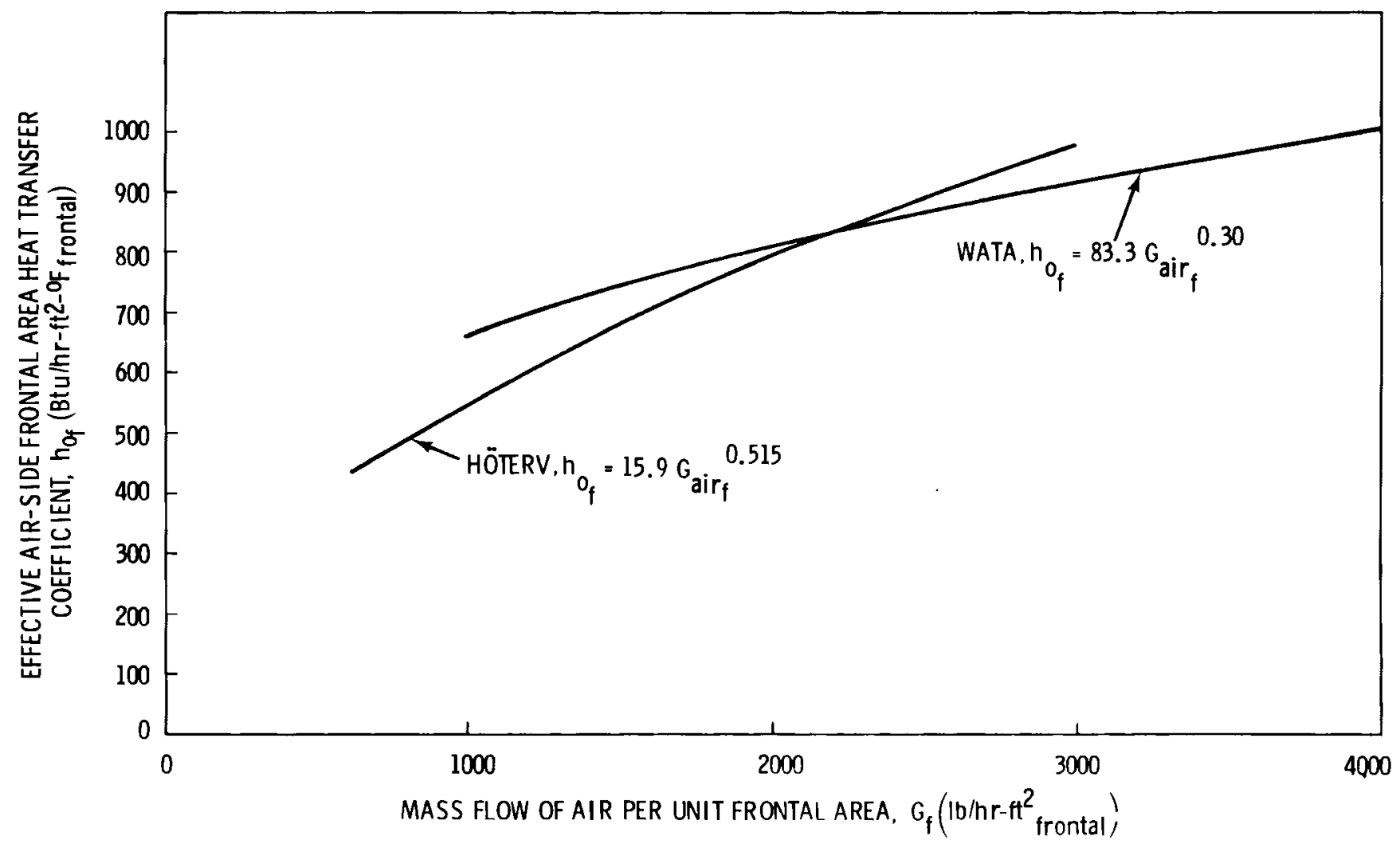

FIGURE F-2. Comparison of Dry Performance Test Results 
Figure F-3 compares the deluged mass transfer coefficient obtained from HÖTERV to that determined from the WATA tests. Note that the deluge mass

transfer coefficient, $\sigma_{f}$, can be shown to be equivalent to $\frac{h_{s f}}{C_{\text {air }}}$ where $h_{s f}{ }^{*}$ is the transformed effective deluge surface heat transfer coefficient based on a unit frontal area and $C_{\text {air }}$ is the specific heat of air.

The HÖTERV and WATA data are in excellent agreement at high air flows, but the performance recorded by HÖTERV at lower air flows is as much as $25 \%$ better than that measured in WATA. However, considering the uncertainty in the data, the overall agreement is good. 


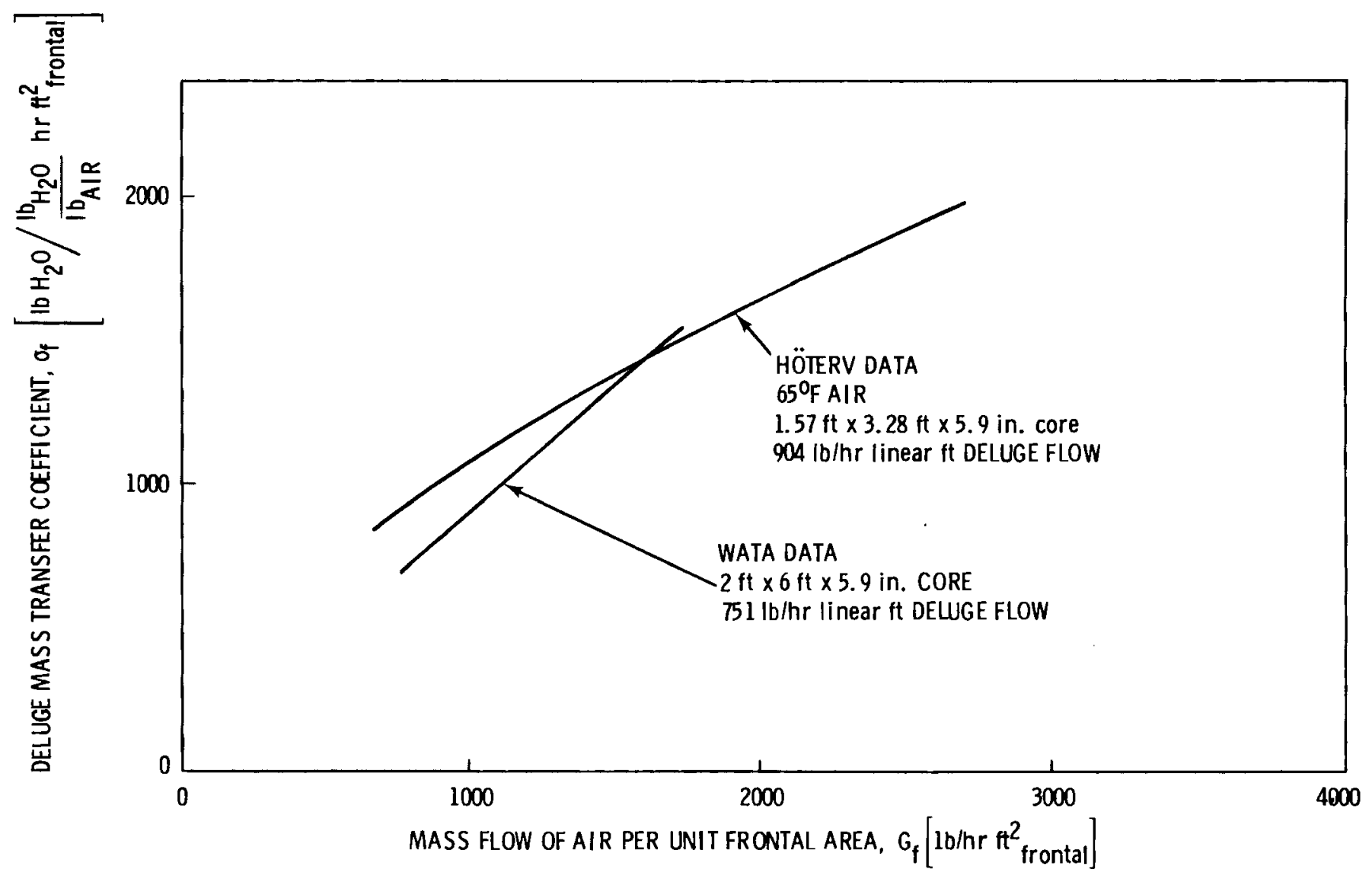

FIGURE F-3. Comparison of Deluged Performance Test Results 
$\therefore$

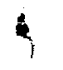




\section{$\underline{\text { DISTRIBUTION }}$}

No. of

Copies

OFFSITE

U.S. Department of Energy

A. A. Churm

Chicago Patent Group

9800 South Cass Avenue

Argonne, IL 60439

U.S. Department of Energy

Office of Assistant General

Counsel for Patents

Washington, DC 20545

27 DOE Technical Information Center

10 U.S. Department of Energy

I. Helms

Division of Advanced Systems and

Materials Production

Washington, DC 20545

U.S. Department of Energy

W. F. Savage

Division of Advanced Systems and

Materials Production

Washington, DC 20545

U.S. Department of Energy

N. Goldenberg

Director, Division of Advanced

Systems and Materials Production

Washington, DC 20545

U.S. Department of Energy

C. Grua

Environmental Control Technology

Office of Environmental

Compliance Overview

Washington, DC 20545
No. of

Copies

U.S. Department of Energy

W. E. Mott

Director, Environmental Control

Technology

Office of Environmental

Compliance Overview

Wasinington, DC 20545

U.S. Department of Energy

J. M. Deutch

Director, Office of Energy

Research

Washington, DC 20545

Allied Chemical Company

B. R. Dickey

550 2nd Street

Idaho Falls, ID 83401

Allis-Chalmers Power Systems, Inc.

J. S. Joyce

1135 South 70th Street

West Allis, WI 53214

Aluminum Company of America

E. T. Wanderer

Alcoa Technical Center

Alcoa Center, PA 15069

American Electric Power Service Corporation

H. J. Janzon

2 Broadway

New York, NY 10004

American Electric Power Service Corporation

C. Swenson

2 Broadway

New York, NY 10004

Aqua-Chem

R. M. Ahlgren

P.0. Box 421

Milwaukee, WI 53201 
No. of

Copies

Arizona Public Service Co.

W. E. Campbe 11

P.0. Box 21666

Phoenix, AZ 85036

Arizona Public Service Co.

T. Woods

2121 W. Cheryl Drive

Phoenix, AZ 85021

Babcock \& Wilcox

M. W. Peterson

Fossil Power Division

20 South Van Buren

Barberton, $\mathrm{OH} 44203$

Baltimore Aircoil Co., Inc.

E. Schinner

P.0. Box 7322

Baltimore, MD 21227

Baltimore Gas \& Electric Co.

G. C. Cree 1

Gas \& Electric Building

Baltimore, MD 21203

Battelle-Geneva

J. P. Budliger

7 Route De Drizi

1227 Geneva, SWITZERLAND

Bechtel Corporation

$P$. Leung

P.0. Box 60860

Terminal Annex

Los Angeles, CA 90060

Bechtel Corporation

G. R. Reti

P.0. Box 3965

San Francisco, CA 94119

R. W. Beck and Associates

J. P. Rossie

400 Prudential Plaza

Denver, CO 80202
No. of

Copies

Betz Environmental Engineers

J. Soost

One Plymouth Meeting Mall

Plymouth Meeting, PA 19462

Black, Crow and Eidsness, Inc.

C. G. Thompson

807 South McDonough

Montogomery, AL 35104

Black Hills Power and Light Company

B. Westre

P.0. Box 1400

Rapid City, SD 57701

Boeing Aerospace Division

D. Gilbert (M.S. 2ROO)

P.0. Box 3999

Seattle, WA 98124

Bonneville Power Administration

E. H. Hall

1002 N.E. Holl aday Street

Box 3621

Portland, OR 97208

Burns and Roe, Inc.

700 Kinder Kamack Rd.

Orade l, NY 07649

California Energy Commission

C. Webb

1111 Howe Avenue

Sacramento, CA 95825

California State Energy Resources Conservation and Development Commission

L. E. Stamets

1111 Howe Avenue

Sacramento, CA 95825

Carolina Power \& Light Co.

J. Sell

336 Fayettesville Street

Raleigh, NC 27602 
No. of

Copies

Catalytic Construction Corp. $\mathrm{J}$. Morse

P.0. Box 15232

Charlotte, NC 28210

Ceramic Cooling Tower Co.

P. A. Frohwerk

P.0. Box 425

Fort Worth, TX 76101

Chicago Bridge and Iron Company

M. Husain

800 Jovie Boulevard

Oak Park, IL 60521

Combustion Engineering Lummus

Engineering Company

R. J. Croke

1515 Broad St

Bloomingfield, NJ 07003

Columbus and Southern Ohio

Electric Co.

L. W. Meridith

General Manager, Generation Department

215 North Front Street

Columbus, $\mathrm{OH} 43215$

Combustion Engineering

H. H. Osborn

Air Preheater Company

Wellsville, NY 14895

Commonwealth Edison

R. H. Holyoak

One First Plaza

P.0. Box 767

Chicago, IL 60690

Consolidated Edison Co. of New York, Inc.

W. A. Messner

4 Irving Place

New York, NY 10003
No. of

Copies

Consolidated Edison Co. of New York, Inc.

C. L. Newman

4 Irving Place

New York, NY 10003

Cooling System, Inc.

C. Mitchel

8490 Avenue 296

Visalia, CA 93877

Cornell University

F. K. Moore

Ithaca, NY 14850

Curtiss-Wright Corporation

R. J. Haberski

One Passaic Street

Wood Ridge, NJ 07075

Dames \& Moore

L. Craton

Suite $1: 00$

1100 Glendon Avenue

Los Angeles, CA 90024

Dames \& Moore

P. Gott lieb

Suite 1000

$1100 \mathrm{Glendon}$ Avenue

Los Angeles, CA 90024

Delmarva Power \& Light

F. Cook

800 King Street

Wilmington, DE 19801

Dow Chemical Company

E. Wagener

2800 Mitche 11 Drive

Walnut Creek, CA 94598

Duke Power Company

S. K. Blackley

P.0. Box 2178

Charlotte, NC 28201 
No of

Copies

Duquesne Light Co.

J. Latshaw

435 6th Avenue

Pittsburgh, PA 15219

Dynatech Company

E. Guyer

99 Erie Street

Cambridge, MA 02139

Ecodyne

J. Slotnik

607 First Street, S.W.

Massillon, $\mathrm{OH} 44646$

Ecodyne Cooling Products Co.

J. K. Swindt

P.0. Box 1267

Santa Rosa, CA 95403

Ecodyne Cooling Products

K. D. Whitehead

P.0. Box 1267

Santa Rosa, CA 95403

Electric Power Research Institute

J. Maulbetsch

3412 Hilview Avenue

P.0. Box 10412

Palo Alto, CA 94304

Empire State Electric Energy Research Corp.

L. Geller

1271 Avenue of the Americas

New York, NY 10020

Environmental Protection Agency

T. G. Brna (MD-61)

IERL/RTP

Research Triangle Park, NC 27711

Environmental Protection Agency

A. Galley (WH-552)

401 M. Street SW

Washington, DC 20460
No of

Copies

Environmental Protection Agency

M. Maxwe11 (MD-61)

IERL/RTP

Research Triangle Park, NC 27711

Environmental Protection Agency

F. H. Rainwater

Pacific Northwest Water Laboratory

200 S.W. 35th Street

Corvallis, OR 97330

Environmental Protection Agency

F. A. Roberts

200 S.W. 35th Street

Corvallis, OR 97330

Environmental Sciences and Services

W. G. Hoydysh

150 East 73rd Street

New York, NY 10021

Environmental Systems Corporation

K. Wilber

P.0. Box 2525

Knoxville, TN 37901

ERG Incorporated

G. M. Benson

Lowe 11 57th Street

Oakland, CA 94608

Exxon Research Center

J. G. Stevens

Bidg. 1, Rm. 2048

P. 0. Box 8

Linden, NJ 07036

Federal Power Commission

E. Sligh

825 N. Capitol Street

Washington, DC 20426

Florida Power \& Light Co.

C. Henderson

9250 W. Flagler Street

Miami, FL 33174 
No. of

Copies

Foster Wheeler Development Corporation

R. J. Zoschak

Technical Director, Applied

Thermodynamics Research

12 Peach Tree Hill Road

Livingston, NJ 07039

Foster Wheeler Energy Corporation

E. L. Damon

110 S. Orange Avenue

Livingston, NJ 07039

Foster Wheeler Energy Corporation

W. H. Fisher, Jr.

Project Manager

110 S. Orange Avenue

Livingston, NJ 07039

Foundation Sciences, Inc.

L. E. Wilkinson

Cascade Building

Portland, OR 97204

Frank 1 in Institute

A. M. Rub in

Twentieth \& Parkway

Philadelphia, PA 19103

Frick Company

J. Bibroff

15302 El Mar Lane

Kerman, CA 93630

GEA Airexchangers, Inc.

B. Davis

P.0. Box 1377

Thomasville, GA 31792

GEA Power Co:ling Systems, Inc.

G. Hesse

P.0. Box 816118

San Diego, Ct 92138

General Atomic Company

A. C. Eulber 1

P.0. Box 81608

San Diego, CA 92138
No. of

Copies

General Atomic Company

H. P. Fay

P.0. Box 81608

San Diego, CA 92138

General Electric Co.

E. H. Miller

Large Steam Turbine Division

300 Nott Street

Schenectady, NY 12301

General Motors Corp.

R. K. Shah

Harrison Radiator Division

Lockport, NY 14094

Georgia Power Co.

T. E. Byer ley

P.0. Box 4545

Atlanta, GA 30302

Gilbert Associates, Inc.

J. F. Sebald

525 Lancaster Avenue

Reading, PA 19603

Heat Transfer Research Inc.

J. E. Taborek

1000 S. Fremont Avenue

Alhambra, CA 91802

Hudson Products

M. W. Larinoff

6855 Horwin Drive

Houston, TX 77036

Hudson Products

E. C. Smith

6855 Horwin Drive

P.0. Box 36100

Houston, TX 77036

H2M Corporation

H. D. Freudenthal

500 Broad Hollow Road

Melville, NY 11746 
No. of

Copies

Ingersoll-R and

W. R. Scott, Jr.

Phillipsburg, NJ 08865

Ital impiant $i-S o c i e t a$ Italiana Impiant $i$ p.a.

C. Rocco

Piazza, Piccapietra 9

18121 Genoe, ITALY

Los Alamos Scientific Laboratory

D. Abbey

S-2, MS 606

Los Alamos, NM 87545

Los Angeles Department of Water and Power

J. L. Mulloy

111 N. Hope Street

Los Angeles, CA 90012

Louisiana Power \& Light Co.

D. L. Aswell

142 Delaronde Street

New Orleans, LA 70174

The Charles T. Main Co.

E. S. Miliaras

Southeast Tower

Prudential Center

Boston, MA 02199

Mar ley

C. A. Baird

12 S. 12th Street

Philadelphia, PA 19107

Mar ley

J. D. Holmber g

5800 Fox Ridge Drive

Mission, KS 66202

Marley

R. Landon

5800 Fox Ridge Drive

Mission, KS 66202
No. of

Copies

Martin Marietta Laboratories

L. Bongers

1450 South Rolling Road

Baltimore, MD 21227

Massachusetts Institute of Technology

L. R. Glicksman

77 Massachusetts Avenue

Cambridge, MA 02139

Massachusetts Institute of Technology

M. W. Golay

77 Massachusetts Avenue

Cambridge, MA 02139

Massachusetts Institute of Techno logy

R. Har leman

Department of Civil Engineering

77 Massachusetts Avenue

Cambridge, MA 02139

McDonnell Douglas Astronautics Company

W. H. P. Drummond

5301 Balsa Avenue

Huntington Beach, CA 92647

McDonnel1 Douglas Astronautics Company

S. O'Hare

5301 Balsa Avenue

Huntington Beach, CA 92647

Minnesota Power Cooperative, Inc. L. A. Hillier

Box 1318

Grand Forks, ND 58201

R. D. Mitchell

Consulting Engineer

4531 East Best Road, SEDC

Larkspur, CO 80118 
No. of

Copies

llont ana Power Co.

$R$. Hof acher

40 E. Broadway

Butte, MT 59701

Niagara Blower

W. Kals

405 Lexington Avenue

New York, NY 10017

Northeast Utilities

R. H. Meyer

P.0. Box 270

Hartford, CT 76101

Northern States Power Co.

R. Stansfield

414 Nicollet Mall

Minneapolis, MN 55401

N.U.S. Corporation

S. Lefton

2 Palo Alto Square (Suite 624)

Palo Alto, CA 94304

Oak Ridge National Laboratory

J. W. Miche 1

OTEC Heat Exchange Project Activity

Box $Y$

Oak Ridge, TN 37830

Orange \& Rockland Utilities, Inc.

R. H. Metzger

Environmental Services Manager

75 West Route 59

Spring Valley, NJ 10977

Oregon State University

L. P. Davis

Department of Mechanical

Engineering

Corvallis, OR 97330
No. of

Copies

Oregon State University

C. E. Wicks

Department of Chemical Engineering

Corvallis, OR 97330

Oregon State University

J. G. Knudson

Engineering Experiment Station

Corvallis, OR 97330

Pacific Gas \& Electric

A. A. Ariey

77 Beale Street

Jan Francisco, CA 94106

Pacific Gas \& Electric

F. F. Mautz

77 Beale Street

San Francis:o, CA 94106

Pacific Power \& Light Co.

W. C. Bruaer

Public Service Bldg.

Portland, OR 97204

Pennsylvania Power \& Light

W. Dussinger

2 North Ninth Street

Allentown, PA 18101

Pennsylvania Power \& Light

D. G. Pfeiffer

2 North Ninth Street

Allentown, PA 18101

PFR Engineering Systems, Inc.

T. Rozenmann, President

Suite 832

4676 Admiralty Way

Mar na del Rey, CA 90291

Philadelphia Electric Co.

J. Allen

2301 Market Street

Philadelphia, PA 19101 
No. of Copies

Philadelphia Electric Co. S. J. Kowalski 2301 Market Street, NZ-1 Philadelphia, PA 19101

Philadelphia Electric Co. J. B. Machel

2301 Market Street, NZ-1

Philadelphia, PA 19101

Philadelphia Electric Co. D. Marano

2301 Market Street, NZ-1

Philadelphia, PA 1.9101

Prof. Ing. Carlo Roma

Piazza delle Muse 8

Rome, ITALY

Pickard Low \& Garrick

L. Rust

1200 18th St. NW

Suite 612

Washington, DC 20036

Power Generation Cooling Systems

G. L. Henderson

4714-52nd Street S.

Seattle, WA 98118

Public Service of Colorado

R. F. Walker

5900 E. 39th Avenue

Denver, CO 80207

Public Service Company of Indiana

S. W. Shields

V. P. Engineering

100 East Main Street

Plainfield, IN 46168

Public Service Company of New Mexico

C. D. Bedford

P.0. Box 2267

Albuquerque, NM 87103
No. of

Copies

Public Service Company of New Mexico

D. J. Jroves

Supervisor, Resource Analysis

Alb iquerque, NM 87103

Quirk, Lawler and Mattusky, Eng.

J. Lawler

5055 th Avenue

New York, NY 10017

Radian Corporation

F. B. Mesich

P.0. Box 9948

Aust in, TX 78766

Research Cottrell

G. E. Collins

Hamon Cooling Tower Division

Box 750

Bound Brook, NJ 08805

Research Cottrel1

R. H. Hannon

Hamon Cooling Tower Division

Box 750

Bound Brook, NJ 08805

Resources Conservation Company

$H$. Herrigel

P.0. Box 936

Renton, WA 98055

Reynolds Aluminum Co.

R. Lindberg

Reynolds Metallurgical Research Laboratory

Richmond, VA 23261

Richmond Field Station

H. H. Sephton

47th and Hoffman Blvd.

Richmond, CA 94804

San Diego Gas \& Electric

R. G. Lacy

101 Ash Street

San Diego, CA 92107 
No. of

Copies

Seatt le City Light

T. R. Miller

Principal Mechanical Engineer

1015 Third Avenue

Seattle, WA 98104

Seattle City Light

R. G. Sheehan

1015 Third Avenue

Seattle, WA 98104

Southern California Edison

R. S. Currie

2244 Walnut Grove Avenue

Rosemead, CA 91770

Southern California Edison

W. C. Martin

2244 Walnut Grove Avenue

Rosemead, CA 91770

Southern California Edison

F. A. McCracken

2244 Walnut Grove Avenue

Rosemead, CA 91770

Southern Services, Inc.

C. H. Goodman

P.0. Box 2625

Birmingham, AL 35202

Stanford University

A. L. London

Department of Mechanical

Engineering

Stanford, CA 94305

Stearns-Rogers, Inc.

J. Y. Parce

Box 5888

Denver, CO 80217

Stewart-Warner Corporation

South Wind Division

V. N. Tramont ini

1514 Dover Street

Indianapolis, IN 46221
No. of

Copies

Stone \& Webster Engineering Corp. D. H. Guild

225 Frank lin Street

Boston, MA 02107

Tampa Electric Co.

H. I. Wilson

P.0. Box 111

Tampa, FL 33601

Tennessee Valley Authority

Energy Research

R. D. Boroughs

1345 Commerce Union Bank Building

Chattanooga, TN 37401

Tennessee Valley Authority

H. B. Flora, II I

1320 Commerce Union Bank Building

Chattanooga, TN 37401

Texas Electric Service Co.

W. Keel

115 W. Seventh Street

Fort Worth, TX 76102

Tucson Gas \& Electric

A. A. Ward

220 W. 6th Street

Tucson, AZ 85701

Union Carbide Corp.

J. A. Bartz

Linde Division

61 East Park Drive

Tonawanda, NY 14150

Union Carbide Corp.

J. M. Vance

ORGDP - K-25

P.0. Box P, Mail Stop 387

Oak Ridge, TN 37803

Union Carbide Corp.

$F$. Notaro

Linde Division

61 East Park Drive

Tonawanda, NY 14150 
United Engineers \& Constructors

G. A. Englesson

30 S. 17 th Street

Philadelphia, PA 19103

United Engineers \& Constructors

M. Hu

30 S. 17th Street

Philadelphia, PA 19103

University of Bremen

K. Simhan

Bremen, WEST GERMANY

University of Iowa

J. F. Kennedy

Hydraulic Research Institute

Iowa City, IA 52240

University of Kentucky

T. E. Eaton

Mechanical Engineering Department

Lexington, $K Y 40506$

U.S. Congress

G. Haimes

214 Massachusetts Avenue NE

Washington, DC 20510

U.S. Fish and Wildlife Service

B. L. Foder

Information Transfer Specialist

National Power Plant Team

1451 Green Road

Ann Arbor, MI 48105

United States Steel Corp.

T. L. Myron

Research Laboratory

Monroeville, PA 15146

Utah Power \& Light

M. W. Russon

1407 W. N. Temple

Salt Lake City, UT 84103
Vermont Yankee Nuclear Power

E. Gaines, Jr.

77 Grove Street

Rutland, VT 05701

Virginia Electric \& Power Co.

S. Ragone

700 E. Franklin Street

Richmond, VA 23261

Washington Public Power

Supp 1y System

J. Chasse

P.0. Box 968

300 George Washington Way

Richland, WA 99352

Washington State University

R. W. Crain, Jr.

Department of Mechanical

Engineering

Pullman, WA 99164

Washington Water Power Co.

D. L. 01 son

E. 1411 Mission Avenue

Spokane, WA 99202

Water Purification Associates

H. Gold

238 Main Street

Cambridge, MA 02142

Western States Water Council

J. A. Barnett

Executive Director

220 South 2nd East

Suite 200

Salt Lake City, UT 84111

West inghouse Electric Corp.

G. E. Jablonka

Power Generation Systems

Engineering

700 Braddock Avenue Room 9L51

East Pittsburgh, PA 15112 
No. of

Copies

Westinghouse Electric Corp.

K. Kesavan

Advanced Reactor Division

P.0. Box 158

Madison, PA 15663

Westinghouse Electric Corp.

G. J. Silvestri

Steam Turbines Division - G108

Lester Branch

Box 9175

Philadelphia, PA 19113

Westinghouse Electric Corp.

K. A. Oleson

Steam Turbines Division - G108

Lester Branch

Box 9175

Philadelphia, PA 19113

William M. Rice University

W. G. Characklis

Environmental Science and

Engineering

Houston, TX 77001

\section{ONSITE}

DOE Richland Operations Office

Energy Programs Division

H. E. Ransom

Westinghouse Hanford Company

Hanford Engineering Development

Laboratory

J. Fletcher

Pacific Northwest Laboratory

R. T. Allemann

J. A. Bamberger

David J. Braun

A. J. Currie

J. W. Currie

D. E. Deonigi
No. of

Copies

Pacific Northwest Laboratory (contd)

R. L. Dillon

D. W. Dragnich

R. L. Drake

F. P. Fabro

D. W. Faletti

J. W. Finnigan

T. J. Foley

J. D. Goodenough

J. J. Hauth

A. J. Haverfield

C. H. Henager

A. B. Johnson

W. S. Kelly

R. S. Kemper

W. V. Loscutoff

R. P. Marshall

D. E. Olesen

M. S. 0lsen

Y. Onishi

H. L. Parry

L. T. Pedersen

G. C. Smith

J. S. Stoakes

A. M. Sutey

R. D. Tokarz

D. S. Trent

R. A. Walter

R. L. Watts

R. D. Widrig

L. E. Wiles

C. E. Willingham

F. R. Zaloudek

File - B. M. Johnson (30)

Technical Information (5)

Publishing Coordination (2)

KE 
. 